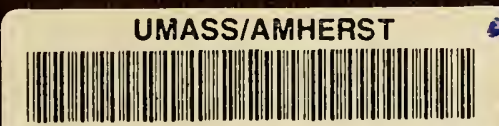

312066005159838 


\section{LIBRARY}

OF THE

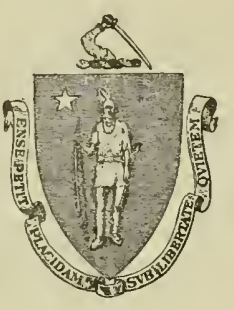

MASSACHUSETTS AGRICULTURAL

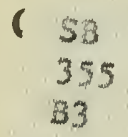

355

33 
This book may be kept out

\section{TWO WEEKS}

only, and is subject to a fine of TWO CENTS a day thereafter. It will be due on the day indicated-below. 





\section{PRACTICAL AND SCIENTIFIC}

\section{FRUIT CULTURE.}





\title{
PRACTICAL AND SCIENTIFIC
}

\section{F R U I T C U L T U R E.}

BY

\author{
CHARLES R. BAKER, \\ OF THE
}

DORCHESTER NURSERIES.

ILLUSTRATED.

BOSTON:

LE A A D S H E A R D.

LONDON: TRÜBNER AND CO.

1866 . 


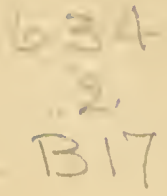

Entered according to Act of Congress, in the year 1866 . BY CHARLES R. BAKER,

In the Clerk's Office of the District Court for the District of Massachusette.

ANDOVER:

GTEREOTYPED BY WARREN F. DTAPER.

Presswork by John Wilson and Sons. 


\section{TH I S V L U M E}

Is

RESPECTFULLY INSCRIBED TO AMERICAN FRUIT-GROWERS, IN THE

HOPE THAT IT MAY ENCOURAGE AND ASSIST BEGINNERS, AND BE FOUND CONFORMED TO THE EXPERIENCE OF THE BEST CULTIVATORS,

î̀ the the Guthor. 



\section{P R E F A C E.}

WHILE there are a number of excellent works descriptive of fruits, and compiled from ripe experience and large observation, yet there are few, if any, which give in detail the arts of cultivation.

The minutiae and practical application of these arts become more important as the interest in fruitculture increases, and the profits are understood. On these topics so much has already been published as to prevent any demand for additional remark. But in the progress of our legitimate business a multitude of inquiries are annually proposed, by customers and others, relative to the various branches 
of these arts, which are important to their success, but to which they cannot readily obtain satisfactory replies. Thus we have felt ourselves called upon to submit the results of our researches and experience to the public in print, hoping that the present volume, though not perfect and complete, may yet be acceptable and useful to beginners in the cultivation of the garden, the orchard, and the vineyard. And, lest our connection with the Hon. Marshall P. WILDER, of enviable renown for his contributions to American Pomology, should lead our readers or the public to think him responsible for what we have written, we feel it to be due to his official position, and to our pleasant and intimate relation to him, to say that he is in no degree accountable for any peculiar sentiments herein expressed.

We have received from him many valuable suggestions, and are largely indebted to his library and 
mature knowledge; and deeply regret that his feeble health, during the preparation of this work, has to a great extent deprived us of his counsel, and the benefits which we and the public might otherwise have derived from his personal revision of our manuscript.

For the original suggestion which led to the preparation of this volume, I gratefully acknowledge my indebtedness to my esteemed friend H. F. Durant, Esq.; also to my beloved father, Rev. A. R. BAKER, for additional assistance.

To the following works and authors $I$ am also indebted for many valuable hints, generally indicated in the text:

The Gardener's Chronicle.

Loudon's Gardeners' Magazine.

Loudon's Encyclopedia of Gardening. 
Jolnnston's Agricultural Chemistry.

Stöckhardt's Field Chemistry.

Johnston's Farmers' Encyclopedia.

Lindley's Introduction to Botany.

Leibig's Natural Laws of Husbandry.

Tull's Horse-Hoe Husbandry.

French's Land Drainage.

Girdwood's Encyclopedia.

Müller's Meteorology.

Blodgett's Climatology.

Annals of Natural History.

Espy on Storms.

Revue Horticole.

Transactions of the London Horticultural Society.

Rivers's Miniature Garden.

Insects Injurious to Vegetation.

Transactions of the American Pomological Society.

Patent Office Reports.

The Philosophical Magazine. 
Squarery's Agricultural Chemistry.

Quarterly Journal of Agriculture.

- Geological Survey of Massachusetts.

Annales de la Chimio.

Sproule's Treatise on Agriculture.

Monographie des Greffes.

Bibliotheca $\Lambda$ graria.

De Re Rustica.

The Theory of Horticulture.

Outlines of Flemish Husbandry.

Dary's Agricultural Chemistry.

Electricity in Theory and Practice.

Jenyns's Observations upon Meteorology.

Synopsis of North American Fungi.

De Candolle's Vegetable Physiology.

Botanische Zeitung. 1854.

Physique des Arbres. 1758.

Comptes Reudus. 1853.

Introduction to Chryptogamic Botany. 
Fitche's Noxious Insects, Published in Transactions of New York State Agricultural Society.

Address to the Meteorological Society of Scotland, by Dr. Jas. Stark.

$W^{\top}$ e also acknowledge the kind and generous assistance of Prof. Glover of the Maryland Institute. 


\section{O N T E T T.}

\section{CHAPTER I.}

METEOROLOGICAL AGENTS.

Altitude - Aspect or exposure - Contiguous bodies of water - Nature of storms - Climate of eastern and western districts comparedSnow storms - Severe wind - Stagnant air - Aqueous vapor Heat - Light - The limits of the vine - Tables - Cold - Electricity - Different exposures; as the summit of hills, northern, southern

\section{CHAPTER II.}

ORIGIN AND PROPERTIES OF SOILS.

Soils the result of disintegration - Causes stated by Sir H. Davy Boussingault - Hitcheock - Alluvial agencies. Properties: Specific gravity - Affinity for moisture - Absorption of moisture from the air - Capillary attraction - State of division - Cohesion and adhesion - Absorption of gases from the atmosphere - absorption and retention of heat 


\section{CHAPTER III.}

\section{CLASSIFICATION AND ADAPTATION OF SOILS.}

Section I. Classification of soils; Section II. Adaptation to different fruits - Varieties of the apple, apricot, berberry, cherry, currant, fig, gooseberry, grape, peach, and nectarine - Varieties of the pear, plum, quince, raspberry, strawberry . • . . . 79

\section{CHAPTER IV.}

\section{DRAINING THE SOIL.}

Method by which the soil is supplied with moisture: rain, springs Description of different strata - Capillary attraction - Methods by which water is removed: running off its surface - Evaporation Percolating through its substance - What lands require drainage The direction of the drains - The distance - The depth - The material to be used-Number of tile to the acre-Manner of operation - The effects of drainage : promoting pulverization Prevention of injury by drought - Increase of the absorption of moisture - Ventilation - Permitting the warm spring showers to enter the soil - Freezing the land deeper - Deepening the soil Destroying weels - Causing a more hardy growth - Production becomes more certain . . . . . . . . 90 


\section{CHAPTER V.}

\section{PULVERIZATION.}

A crumbling consistency of soils necessary - The importance of pulverization - Stiffness of elays - The non-retention of sandy soils Coldness of heavy earths - Summers - Injurions effects of drought - Example of proper valuation of arable soil - Theory of Jethro Tull - Effect of inseets upon pulverization - Depth - Digging cireles around trees deprecated - Power of extension by roots Deep cultivation affords fresh earth - Nanner of operation - The season - Results of it : rapid absorption of moisture - Free admission of the air - The mixture of earths - The destruction of insects - The increase of heat $\quad$ • . . . . . 126

\section{CHAPTER VI.}

\section{FERTILIZATION.}

Selective power of plants - Form in which food is taken up - Excretion - Circulation of the sap - Organic substances : Oxygen, hydrogen, carbon, nitrogen - Inorganic substances - Manures adlapted to different soils: to clays, to peaty soils, to sandy lands - Plants to be used in green-manuring - Application of manures . . 164 


\section{CHAPTER VII.}

\section{SELECTION OF VARIETIES.}

Evils of indiseriminate selection - Fruits suitable for the amateur, for family use, for the market - Catalogue of the different varieties adapted to the different sections of the country - The best six, twelve, twenty, or one hundred sorts, for each state • • 201

\section{CHAPTER VIII.}

\section{SELECTION, ARRANGEMENT, AND TRANSPLANTATION.}

Section I. Selection of the tree: The apple - Root-grafted treesHeight of the tree no criterion of its value - Where they should limb - The peach - The vine - The currant and gooseberry The strawberry, raspberry, and blackberry. Section II. Arrangement: Intensive planting - A garden of one square rod $-\mathbf{A}$ garden of sixteen square rods - Apple orehards - Square planting for the pear - Quincunx - Distances, and number of trees upon an acre. Section III. The transplantation: Season of - Conditions most farorable to - Depth of - The dwarf pear - Manner of operation - The movement of large trees by machinery . . • 271 


\section{CHAPTER IX.}

PRUNING AND TRAINING.

The amputation of the limbs of a tree based upon scientific principles - Facts necessary to be kept in mind: Importance of a sharp knife - The method of making the cut-Severe pruning productive of vigor and sterility - The removal of a part of the wood of a weak plant strengthens the remainder - Importance of sunshine to all parts of the tree-Circulation of air - Distinguishing the peculiarities of the variety - The prevention and cure of disease - The season : Spring and summer - Pruning after transplanting - Training the peach and nectarine: Seymour's system-Oblique rod - Oblique double rod - Double oblique rod - Standard - Horizontal trellistraining - The apricot - The pear - Standard, quenouille, wineglass, etc. - The cherry - The vine - The system of the Ionian islands Simple cane - Simple thomery. Plan practised in Ohio - The currant - The gooseberry - The raspberry - The blackberry - The strawberry - Root-pruning • • • • • • • 301

\section{CHAPTER X.}

SUMMER CULTIVATION.

Removal of moss and decayed bark - Loosening the soil - Mulching - Thinning the fruit - Ringing - Watering, tying, supporting, and gathering the fruit-Preservation . . . . . 


\section{CHAPTER XI.}

\section{GRAFTING AND BUDDING.}

Influence of the stock - Of the scion - The season - The wax Methods - The cleft - Gerffe a un seul ramean, dont une partie du sujet est conpee en biseau - The crown - Tubular budding with dormant eyes - The peg - Greffe sylvain, renewal, side, whip - Greffe ferari de Thouin - Grafting fruit-spurs -- Inarching - Greffe morceat - Common inarching, in the axis of the leaf, square bud, tubular bud - Greffe en eeusson - The budding-machine - For immediate fruiting - Renewal — Grafting the vine - Midsummer Embryonic

\section{CHAPTER XII}

THE PRODUCTION OF NEW VARIETIES.

Change in the vegetable world - Effect of elimate, soil, and position Cultivation, degeneracy, or deterioration - Decrepitude - Metloods of produetion - Seleetion - Van Mon's theory as distinguished from it - Cultivated fruits not deseended from their mild types - Importance of securing seed from a young tree - Hybridization - Experiments of Kolrenter, IIerbert, Knight, Gærtner, Lindley, Purkinje, Mirbel, Adolphe Brogniart, Conrad Sprengel, Cassini, Alphonse de Candolle, Sehleiden, Fritsche, Thwaites, Mr. Rogers - Manner of operation 


\section{CHAPTER XIII.}

\section{THE DISEASES OF FRUIT-BEARING PLANTS.}

Section I. General observations - Berkeley's theory of classification Weigmann - Causes of disease-Insects. Section II. Diseases of the apple - of the leaf - Fall of the leaf - Fungi - Clados porium dendriticum, ceratites, raestelia - Insects - Apple-tree louse, common apple-tree caterpillar, the oak-tree eaterpillar, the vaporer moth, the palmer worm, the hag moth, the unicorn moth, the eanker worm, the handmaid moth, the dotted apple-leaf worm; of the fruit and flower - Sterility - Immaturity of the fruit-Insects - The sawfly, the midge, the codling moth, the rose-bug ; of the stem - Insects - The goat moth, the eommon borer, root-blight insect, the snapping beetle, the bark louse, the loeust of the seventeenth year; of the tree generally - Profusion of sap, hunger, stagnation from transplantation, eanker, freezing, splitting, wind shakes, dropsy, sun-strokes, wounds, lichens, vitiation of the sap. Section III. Diseases of the pear - Of the leaf - Amerioan pear blight - Insects - The goldsmith beetle, the red mite, the fly, the lyda, the astyages, the hispa quadrata, fungi, discolorations; of the fruit and flower - Rotting at the core, induration, loss of bloom, ete. ; of the stem - Root blight Insects - The blight beetle, the bark louse, fungi, ete. Seetion IV. Diseases of the peach - The dotted apple-leaf worm, premature fall of the fruit, the borer, gumming, etc. Section V. Diseases of the plum - Plum louse, curculio, the plum wart, ete. Section VI. 
Diseases of the cherry - The louse, the May beetle, etc. Section VII. Diseases of the gooseberry - The caterpillar, the swallow-tailed moth, the midge, the mildew, etc. Section VIII. Diseases of the currant-Fall of the leaf, the borer, etc. Section IX. Diseases of the raspberry - The grub, etc. Section X. Diseases of the vine Of the leaf-Insects - The vine plume, the saw-fly, the anomola vitis, the spotted beetle, the pyralis, the procris Americana, the haltica chalybea, the leaf hopper, the bombyx quata, the philampelus, the choerocamepa, the rhynchitis, fungi, common mildew, erysiphe, botrytis; of the fruit and flower - The rose-bug, shanking . 


\title{
FRUIT CULTURE.
}

\section{CHAPTER I.}

\author{
METEOROLOGICAL AGENTS.
}

\begin{abstract}
ALTITUDE - ASPECT OR EXPOSURE - CONTIGUOUS BODIES OF WATER NATCRE OF STORMS - CLIMATE OF EASTERN AND WESTERN DISTRICTS COMPARED - SNOW STORMS - SEVERE WIND - STAGNANT AIR - AQUEOUS VAPOR - HEAT - LIGHT - TIE LIMITS OF TIIE VINE - TABLES COLD - ELECTRICITY - DIFFERENT EXPOSURES: AS THE SUMMIT OF HILLS, NORTHERN, SOUTHERN.
\end{abstract}

TIIE meteorological agents which affect the production of fruit have never received from horticultural writers the notice which they deserve. They are necessarily more recondite than the qualities or condition of the soil ; and because less evident, they have been passed over in silence; yet the importance of understanding atmospheric phenomena is, in some respects, even greater than a knowledge of the soil.

In one part of a country a certain fruit is utterly worthless; its wood is killed by the winter, and its skin becomes spotted and cracked in summer. This same variety may, in another district, be universally fair and delicious, while its wood remains as free from damage in the winter as the native trees of 
the forest. This phenomenon is often noticed upon different sides of the same hill. In the latter case, it cannot certainly be the soil which causes such varied results; but we must refer them to atmospheric agencies.

Among the most important facts to be determined is the effect of different altitudes upon vegetation. It does not require more than a child's discrimination to discover that the temperature upon the summit of a mountain is much lower than at its base, and therefore that a fruit which flourishes at its foot would not do so if planted in the most propitious place upon its top. Naturalists tell us that if we start where the first glimpses of vegetation appear at the frigid zone, and approach the tropics, we shall perceive all the different stages of the vegetable creation, in the same order in which they were placed upon the earth. As we ascend a mountain the effect is reversely the same. Hence it becomes evident that to determine properly the limit for the cultivation of a plant, it would be useless to draw parallel lines, like those which we use for latitude, because the same line would pass over valley and mountain in which the temperature would vary several degrees.

In assigning a position to the isothermal lines, now quite common in geographical maps, there are several other facts to be considered.

Aspect, or exposure, exerts a powerful influence 
upon fruit cultivation. For instance, while some varieties of grapes will not ripen if exposed to the north or west, they mature quite early on a southern or eastern slope. Therefore, if an isothermal line is to be an infallible guide, it should run down on the latter, and up on the former. Some slopes are open to furious and chilling winds from the cold regions, which tend to depress the line.

These are among the more general facts to be considered. It can readily be seen that perfect accuracy must be practically impossible. The cultivator must exercise a wise judgment with regard to these principles, or his efforts will not be crowned with complete success.

Among the more general facts which should guide us in determining the limits of the successful cultivation of different fruits, and the proper selection of exposure for each variety, let us notice the effects of large, contiguous bodies of water; or the difference between island or coast, and inland or continental climate, - a difference which is very striking in respect to the limits of cultivating a particular plant. This is owing to the greater ease with which land rather than water absorbs and radiates heat. Land becomes warm much sooner, but falls in temperature with equal rapidity. On the contrary, the sea is not so soon heated, on account of its brilliant surface, which reflects the rays of the sun; neither is it so soon cooled, owing to the great 
amount of its specific heat. While the land changes its temperature very considerably with the diurnal and annual alternations, the sea does so to a less degree. During the night, the effect of water upon the coast is to warm, and in the day to cool the land. The same results are produced on the change of the seasons: both the spring and autumn are later. Places on the shore of large bodies of water have frequently a clouded sky, and these arrest the rays of heat from above, as well as prevent its loss by radiation from beneath. Therefore, island or coast climates are never subject to such extremes of weather as are those of the interior. M. Boussingault states that the temperature of London and Paris is about the same, while the latitude of the latter is nearly three degrees lower.

As we travel from the coast toward the interior, the difference between the mean temperature of summer and winter is much greater than on the seaboard. Rivers, lakes, and ponds possess to some extent the same power of equalizing temperature, according to their size; and therefore we can perceive the great value of isothermal lines established by Baron Von Humboldt, which are a guide to the general temperature, independent of the parallels of latitude.

By reference to an isothermal map which gives the mean temperature of the United States for the four seasons, we shall ascertain that this mean 
degree is the same at Fort Snelling, Minnesota, and at Boston; while there is a difference in the latitude of these places of two and a half degrees. The autumn of the former is colder than that of Boston ; therefore, if we possessed no more information, we should determine that the growing season was shorter and colder than that of the Atlantic coast, and that fruits which succeed near the latter would not flourish in Minnesota. But we must remember that the effect of ocean upon the coast in the spring is to cool it; and, consequently, that the ground at Fort Snelling becomes sensible of the warm spring sun much quicker, and is free from the cooling influence of the water all summer. The mean spring temperature is like that of Southern Connecticut or New York. Those fruits which hardly reach maturity in the Northern Atlantic States, ripen fully and much earlier there, because the heat of spring and summer is so much more intense.

From the manner in which altitude, exposure, and the presence of bodies of water affect climate, the importance of considering atmospheric influences in the selection of sites for our orchards must have become evident. Let us investigate further the general phenomena which produce good or bad results in the growth of fruits.

1. The nature of storms. The difference in these $3^{*}$ 
and in the climate east and west of the Rocky Mountains is very marked. The prevailing winds of our continent are western. Although the eastern district comprises a most extensive area in several latitudes, yet its general features are similar. It is subject to great extremes, - a cold winter, and a semi-tropical summer. The variety of its indigenous plants is very great. The vapor arising from the Gulf of Mexico is condensed as it passes over the land, and, falling until it is taken by this western current, it is spread over the whole eastern portion of the continent. When these winds are most severe, as in the autumn, when the trees are laden with fruit, as well as in early spring, the importance of shelter in exposed positions will readily occur to every practical cultivator. But this will be considered hereafter.

While there are some benefits resulting from the variableness of temperature in the Eastern States, there are also serious disadvantages, - such as the destruction of the fruit-buds of the most tender species and varieties in the more northern States, and the encouragement of the fungi, as well as of other diseases incident to a sudden check or acceleration of the sap-flow.

On the contrary, the climate of the Pacific coast is characterized by great equanimity. If the diseases resulting from sudden changes and extremes of temperature exist at all, it is in their most ameli- 
orated form. The temperate climate of Spain finds there a rival; and the wine-grapes of Germany, Italy, and even those of our hothouses, succeed there perfectly. The thermometer seldom falls below fortyseren degrees Fahrenheit, or rises above sixty.

2. Snow storms. The benefits and evils resulting from these are about equal. Upon strawberies the effect is decidedly good, as it defends the tonder crown-buds which are to produce the fruit of the next year. The result is the same upon all small fruits, such as currants, gooseberries, and raspberries, as it modifies the extremes of temperature. When the snow has melted, if the water stands upon the gound, the subsequent effect may be disastrous: it becomes frozen, and settles down upon strawberries, frequently occasioning their death. The cause may not be uniform ; sometimes it may be owing to the exclusion of air: and yet it is difficult to understand that plants in a dormant or frozen state should require air. If the snow first melts, then freezes, it forms a crust of ice, that may act as a lens to concentrate the sun's rays and burn the plant. The presence of ice upon the ground about all trees or plants is very dangerous. The radiation of heat from the tree near the surface of the ice prevents it from being frozen so solid that the plant cannot move, else the result might not be so ruinous. A little unfrozen belt surrounds the tree, and 
against the sharp edge of the ice the tree is blown by the wind until the bark is cut through, when the plant is completely girdled. The sap passes from the roots to the leaves, through the wood of the tree, and this will not be impeded by the wound; but as the juice descends in the liber, or imner bark, it finds its course stopped, and the superfluous sap produces a large swelling in its endeavor to provide a channel. If the cut is not very wide, and the injury las taken place recently, so that the lower edge of the bark is still fresh, a junction will sometimes be formed. If, however, the case be otherwise, it will be necessary to resort to artificial means.

The strongest and most luxuriant shoots of the previous year's growth may be cut a little longer than the width of the wound, and after the ends are sharpened upon both sides, they may be placed under the bark above and below, - the flat side of the shoot facing the centre of the tree, thus bridging over the cut.

Heavy falls of snow, such as we frequently have in the northern parts of the country, sometimes do great injury. As it melts in the spring, it breaks down the spreading limbs, and makes most unsightly wounds. In such localities, those varieties which naturally produce such limbs should be avoided; or, if cultivated, the branches should not be allowed to start from the trunk lower than the average height of snow during the winter. 
3. Severe winds are often followed by most disastrous results. Trees are broken down, and frequently torn out of the ground by the roots, when exposed to its full powcr upon an unprotected plain. This is one of the most serious difficulties of fruitgrowing upon some of the prairie lands of the West, but one which is easily overcome. Belts of pines, or other evergreens, planted at the most exposed point, will in a great measure prevent injury. In more hilly districts the strong winds may not be from the west; currents draw through the valleys, and the shields must be placed at the point of exposure. In early summer, when the tree has just started its young growth, a more than ordinary wind will so whip these young shoots against each other as to change the whole appearance of the orchard in a very short time: when, a few hours before, each tree was beautifully green, now all of the young leaves upon the ends of the shoots have become bruised, black, and dead. The tree will soon recover from the injury; but the rapid elaboration of the sap has been checked, and much growth lost.

In the vicinity of Boston there prevails annually a severe northwest wind, about the twentieth of September, which strips from the trees hundreds of bushels of fruit. This injury might be prevented, in a great measure, by proper shelter.

Positions where the air is stagnant should be also carefully avoided. The atmosphere contains a cer- 
tain proportion of carbonic acid, which is the chief source of the carbon of plants, constituting the greater part of their wood. 'This is received by the plant not only through the roots, but by means of all the green portions of the tree. If the air was not in circulation, it can readily be imagined that this gas would be more or less exhausted in that part of the atmosphere which immediately surrounds the plant, and that the tissue would consequently be pithy and soft. Therefore we can discern the use, in the great system of Nature, of those gentle breezes which so lightly rustle the foliage, and supply to the most minute leaf its proper share of this great element of life. The stagnation of the air, together with electrical influences, we shall discover, when we investigate the diseases of fruit-bearing plants, to be the probable causes of the American pear-blight.

4. Aqueous vapor. Not only does the air contain carbonic acid with hydrogen and oxygen, but aqueous vapor, which affects plants powerfully. The first three constituents form the primary elements of the bodies of both animals and plants; these, by their death and decay, restore the gases to their original condition; but the rapidity of these phenomena is regulated, in a great measure, by the presence of watery vapor. Its quantity varies with the locality and the season of the year. Its absence would cause 
sterility. If the atmosphere in the African deserts could be saturated with moisture, they would become as verdant as any other portion of the earth.

The amount of moisture, or water, which the atmosphere is capable of containing, to become fully charged, varies with the degree of temperature. If it is eighty degrees Fahrenheit, it will contain ten grains to the cubic foot; if it be twenty degrees Fahrenheit, the amount of vapor would be little more than one or one and a half grains. Such being the case, a sudden fall of the temperature would result in the precipitation of the superfluous moisture. The diurnal depression of the thermometer is followed by dew, in consequence; or, when cold enough to freeze, by hoar-frost, which is merely frozen dew. Every one is aware of the clearness of the air in the winter, because its low degree of temperature does not allow it to absorb much aqueous vapor. When the air becomes heated in the spring, evaporation goes on very rapidly to supply the deficiency in the atmosphere, and thus nature dries up the soil.

The vapors contained in the atmosphere, and its reluctance to part with heat, are among the reasons why, in our latitude, the temperature does not sink to the freezing-point every night. Late frosts in the spring are not so injurious to regetation on the coast as inland, because, when the sun is up, and the temperature begins to rise, a fine mist immediately ascends to supply the want of the atmosphere, 
and thus shades the plant from the otherwise destructive rays of the sun.

5. Heat is an important stimulus to vegetable life. The functions of most plants cannot be performed without a certain degree of this agent. The more rapidly the tree is growing, the more is it dependent on the maintenance of a high temperature. The requisite degree, however, differs widely with the species, or even variety. Mr. Lymburn speaks of a plant of Marchantia which was growing in a hot spring on the island of Amsterdam, where the water was above the boiling-point; while, on the other hand, the curious Protococcus nivalis adorns the polar regions, where the frost scarcely gives way under the heat of midsummer : and yet this plant spreads over vast plains, and illumines them as if by crimson snow.

A high degree of heat is generally favorable to the growth of fruit, if it be not accompanied with drought. By the management of artificial heat, gardeners make plants perform curious freaks. Sir Thomas A. Knight caused melons and cucumbers to produce all male blossoms in excessive heat, and all female in a low temperature. Heat stimulates evaporation from the leaves, and therefore excites the roots to absorb nourishment from the soil. With the aid of light it paints the colors upon the fruit, which show that the saccharine fermentation has been well performed. 
It is often noticed that the sweetest fruits are nearest to the ground, because they obtain a greater amount of heat by its radiation from the earth. Mr. Murray, of England, proved that this was very different on the side of a hill from what it was in the valley. In one case the thermometer was thirty degrees higher on the inclined surface than in the plain. He states that upon the plains of Piedmont, in Italy, the vignerons are obliged to detach their vines from the poles, and cover them during the winter, to prevent injury; while on the acclivities which surround the city of Genoa, the pomegranate, the lemon, and the orange, flourish.

The principles of radiation were understood in very ancient times. In the land of Judea the vineyards and orchards were often planted upon terraces, to acquire additional heat.

In Europe they fixed the limits of the vine by the mean temperature of the summer months. The least mean degree required for the ripening of grapes suitably for wine is sixty-seven degrees. Boussingault thus states the effects of the temperature upon the quantity and quality of wine produced. ${ }^{1}$ (See Table A, next page.)

"In 1833 and 1837, the wines were scarcely drinkable. A summer whose mean temperature is below sixty-seven degrees will not produce valuable wine."

1 Blodgett's Climatology, p. 439. 
COLD.

TABLE A.

\begin{tabular}{|c|c|c|c|c|}
\hline YEARs. & $\begin{array}{c}\text { Mean } \\
\text { Temperature } \\
\text { of whole } \\
\text { Time of Growth. }\end{array}$ & $\begin{array}{c}\text { Mean } \\
\text { Temperature } \\
\text { of } \\
\text { Summer. }\end{array}$ & $\begin{array}{c}\text { Gallons } \\
\text { of } \\
\text { Wine per Acre. }\end{array}$ & $\begin{array}{c}\text { Pcr-centage } \\
\text { of } \\
\text { Alcohol. }\end{array}$ \\
\cline { 1 - 2 } 1833 & 58.4 & 63.1 & 311 & 5.0 \\
$1 \mathrm{~S} 34$ & 63.1 & 68.5 & 413 & 11.2 \\
$1 \mathrm{~S} 35$ & 60.4 & 67.0 & 625 & 8.1 \\
1836 & 60.4 & 71.0 & 544 & 7.1 \\
$1 \mathrm{~S} 37$ & 59.3 & 66.0 & 184 & 7.7 \\
\hline
\end{tabular}

Mr. Blodgett gives an excellent table of the temperature of the principal wine districts of this country. (See Table B. p. 39.)

6. It has been shown that heat is a great stimulus to vegetable life. Cold, on the other hand, diminishes the activity of plants. At certain seasons of the ycar a sudden fall in the temperature produces in some kinds of vegetation disease and death. If a frost occurs late in the spring, when all the organs of the tree are performing their work with great rapidity, the leaves and all those soft parts which are filled with fluid become black and stained, and lose their vitality. The green portions of a tree are made up of cells, whose membrancous walls are very thin. On the contrary, those of the wood are very thick; but this varies according to their age. When the juice contained in the former, or young cells, has become frozen, it ex- 


\begin{tabular}{|c|c|c|}
\hline & 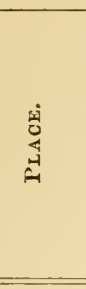 & 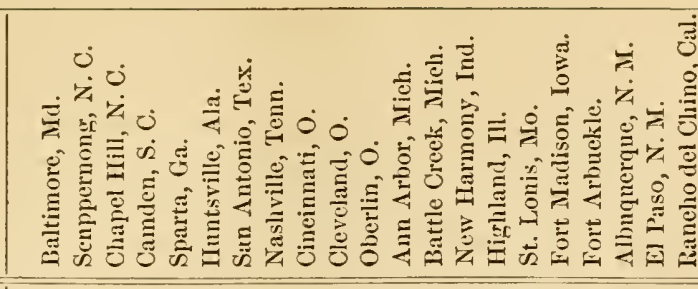 \\
\hline & 产 & 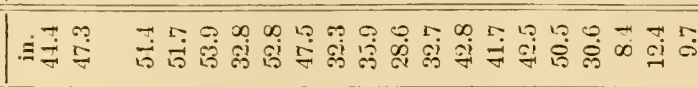 \\
\hline & 童: & $\mid \begin{array}{lll}0 & 0 \\
\end{array}$ \\
\hline & 辛言 & 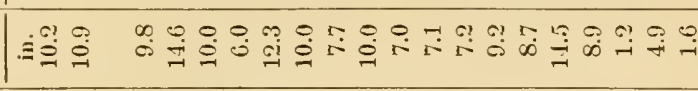 \\
\hline & 棓 & 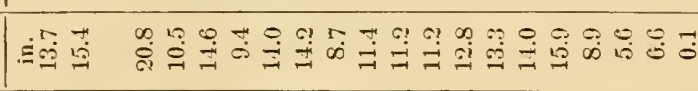 \\
\hline & 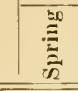 & 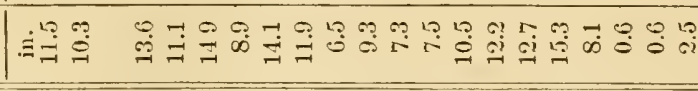 \\
\hline & 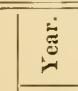 & 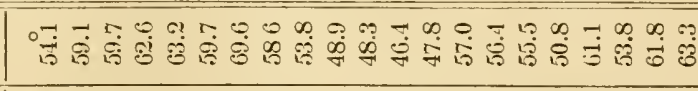 \\
\hline & 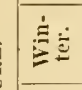 & 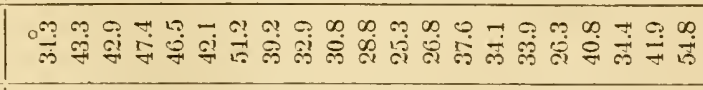 \\
\hline & 雀 & 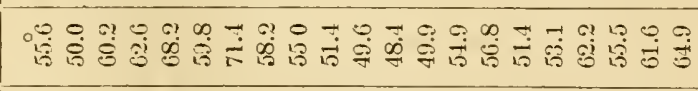 \\
\hline & 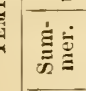 & 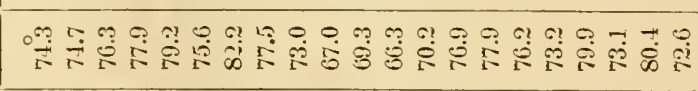 \\
\hline & 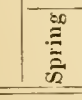 & 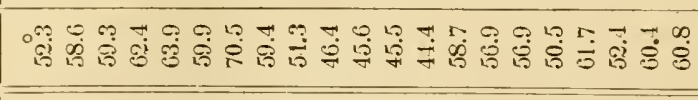 \\
\hline & 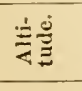 & 든 \\
\hline & 总 & 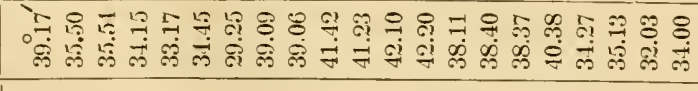 \\
\hline & 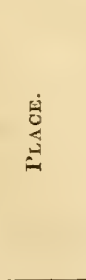 & 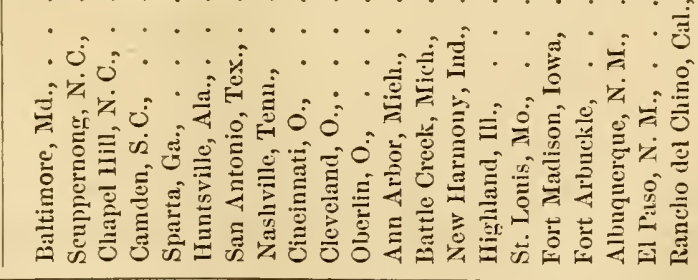 \\
\hline
\end{tabular}


pands the slight walls until they are unable longer to withstand the pressure, and burst. When their temperature is restored, the sap, of course, runs out among the tissues of the wood, and its nutritive action is lost. As the injury done by freezing is thus not made manifest until the heat is restored, it has often been thought that it was in the thawing that the leaf was destroyed. It is no doubt true that by shading from the sun, or by washing with water, these organs are sometimes enabled to bear the immense damage which they have sustained, and to recuperate their energies, through the action of those parts which have not been injured; but the harm is accomplished before it becomes evident to the casual observer.

A low degree of temperature, even though it be not at the freezing-point, is injurious to plants, as it causes stagnation of the sap, in which case fungi are liable to attack their tissue. Severe cold during the winter is generally not productive of injury, because these membrancous walls have then become thickened by layers of woody fibre, and have greater resistive force; the flow of sap also being then so much less, the danger to the tree from its expansion by freezing is lessened. Steady cold weather during the winter is beneficial to vegetation. Many tender plants will endure our climate if protected from the sun, which defends them from these variations in temperature. This is the principle which should 
be followed in covering all half-hardy trees or shrubs. It is not necessary to shield them from the cold, which one would judge was the object from the immense bundles of straw with which many such plants are surrounded, but to shade them so as to prevent those sudden changes, from heat to extreme cold, which destroy the tissue.

Mild winters are those most destructive to vegetation, as they are generally characterized by great reverses of temperature. A writer says: " "We speak of one year as warmer or colder than another; but it is a wonderful example of unchanging law, that they seldom differ materially in the mean temperature of the year. That of London is fifty degrees, four minutes; and, however hot or cold the seasons were, it did not cause the average of the year to vary more than one-half a degree; and this was probably owing to the imperfection of our implements."

A warm summer is very beneficial to vegetation, because, as we have already seen, a constant high temperature at that time stimulates their vital energies. But as the mean of every year is nearly the same, in order to have a warm summer the preceding winter must have been cold. Sometimes, however, the heat following a cold winter secms to be misplaced, either by an unusually warm spring or autumn, which produces the mean, even though the

${ }^{1}$ Loudon's Gardeners' Magazine, Vol. XVII. p. 147. 
temperature of the summer should be moderate. Thus the seasons following a cold winter are the golden ones for the fruit-grower.

7. The effect of electricity may be considered in treating of the causes of American pear-blight.

8. Light is another essential requirement of vegetation. It has a great influence in maturing the wood of the plant. In places where it is absent the foliage becomes sickly, and a poor, unripe growth is the consequence. It affects not only the growth of the tree, but also the quantity and quality of the fruit. A writer ${ }^{1}$ in the Gardeners' Chronicle says: "I send you a few peaches, taken from a tree which was brought to this garden as a nursery-plant in 1832; the following winter it was planted where it now stands, the wall and border being both new. For the first ten years I do not recollect that it ever bore a fruit, owing to a large sycamore which overshadowed the wall where it stood. The tree being an object visible from various parts of the premises, my master felt the greatest reluctance to take it down; but about ten years ago he consented to remove it, and since that time the peach tree, which had never before that carried a single fruit, has rewarded us with a fine crop every year. The number this year upon the tree was thirty dozens;

1 John Povey, Thorneycroft Hall, England. 
in 1851, thirty-three dozens; and in 1850, thirty dozens."

The rays of the sun possess certain chemical properties which produce saccharine fermentation in the fruit. Every one who eats it knows how much superior the flavor is of those which have been beautifully colored to others of the same variety which are green. In no sort is this difference more strongly marked than in the Vicar of Winkfield's pear. 'Those which are colored ripen easily, their flavor is very good, while in the remainder the saccharine fermentation has never commenced, and they are only fit for culinary purposes. When we examine the best system of pruning, we shall see that the most successful cultivators have adopted those plans which give abundant opportunity for the rays of the sun to reach every fruit.

Not only does the light of the sun influence vegetable growth, but that of the moon affects them more than might be expected. It is well known that during the day the leaves are constantly decomposing the water contained in their sap, and setting free the oxygen, while they store up the carbon. In the night this function ceases: the oxygen is slowly absorbed, and carbonic acid evolved. Therefore, in the morning the plant must first replace the carbon which was lost during the night before it can grow.

According to Professor Zantedeschi, in moonlight 
nights this loss of carbon is not only prevented, but carbonic acid is slowly acquired. He placed several plants, which were in full growth, where they would receive no light, and at the rise of the moon he exposed a part of them to its rays. These kept their green color and healthy appearance, while the others perished. He states that this influence of the moon, if true, is probably the cause of the increased growth of plants during the full of the moon, which has been noticed by some naturalists.

The meteorological phenomena which influence the growth and productiveness of fruit-bearing plants have now been considered, and it remains for us to name those fruits which are adapted to the different exposures.

The summit of hills cannot easily be protected from severe winds in the manner which was suggested upon plains, but must be more or less subject to them. Therefore, in the selection of fruits for such a position, those should be chosen which hold fast to the tree. The Flemish Beauty pear is notorious for the ease with which it separates from the spur. If we examine for the cause, we find that all those large pears which have slender stems, drop easily; the wind swings them, the stem breaks, and the fruit falls. This style of stem is more generally found in the Bergamottes, as in figure 1. Where the stem is thick and fleshy, and especially if it has 
a lip on one side, as at (A) in figure 2 , it will be likely to maintain its hold. Among those pears which are most reliable upon such a site, may be named, the Bartlett, the Beurrè d' Anjou, the Beurrè Bosc, the Merriam, the Nouveau Poitean, the Onondaga, the Glout Morceau, and the Vicar of Winkfield. Such an exposure is desirable for the cherry, and most partially tender fruits, because they must
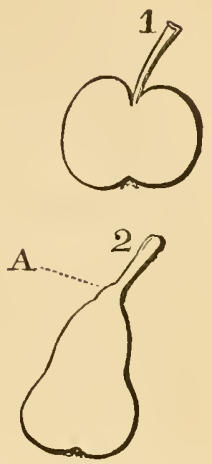
have abundant air to ripen their shoots. All of the small fruits will succeed admirably.

Northern exposure is best adapted to the most tender species, because it is comparatively free from those vicissitudes of temperature which are found on a southern slope. It is a well-known fact that where ivies and rhododendrons will perish during the first winter in which they are exposed on the sonthern or eastern side of a building or declivity, they flourish often for years on the northen.

If we examine closely the bud of a hardy tree during the winter, we shall discover that it consists of many layers of minute leaves, and that the whole is covered with a coat of scales that is lined with a thick pubescence, which acts as a non-conductor of heat. This is generally true of the buds of all trees of a cold climate. Consequently they require regular 
heat for a long time to bring them forth from their dormant state. Thus it will be seen that such species as possess this quality will not be subject to injury during the warm days of winter. Those fruits, however, which are indigenous to a more tropical clime, do not possess these outer scales, and therefore a few warm days bring them immediately into blossom. Even if they do not fully open their petals, the heat has started the sap and irritated the bud, and a sudden fall of temperature will kill the tender germ. Such are the peach, apricot, and nectarine.

This is not only a property of species, but is more or less modified in varieties. Nature does not bestow her gifts umnecessarily. A variety which originates where such protection would not be required, has this property so modified as to render it tender in severer latitudes. Therefore native varieties of fruit are generally better adapted to cultivation, and freer from disease, than those of foreign origin.

On a northern or northwestern exposure, these tender species or varieties remain frozen during the whole winter, and do not start in the spring until all danger from severe frost is past.

When we desire to extend the time of maturity in a variety, it should be planted on such a site; while to hasten it, the opposite exposure should be chosen. Grapes should not be planted on a slope to 
the north, as they require the direct rays of the sun to bring them to sufficient maturity to produce wine, and the cold temperature of the north would delay this until the early frosts of autumn would have prevented it.

Southern exposure. This is much more liable to extremes than the northern. All except the most hardy fruits will be affected injuriously by the thaws of winter. But those which do successfully baffle with these hardships produce the most luscious specimens, as the power of the sun is greater here, and the saccharine fermentation proceeds with vigor. On this exposure the amateur would not think of planting any but the most hardy varieties. There are some fruits, such as the grape, which flourish on a southern slope. There they receive a greater degree of heat, and their maturity is therefore hastened before the early frosts of autumn. In such a case the cold does not injure them, because they contain so much sugar, while it destroys those which are immature. The air is dryer, too, and they are not so subject to mildew and other diseases.

The cultivation of fruit in low valleys is accompanied with great risk; while it is superior to all others in beauty, yet the succulent growth consequent upon a stagnation of the air, and a partial exhaustion of its carbonic acid, renders the wood 
liable to be killed during the winter. Generally these should be avoided; but in the hands of a skilful cultivator, with a judicious selection of varieties and proper pruning, the result may be more favorable. 


\section{CHAP'TER II.}

\section{ORIGIN AND PROPERTIES OF SOILS.}

SOILS TIE RESULT OF DISINTEGRATION - CAUSES STATED BY SIR H. DATY

- BotssingaUlt - HitchCOCK - Allutial agexcies. properties : SPECIFICGRAVITY - AFFINITY FOR MOISTURE - ABSORPTION OF MOISTURE FROM THE AIR - CAPILLARY ATTRACTION - STATE OF DIVISION - COMESION AND ADHESION - ABSORPTION OF GASES FROM THE ATMOSPHERE - ABSORPTION AND RETENTION OF HEAT.

WHE earth presents a great diversity of soils, upon which widely different kinds of plants flourish, each adapted to some peculiar genus, species, or variety of plant in the vegetable kingdom. The failure of one orchard, while another, receiving the same treatment, succeeds, evinces the necessity of a proper selection of the land for the growth of fruit.

"All soils are the result of the disintegration and decomposition of rocks, with the addition of saline and decayed vegetable and animal substances." The materials derived from the rocks constitute by far the larger part, and therefore by an examination of these we can form an idea of the composition of the soil produced from them. Soils may be almost wholly composed of disintegrated rocks, in which 
case the ingredients of the earth which result from them will maintain their original character; but if these are decomposed, their relations may be changed. Soils do not always contain those substances alone which are found in the rocks of their immediate neighborhood, for by the action of diluvial currents the loose matter of different rocks is frequently intermingled, while sometimes the foreign entirely covers the native material. Alluvial land is formed by the deposits of streams, and has in its composition the substances inherent in the various rocks through which it has passed. Peaty soils are mostly the result of the decay of vegetable matter, and have but little of the components found in the original rocks. The fertility of soils depends in a great measure upon its admixture and subdivision. An earth, if it may be properly so called, composed entirely of pebbles, would not support vegetation. Coarse sand may be knit together by the roots of a few plants, but in a fine state of division and decomposition it can nourish almost any plant. The benefit resulting from the mixture of soils is shown by the fact that those lands formed from the decomposition of conglomerate rock are very fertile. Dr. Hitchcock, in his "Geological Survey of Massachusetts," says that soils consist, "first, of their earthy and metallic ingredients, which are mostly silicates; secondly, the acids, alkalies, and salts which existed originally in them, or are introduced by cultivation; 
and thirdly, of the water and organic matter which they contain. The latter constitutes the principal nourishment of plants derived from the soil, while the salts are necessary to prepare that nourishment to be taken up and assimilated by their delicate vessels. The earth serves as a basis of support for the plant, as a receptacle for the nourishment, and probably also, in connection with the roots, as a galvanic combination for the development of those electrical agencies by which the food of plants is taken up and converted into vegetable matter. Soils, to be fertile, should contain silica, allumina, and lime, and should be in a good state of subdivision, as this has much influence on the retention of moisture. The proportion of earthy materials is not of so much importance, if they are only present, because the amount consumed is so small compared with the humic acid, or organic remains. Dr. Dana aptly says that the earths are the plates, the salts the seasoning, and the geine (or humic acid) the food of plants." Cultivation àoes not materially alter the natural composition of the earths, but it modifies its salts and humic acids. Plants cannot flourish without this latter element. Alluvial and sandy diluvial contain the least of it, and should therefore be supplied with manure; the crops then gathered may be even larger than those from a soil in which it naturally exists, because such lands, being porous, the atmosphere is able to 
penetrate and prepare the whole of it for the nourishment of plants. The amount possessed will not necessarily effect the first crop; but it may soon become so exhausted that it will not produce another. Upon the amount of humic acid which is contained in the soil will depend the length of time in which it will continue to produce good crops.

Humus, by absorbing oxygen from the atmosphere, is able to furnish the plant with carbonic acid, which is thus produced, and also with oxygen. While there are soils which are unfertile from want of humus, yet this element, which exists in such vast quantities in the peaty deposits of swamps, would, if mixed with them, render all such fertile. Dr. Dana says that "the fact that peat, or turf, is very soluble in alkali, seems not to be known among our farmers. The usual practice of mixing lime with peat is decidedly the worst which can be followed, as the geine, which forms the largest part of peat bogs, forms with lime a compound which is very insoluble. With allumina geine forms a compound still more insoluble than with lime; and though the vegetable matters in combination with these earthy bases are actually absorbed by the ronts of growing plants, still the geine is in a state much less favorable than when in combination with alkali. If we mix the lye of wood ashes with peat, we form a dark-brown vegetable solution; the alkaline properties are completely neutralized by the 
geine, and very often ammonia escapes from turf when treated with caustic alkali."

Professor Schübler says that pure earths, such as sand, lime, magnesia, and gypsum, when dry, are nonconductors of electricity, and that clays are also imperfect conductors. When oblong pieces of all the earths are scraped with a knife, they develop negative electricity. Experiments show that when solutions of humus are exposed to a current of galvanic electricity decomposition immediately ensues; the geine collects about the positive pole, and the earths around the negative. Dr. Dana supposed that by means of this galvanic agency the rootlets of plants were enabled to attract alkali even from the particles of felspar and mica in the soil, while it was yet in an insoluble condition. If this is true, it would depend, says Dr. Hitchcock, to a considerable extent, on the subdivision of its particles. If this be allowed, the presence of alkali in a soluble condition in the soil is not important when the rocks are present which contain it in an insoluble state, as the rootlets will supply themselves from this source. This may be another of the wonderful provisions of Providence for the wellbeing of the plant, because of the liability of the soluble alkalies to be washed away by rains, while in their original condition these little rootlets alone contain the key to their treasures.

Earths are composed of different substances, be- 
cause the rocks of which they are the particles are so various. Thus the stratum may have been of sandstone, when the soil produced will of course be sandy; if of limestone, then the calcareogus element will prevail ; if of slate, then clay. The minerals which are generally found in the rocks are quartz, felspar, mica, amphibolite, pyroxenite, talc, serpentine, and diallage. These, according to Boussingault, are formed of metals which enter into the structure of plants. Thus quartz is almost pure silica, or sand.

Sir Humphrey Davy observed, with regard to the chemical causes of disintegration: "The manner in which rocks are converted into soil may be easily conceived by referring to the instance of soft or porcelain granite. This substance consists of three ingredients - quartz, felspar, and mica. The quartz is almost pure silicious earth in a crystalline form. The felspar and mica are very compounded substances; both contain silica, allumina, and oxide of iron. In the felspar there is usually found lime and potassa; in the mica, lime and magnesia. When a granite rock of this kind has been exposed to the influence of air and water, the lime and potassa contained in its constituent parts are acted upon by water, or carbonic acid; and the oxide of iron, which is generally in its least oxidized state, tends to combine with more oxygen. The consequence is that the felspar decomposes, and also the 
mica; the first the most rapidly. The felspar, which is the cement of the stone, forms a fine clay; the mica, partially decomposed, mixes with it as sand; and the undecomposed quartz appears as gravel or sand of different degrees of fineness. As soon as the smallest layer of earth is formed on the surface of a rock, the seeds of lichens, mosses, and other imperfect vegetables, which are constantly floating in the atmosphere, and which have made it their resting-place, begin to vegetate; their death, decomposition, and decay afford a certain quantity of organizable matter, which mixes with the earthy material of the rocks. In this improved soil those perfect plants are capable of subsisting. These in their turn absorb nourishment from water and the atmosphere, and, after perishing, afford new material to that already provided. The decomposition of the rocks still continues; and at length, by such a slow and gradual process, a soil is formed in which even forest trees can fix their roots, and which is fitted to reward the labors of the cultivator."

Boussingault thus gives the mechanical causes effecting segregation. "Water, by reason of its fluidity, penetrates the masses of rocks that are at all porous, and filters into their fissures. If the temperature now falls, and the water congeals, it separates by its dilatation the molecules of the minerals from one another, destroys their cohesion, produces clefts, and slowly reduces the hardest 
rocks, first to fragments, then to powder. During its frozen state, the ice may serve as a cement, and hold together the disintegrated particles; but with a thaw, the slightest force, currents of water, or the effect of weight, suffices to carry the fragments to the bottom of the valley; and the rubbing and motion to which these are exposed in torrents, tend to break them still smaller, and reduce them to sand."

It is well known that water, by an apparent exception to a general law, expands with great force when freezing. Over a large extent of surface the effect may be very considerable, and when boulderstones lying in shallow ponds become partially enveloped in the ice, they must feel the effects of this expansion, and be driven toward the shore; since the force must always act in that direction. As nothing exists to bring back the rock to its original position, the ultimate effect must be to crowd it entirely out of the water; and perhaps to this cause we may impute the fact, that on the margin of some ponds we find a ridge of boulders, while the bottom, to a consiclerable extent, is free from them. ${ }^{1}$

"There is, however, one agent of excavation that still operates to some extent, and this is called icefloods. Their effect is most powerful upon the smaller and more rapid streams. Whoever has not

1 Gcological Survey of Massachusetts, by Dr. Iitchcock. 
witnessed the breaking up of a river in the spring after a severe winter, when its whole surface has been covered by ice several feet thick, has but a faint idea of the prodigious force exerted at such a time. The ice high up the stream is usually first broken in pieces by the swollen waters. Large masses are thus thrown up edgewise, and forced underneath the unbroken sheet, and the whole bed of the river is blocked up - perhaps, too, where the banks are high and rocky. The water accumulates behind the obstruction until the resistance is overcome, and the huge mass of water and ice urges on its way, crushing and jamming together that which it meets, and thus gaining new strength at every step. Often for miles the stream, prodigiously swollen, is literally crammed with ice, so that the water disappears, and a slowly-moving column of ice is all that is seen. This presses with such force upon the bottom and sides of the river-bed as to cause the earth to tremble, with a sound like heavy thunder, for a distance of miles. Sometimes the body of ice becomes so large, and the friction so great, that the waters are unable to keep it in motion, and it stops, while the river is turned out of its channel, and is compelled to flow in a new bed for weeks and even months."

This cause has a wonderful effect in excavating the beds of rivers. It sometimes tears up great rocks, and pushes them for a considerable distance. 
Dr. Hitchcock divides the deposits from diluvial currents into "first, boulder-stones, formed generally of the least yielding rocks; second, gravel or sand mixed, or the more yielding rocks; third, beds of clay; fourth, consolidated sand and pebbles; and fifth, beds of sand. The depositions are generally horizontal, although some of them dip a little, and lay according to the degree of their pulverization. Sometimes, by an action which appears to have been lateral pressure, the strata becomes somewhat contorted.

"From alluvial agencies are produced -

"1. Soil, or disintegrated and decomposed rock, with such an admixture of vegetable and animal matter as will support the growth of plants.

"2. Those vast accumulations of sand which are found in the beds of the ocean and of lakes, and which, when driven upon the land by the wind, are called downs. These are constantly shifting, and are destitute wholly of organic matter, and are therefore entirely barren.

"3. Peat. This consists almost wholly of organic remains, which are deposited by the death of plants. It is a powder when dry. These beds occur only in the temperate zones.

"4. Alluvial marl. This varies somewhat in composition, but consists of carbonate of lime, cliay, and soluble and insoluble geine. It often lies be- 
low peat in limestone countries, and is sometimes found at the bottom of ponds.

"5. Calcareous tufa, or travertine. This is a deposit of the carbonate of lime from springs, and forms a substance like stalactites.

"6. Coral reefs.

$" \%$. Silicious sinter, which is a deposit of silica from thermal springs.

"8. Silicious marl, much resembling calcareous marl, but composed almost entirely of silica, deposited from the skeletons of minute infusoria, which at death sink to the bottom of the pond.

"9. Bitumen, deposited from springs in the form of naphtha and asphaltum.

"10. Sulphate of lime, very rarely deposited by springs.

"11. Hydrate of iron.

"12. Hydrate of manganese.

"13. Chloride of sodium.

"14. Sandstones, conglomerates, and breccias. Sand cemented, is called sandstone; when it contains rounded pebbles, it is said to be conglomerate ; and when it has angular fragments, it is called breccia."

The substance deposited by rivers differs with the distance from the mouth. When it comes forth from the mountain, coarse stones and boulders are rolled along, the finer materials are carried further, and the finest are found near the mouth of the stream. Alluvial deposits are made from current: 
of the ocean. Alluvium is formed upon marshes, near the coast, by the decay of regetation, by material retained after the flow of the tide, and by that deposited by streams. In northern latitudes, peat is thus formed. In the muddy deposit at the bottom of lakes, ponds, or inlets, aquatic plants begin to flourish, and by their decay increase the depth of the deposits; at last it reaches the surface of the water, and becomes a marsh. The top of this deposit is composed of vegetable fibre hardly decomposed at all, and from this is a regular gradation to perfectly-formed peat in the lower strata.

Dr. James E. De Kay, Zoologist for the State of New York, says: "In a calm, still day $I$ have frequently noticed the surface of the water covered with patches of sand, varying in extent from one to six or eight inches square. These patches are composed, of course, only of the finer portions of sand, adhering to each other by a thin film of gelatinous matter, which gives buoyancy to the mass. I have been surrounded frequently by patches of this kind in tolerably close contact, and covering a surface of several hundred acres. The lightest touch of an oar, or a slight breeze, causes them to sink immediately. The rationale of their formation I conceive to be this: the shore we know to be peopled with myriads of minute mollusca, furnishing, either by their excrements or their own proper borlies, a gelatinous substance, which hardens upon exposure 
to the sun, and forms a crust including the subjacent sand. In this state the water comes in quietly, detaches successive portions of this crust, in large or smaller pieces, which are borne away by the retreating tide. May not this silent and hitherto unnoticed transportation counteract, to a certain extent, the operation of other known agents? It is not philosophical, I admit, to impute important effects to slight and apparently inadequate causes; but it is equally unphilosophical to neglect trifling phenomena until the nature and extent of their agency has been thoroughly investigated."

Boussingault says: "The final result of the disintegration of rocks, and of the decomposition of those minerals which enter into their constitution, is the formation of those alluvia which occupy the slopes of mountains that are not too steep, the bottoms of valleys, and the most extensive plains. These deposits, however formed, - whether of stones, pebbles, gravel, sand, or clay, - may become the basis of a vegetable soil, if they are only sufficiently loose and moist. Vegetation of any kind succeeds upon them at first with difficulty. Plants, which by their nature live in a great measure at the expense of the atmosphere, and which ask from the earth little or nothing more than a support, fix themselves there when the climate permits. Cactuses and fleshy plants take root in sands; mimosas, the brocua, the furze, and others, show themselves upon gravels. 
These plants grow, and after their death, either in part or wholly, leave a debris which becomes profitable to succeeding generations of vegetables. Organic matter accumulates in the course of ages, even in the most ungrateful soils, in this way, and by these repeated additions they become less and less sterile. It is probable that the virgin forests of the New World have thus supplied the wonderful quantity of vegetable mould in which the present generation of trees is rooted. At Larega de Supia, in South America, the slipping of a porphyritic mountain covered completely with its debris, to the extent of nearly half a league, the rich plantations of sugar-cane which were there established. Ten years afterwards I saw the blocks of porphyry shadowed by thick groves of mimosas; and the time, perchance, is not very remote when this new forest will be cleared away, and the strong soil, enriched with its spoils, will be restored to the husbandman.

"The chemical composition of the earth adapted for vegetation must of course participate in the nature of the rocks and substrata from which it was derived; and the elements which enter into the constitution of mineral species onght to be found in the soils, which, by the effect of time or human industry, may serve for the reproduction of vegetables. It is on this account that it becomes interesting to study the composition of the minerals, which are the most abundantly dispersed in the solid mass of the globe." 
Professor Stockliardt says of the weathering and decay of rocks, that the crumbling of rock into earth still continues, and renders it capable of becoming and remaining a supporter and sustainer of vegetable growth. The principle on which it acts may be thus described:

"Through the alternations of heat and cold, cracks and fissures are formed in the most solid rocks; with the assistance of air and water, these are deepened and widened, and separate fragments are detached from their connection with the great mass. Through the same alternations of temperature a daily circulation of air is produced in the porous soil. Moreover, all chemical processes go on more rapidly and energetically at a high temperature than at a low ; therefore, the warmer a soil is, the more rapidly will weathering and decomposition proceed in it.

"Air, in union with the watery vapor always present in it, affords oxygen, or water, to all bodies which have a tendency to combine with these substances. The particles of iron (protoxide), which scarcely any rock is without, make use of it, and become converted into iron-rust, which does not possess a fixing or binding power, like the protoxide of iron, and therefore no longer offers any obstacle to its disintegration. The fact that all rocks which are traversed by a yellow vein of iron-rust may be split or broken readily, demonstrates this clearly. 
'The avidity with which organic substances, whether' derived from dead plants or animals, absorb oxygen, is still greater than that of iron. The breaking down, decay, gradual solution, and disappearance of these, is caused principally by air ; for decomposition consists of a constant absorption of oxygen, which forms with the elements of these organic substances ncw, soluble, and volatile compounds, which, where vegetation abounds, are in great part absorbed by the roots and foliage; otherwise they are lost by evaporation. Air in motion, as in winds or storms, may also, by its mechanical porver, directly or indirectly promote the cracking or loosening of the earth, as also the circulation of air in the soil, by its pressure on the crown of a tree, thus exercising a leverage on the roots."

We have before stated that it was unsafe to judge wholly of the nature of the soil by the rocks which underlie it, on account of the numerous chemical and mechanical agencies which are at work in their disintegration, decomposition, and mixture. If the surface of the earth was a vast level, the substratum of rock would be a more correct index to the nature of the soil; but such a condition of things would be decidedly unfavorable to fertility, as it would entirely prevent the mixture of the separated particles of the different rocks. "The agency of water to produce this result is almost beyond conception. In a violent storm, we can perhaps form an idea 
how the breakers of the ocean eat away the shore, by referring to the North of Germany, where it has swallowed up large tracts of the continent and islands. Of twenty-four islands of East Friesland, which existed at the time of the birth of Christ, only sixteen at present remain. In like manner we have examples of the opposite effect of water, showing that at least a portion of that which it has taken from the land in one place is deposited in another; - in the delta of the Nile, which is almost half as large again as the kingdom of Saxony; in the delta of the Ganges, twice as large; in the south coasts of France and Italy, where a band of solid land, from one to two leagues wide, has been formed by alluvial deposits since the time of the Romans; in the Low Countries, in the Coral Islands, etc." In the polar regions immense bodies of ice are often detached from the land, bearing large quantities of earth with them, and often transport it great distances. Sometimes glaciers separate from the mountain-top on the approach of summer, and, in sliding toward the valley, wear off the rock, and push the heaps of gravel before them to the plain.

"Rain, frost, and gravity," says Dr. Hitchcock, "are the three principal causes which operate to degrade the hills and fill up the valleys."

Let us now consider the PROPERTIES of soILs.

Specific gravity. Those soils which weigh the 6* 
most are the least fertile. Pure sand has the greatest specific gravity, and we know it to be sterile. In proportion as it becomes light does the organic matter, and therefore the fertility, increase. IIumus, or soil of decayed regetation, is the lightest of all ; then clay, calcareous earths; then sand.

Mr. Johnston found one cubic foot of dry

Silicious or calcareous sand to weigh . . . . $110 \mathrm{lbs}$.

Half sand and half clay, . . . . . . . 95

Common arable land, . . . . from 80 to 90

Pure agricultural clay, . . . . . . . . 75

Garden mould, richer than the last in vegetable matter, 70

Peaty soil, . . . . . . . from 30 to 50

Affinity for moisture. As the plant receives its food through the medium of water, it is necessary that arable land should have the power of imbibing a considerable quantity. To be of value for fruits, a soil should be able to absorb from forty to seventy per cent. of its weight in water. Mons. Schuibler made a series of very interesting and useful experiments upon the character of soils, which was published in the annals of French agriculture, and whose tables we take the liberty to use, in considering this and other properties of soils.

The degree of absorption in different kinds of earth is nearly as follows:

Kinds of Earth.

Silicious sand,

Gypsum, .

Calcareous sand,

Sandy clay,

Strong clay,

Fine calcareous earth,
Per cent. of Water absorbed.

25.0

27.0

29.0

40.0

85.0 
Kinds of Earth.

Per cent. of Water absorbed.

Ifumus,

190.0

Garden earth, . . . . . . . . . 83.0

Arable soil, . . . . . . . . . . 52.0

Arable soil, . . . . . . . . . . . 48.0

Retention of moisture. When soils become wet with dew or rain they part with it by evaporation with very different degrees of rapidity. Those which absorb the most are generally the ones which dry the slowest, and this quality constitutes the difference between warm and cold soils, as seen below :

One hundred parts of the water contained in the soil loses in the course of four hours, at $66^{\circ}$ Fahr., the following per centage:

Kinds of Soil.

Per cent. of Loss.

Silicious sand,

88.4

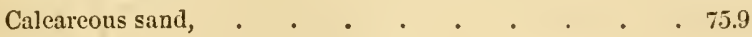

Gypsum, • • • • . . . . . . 71.7

Sandy clay, . . . . . . . . . . . 52.0

Stiffish clay, . . . . . . . . . . 45.7

Stiff elay, . . . . . . . . . . . . 34.9

Pure clay, . . . . . . . . . . . 31.9

Calcareous soil, . . . . . . . . . 28.0

Garden earth, • • • • • • . • . 24.3

Humus, . • . . . . . . . . . 20.5

Thus it will be seen that those soils which absorb the least moisture lose it the quickest by evaporation. As the earth dries, it shrinks. This causes the cracking of clays, which, as will be perceived in the chapter on drainage, is such an important quality, because it permits the water to pass off through these crevices, when tenacious earths would otherwise be impervious. 
Kinds of Soil.

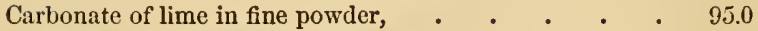

Sandy clay, . . . • • • • • • . 94.0

Stiffish clay, •

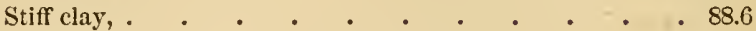

Pure clay, • • . . . . . . . 81.7

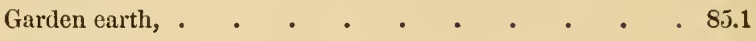

Humus, .

Absorption of moisture from the air. This is a quality of great value, particularly in a hot and dry country, where the amount of rain for several months is very small. It restores to the soil a part of the moisture which has escaped by evaporation. Sir Humphrey Davy deemed this an index to the good quality of land. It will be found, according to $\mathrm{M}$. Schiibler's experiments, that this property of the absorption of moisture from the air is in proportion to the fertility of the earth, since clay and peaty soils possess it most abundantly, and sandy and calcareous lands the least. Schübler ascertained the following facts by exposing soils to the atmosphere at the point of saturation with moisture, the temperature being from sixty to sixty-five degrees Fahrenheit.

"Seventy-seven and one hundred and sixty-five thousandths (77.165) grains of Troy weight of soil spread upon a surface of one hundred and fortyone and forty-eight one hundredths (141.48) square inches, absorbed in twelve, twenty-four, forty-eight, and seventy-two hours respectively, as shown in the following table. 
TABLE C.

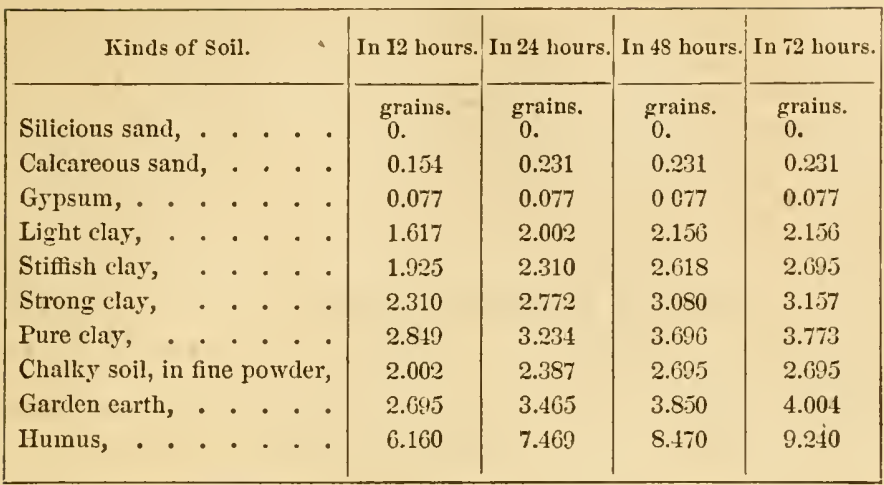

Capillary attraction. This consists of the sucking up of the moisture from the subsoil to the surface of the earth. It takes place in different degrees in all soils. In some it is not sufficient to sustain vegetation when the surface becomes dried by the heat of the sun, and therefore the crops suffer from drought. In others it is in excess, and constantly keeps the soil cold and wet, which it is the object of draining to prevent. Capillary attraction, to a certain extent, is of great importance to the growth of vegetation, as the moisture which arises generally contains valuable saline properties, which are left in the soil when the moisture escapes by evaporation.

State of division, cohesion, and adhesion. In very stiff lands, the labor of the cultivator is principally expended ir producing that friability which is ne- 
cessary to productiveness. 'This is one reason why the chemical analysis of a soil is not always an index to its value, nor a guide to the quality which it lacks, because in such an experiment its mechanical division cannot be considered. The frost is a powerful natural agent in promoting the looseness of land; but the artificial means of subdivision will be fully considered in the chapter upon Pulverization.

TABLE D.

\begin{tabular}{|c|c|c|c|c|}
\hline Kinds of Soil. & $\begin{array}{l}\text { Tenacity } \\
\text { of Soil, that } \\
\text { of pure Clay } \\
\text { being } 100 .\end{array}$ & $\begin{array}{l}\text { Tenacity } \\
\text { expressed in } \\
\text { Weight. }\end{array}$ & $\begin{array}{c}\text { Cohesion } \\
\text { in the } \\
\text { moist state. }\end{array}$ & $\begin{array}{l}\text { Vertical } \\
\text { adliesion to } \\
\text { Iron and } \\
\text { Wood on the } \\
\text { surface of } \\
3.937 \text { square } \\
\text { inclies. }\end{array}$ \\
\hline Silicions sand, . . . & 0 . & $\begin{array}{c}\text { kilogr. } \\
0 .\end{array}$ & $\begin{array}{c}\text { kilogr. } \\
0.17\end{array}$ & $\begin{array}{c}\text { kilogr. } \\
0.19\end{array}$ \\
\hline Calcareous sand, . . & 0. & 0. & 0.19 & 0.20 \\
\hline Fine calcareous earth, & 5. & 0.55 & 0.65 & 0.71 \\
\hline Gypsum, . . . . & 7.3 & 0.81 & 0.49 & 0.53 \\
\hline lInmns, . . . . . & 8.7 & 0.87 & 0.40 & 0.42 \\
\hline Sandy clay, . . . & 57.3 & $6.36^{\circ}$ & 0.35 & 0.40 \\
\hline Stiff clay soil, . . . & 68.8 & 7.61 & 0.48 & 0.52 \\
\hline Strong clay,. . . . & 83.3 & 9.25 & 0.78 & 0.86 \\
\hline l'ure clay, . . . & 100. & 11.10 & $1.2 \%$ & 1.32 \\
\hline Garden earth, . . . & 7.6 & 0.81 & 0.29 & 0.34 \\
\hline
\end{tabular}

The cohesive and adhesive power of soils is, of course, increased when they are wet. Every one knows how difficult it is to separate two wet pieces of glass. Clay soils possess this quality in the greatest degree; it is, however, lessencd by the methods described in the succeeding chapters. Schïbler called the tenacity of pure clay one hundred, 
and gave that of other soils relatively. The difficulty of working land is shown in the last column, also by its adhesion to the plough. The relative tenacity of different soils may be learned from the preceding table (D).

Absorption of oxygen, carbonic acid, etc., from the atmosphere. The power of the soil to absorb these gases which are so important to vegetation, is dependent, to a large degrec, upon the state of division of its particles. Baron Liebig maintains that the property of absorbing fertility from rain-water is dependent upon the amount of humus present in the soil. We give his words:

"Arable soil possesses in these respects the same properties as charcoal. Diluted liquid manure, of deep-brown color and strong smell, filtered through the land, flows off colorless and inodorous; not merely does it lose its smell and color, but the ammonia, potash, and phosphoric acid which it holds in solution are also more or less completely withdrawn from it, and this in a far greater degree than by charcoal. The rocks which by disintegration give rise to soil, if reduced to fine powder, are just as little possessed of this property as pounded coal. 'There is no perceptible connection between the composition of a soil and its power of absorbing potash, ammonia, and phosphoric acid. Earth abounding in clay with a small proportion of lime 
in it, possesses this absorbent power in the same degree as a lime soil with a small admixure of clay; but the quantity of humus present will alter the absorbent relation.

"By a closer examination, we perceive that this power of arable soil differs in proportion to its greater or less porosity; a dense, heavy clay, and a loose sandy soil possess this absorbent power in the smallest degree."

Dr. Seller calculated the annual conversion of the carbon of organic matter into inorganic carbonic acid at not less than six hundred millions of tons; and infers, on the most favorable aspect of the amount of soil over the earth's surface, that such an annual loss could not be withstood beyond six thousand years; and on a less exaggerated assumption of its amount, probably very near the truth, that the waste would absorb the whole of the existing organic matter of the soil in about seven hundred and forty years. Dr. Seller contends that the truth of these conclusions remains unaltered, even if it be considered that much of the carbon of plants is drawn, not from the organic matter of the soil, but from the inorganic carbonic acid of the atmosphere, unless some inorganic source of their hydrogen and oxygen be at the same time admitted. He therefore regards Liebig's view of the inorganic nature of the food of plants as supported not only by many special facts, - such, for example, as that increase 
of the organic matter of the soil, which is often observed during the growth of plants, - but also by the general view of the earth's surface just taken; because there is nothing in its aspect to warrant the idea that its ineans of maintaining the organic kingdoms are declining with the rapidity indicated in the statements just made. ${ }^{1}$

Although there is no doubt that plants depend largely upon the atmosphere as well as on the soil for their carbonic acid, still there is probably no fixed law which governs the exact proportion which it shall receive from either, under all circumstances. If the soil is wanting in this element, or in the power of setting it free by decomposition, there is reason to believe that the foliage will endeavor to make up for the deficiency by imbibing it from the atmosphere. If, on the other hand, the soil is overcharged with carbonic acid, it may be also true that the leaves of those plants which are seen upon its surface exude, like a safety-valve, the surplus material. Such a theory, it appears to us, is consistent with the belief that God made all his natural laws so perfectly adapted to each other that, to all appearances, they are, like the stones which form the arch, self-supporting.

Absorption and retention of heat. The fact is well known that the earth, by absorbing the rays of heat

I Dr. Lindley's quotation from Annals of Natural History. 
from the sun, often becomes much hotter than the surrounding atmosphere. The soil is firequently raised to a temperature of one hundred degrees Fahrenheit, and sometimes to one hundred and fifty. This fact explains the reason for the immense growth of trees at such times, if moisture is also present, while the air is only about eighty-five degrees.

The exposure of the soil has an influence upon this quality, as the degree of heat will be much higher if it is protected from cold winds. Its color is also a great consideration, as the darker earths will, of course, absorb the most. But the power of retaining this heat after it is absorbed is a different matter. Schübler's tables will again supply us with a valuable guide.

TABLE E.

\begin{tabular}{|c|c|c|}
\hline \multirow{2}{*}{ Kinds of Soil. } & \multicolumn{2}{|c|}{$\begin{array}{l}\text { Highest Temperature acquired by the } \\
\text { Upper Layer, the Mrean Temperature } \\
\text { being } 25^{\circ} \text { Ceut., } 77^{\circ} \text { Fahr. }\end{array}$} \\
\hline & $\begin{array}{c}\text { MIoist Soil. } \\
\text { Degrees Centigrade. }\end{array}$ & $\begin{array}{c}\text { Dry Soil. } \\
\text { Degrees Centigrade. }\end{array}$ \\
\hline Silicious sand, yellowish gray, . & $37.25 \quad(99.0 \mathrm{~F})$. & 44.75 (112.5 F.) \\
\hline Caleareous sand, whitish gray, . & 37.38 & 44.50 \\
\hline Bright gypsum, whitish gray, . & 36.25 & 43.62 \\
\hline Poor clay, yellowish, . . . . & 36.75 & 44.12 \\
\hline Stiff elay, . . . . . . . . . & 37.25 & 44.50 \\
\hline Argrillaccous earth, yellowislı gray & 37.38 & 44.62 \\
\hline Pure clay, bluish gray, . . . . & 37.50 & 45.00 \\
\hline Calcarcous eartl, white, . . . & $35.63 \quad(96.1 \mathrm{~F})$. & 43.00 (109.4 F.) \\
\hline IInmus, blackish gray, . . . . & 39.75 (103.5 F.) & 4737 \\
\hline Garden earth, blackish gray, . & 37.50 & 45.25 \\
\hline
\end{tabular}


TABLE F.

\begin{tabular}{|c|c|c|}
\hline Kinds of Soil. & $\begin{array}{l}\text { Power of retaining Heat, } \\
\text { that of Calcareous Saud } \\
\text { being } 100 \text {. }\end{array}$ & $\begin{array}{l}\text { Time which } 232.2 \text { cubic inclies } \\
\text { of Soil required to cool from } \\
144^{\circ} \text { to } 70^{\circ} \text { Fals.. the tem- } \\
\text { perature of the surrounding } \\
\text { air being about } 61^{\circ} \text { Falir. }\end{array}$ \\
\hline $\begin{array}{l}\text { Calcareous sand, . } \\
\text { Silicious sand, . } \\
\text { Gypsum, . . . } \\
\text { Sandy clay, . . . } \\
\text { Stiffish clay, . . } \\
\text { Stiff clay, . . } \\
\text { Pure clay, . . . } \\
\text { Calcareous soil, . } \\
\text { IIumus, . . . } \\
\text { Garden earth,. . }\end{array}$ & $\begin{array}{r}100.0 \\
95.6 \\
73.2 \\
76.9 \\
71.1 \\
68.4 \\
66.7 \\
61.8 \\
49.0 \\
64.8\end{array}$ & $\begin{array}{ll}\text { l. } & \mathrm{m} . \\
3 & 30 \\
3 & 27 \\
2 & 34 \\
2 & 41 \\
2 & 30 \\
2 & 24 \\
2 & 19 \\
2 & 10 \\
1 & 43 \\
2 & 16\end{array}$ \\
\hline
\end{tabular}

In examining all soils, we find that they consist of two layers, or strata, of varying thickness. The upper or surface soil is of a darker color than that which underlies it, because it possesses the organic remains of vegetable matter. Sometimes it is only three or four inches in depth, although in many fertile lands it may be found to as many feet. Beneath this lies the inferior layer, or subsoil. MI. Boussingault, in the translation by W. Law, says :

"In plains, on high table-lands, the analogy, in point of constitution, between the soil and subsoil is not so constant as in some other places. In such situations the arable land is frequently an alluvial deposit, proceeding from the destruction or disintegration of rocks situated at a great distance. When the superior strata possesses properties that are 
entirely different from the subsoils, it is easily understood how the vegetable earth may be improved by the addition of a certain quantity of the subsoil. The impermeability of the subsoil is one grand cause of the too great humidity of much-cultivated land. A strong soil, very tenacious through the excess of clay which it contains, has its disadvantageous properties considerably lessened if the subsoil upon which it rests is sandy; first, from the evident amelioration which must result from an admixture of the two layers; and next, because it is always a positive advantage to have a soil which has a strong affinity for water superposed upon a subsoil which is extremely permeable. The inverse situation is scarcely less desirable. A light, friable soil will have a greater value if it lies upon a bottom of a certain consistency which is capable of retaining moisture; with this condition, however, - that the clayey layer shall not be too uneven in its surface, that it shall not present great hollows in which water shall collect and stagnate. An impermeable subsoil, to act beneficially in such circumstances, must have a sufficient inclination to admit of its draining itself. The most essential question, then, to be considered with regard to the nature of subsoils, is, whether they are or are not permeable. Acquainted with the nature of vegetable earth, it is easy to judge of the advantages or disadvantages which will be presented by subsoil having the 
faculty of maintaining or permitting the escape of moisture.

"Generally, clayey lands answer better in dry climates, and light sandy soils in countries where rains are frequent. Kirwan made this remark long ago with reference to the analysis of wheat lands. The conclusion to which this celebrated chemist came was, that the soil best adapted for wheat in a rainy country must be of a different composition from that required where rains were less frequent. The fertility of sandy soils is notoriously in intimate relationship with the frequent fall of rain. Sandy deserts are sterile because it never rains. Upon the sandy downs of the coast of the Southern Ocean a brilliant vegetation. is seen along the course of the few rivers which traverse them; all beyond is dust and sterility. A sandy and little coherent soil is by so much the more favorably situated as it lies in the least elevated parts of a district, since it is there less exposed to the effects of drought. Any considerable degree of inclination is unfavorable to such a soil, inasmuch as the rain drains off too quickly, and because it is itself apt to be washed away. It is to prevent this action of the drains that the abrupt slopes of hills are generally left covered with trees; and the deplorable consequences which have followed from cutting down the wood in mountainous countries are familiarly known.

"Strong soils, on the contrary, are better if thus 
placed. A certain inclination is peculiarly advantageous to them; and, indeed, in working clayey lands that stand upon a dead level, we are careful to ridge them in such a way as to favor the escape of water." 


\section{CHAPTER III.}

CLASSIFICATION AND ADAPTATION OF SOILS.

SECTION I. CLASSIFICATION OF solls; SECtroN II. ADAPTATION TO DIFFLRET FRUITS - TARIETIES of tIR APPLE, APRICOT, BerberRT, CHERRT, CURRANT, FIG, GOOSEBERRY, GRAPE, PEACII, AND NECTARINE -

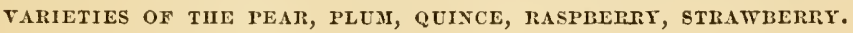

SECTION I. CLASSIFICATION OF SOILS.

TN arranging soils according to system, we shall adopt, as the most simple, that which was used by Loudon. The classes are formed from the presence or absence of organic or inorganic matter in their bases; therefore they are divided into primitive and secondary earths. These classes are subdivided according as they are founded on saline, metallic, or carbonic matter: the genera, on the principal earths, salts, metals, or carbon; species, on different mixtures; varieties, on color and texture; sub-varieties, on moisture, dryness, richness, or lightness. Mr. Loudon observes:

"In naming the genera of soils, the first thing to discover is the prevailing earth or earths; either the simple earths, as clay, lime, and sand, or the particular rocks from which the soil has been produced, as granite, basalt, etc. Where one prevails, 
the generic name should be taken from that, as clayey soils; where two prevail, to all appearance equally, then their names must be conjoined in naming their genus, as clay and sand, or lime and clay, etc. The great thing to be observed is precision in applying the terms. Sir Humphrey Davy observed: 'The term sandy soil should never be applied to any that does not consist of at least seveneighths sand; sandy soils which effervesce with acids should be distinguished by the name of calcareous sandy soils. The term clayey soil should not be applied to any land which contains less than onesixth of impalpable earth matter not considerably effervescing with acids; the word loam should be limited in its application to soils containing at least one-third of the same, copiously effervescing with acids. A soil to be considered as peaty should consist of at least onc-half of vegetable matter. In cases where the earthy part of a soil is eviciently the decomposed matter of one particular rock, a name derived from it may with propriety be applied. Alluvial soils may be designated as silicious, calcareous, or argillaceous; and in some cases the term saline may be added as a specific distinction applicable, for example, at the embouchure of rivers, when the alluvial remains are overflown by the sea.

"In naming the species, greater nicety is required than in naming the genera. The species are always determined by the mixture of matters, and never by 
the color or texture of that mixture, which belongs to the nomenclature of varieties. Thus a clayey soil with sand, is a sandy clay; this is the name of the species: if the mass is yellow, and it is thought worth while to notice that circumstance, then it is a ycllow sandy clay, which expresses at once the genus, species, and variety. A soil containing equal parts of clay, lime, and sand, would, as a generic term, be called clay, lime, and sand; if it contained no other mixture in considerable quantity, the term entire might be added as a specific distinction; and if notice was to be taken of its color or degree of comminution, it might be termed a brown, a fine, a coarse, a stiff, or a free entire clay, lime, or sand."

The following table (p. 82) is used not only by $\mathrm{Mr}$. Loudon, but by the agricultural establishments of Fellenberg, at Hofwyl, in Switzerland, at Moegelin, in Prussia, and also by Prof. Thouin.

\section{SECTION II. ADAPTATION OF SOILS.}

The choice of a suitable soil for the different species of fruits is a matter of great importance.

That which is adaptcd to the growth of the apple differs somewhat according to the variety. Yet we find certain general qualities of the soil applicable to all. Those lands which part with their moisture readily are not suited to the growth of the apple, 
TABLE G.

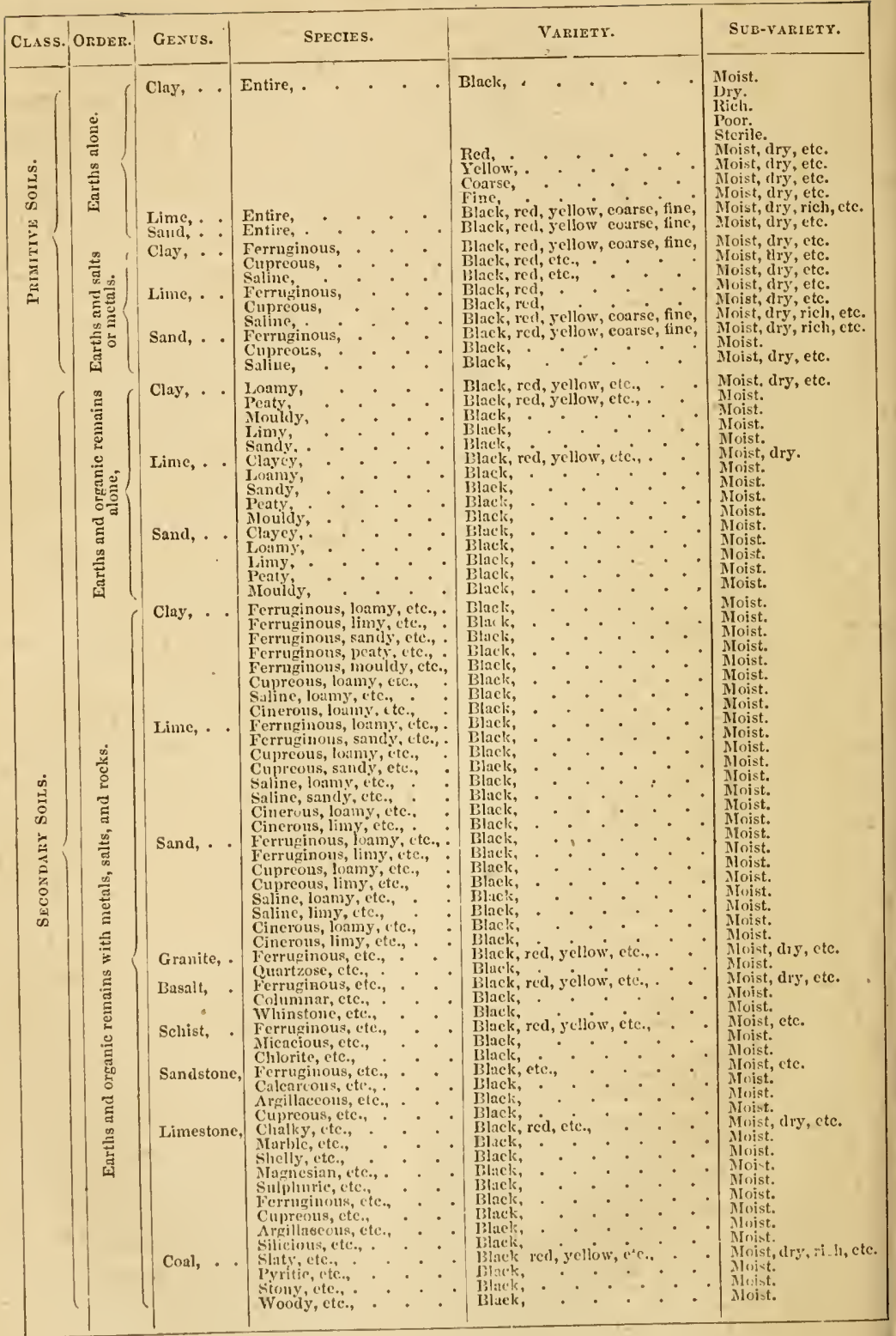


because it requires abundant nutriment, and in the absence of water this cannot be obtained. Neither does this fruit flourish in a soil which contains water in excess. The favorite earth of the apple is one which is deep, loamy, and calcareous. In those regions where the substratum is limestone, we expect and find the most beautiful fruits of this species. Marly earths are therefore adapted to it, because they contain carbonate of lime. Loamy clays are also often well adapted to the apple. A table is suffixed containing, as far as possible, the soils best suited to the leading varieties of this fruit. We do not assert that a certain variety will not grow upon those soils which are here left blank, but that they generally succeed better upon those indicated.

Name of Variety.

American Pcarmain,

Baldwin,

Belmont,

Early Joe,

Fameuse,

Fall Pippin,

Golden Sweet,

Green Sweet,

Gravenstein,

Jersey Sweet,

Ladies' Sweet,

Newtown Pippin,

Northern Spy,

Peck's Pleasant,

Porter,

Rambo,

Red Astrachan,

Rhode Island Greening,

Roxbnry Russet,

$\begin{array}{ccc}\text { Lime. } & \text { Loamy Clay. } & \text { Loamy Sand. } \\ \text { well, } & \begin{array}{l}\text { tolerably, } \\ \text { well, }\end{array} & \text { tolerably. } \\ \text { " } & \text { well, } & \text { well. } \\ \text { " } & \text { " } & \\ \text { " } & \text { " } & \text { well. } \\ \text { " } & \text { " } & \text { tolerably. } \\ \text { " } & \text { " } & \text { well. } \\ \text { " } & \text { " } & \\ \text { " } & \text { " } & \text { well. } \\ \text { " } & \text { well, } & \text { tolerably. } \\ \text { " } & \text { " } & \text { tolcrably. } \\ \text { " } & \text { " } & \text { well. } \\ \text { " } & \text { " } & \text { " }\end{array}$




$\begin{array}{lccc}\quad \text { Name of Variety. } & \begin{array}{c}\text { Lime. } \\ \text { well, }\end{array} & \text { Loamy Clay. } & \text { Loamy Sand. } \\ \text { Swaar, } & \text { " } & \text { well, } & \text { well. } \\ \text { Large Early Bough, } & \text { " } & \text { " } & \\ \text { Talman's Sweet, } & \text { " } & \text { " } & \text { well. } \\ \text { Wine, } & \text { " } & \text { " } & \text { " } \\ \text { Wine Sops, } & \text { " } & \text { " } & \text { " } \\ \text { Lyman's Swcet, } & \text { " } & \text { " } & \\ \text { Keswick Codlin, } & \text { " } & \text { " } & \end{array}$

The Apricot. This truly delicious fruit is of foreign origin, and the great difficulty in its cultivation in the northern part of the United States is the prevention of injury during the winter. When it finds no such difficulty, decp limestone soils are those in which it delights. But at the north such land would induce too free and late a growth, which would result in the death of the tree. Therefore a gravelly or sandy soil must be selected, which shall in a measure stunt it, and produce a dwarfish habit. Then the growth will be short, and will ripen, although the fruit will not be so fair as in regions where it is not injured by the winter.

The Berberry. This flourishes on almost any soil, from loamy sands to stiff clays, but its most natural condition is in a rich, peaty, limey earth.

The Cherry. The observations already made with regard to the apricot apply equally well to this fruit; but the morello varieties require clay soils.

The Currant. A peaty or clayey soil is that 
which is best adapted to the growth of this berry. On dry sands the foliage of the old varieties drops off, and the fruit becomes shrivelled before it is ripe. Where it is grown on such lands, la Versaillaise, la Fertile d'Angers, and la Hative de Bertin are much superior, as they very persistently retain their foliage, and the fruit is therefore of greater size and duration.

The Fig, in those regions where it is hardy, flourishes upon a loamy lime, or clay soil ; but in northern latitudes, if planted upon such lands, its succulent shoots are killed during the winter. In the latter they should be grown upon loamy sands, which will check their free growth, and induce hardness and ripeness of wood.

The Gooseberry requires a rich loamy clay for its perfect development. This applies only to such varieties as are free from mildew; others are not worth cultivation.

The Grape. Mr. R. Bucnanan, of Ohio, in his work entitled "Grape Culture," speaks thus: "The soil best suited for a vineyard is a dry, calcareous loam, with a porous subsoil, not retentive of moisture ; if mixed with some gravel or small stones, so much the better. Some vignerons prefer a sandy soil with a gravelly substratum, as in this the 
grapes are less subject to rot; the juice, however, is not so rich, - lacking saccharine matter, - and in dry seasons the vines will suffer from the drought, shedding their leaves prematurely, and preventing the grapes from ripening properly. On warm sandy soil, the fruit-buds, if swelled in the autumn, are sometimes killed by the frosts of a severe winter. Soils underlaid by a stiff wet clay are to be avoided, as also wet or spongy lands."

Mr. Jolnn Williamson, whose wines have a high reputation, writes, in a letter to Mr. Buchanan: "I consider the proper selection of the soil almost everything in the successful cultivation of the grape for making wine. I luave visited nearly all the vineyards near Cincinnati, and feel confident that many of them must eventually fail from a want of sclecting at first the right kind of soil ; and yet, in my opinion, there is plenty of suitable land in almost any neighborhood. Some have planted on that of a grayish, gravelly surface, with a heavy blue clay subsoil, impervious alike to water and the roots of the vine, further than it is loosened by the spade or the plough in trenching. Such, if it does produce a growth of wood, causes the grape to rot.

"Another soil unsuited to the grape is that with a surface of rich mould, underlaid with a stratum of fine, bright yellow sand, clammy and adhesive. This is well calculated to deceive; but it has no strength below the mould, and the vines invariably 
become weak, and of small growth. Such lands may be improved by lime and ashes. The soil on which I rely, and, from the experience of seven or eight years, place the greatest confidence in, is of a grayish black, breaking up into square lumps in cultivation, deep, and rumning into a reddish yellow subsoil, friable like the surface in working, and generally resting on limestone rock. On such soils, with proper cultivation, I have never known the vine to fail."

Mr. N. Longworth, in a communication to the Cincinnati Horticultural Society, says: "In my vineyards, at Tusculum, the rot has prevailed, and this season two-thirds of the crop was lost. The subsoil was a stiff clay, and to this fact I chiefly attribute it. Among my vines near the foot of the hill, where the ground was more porous, there was less rot, and at the bottom, or near it, where the rain immediately sank deep into the earth, there was no rot. And this I have found to be the case also at other vineyards. Where the subsoil was a compact clay, it prevailed ; where it was mixed with sand or gravel, or where it was porous, there was no rot."

The Peach and Nectarine delight in a deep loamy sand, but will succeed in almost any light soil. In the north, the soil should not be so generous as to induce too free a growth. 
The Pear succeeds generally upon such a soil as that described for the apple; but at the same time it should be porous, that the roots may roam freely. The labors of amateurs have resulted, however, in the production of varieties adapted to almost all soils; and in the table which follows will be shown, as nearly as it is possible to do in a new undertaking, the soils on which particular varieties succeed. Let it not be surmised that they grow only on such lands, for in other soils they may flourish with more or less success; yet those below enumerated are the soils which experience has proved to be best suited to them :

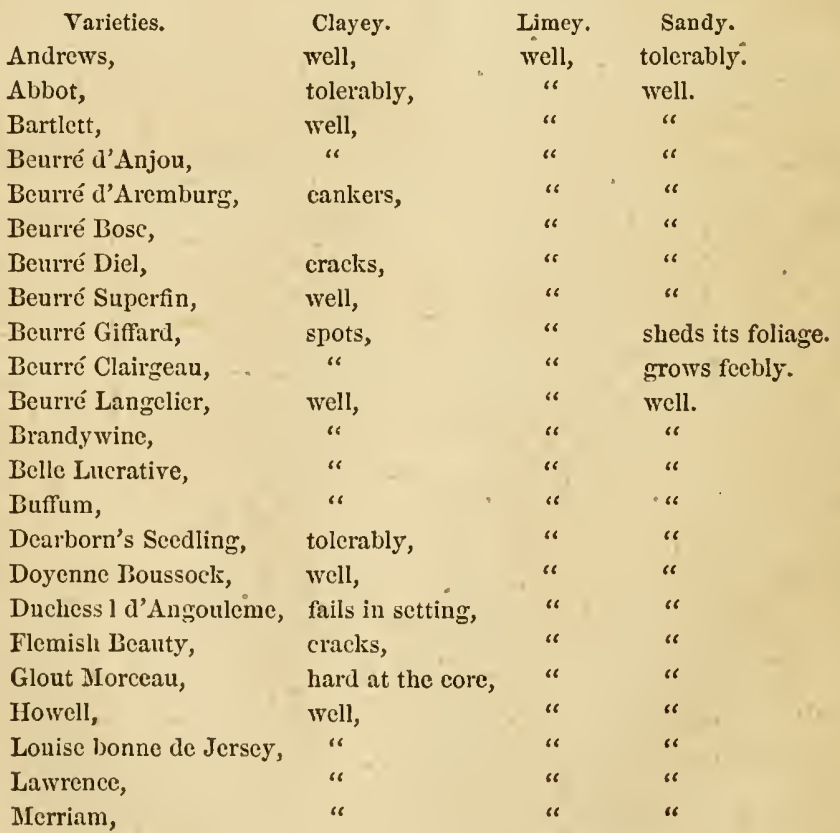




$\begin{array}{lccc}\quad \text { Varieties. } & \text { Clayey. } & \text { Limey. } & \text { Sandy. } \\ \text { Onondaga, } & \text { well, } & \text { well, } & \text { well. } \\ \text { Rostiezer, } & \text { " } & \text { " } & \text { " } \\ \text { Seckel, } & \text { " } & & \text { " } \\ \text { Urbaniste, } & \text { spots, } & & \text { " } \\ \text { Vicar of Winkfield, } & \text { well, } & \text { " } & \text { grows feebly. } \\ \text { Winter Nelis, } & \text { " } & & \end{array}$

The Plum seems to succeed best upon a stiff clay; but many cultivators have been very successful with it on quite light soils.

The Quince has few large roots ; these are mostly fibrous, and extend but a little distance from the trunk. It delights in a rich, deep, peaty, or loamy clay or lime soil.

The Raspberry and the Strawberry require a deep loamy clay, but for immediate and early production they are often planted upon sharp sands. The soil should be retentive of moisture for the general crop, as these little plants drink freely during the growth of their fruit.

We have now considered the origin of the soil, its properties, and its adaptation to the various species and varieties of fruits. In the succeeding three chapters we shall notice the improvement in them resulting from cultivation. 


\section{CHAP'TER IV.}

DRAINING TIIE SOIL.

METHOD BY WHICH THE SOIL IS SUPPLIED WITH MOISTURE: RAIN, SPRINGS - DESCRIPTION OF DIFFERENT STRATA - CAPILLARY ATTIACTION, METHODS BY WHICH WATER IS REMOVED: RUNNING OFF ITS

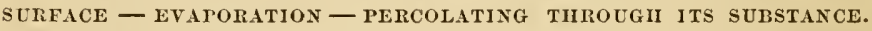
WHAT LANDS REQUIRE DRAINAGE - THE DIRECTION OF THE DRAINS - tIE DISTANCE-TIE DEPTII - THE MATERIAL TO bE USED - XUMBER OF TILE TO TIE ACRE - MANNER OF OPERATION. THE EFFECTS OF DRAINAGE: PROMOTING PULVERIZATION - PREVENTION OF INJURY BY DROUGITT - INCREASE OF THE ABSORPTION OF MOISTURE-VENTILATION - PERMITTING TIE WARM SPRING SHOWER TO ENTER THE SOIL - FREEZING TIIE LAND DEEPER - DEEPENING THE SOIL - DESTROYING WEEDS - CAUSING A MORE HARDY GROWTII-PRODUCTION BECOMES MORE CERTAIN.

$\mathrm{A}_{\mathrm{S} \text { food enters plants through the medium of }}$ water, the proper regulation of it is of paramount importance. Rain-water is not only a powerful solvent, but it extracts ammonia from the atmosphere, which increases and elaborates those elements of fertility in the soil on which vegetation . depends for health and fruitfulness. There are three methods by which the earth is supplied with moisture.

1. By rain. The average ammual quantity which falls throughout the United States is between thirty and forty inches. It is a source of great wealth, and 
contains one-half more oxygen, and four times the amount of carbonic acid which is found in the atmosphere through which it falls. The Cyclopedia of Agriculture remarks: "Rain-water always contains in solution air, carbonic acid, and ammonia. The first two ingredients are among the most powerful disintegrators of a soil.

"The oxygen of the air and the carbonic acid, being both in a highly condensed form by being dissolved, possess very strong affinities for the ingredients of the soil. The oxygen attacks and oxidizes the iron; the carbonic acid, seizing the lime and potash, and other alkaline ingredients of the soil, produces a further disintegration, and render's available the locked-up resources of this magazine of nutriment.

"Before these can be used by plants, they must be rendered soluble; and this is only effected by the free and frequent access of rain and air. The ready passage of both of these, therefore, enables the soil to yield up its concealed treasures."

The anount of ammonia contained in the rain-fall of a year upon a single acre is equivalent to the amount found in from one to two hundred weight of Peruvian guano. To retain this in the soil, it is obvious that the water in which it is contained must percolate through its particles. This it cannot do if the land is already overcharged with moisture, as is the case in most of our soils. When it camnot 
filter through the earth, it is either lost by evaporation, or is washed into the valleys to create unhealthy swamps.

2. The soil is supplied with moisture by springs. To illustrate this we quote at length from $\mathrm{Mr}$. French's useful book upon "Land Diainage," which should be in the hands of every enterprising farmer and fruit-grower. " Usually we find the crust of the earth in our cultivated fields in strata or layers. First, a surface-soil of a fer inches, of a loamy nature, in which clay or sand predominates; then, it may be, a layer of sand or gravel which freely admits the passage of water; and perhaps next, and within two or three feet of the surface, a stratum of clay, through which water passes very slowly, or not at all. These strata are sometimes regular, extending at an equal depth over large tracts, and having a uniform dip or inclination. More frequently, however, in hilly regions especially, they are quite irregular, - the impervious stratum often having depressions of greater or less extent, and holding water like a bowl. Not unfrequently, as we cut a ditch upon a declivity, we find that the dip of the strata below has no correspondence with the visible surface of the field, but that different strata lie nearly level, or are much broken, while the surface has a regular inclination.

"Underlying all soils, at a greater or less depth, but usually only a few feet below the surface, is 
found some bed of rock or clay impervious to water. The tendency of the rain which falls upon the earth is to sink directly downward; but, turned aside by the many obstacles referred to, it often passes obliquely, or almost horizontally through the soil. The drop which falls upon the hill-side sinks perhaps a few inches, when it meets with a bed of clay, upon which it glides along for many days, until at last it is borne out to the surface, to be drunk up by the sun on some far-off slope. Another, falling upon the sandy plain, sinks at once to the waterline which rests on clay beneath, and, slowly creeping along, helps to form a swamp or bog in the valley. Sometimes the rain which falls upon the high land is collected together by fissures in the rocks, or by seams or ruptures in the impervious strata below the surface, and finds its vent in a gushing spring upon the hill-side."

When rain falls on a tract of country, part of it flows over the surface, and makes its appearance in the numerous natural and artificial courses which may exist, while another portion is absorbed by the soil and the porous strata which lie under it. Let the following diagram represent such a tract of country, and let the portion (e) represent clay, or other impervious strata, while the remaining portions exhibit those layers of gravel, sand, or chalk which permit a free passage for the water. ${ }^{1}$

1 Cyclopedia of Agriculture, by Girdwood. 
"When rain falls in such a district, after sinking through the surface layer (represented in the diagram by a narrow band) it reaches the stratified

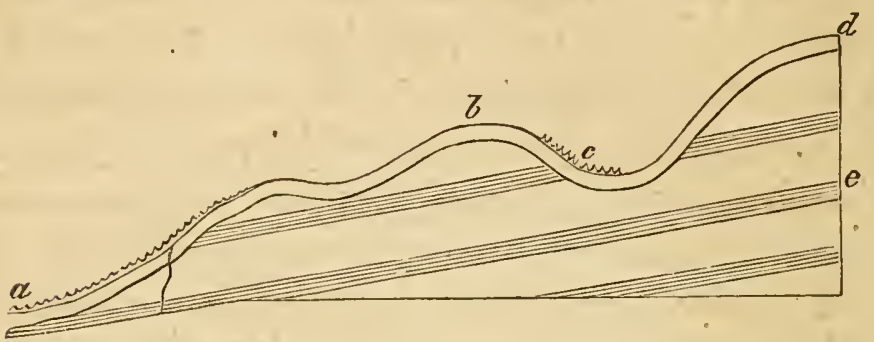

layers beneath. 'Through these it still further sinks, if they are porous; until it reaches some impervious stratum, which arrests its progress directly downward, and compels it to find its way along its upper surface. Thus the rain which falls on the surface represented between $(b)$ and $(d)$ is compelled by the impervious stratum to flow toward $(c)$; here it is at once absorbed, but is arrested by the impervious layer $(e)$; it is therefore compelled to pass through the porous stratum $(c)$, along the surface of $(e)$, to (a), where it pours forth in a fountain, or forms a morass or swamp, proportionate in size and extent to the tract of country between $(b)$ and $(d)$, or the quantity of rain which falls upon it. In such a case as is here represented, it will be obvious that the spring may often be at a great distance from the district from which it derives its supply, and this accounts for the fact that drainage-works, on a large 
scale, sometimes materially lessen the supply of water at places remote from the scene of operations.

"In the instance already given, the water forming the spring is represented as gaining access to the porous stratum at a point where it crops out from beneath an impervious one, and as passing along to its point of discharge at a considerable depth, and under several layers of various character. Sometimes, in an undulating country, large tracts may rest immediately upon some highly porous stratum, as from $(b)$ to $(c)$ in the following diagram, rendering the necessity of draining less apparent, while the country from $(a)$ to $(b)$ and from $(c)$ to $(d)$ may be full of springs and marshes. This arises partly from the fact that the rain which falls in these latter districts is unable to find a way of escape, and partly because the natural drainage of the more porous soils adjoining is discharged upon it.

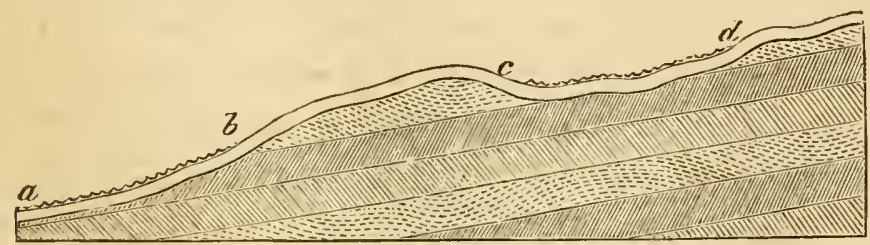

"Again: the rocks lying under the surface are sometimes so full of fissures, that although they themselves are impervious to water, yet so completely do they carry off rain, that in some parts of the county of Durham [England] the sinking of wells is rendered useless, and the farmers find it 
necessary to drive their cattle many miles for water. It sometimes happens that these fissures or cracks penetrate to enormous depths, and are of great width, and filled with sand or clay. These are termed 'faults' by miners; and some which we lately examined, at distances of from three to four hundred yards from the surface, were from five to fifteen yards in width. These faults, when of clay, are generally the cause of springs appearing at the surface; they arrest the progress of the water in some of the porous strata, and compel it to find an exit by passing to the surface between the clay and the face of the upturned strata. When the fault is of sand or gravel, the opposite effect takes place, if it communicates with any porous stratum, and water which may have been flowing over the surface is at once absorbed.

"In the following diagram, let us suppose that (b) represents such a clay fault as has been de-

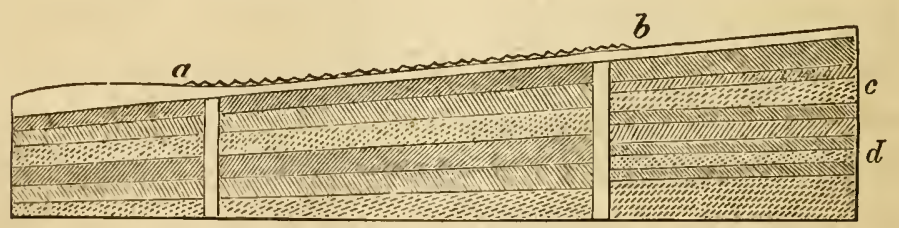

scribed, and that (a) represents a sandy one, and that $(c)$ and $(d)$ represent porous strata charged with water. On the water reaching the fault at $(b)$, it will be compelled to find its way to the surface, forming a spring, and rendering the retentive soil 
from $(b)$ to $(a)$ wet; but as soon as it reaches the sandy fault at (a), it is immediately absorbed, and again reaches the porous strata, along which it had travelled before being forced to the surface at $(b)$. It will be observed that the strata at the point of dislocation are not represented as in a line with the portions from which they have been dissevered. This is termed the upthrow of the fault, as at $(b)$; and the dethrow, as at $(a)$. For the sake of the illustration, the displacement is here shown as very slight; but in some cases these elevations and depressions of the strata extend to many hundreds of feet, as for instance at the mines of the British Iron Company at Cefu Mawre, in North Wales, where the dethrow of the fault is three hundred and sixty feet.

"Sometimes the strata are disposed in the form of a basin. In this case, the water percolating through the more elerated ground, near what may be termed the rim, collects in the lower parts of the strata toward the centre, then forcing its way to the surface, if the upper impervious beds be thin; or, if otherwise, remaining a concealed reservoir, ready to yield its supplies to the shaft or boring-rod of the well-sinker, and sometimes forming a living fountain capable of rising many feet above the surface.

"It is in this way that what are called artesian wells are formed. 'The following diagram repre- 
sents such a disposition of the strata as has just been referred to. The rain which falls on the tracts of country at $(a)$ and ( $b)$ gradually percolates toward the centre of the basin, where it may be made to give rise to an artesian well, as at $(c)$, by boring through the superincumbent mass of clay; or it may force itself to the surface through the thinner part of the layer of clay, as at $(d)$, there forming a spring or swamp.

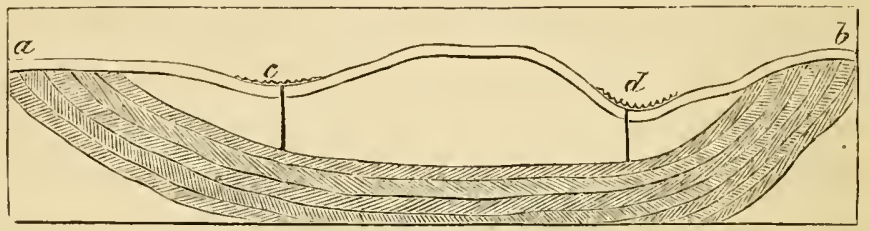

"Again : the ligher parts of hilly ground are sometimes composed of very porous and absorbent strata, while the lower portions are more impervious, - the soil and subsoil being of a very stiff and retentive description. In this case, the water collected by the porous layers is prevented from finding a ready exit, where it reaches the impervious layers, by the stiff surface-soil. 'The water is by this means dammed up in some measure, and requires a considerable degree of pressure; and, forcing itself to the clay at various places, it forms those extensive 'wecping'-banls which have such an injurious effect upon many of our mountain pastures. 'This was the form of spring, or swamp, to the removal of which Elkington principally turned his attention; 
and the following diagram, taken from a description of his system of draining, will explain the stratification and springs more clearly.

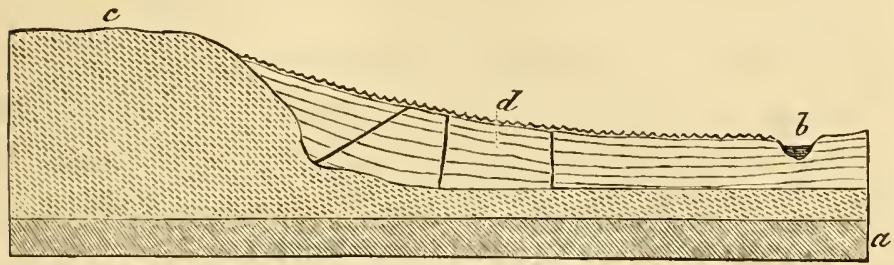

"In some districts, where clay forms the staple of the soil, a bed of sand or gravel, completely saturated with water, occurs at the depth of a few feet from the surface, following all the undulations of the country, and maintaining its position, in relation to the surface, over considerable tracts - here and there pouring forth its waters in a spring, or denoting its proximity by the sub-aquatic nature of the herbage.

"Such a configuration is represented in the following diagram, where (a) represents the surface-soil ;

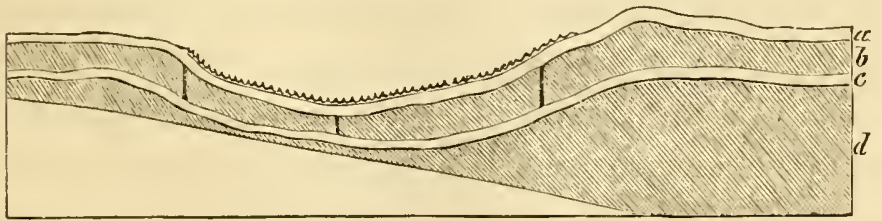

(b) the impervious subsoil of clay; $(c)$ the bed of sandy clay or gravel; and $(d)$ the lower bed of clay resting upon the rocky strata beneath."

3. The moisture rises to the soil by capillary attrac- 
tion exerted upon a wet subsoil. The power of this agency varies widely in different soils. In those of a porous character, it is far less potent than in a close firm clay or loam; because, in the former, the interstices are greater, and the attraction is overcome by the gravity of the water. This principle should be borne in mind when we investigate the required depth of the drain; as one of four feet, in a retentive soil, will thoroughly drain less depth of earth than if placed at the same distance below the surface in a loose sand or gravel.

As there are three sources from which the soil is supplied with moisture, so there are also three ways by which it is deprived of it.

1. By ruming off its surface. In this way it is unproductive of benefit, as the fertility which it contains is lost. It fails to comminute and disintegrate the soil by percolating through its particles. If the warm showers gain admittance to the earth in the spring, they raise its temperature, and vegetable growth commences earlier.

2. By evaporation. As by perspiration the body of an animal is kept cool, so the soil in evaporation parts with a great amount of heat, which would otherwise be retained to encourage the growth of the plants. A writer in the Gardeners' Chronicle, of England, observes, that " the principal result of the loss of water by evaporation is indicated by the 
fact, that during the conversion of every pound of it into vapor, as much heat is consumed and lost as would be produced by burning two or three ounces of coal; and when you think that an ordinary rain-fall amounts to three thousand tons per acre every year, you can easily perceive that the loss of heat by the evaporation of a comparatively inconsiderable portion of this must involve a great cooling of the land."

Although some evaporation will take place even upon drained land, yet, if we can convey off the most of the surplus water after it has passed through the substance of the soil and has deposited its fertility, just that amount of heat is gained which would have been required for its evaporation.

The drained field will be in readiness to till in the spring ten days before that which is undrained, and vegetation upon it will not become checked so suddenly in the fall, but will be hastened to maturity during the entire summer by the increased degree of its heat. The difference in the temperature of the two soils is often from ten to fifteen degrees Fahrenheit.

3. By percolating through its substance. The same writer again says: "Let us now consider what water does by percolation; and its effects we can do little more than enumerate. They are briefly these: It carries the temperature of the air into the soil, a thing, the possible injury of which in the autumn 
and winter, when the air is colder than the soil, is as nothing when compared with the benefits resulting from it in spring, when the air is warmer, and when the advantages of early growth are great. The most important experiments which we think of as proving the influence of draining upon the temperature of the soil, are those described by $\mathrm{Mr}$. Stephens in his exceedingly instructive book with regard to the operations of the Marquis of Tweeddale at Yester Mains. 'There the temperature of the soil in an undrained state was forty-eight degrees Fahrenheit; but by the cutting of a drain near it, and the setting in of a current through it, its temperature was raised one and one-half degrees in six hours.

"Another effect of water in percolating through the land is seen in the introduction of the atmospherical elements which it holds in solution. The carbonic acid, by its operation on the alkalies and alkaline earths, is a powerful solvent and disintegrator. The oxygen keeps in check the deoxidating effect of vegetable matter in the soil, which in its absence tends to reduce the higher state of oxidation of the iron present in the soil into the lower state, where it does mischief by forming, with acids in the soil, soluble salts, which are injurious to vegetation.

"But the main purpose served by water during its percolation through the land is that of a feeder 
of the plants. A fertile soil, cultivated so as to exhibit its fertility in the most profitable mamner, has growing upon it crops whose habit and specific character are adapted to the climate in which they are placed, and to the character of the soil itself. It yields these crops in the order in which each, succeeding to the cultivation of its predecessor, shall find the soil, chemically as regards its contents, and mechanically as regards its texture, and practically as regards consequent cleamness of the land, and the fitness of their respective times of cultivation to one another, in best condition for the supply of the wants of the crop in question. It is annually manured and cultivated so as best to meet the current wants of the plants raised upon it; but it is especially dependent for all its powers to bring these crops to a fruitful maturity upon the fact that there is, during and after every shower of rain, a continual current of water and of air passing throughout its substance. This current should not be too rapid, lest its soluble parts should be washed to water; indeed, it is hardly possible that it should be too slow; slow enough, however, to dissolve from the soil whatever it contains of food for plants, and fast enough to be continually bringing fresh supplies by every mouth which the absorbing extremities of the roots present.

"All these purposes of warming the soil, of introducing substances into it which shall operate 
chemically upon its minerals, and of converting it into an efficient vehicle of the matter which it contains, are answered by the percolation of water through the soil. You must not think, then, of drainage as a contrivance for getting rid of water from the land as an enemy; nor must you think of a wet and ill-drained field as being merely an illustration of the injury done by water in excess, as it is called. Water need hardly ever be an enemy, and need rarely be in excess. Drainage is a contrivance for making use of it as a friend, and an ill-drained field is an illustration of the mischicf done by water, whether there be little of it or much, when not in motion."

We desire, then, to promote the percolation of the water through the soil, and to do this we lay conduits beneath its surface to carry away the surplus moisture, and to produce currents of water and of air. We intend to enumerate several points which are of importance to its accomplishment.

1. What lands require drainage? That it is necessary in land where water stands upon its surface in summer, is evident to every one; but that soils where the evil is hidden are as much in need of it, is difficult for the uninitiated to comprehend. If rushes, or any aquatic plants make their appearance, it is a sure sign of the necessity of drainage; for all the fruit-growing plants flourish alone upon dry 
land, and these water-loving weeds would not appear did not the wetness of the soil encourage them. If the earth is wet and elammy in the spring, so that it is impossible to cart muck upon it, or prepare the ground properly for the crop until late in the season, it is manifest that to gain a wcek or ten days in this most important time is a very decided advantage. When trees or grain heave badly during the thaws of winter, or generally when the foliage of plants is pale and sickly during the summer, it is an index of the necessity of thorough drainage.

2. The direction of the drains. While there are some general rules applicable in most eases, yet it is sometimes necessary to vary them with reference to the outlet and the undulating character of the ground.

"In many subsoils there are thin partings, or layers, of porous materials, interspersed between the strata, which, though not of sufficient capacity to give rise to actual springs, still exude enough water to indicate their presence. These partings occasionally crop out, and give rise to damp spots, which are to be seen diversifying the surface of fields, when the drying breezes of spring have begun to act upon them. In the following cut the light lines represent such partings. ${ }^{1}$

"Now, it will be evident, in draining such land, that if the drains be disposed in a direction trans- 
verse or oblique to the slope, it will often happen that, no matter how skilfully planned, they will not reach these partings at all, as at $(a)$. In this case, the flow will continue in its accustomed channel, and discharge its waters at (b). But again,

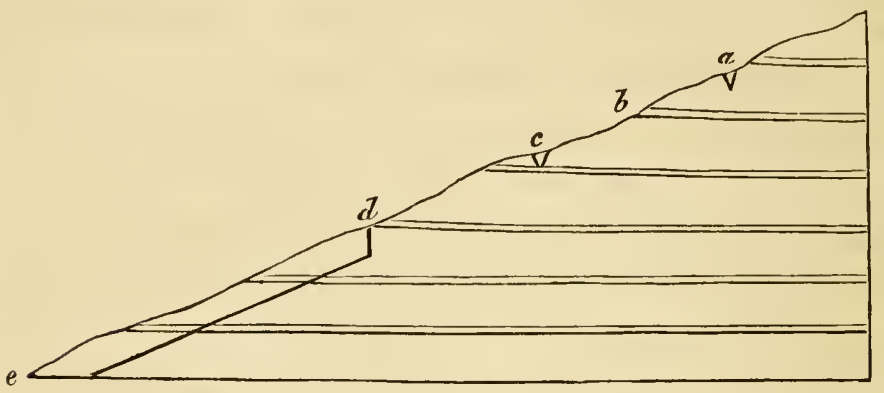

even though it does reach these partings, as at $(c)$, a considerable portion of water will escape from the drain itself, and flow to the lower level of its old point of discharge at $(d)$. Whereas, a drain cut in the line of the slope, as from $(d)$ to $(e)$, intersects all these partings, which furnishes an outlet to them at a lower level."

Mr. French in his "Land Drainage," in remarking on this description by Mr. Girdwood, says : "The line of the greatest fall is the only one in which a drain is relatively lower than the land on either side of it. Whether we regard the surplus water as having recently fallen upon the ficld, and as being stopped near its surface by an impervious stratum, or as brought down on these strata from above, we have it to be disposed of, as it rests 
upon this stratum, and as borne out by it to the surface.

"A drain down the slope gives to the water borne up by these strata an outlet of the depth of the drain. If it be four feet, it cuts the water-bearing strata each at that depth, and takes off the water. In these cases the different layers of clay, or other impervious partings, are like the steps of a huge staircase, with the soil filling them up to a regular grade. The ditch cuts through these steps, letting the water that rests on them fall off at the ends, instead of running over the edges.

"Now, looking at the operation of drains across the slope, and supposing that each ditch is draining the breadth next above it, we will suppose the drain to be running full of water, what is there to prevent it from passing out of that drain in its progress at every joint of the tile, and so saturating the breadth below it? Drain-pipes afford the same facility for water to soak out at the lower side as to enter on the upper, and there is the same law of gravitation to operate in each case.

"Mr. Denton says: "With respect to the direction of drains, I believe very little difference of opinion exists. All the most successful drainers concur in the line of the steepest descent as essential to efficiency and economy.'

"To produce perfect drainage of a portion of this land, which we will suppose to be a gentle slope, 
the first object must be to cut off the flow of water upon or near the surface. An open ditch across the top would most certainly effect this purpose, and it may be doubtful whether any other drain would be sufficient. This would depend upon the quantity of water flowing down; if it be very great at times, a part of it would be likely to flow across the top of an under drain, from not having time to percolate downward into it.

"In all cases it is advised, when the work stops upon a slope, to introduce a cross-drain connecting the tops of all the minors. This is called a header. Its object is to cut off all the water that may be passing along in the subsoil down the slope, and which would otherwise be likely to pass downward between the system of drains to a considerable depth before finding them."

In deciding the direction of the drains we must be careful to ascertain the source from which the water proceeds. If it arises from springs, the aim must be to direct them so as to cut off the fountain, - and at this point they must be frequent, - while below it may not be necessary to place them at less than double the distance. If the surplus water is rolled down from higher land, the direction must be such as to head off and carry it away: the size of the pipes and fiequency of the drains must correspond with the amount of water to be disposed of. When we have only to contend with the mois- 
ture which the land itself receives from rain, it is a comparatively easy matter, and the drains may be laid with greater uniformity, while in either of the preceding cases the same rule which we now pursue would have entirely defeated the object. Generally it is more economical for the fruit-grower who proposes to drain his land to engage the services of a competent engineer, as drainage, unlike manuring or cultivation, is a permanent improvement. The system, as a whole, must be formed before the work is commenced as far as relates to the place of outlet and the position of the main drain and its stronger branches, else it would be difficult to decide on the size of the pipe which was required.

3. The distance at which the drains should be fiom one another is an important consideration. This also must be decided from a knowledge of the cause of the superfluous moisture. 'This is well illustrated in a letter from Mr. Denton by the same author.

"The wetness of land, which for distinction's sake I will call the water of pressure, like the water of

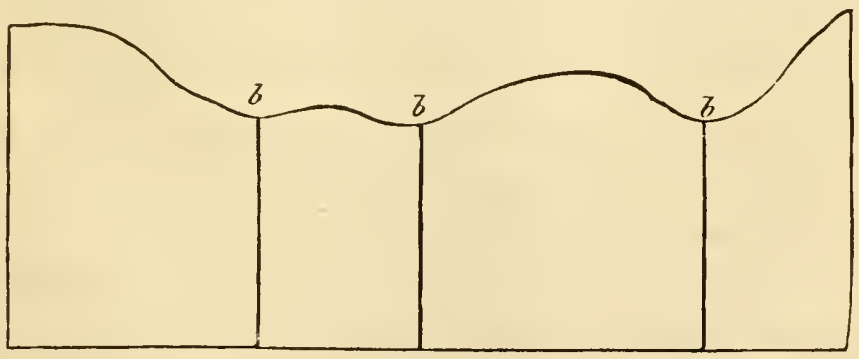

springs, to which it is nearly allied, can be effectually 
and cheaply removed only by drains devised for and devoted to that object. Appropriate drains at $(b b b)$, for instance, as indicated in the dark vertical lines above, are found to do the service of many parallel drains, which as frequently miss as they hit those furrows or lips in the horizontal outcrop of water-bearing strata, which continue to exude wetness after the higher portions are dry.

"A consideration, too, of the varying inclination of surface, of which instances will frequently occur in the same field, necessitates a departure from uniformity, not only in direction, but in the intervals between the drains. Take, for instance, the orclinary case of a ficld in which a comparatively flat space intervenes between quickly rising ground and the outfall ditch. It is clear that the soak of the hill will pervade the soil of the lower ground, let the system of drainage adopted be what it may; and therefore, supposing the soil of the hill and flat to be precisely alike, the existence of bottom water in a greater quantity in the lower lands than in the higher, will call for a greater number of drains. It is found, too, that an independent discharge, or relief, of the water coming from the hill at $(b)$ should always be provided, in order to avoid any impediment by the slower flow of the flatter drains. "Experience shows that, with few exceptions, hollows or slacks observable on the surface, as at (bb), have a corresponding undulation of subsoil; 
and that any system which does not provide a direct release for water, which would otherwise collect in

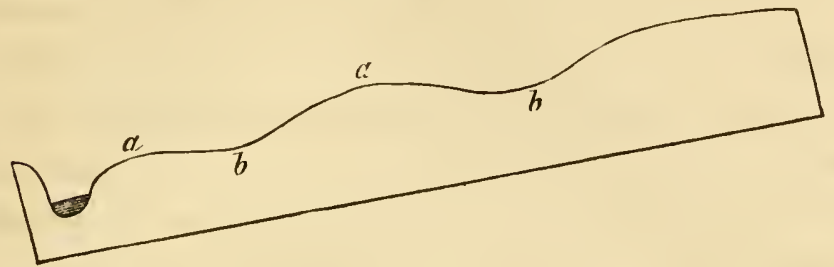

and be drawn toward these spots, is imperfect and unsatisfactory. It is found to be much more safe to depend on relief drains, than on cutting them sufficiently deep through the banks at $(a a)$, to gain a fall at a regular inclination.

"Still, in spite of experience, we often observe a disregard of these facts, even in works which are otherwise well executed to a depth of four feet, but fettered by methodical rules; and I feel compelled to remark that it has often occurred to me, when I have observed with what diligent examination the rules of depth and distance have been tested, that if more attention had been paid to the source of injury, and to the mode of securing a permanent and effective discharge of the injurious water, much greater service would be done."

The distances between the drains should be modified also by the amount of annual fall of rain in the district. In some parts of our country the number of inches of yearly fall is double that in others. The spaces between the drains should also 
be regulated with reference to the influence of climate on evaporation. Drains have been known to emit water on account of the density of the atmosphere; therefore, when the predominating weather is cloudy, and the air dense, much more water will remain to be carried off than when a bright, unclonded sun increases the evaporation. Besides this, the intervals should depend upon the character of the soil. If the drains are forty feet apart, the moisture could find its way more easily and in quicker time through a porous than a close soil, because of the less degree of attraction. In the former the distance might be made fifty feet, while in the latter it would be necessary to reduce it to thirty or even twenty.

The depth of the drain should also affect the intervals between them in porous soils. It is selfevident that a drain four feet in depth will reach further, and draw off the water from a greater distance, than one of three feet in such a soil; yet in clay it is not safe to rely upon it to a great extent. There is an argument of still more force for the frequency of drains in the orchard, which is seldom alluded to, but which is, nevertheless, a consideration of importance. It is the prevention of obstruction from the roots of trees growing into the pipes. This sometimes occurs on account of the moisture in them during the summer; and, although there have been few instances in which drains have been 
stopped in their operation by the roots of fruit trees, still it is very desirable to place them so frequently that the water will pass off speedily and leave the pipes dry.

4. The depth at which drains should be placed. The first argument that we shall use for placing them deep is that they may be out of reach of the subsoil plough, or the spade of the trencher. The necessity for deep cultivation, in preparing the ground for the orchard, is considered in the chapter devoted to pulverization; suffice it now to say, that in trenching three feet in depth, the spade will often be plunged a few inches further, and that one blow might break a tile, and result in the stoppage of the whole system. ${ }^{1}$ Then it must be remembered that as the air penetrates more into drained than undrained soils, they will freeze deeper. If we place the drain at four feet deep, in a retentive soil, we shall often find that we have not more than two or three feet of dry earth, on account of capillary attraction.

.The greater sphere which it gives to the roots of plants for their supply of food, is of itself a sufficient argument for deep draining. Of equal force is the fact, that it wards off the evil effects of drought. It may seem to some an anomaly, that to drain the surplus water from land would make it less likely to suffer from the want of it; and yet such is the truth. On an undrained soil the roots of

1 See mode of detecting obstructions. 
plants do not penetiate much below the surface. The cold and damp subsoil is repugnant to them; when a drought occur's, and they meet the destroyer not only in the parched earth from above, but in the cold water, charged with noxious gases, from beneath, what choice have they but cieath? When a depth of four feet is prepared for the roots, they cannot suffer to any great extent, as the drought does not penetrate so deep. The following diagram will illustrate this; (a) represents the surface soil which is deprived of its superfluous moisture by evaporation, and which thereby loses lieat which would be genial to the roots of the tree; (b) rep-

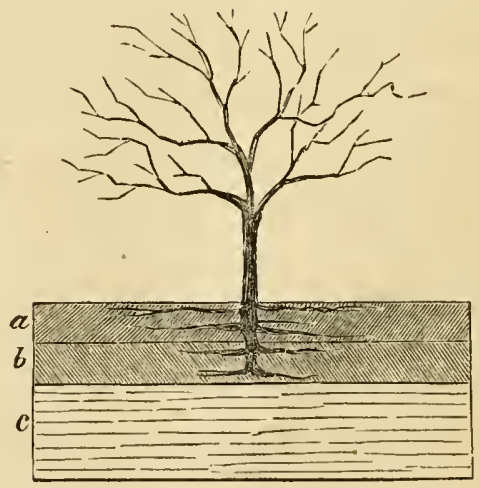

resents the subsoil, which, although it lays, above the surface of the stagmant water, is yet filled with moisture by capillary attraction, and is so cold that it repels the roots; yet they are obliged to enter it for partial protection from drought.

The next figure represents the condition of a 
tree in a soil which is thoroughly drained; (A) the surface soil; (B) the subsoil, which has now been much deepened, and has encouraged the roots to roam in its substance; (C) is that part of the subsoil above the drain which is rendered wet by capillary attraction; (D) is the stagnant water, which has been reduced three feet by the drains which are upon its surface.

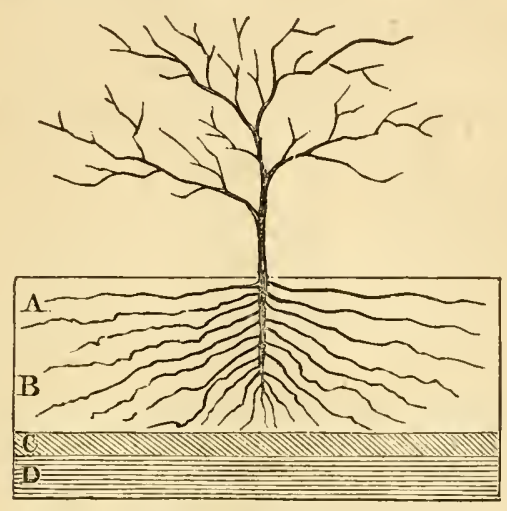

Therefore, at a depth of four foet or more, the roots have a source of nutriment and moisture beyond the reach of a drought.

5. The materials which should be used in draining. The fact must be kept in mind, in laying a drain for an orchard, that the trees are to remain for years, and therefore it would be folly to adopt a superficial method, which might answer for an annual crop. The question for the fruit-grower to ascertain is, what materials do, and what do not, make a superficial drain. Is this the case with 
brush? It makes a good drain for a few years, if properly laid, when upon strong and retentive soils; but upon light land it soon becomes choked with sediment, and is rendered useless. Is stone draining superficial ? The blind stone drain represented in the following figure has the same defect as the brush; that the water, in percolating

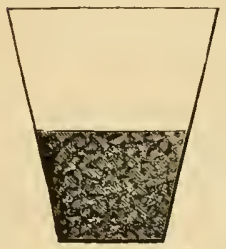
through it, deposits fine sand, which fills up the interstices, and renders the drain inoperative. Notwithstainding stone is not the best material for drains, yet some prefer to use it, even if it is not so cheap, because it is immediately at hand ; and being otherwise a nuisance, its use in the construction of drains answers a double purpose. We shall therefore endeavor to illustrate the proper method of constructing a permanent stone drain. (A) represents three stones placed in the form of a triangle with the point down (boards answer a better purpose if laid in the same position). Some will suggest laying them with the broad side down, but experience op-

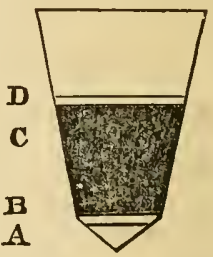
poses this. A certain quantity of water which would pass sluggishly over the broad surface, and leave a sediment after it to obstruct the flow, would, if run through such a drain as is represented in our cut, gain considerably in velocity, the surface to create friction would be less, and sand which might 
be washed in would be carried off. (B) is a square of turf, old hay, coarse gravel, tan, or sawdust placed over the stones to filter the water as it passes to the drain; (C) is the position of the rubble, or small stones; and (D) represents another layer like (B). 'The great objection to this drain is, that workmen, unless very careful, will lay the stones forming the triangle irregularly, so that one will act as an obstruction to the other, and thus cause a deposit of sediment. Boards are greatly to be preferred on this account, especially if planed upon the inside, as they diminish the friction and prevent obstructions.

Is tile-pipe superficial? It is, unless baked hard, when it becomes the most durable and perfect drain. But, as there are many different ways of constructing them, it is necessary that we should be more explicit.

The horse-shoe tile is not the most perfect, although in many parts of our country it has been used to a considerable extent; yet we are assured that it is not the most desirable. Being open at the bottom, the earth often becomes pushed up in the interior, and partially or wholly stops the flow. In some instances, where obstructions have occurred, the drain has been opened and the pipe found completely filled. Sometimes it is laid upor: a sole, or a board; but it is then open to the same objection as was the stone drain with the flat side down, - 
that of increased friction and loss of velocity. This is a more serious matter than might be supposed, especially in a main drain; for if several branches deliver into it, and the main has more velocity than the branches, it is evident that, in that proportion, can a smaller pipe be used to convey the same amount of water. In consequence, we lessen the cost of the material, as well as increase the effi-. ciency of the work.

The sole-tile is the best. If laid on strips of board it is more efficient, and in (1) the hands of a skilful workman becomes an excellent drain. A square of turf, strips of waste tin, or, what is better than either, tarred paper, should be placed over the joints to keep out the sand. Many have supposed that the water entered mostly through the substance of the tile. Although this is true to some extent, yet the principal quantity runs in at the joints, and therefore it is necessary that they should be defended from the loose sand which often accompanies it.

We suffix a table from the "Farm Drainage."

TABLE H. - Showixg the Cost of Sole-Thle of different Sizes.

\begin{tabular}{|c|c|c|}
\hline Size. & \multicolumn{2}{|c|}{ Cost. } \\
\hline 2 inclies, & \multicolumn{2}{|c|}{$\$ 12$ per 1000 pieces. } \\
\hline 34 & $\$ 18$ & “ \\
\hline $4 \approx$ & $\$ 10$ & $"$ \\
\hline 54 & $\sin 0$ & “ \\
\hline $6 \%$ & $\$ \$ 0$ & “ \\
\hline $8 \quad "$ & 512; & “ \\
\hline
\end{tabular}


TABle I. - Showing the Number of Cunid Yatds of Earth ix eaci Rot in LexGTI in Draixs of Variods DimeNsions.

\begin{tabular}{|c|c|c|c|c|c|c|c|c|c|c|c|c|}
\hline \multirow{2}{*}{$\begin{array}{l}\text { Depth } \\
\text { in } \\
\text { niches. }\end{array}$} & \multicolumn{12}{|c|}{ Miena Widtu. } \\
\hline & 7 in. & $8 \mathrm{in}$. & $9 \mathrm{in}$. & $10 \mathrm{in.}$ & $11 \mathrm{in.}$ & $12 \mathrm{in.}$ & $13 \mathrm{in.}$ & $14 \mathrm{in}$. & $15 \mathrm{in.}$ & $16 \mathrm{in.}$ & $17 \mathrm{in.}$ & $18 \mathrm{in.}$ \\
\hline 30 & 0.89 & 1.02 & $1.1 * 6$ & $1.2 \bar{\tau}$ & 1.40 & 1.53 & 1.655 & 1.78 & 1.91 & 2.04 & 2.164 & 2.29 \\
\hline 33 & 0.98 & 1.12 & 1.26 & 1.40 & 1.54 & 1.68 & 1.82 & 1.96 & 2.10 & 2.24 & 2.38 & 2.52 \\
\hline 39 & 1.07 & 122 & 1.375 & 1.53 & 1.68 & 1.83 & 1.986 & 2.14 & 2.29 & 2.244 & 2.60 & 2.75 \\
\hline 39 & 1.16 & $1.3 \% 4$ & 1.49 & 1655 & 1.82 & 1.986 & 2.15 & 2.32 & 2.48 & 2.65 & 2.81 & 2.98 \\
\hline 42 & 1.25 & 1.426 & 1.604 & 178 & 1.96 & 2.14 & 2.32 & 2.495 & 2.674 & 2.85 & 3.03 & 3.21 \\
\hline 45 & 1.34 & 1.53 & 1.72 & 1.91 & 2.10 & 2.29 & 2.48 & 2.67 & 2.865 & 3.055 & 3.246 & 3.438 \\
\hline 48 & 1.426 & 163 & 1.833 & 2.04 & 2.24 & 2.444 & 2.65 & 2.85 & 3.056 & 3.26 & 3.46 & 3.667 \\
\hline 51 & 1515 & 1.73 & 1.95 & 2.164 & 2.38 & 2.60 & 281 & 3.03 & 3.25 & 3.46 & 3.68 & 3.896 \\
\hline 54 & $1.60 t$ & 1.83 & 2.06 & 2.29 & 2.52 & 2.75 & 2.98 & 3.20 & 3.44 & 3.666 & 3.895 & 4.125 \\
\hline $5 \bar{i}$ & 1.69 & 1.935 & 2.18 & 2.42 & 2.66 & $\dddot{2.90}$ & 3.14 & 3.35 & 3.63 & 3.87 & 4.11 & $4.3 \overline{5} t$ \\
\hline 60 & $1.7 \mathrm{~s}$ & 2.036 & 2.29 & 2.546 & 280 & 3.056 & 3.31 & $3.56 t$ & 3.82 & 4.074 & 4.33 & 4.584 \\
\hline
\end{tabular}

TABLE J.-Showixg the Number of Tiles necessari per ACre to LAT DraINS AT DIFFEREXT INTERTALS.

\begin{tabular}{|c|c|c|c|c|}
\hline $\begin{array}{c}\text { Intervals } \\
\text { between the Drains, } \\
\text { iu teet. }\end{array}$ & $\begin{array}{c}\text { Twelve-inch } \\
\text { l'ipe. }\end{array}$ & $\begin{array}{c}\text { Thirteen-inch } \\
\text { l'ipe. }\end{array}$ & $\begin{array}{c}\text { Fourteen-inch } \\
\text { l'ipe. }\end{array}$ & $\begin{array}{c}\text { Fifteen-inch } \\
\text { l'ipe. }\end{array}$ \\
\hline 15 & 2904 & 2680 & 2459 & 2323 \\
18 & 2120 & 2234 & 2074 & 1936 \\
21 & 2074 & 1915 & 1778 & 1659 \\
24 & 1515 & 1676 & 1555 & 1452 \\
27 & 1613 & 1489 & 1383 & 1290 \\
30 & 1452 & 1340 & 1214 & 1161 \\
33 & 1320 & 1219 & 1131 & 1056 \\
36 & 1210 & 1117 & 1037 & 968 \\
39 & 1117 & 1031 & 957 & 893 \\
42 & 1037 & 958 & 888 & 829 \\
\hline
\end{tabular}

TABLE li. - Showixg th̆E Number of lods per ACre of Drains at difFEREXT DISTAXCES.

\begin{tabular}{|c|c||c|c|}
\hline $\begin{array}{c}\text { Iuterrals between the } \\
\text { Drains, in feet. }\end{array}$ & $\begin{array}{c}\text { Rods } \\
\text { per } \Lambda \text { cre. }\end{array}$ & $\begin{array}{c}\text { Intervals between the } \\
\text { Drains, in feet. }\end{array}$ & $\begin{array}{c}\text { Rods } \\
\text { per Acre. }\end{array}$ \\
\hline 15 & 176 & 30 & 85 \\
18 & $141 i_{3}^{2}$ & 33 & 80 \\
21 & $125_{3}^{2}$ & 36 & $73 \frac{1}{3}$ \\
24 & 110 & 39 & $67_{3}^{2}$ \\
27 & $97 \frac{2}{3}$ & 42 & 63 \\
\hline
\end{tabular}


6. Manner of laying the tile and completing the drain. Beginning at the outlet, the trench can, of course, be dug as narrow as possible, only allowing space enough for the workman to place the tile. 'The pipes should then be laid along the bank. If turf is to be used for covering the joints, it should be cut, and immediately at hand. 'The size of the pipes for the mains must be determined by the number of minors and the amount of water to be conveyed. Generally one of four or five inches is sufficient; but when it is not, two can be placed abreast, or one more above them. The workman, walking backwards, should commence to lay the pipe carefully, securing a continuous channel, and preserving the proper grade by the use of the line. 'The joints are secured as the work goes on, and the earth carefully shovelled in, and trodden down as hard as possible, to prevent the washing of the sand. Where the minors join the main, the junction must not be too abrupt, but should turn gradually, and enter it upon a curve, that neither may be obstructed by the meeting of the currents.

There are many places where it is impossible to find an outlet. If wells in the vicinity do not rise to less than twelve or fifteen feet from the surface, such tracts can be drained by digging dry wells, and turning the water into them.

It is very convenient to construct traps in the orchard when draining. These are formed by 
sinking a hogshead, or, more permanently, by building a small reservoir of brick or stone. 'The drain above leads into it, and the one below takes off the surplus water. These are very convenient for use in the orchard, and in furnishing the workmen with cool water. They are also interesting, as they show the operation of the drains.

7. The discovery of obstructions. All drains will sometimes become stopped, either by some animal which has taken refuge in the pipe, or by sediment. When such is the case, and the ground is wet, the point can generally be detected by the external appearance of the land. On a slope, the water will often burst forth upon the surface. When this does appear, the tile must be taken up at the obstructed part and cleaned. Over drains from which there is a continual flow of water, no crop should be planted whose roots will be attracted by it so as to fill up and choke the pipe; but there is no danger of this over those whose flow is confined to the wet season, and after heavy rains.

We have now considered the sources of moisture in the soil, and the means of removing it, and thus are prepared to notice the effect produced.

It promotes pulveriation. The comminution of the soil is of great importance, as it permits the free entrance of the air among its particles. Indeed, of so much value is this pulverization of the ground, 
that a system of cultivation was based upon it, and the effects were remarkable, even without the addition of the least manure. Before drainage has taken place, this is impossible, as the ground is so wet that the more it is worked the closer it becomes; but when it is dry it crumbles in handling.

The prevention of injury from drought, which we have already commented upon, is another benefit which arises from draining.

The power of absorbing moisture. The dry and friable soil is better prepared to drink in the dews of the night, and thus is partially compensated for what it has lost during the day by evaporation. This is a potent source of fertility, for the air is freighted with fertilizing gases, which the soil imbibes with the water.

The ventilation of the soil is also accomplished by drainage. The earth contains substances which require the oxygen of the atmosphere to decompose and prepare them to become the food of plants. While the soil is filled with stagnant water, decomposition is arrested; but when the air takes its place, it progresses rapidly. 'This decomposition is slow combustion, and therefore generates heat, which increases the warmth of the earth in the spring, at which time it is so desirable.

It permits the warm, early showers to enter the soil and aid decomposition, by augmenting the heat of the ground. 
Drained land fieezes deeper. 'This is a matter of great importance to the orchardist, because the roots of the trees remain frozen through the winter, and are not liable to be affected so severely by the vicissitudes of the climate, which often proves so injurious to the fruit trees in the eastern portion of our country. ${ }^{1}$

Draining deepens the soil, and furnishes a wide feeding-ground for the roots, as before shown.

The weeds are destroyed more easily. The difference is just that which the farmer has observed in killing them upon a wet and dry day. In the former case the carth adheres to them, and they soon take root again; while in the latter, they are readily torn up and withered. All aquatic plants are also driven out.

The trees themselves become more hardy, bear nore abundantly, and continue more healthful; the fruit is less liable to become spotted ; the flavor is greatly improved; and the trees are more uniform in growth. A gentleman of England, who had clrained a field of ten acres, desired to ascertain the practical result of the acration of the soil. The field was divided into five sections, each containing an equal number of drains. Learing that in the centre, and one on each side, he selected the other two for experiment, and conducted the termini of the drains, and supplied them with a ventilator at each end. Imme-

1 See Exposure, p. 27. 
diately after the conclusion of the work a heavy shower fell, and on the next day the difference was very marked in their relative dryness. The land was all planted with the same crop, and the returns from those sections which were aerated was estimated to be one-half more.

Prof. Stockhardt, in his "Agricultural Chemistry," as translated by Dr. Henfry, thus enumerates the effects of drainage:

" Wet soils become drier. All our cultivated plants are land plants, and these require for vigorous growth a soil which has moisture, but not in that liquid form which it presents in standing water. When the latter is the case, the roots can only penetrate the earth to the depth at which the water stands, and aquatic plants are likely to make their appearance and displace those of land growth.

"Some peaty soil becomes too mellow, because air enters it, where the water had previously been, and makes the humus produced by putrefaction decay in too soft a state.

"Cold soil becomes warmer, for it now retains the heat of the sun and air, which previously was in great measure expended in producing evaporation.

"Mcavy soil becomes looser, more easily crumbled, and softer; when it dries, finer cracks are formed tian in the undrained, tenacious soils, and it is tuore readily worked.

"Sluggish soil becomes more active and powerful; 
for, by becoming more open and warmer, the two great natural processes by which the food of plants is prepared and rendered soluble (weathering and decay) proceed more rapidly, and to a greatcr depth. Hence the same quantity of manure is more effective on drained than on undrained land.

"Finally, production becomes more certain. It is evident the farmer, by draining, changes a fickle and less fertile into a surer and far moie productive and grateful soil, and renders it, to a certain degree, independent of the weather, inasmuch as he carries away harmlessly those extremes to which the inhabitants of the northern hemisphere are most commonly exposed. The dread that the rain and snow-water would wash the manure out of the soil, and rob it of its soluble nutriment in filtering through the earth, has proved quite unfounded in deep draining." 


\title{
CHAP'TER V:
}

\author{
PULVERIZATION.
}

A CRUMBLING CONSISTENCY OF SOILS NECESSARY - THE IMPOTTANCE OF PULVERIZATION - STIFFNESS OF CLAYS - THE NOX-RETENTION OF SANDY SOILS - COLDNESS OF IIEAYY EARTHS - SUMMERS - INJURIOUS EFFECTS OF DROUGIIT - EXAMPLE OF PROPER VALUATION OF ARABLE SOIL - TIEORY OF JETHIO TULL - EFFECT OF INSECTS UPON PULVERIZATION - DEPTII - DIGGING CIRCLES AROUND TREES DEPIRCATED - POWER OF EXTEXSION BY ROOTS - DEEP CULTIVATION AFFORDS FRESI EARTI - MANNER OF OPERATION - THE SEASON - RESULTS OF IT: RAPID ADSORPTION OF MoISTURE-FreE ADMISSION OF THE AIR - TIE MIXTURE OF EARTIIS - THE DESTRUCTION OF IXSECTS THE INCREASE OF HEAT.

A CRUMBLING consistence of the soil is a necessary quality to the perfection of its fertility. A tenacious clay is unproductive because it is stiff, and it is therefore rendered an unsuitable pasture for the roots of plants. Being solid, it resists the attempt of the spongioles to extend themselves for food; and even though there be an abundance of pabulum present, still, as they cannot reach it, it is as useless to the cconomy of plant life as though it did not exist. 'This tenacity of the soil prevents the air from penetrating and warming it, and also prevents the decomposition of manurial substances. It absorbs too much moisture, and holds it in a 
stagnant condition. We have already demonstrated, in the chapter on "Drainage," that water should be in motion, by percolation, to be beneficial. Clay soils, or those having such a subsoil, prevent the free action of drains, because the impervious clayey stratum holds in check the water in its flow toward the pipes. But this will be again considered.

Soils are often unfertile because of their too light consistency. Such land may be made productive by pulveriation. The idea which first presents itself is, that such a course would render it lighter, and consequently more sterile. WVe argue, however, that its openness is decreased by such treatment, and its firmness augmented. The coarse particles of the soil become disintegrated by frequent exposure to the atmosphere, and they consequently lie more compactly in proportion as their size is lessened. A practical illustration is at hand.

A gentleman, when purchasing an estate in Massachusetts, hesitated at first, on account of the extreme lightness and sterility of the land. The surface-soil was but two inches in depth, while the subsoil consisted of but four, of light yellow, sandy loam, which rested upon sand and gravel. The depth of cultivation in the neighborhood was not more than from three to four inches, as the farmers dreaded to plough up the sand, because it was thought that it still more impoverished the soil. Contrary to these agricultural traditions, he ploughed 
the whole of his estate to a depth of from ten to twelve inches. The first year his crops were very light, compared with those about him; but still he persisted in frequent and deep cultivation. Six years after, his crops were more than double; he possessed a firmer soil than any other farmer in the neighborhood, and that to a depth of from ten to thirteen inches, where formerly existed but two. Not only was its fertility increased, but its capacity for sustaining drought was placed beyond dispute.

Light soils both absorb and part with heat readily. By pulverization they become so much more compact that their capacity for the retention of heat and moisture is increased. Prof. Stockhardt thus illustrates the binding effect of the roots of vegetation upon light lands.

"The first and principal condition of productiveness in a soil is a crumbling, soft consistency, and this must not be lost through the operations of tillage. The German farmer terms this condition, which is especially favorable to growth, 'gahu' (mellow). Whether this name be derived from gar, which means completely, well, or from gahren (to ferment), it is in cither case expressive, but especially in the latter, since it is beyond doubt that those processes of decomposition taking place in the soil, which may be rery properly regarded as a kind of fermentation, contribute essentially toward bringing it into this condition. What this is, and 
how it arises, I conjecture, may be explained as follows :

"In the more tenacious soils the carbonic acid crolved in the decomposition of humus forms a little carity of humous substances; consequently the whole mass becomes traversed by fine pores, just as the carbonic acid in the fermentation of bread renders the tough mass of paste porous. The legुion of animals, from the earth-worm to the infusorium, act in the same way, namely, to loosen; since they penetrate and perforate the soil in all directions, as do, moreover, the roots of plants in proportion as the tenacity of the soil allows them to spread. The effect will be greatest in all these directions when the soil is kept for a long period undisturbed and in a uniform state of moisture, as is the case when it exists under an overshadowing cover of vegetation. Hence the soft and open consistence which the soil exhibits where it has borne clover, lucerne, rape, or lupines, or has lain fallow for some time. If such soil is worked while wet, the cavities become effaced, and the mass close and clammy, just as wet fermented dough would be if violently beaten. In freer, looser soils, or those too loose by nature, the earth also attains a mellow condition through the cultivation of the above-named crops ; in such, however, this condition is characterized by the soil becoming less loose, pulverulent, and consequently more cohesive. This beneficial 
change, therefore, by which is produced a crumbling consistence of the soil, not however through subdivision, but rather by binding, is doubtless to be ascribed to the strong net-work of fine root-fibers, which can develop, spread, and ramify much more in the loose than in heavy and close soils."

The importance of pulverization appears from these considerations.

1. The stiffness of clay soils prevents the drains from accomplishing the work for which they were intended.

2. Silicious and gravelly soils are unproductive, because they do not retain the heat, gases, and moisture, as they would if properly pulverized.

3. Heavy earths are cold if not pulverized. They cannot absorb heat from the atmosphere, because it does not penetrate them; and they do not receive it from the decomposition of manurial substances, as such a process is arrested by the absence of the oxygen of the air, and the presence of stagnant water. The fact that air fills pulverized and cultivated land, can be proved by plunging a pot of earth under water, when bubbles will rise containing the air which was forced out when the water ran in.

The editor of that excellent periodical, "The Gardeners' Chronicle," thus beautifully illustrates the influence of "underground climate": "The 
roots of plants, although they burrow beneath the surface, are not on that account insensible to the influences which are felt by the stem and branches above. On the contrary, they are fully as sensitive, or even more so. If leaves and flowers wither beneath the scorching air, so do roots when the earth around them becomes parched; if the verdant foliage rejoices in the rain-clrop, not less is it grateful to the earth-bound root; if cold paralyzes the blossom, and compels the foliage to shrink and perish, roots also are affected in like manner. On the other hand, that warmth which causes the blossom to unfold and the leaf to open its bosom to the gentle breath of spring, acts equally upon the root, exciting it to growth, and putting in action all the sucking force by which the leaves and flowers are nourished. Nor is the access of air less important to one than to the other; both extremities of plants feed on air, - the roots even more than the leaves. Place a plant where the air can gain no access to its leaves, and they fall off, and are followed by the decay of the stem. Roots, if entirely deprived of air, will gradually shrink and die. Hence it is that the condition of the air in the ground, the temperature and moisture of the soil itself, require to be regulated, as well as that of the atmosphere which rests upon it; and thus the importance of regulating properly underground climate becomes evident." 
Heat in the earth occupied by fruit trees has been said by some cultivators to be so important that borders have been prepared, walled, and floored with cement, and pipes have been introduced containing it. The trees planted in soil thus prepared have been remarkable for their fine foliage, perfect fruit, and the greater maturity of their wood. This bottom-heat is esteemed highly by all good gardeners, and its effect on many plants is wonderful. Compare, as an example, two specimens of the same species, - the one growing in an unprepared open soil, and the other plunged in the warm borders of a green-house or hot-bed.

4. Unpulverized land is sour. Mr. Jos. F. W. Johntson remarks upon this subject: "Under the influence of air, the decomposition of the regetable matters of the soil proceeds more rapidly; it is more speedily resolved into those simple forms carbonic acid and water, chiefly - which are fitted to administer to the growth of new vegetable matter. In the absence of air, not only does decomposition proceed more slowly, but the substances immediately produced by it are frequently unwholesome to the plant, and therefore are fitted to injure or materially retard its growth.

"When the oxygen of the air is more or less excluded, the vegetable matter of the soil takes this element from such of the earthy substances as it is capable of decomposing, and reduces them to a 
lower state of oxidation. Thus it converts the red, or per-oxide of iron, into the prot-oxide, and acts in the same manner upon the oxides of manganese. It also takes their oxygen from the sulphates (as from gypsum), and converts them into sulphurets. These lower oxides of iron and manganese are injurions to regetation; and it is one of the beneficial purposes served by turning up the soil in ploughing, or by otherwise loosening it, so as to allow the free admission of the atmosphere, that the natural production of these oxides is either in a great measure prevented, or, when produced, they speedily become harmless by the absorption of an additional dose of oxygen."

5. Drought has an injurious effect on unpulverized land.

The pulverization of the soil increases capillary attraction, and therefore, to a great extent, prevents drought. Prof. Leslie found, upon investigation, that capillary attraction increased in an inverse ratio of the diameter of the soil: if the spaces were one hundredth of an inch, the attraction would extend about four inches, but with those of one ten thousandth, it was increased to twenty-five feet.

The illustration of the effect of pulverization upon the soil in preventing drought is somewhat similar, as is the result, to that under the same head in the chapter upon draining. (a) in the figure represents the soil which is tilled of only a few 
inches in depth, and from which the roots draw all their nourishment; (b) is an impervious stratum,

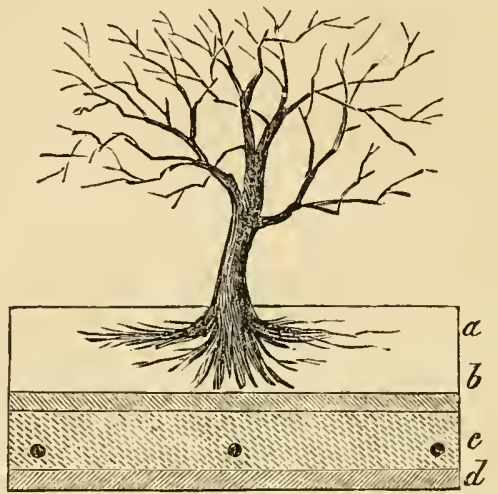

or very firm subsoil, which the roots can hardly enter, and the noxious gases which it contains are poisonous, because the air does not gain admittance to it. Not only does this stratum retard the extension of the roots downwards, but it prevents any benefits from accruing to the surface-soil from the drainage below; $(c)$ represents the underlying stratum, which was formerly filled with stagnant water. This was removed by the drains, and would add a fine and inviting field to the roots, if the impervious stratum could be broken up, and the air gain admittance; $(d)$ shows the position of the drains, which have performed their work, and yet the cultivator is dissatisfied because they do not, on account of this hard subsoil, prevent the eril effects of drought. Thus, when a dearth of rain occurs, it can be readily seen that the surface-soil must be- 
come parched, and the effect upon the tree be the same as when without efficient drainage.

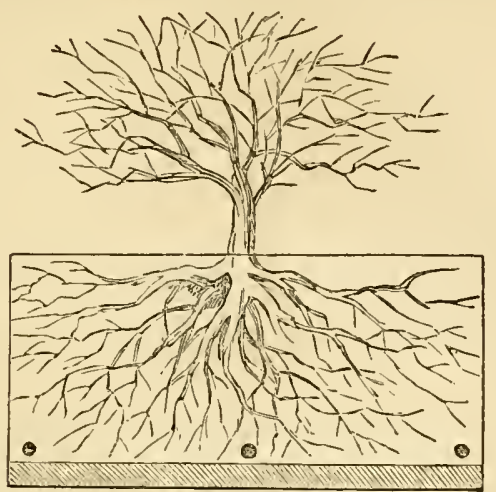

But remove the stratum (b), in the last diagram, and the whole earth which was drained is penetrated by the atmosphere, decomposition commences, heat is obtained, fertility increased, the drains are made efficient, and the pasture-ground of the roots is largely increased.

The purchaser generally values land by the square foot, but the judicious cultivator estimates it by the cubic foot. If he wishes to increase his income, and is about to add to the superficial area of his arable land, let him consider whether the same amount of money spent in placing another acre of fertile earth immediately under that which he now possesses would not yield a more profitable return.

Jethro Tull considered this subdivision of the soil as the great secret of husbandry, and thought 
that manure was superfluous. By this pulverization he raised several successive crops of wheat upon the same land, while his neighbors were compelled to resort to a rotation of crops. Considering the state of agricultural science at the period in which he lived, and the numerous obstacles which he surmounted in popular prejudice, and his own enfeebled health, he is certainly entitled to great praise. In his "Now Husbandry," he says: "It is without dispute that one cubical foot of this minute powder may have more internal superfices than a thousand feet of the same soil tilled in the common manner; and I believe no two arable earths in the world do exceed one another in their natural fertility twenty times; that is, one cubic foot of the richest is not able to produce an equal quantity of vegetables, ccteris partibus, as twenty cubic feet of the poorest: therefore, it is not strange that the poorest, when by pulverizing it has obtained one liundred times the internal superfices of the rich, untilled land, should exceed it in fertility. Or, if a foot of the poorest were made to have twenty times the superfices of a foot of such rich land, the poorest might produce an equal quantity of vegetables with the rich.

"There is another manifest advantage when a soil has been finely pulverized, - the roots are supplied with nourishment nearer to them on all sides than they could be if the soil was coarser, as 
it is in common tillage; and the roots in the one must extend much further than in the other to reach an equal quantity of nourishment; they must fill above twenty times the space to collect the requisite amount of food."

The part which insects perform in the pulverization of the soil is often overlooked. White, in his "Natural Ifistory of Selborne," remarks upon this subject: "The most insignificant insects and reptiles are of much more consequence, and have a greater influence in the economy of nature, than the incurious are arare of. They are mighty in their eifects, from their numbers and fecundity, as well as from that minuteness which render's them so little an object of attention. Earth-worms, though in appearance a small and despicable link in the chain of nature, would, if lost, make a lamentable chasm. To make no mention of the bircls and quadrupeds which are supported by them, worms are great promoter's of vegetation, by boring, perforating, and loosening the soil, and rendering it pervious to the rain and fibers of plants, by drawing straws, and stalks of leaves and twigs into it; they also throw up an infinite number of lumps of earth, called worm-casts, which, being their excrement, is a fine manure for grass and grain. TVorms also probably provide new soil for hills and slopes when the rain has washed the earth away. Gardeners and farmers often express their detestation of worms; 
the former because they render their walks unsightly, and cause them much work; and the latter because, as they think, they eat their green corn. But they would find, if deprived of them, that the earth would soon become cold, hard-bound, void of fermentation, and consequently sterile."

Mr. Mechi, of England, so distinguished for his appreciation of manure in a liquid form, thus enumerates the benefits of pulverization in a speech upon deep cultivation: "Nature herself has proved the necessity of some degree of cultivation of the soil by disintegrating the surface of our globe by the use of the chemical aid of air and water; by clothing the earth with a vegetation which was adapted by Almighty wisdom to its soil and climate. In vain does man select the most imperishable material as a record of his skill; chemical affinity, ultimately, by the action of heat and cold, of air and water, decomposes and crumbles to dust the architectural beauties of antiquity. It is a singular fact, that rarely do we meet with a farmer who would deny the benefit of a long summer fallow for tenacious soils - I mean a frequent ploughing of the surface-soil; and yct, how few are prepared to admit the advantage of a similar operation on the subsoil! 'This fact, however, can hardly be wondered at when we consider that the greater part of the heavy and hard-bottomed land of this lingdom [England] is undrained, or clrained in too 
shallow a manner to admit of subsoiling. Experience has shown that subsoiling without previous draining is injurious. On undrained lands the open furrows act as drains to the disturbed soil; but when the subsoil is broken up below, these furrows, having no subterranean escape for water, become after rains a puddled mass, into which the horses' feet force the upper soil, very much to its injury. In fact, it is a great impediment to cultivation, and is hurtful to the crops, and therefore drainage must precede subsoiling.

"There are many reasons why a disturbance of the subsoil may be profitable where deep ploughing or digging would be ruinous. Let us beware against burying our surface-soil, which has so long been cultivated and manured; if we do this, and bring to the surface a bad, stagnated, undecomposed subsoil, we shall feel its ill effects for years. I speak practically in this matter; for wherever the yellow, soapy subsoil of the new ditches has been spread on the surface, it makes a miserable seed-bed, and is difficult to work. Let us keep the surfacesoil where it is, for in breaking up the subsoil quite enough of it will become mixed with the upper. As the solutions of lime and manure, as well as atmospheric influences, gradually ameliorate the condition of the under soil, we can year by year gain one inch by deeper ploughing; remembering, however, that this will be a hundred tons of new 
earth per acre, which is a pretty strong dressing. I will now state what soils require deep cultivation. Strong, heavy, tenacious clays of almost every description are of this class. These should be broken up in dry weather, because the treading of many horses is not then injurious; besides, when the subsoil is dry, it is torn or broken up into fragments and irregular masses, which freely admits the summer heat and evening dew. If done in wet weather, the putty subsoil would collapse, and the surface become kneaded by the treading of horses. Sandy, silty, or gravelly soils, having a hard bottom of ironsandstone, or masses of puclding-stone, are much benefited by subsoiling.

"I find by breaking up these soils to the depth of from twenty-one to twenty-four inches, instead of four to five, as is usual, that all plants succeed better, particularly roots, green crops, and clover. They descend deeper, and of course are much less subject to injury from extreme cold or drought; and drainage secures them from stagnant water. I speak feelingly on this subject; for before I drained and subsoiled my land, my winter as well as my summer crops were often injured. I am convinced that it is the freezing of the roots in our shallow soils that often destroys our clover or tares, and our wheat. I have traced the roots of wheat and tares from nine to eighteen inches below the surface, as early as Christmas, when the soil has been suf- 
ficiently moved and pulverized; and we all know that clover roots descend rery deeply into good friable subsoils. 'The pan, or impervious mass that is often formed immediately below the plough, is a great impediment to the roots of plants; but subsoiling remedies this evil. It often requires great force to break up this pan; but the advantages accruing from subsoiling such lands as I have described, are observable for several years. One result of deepening the staple is, that it causes a less rapid but more perfect development of the plants; their growth is prolonged, and forms a striking contrast to the hasty prematurity and inferior produce of shallow soils, which have a hard and unpulverized substratum.

"Another advantage of subsoiling is the destruction of deep-rooted weeds. I know of instances where the roots of thistles and other obnoxious plants, as thick as one's finger, have been disturbed by the fork and in subsoiling, which were merely pruned by the ordinary plough."

Depth of pulverization. As was noticed under the last head, the more we gain in the depth of fertile soil, the more valuable does our land become, because the root-pasture is increased. It is impossible to go too deep as long as we do not interfere with the drains. The usual number of inches of cultivation is from twenty-four to thirty-six. The 
importance of deep pulverization may be stated as follows :

1. The range of the roots is increased. It is scarcely possible to limit the extent to which the minute roots of trees may spread themselves in search of food in well-prepared ground. It has been said by some writers that the distance from the truuk to the termination of the roots was the same as the height of the tree; but careful investigators have discovered that fibers, invisible to the eye, extend far beyond this. An experiment of Tull's is presented which aptly illustrates this point.

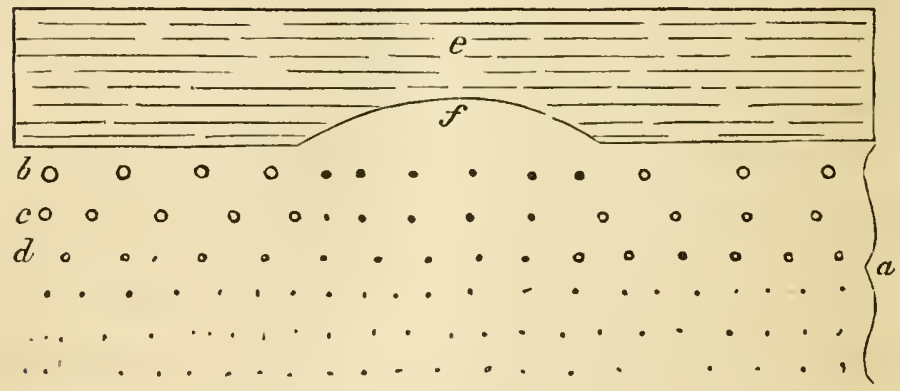

"Two pieces of land, or ridges, were drilled with turnips, in rows a foot apart, and were very even in them; the ground at both ends and on one side was hard and unploughed, and the turnips, not being hoed, were very poor, small, and yellow, except the outside three rows ( $b c$ and $d$ ) which stood next to the ridge $(e)$, which land, having been ploughed and harrowed at the time $a$ should have been, gave a dark flourishing color to these three 
rows. The turnips in the row $(d)$ which stood furthest off from the newly-ploughed land $(e)$ received so much benefit from it as to grow twice as large as any of the more distant rows; the row (c), being a foot nearer, became twice as large as those in $(d)$; but the row $(b)$ which was next to the land (e) became larger still.

"A like observation to this on the land (e) has been made in the turnip-fields of several farmers, where lands adjoining the turnips have been well tilled, and all the turnips of the contiguous lands, which were within three or four feet, received great benefit, in the same manner as did the rows $(b c d)$. This is a still stronger proof of the length of roots and the benefits of deep hoeing than the former illustration, as all these turnips had been well handhoed, which is a good reason why the benefits of the deep pulverization should be perceivable at a greater distance from it than in mine, because, as mine were not hoed at all, they had not strength to send out thcir roots through so many feet of unpulverized earth, as these through the soil which had been pulverized by the hoe, although but shallowly.

" $(f)$ is a piece of hard ground of about two perches in length, and about two or three feet broad, lying betwixt those two lands, which had not been ploughed that year. It was remarkable that during the length of this interjacent hard ground the 
turnips in the rows $(b c d)$ were as small and yellow as any in the land. As those in the row $(d)$, about three feet distant from the land $(e)$, received a double increase, it proves that they drew as much nourishment from the land (e) as from (a) where they stood. In their own soil they must have extended a yard all around, or else they could not have reached the land $(e)$, and it is therefore probable that these few roots penetrated more than another yard, which gave these turnips their increased size.

"A chalk-pit, contiguous to a barn, the area of which was about fifty perches, was made clean, and swept, so that there was not even the appearance of a regetable, any more than upon the barn-floor; straw was then thrown into the pit for the cattle to lie on. About three years after, when the dung which had been made thereon was hauled away, it was found that the top of the chalk was covered all over with roots, which came from a witch-elm which was not more than five or six yards in length from top to bottom, and which was about five yards above, and eleven yards from the area of the pit. Thus in three years these roots had extended themselves eight times the height of the tree."

If, as was perceived in the first illustration, turnips cast their roots six and nine feet horizontally to obtain nourishment, the distance to which a fullgrown fruit tree will throw out its fibrous roots can hardly be computed. Mr. J. J. Thomas, of New 
York, in a report to the American Pomological Society says, "I have just examined with some care the length of the roots of my dwarf pears, which were set out last year on my newly-occupied piece of ground in this village. They were two years from the bud when transplanted, and had received moderately good, but not high or rich culture. I found no difficulty in tracing the roots three and one-half feet from the trees, beyond which the fibers were too small to follow easily through a dry and tenacious soil. They had evidently extended themselves over four feet, and thus, small and young as the trees were, they had already formed a circle of roots about them eight feet in diameter. I have no doubt that in richer and more porous soil the roots would have run to a greater distance.

"A most important suggestion is afforded by this fact, which is, the indispensable necessity of great breadth of culture when applied to young trees. These of which we have spoken were dwarfs, and the quince stocks on which they were grown are generally supposed to confine their roots to a comparatively small circle; still they had already gained a diameter of nearly twice the height of the tree. 'The practice, then, of digging circles about the stems, instead of cultivating the whole surface, is comparatively useless, unless those circles embrace the whole extent of the roots, besides the soil which the roots of the surrounding grass may penetrate. 
It is not usual for grass plants to send out fibers two feet; but, admitting the distance ordinarily to be only one foot, there must still be dug a ring a foot wider on every side of the tree, if we would prevent the grass from injuring the newly-extended roots. Two feet added to the eight feet circle already required, would make ten feet, which would be the smallest dimension for cultivated circles for dwarf pears the second year after they have been transplanted, when surrounded by grass land. When the trees have grown a few more years, the cultivation should extend much further; in other words, it should cover the whole surface, and nothing less will answer under any circumstances.

"There are many who do not cultivate their trees at all, but allow them to stand in ground occupied with weeds and grass, or hardened by summer drought. The roots of such trees will not, of course, travel very far; and they will make but little growth, or remain stationary. There are many others who think it quite sufficient to spade a small circle around each, according to the rule once given by Mr. Downing, and copied since by other writers, which is to extend the circle as wide as the spread of the branches. The heads of my dwarf pears, already spoken of, average two feet in diameter, and a circle dug of this size, according to the rule, would be only one-fourth the diameter of the roots, and extend over but a sixteenth of their surface, producing scarcely a perceptible benefit. 
"The practice, then, of digging circles may be set down as positively injurious, by inducing cultivators to believe that they are doing something really useful, when in fact they are doing almost nothing at all. It should be wholly discarded, and thorough broadcast culture only relied upon.

"A few years since I performed an experiment to determine definitely the distance at which the peach would draw nourishment through its roots. A dozen trees, of the same size and variety, were set out on a piece of uniform land, and were cultivated for a few years until they were about ten feet high, when the land was laid to grass. A portion of the trees were within three feet of a compost heap, the rest at various distances from it. Those standing nearest the compost made a summer's growth of four feet eight inches. The tree that stood seven feet off, almost as far as the height of the tree, threw out shoots two feet five inches long. The next, at a distance of fifteen feet, made shoots fourteen inches long, while all others, twenty or more feet distant, grew but seven inches.

"'Thus we see that a peach tree ten feet high was doubled in its linear growth by a heap of manure fifteen feet distant, from which only a small portion of the roots on one side could derive any nourishment, proving conclusively that the roots must extend on each side to at least an equal distance; that is, that they form a radiating circle of fibers, 
no less than thirty feet in diameter, or three times as great in breadth as the height of the tree. How perfectly futile the attempt to benefit such a broad surface by spading a circle two or three feet in diameter, which would be but a hundredth part of the whole area of the branching fibres!"

The importance of an extensive plant-pasture has been proved by the previous examples. Deep, thorough pulverization of the soil is absolutely essential to the growth and success of trees, and their fruit shows clearly whether or not this fact has been regarded.

2. Deep cultivation introduces a fresh virgin soil from below into the old, exhausted earth above; and frequently lands which are unproductive have a subsoil of great wealth. Rains which have percolated through the surface have carried to the under soil the fertility which they themselves contained, and much of that which was before held in the upper; and, by turning and composting them, a soil which has never been disturbed, rich in those substances which the atmosphere elaborates into food for vegetable life, is brought up for use. But in some localities the subsoil contains those properties which are decidedly noxious to plants, and therefore the immediate mixture of these with the arable earth would be an injury. When fertilizing substances from bencath are added to the surface mould, the effect is of course bencficial; but when 
injurious matter is known, or thought to exist, the mixture of the strata should not be effected until the drains have rum for a few months to temper them, and reduce these elements of injury to those of fertility.

The result of the mixture of soils will be considered under our next subdivision.

3. By deep pulverization soils become mixed. We agree with Mr. Johnston, that many soils are deficient in some qualities which are necessary to productiveness. Thus humus abounds to an excess in peaty soils, and an addition to their earthy substance is a means of improrement. This is understood by farmers, and therefore sand or gravel is applied with good effect; and likewise muck or clay is carted upon and mixed with porous soils, and sand with tenacious earths. This alters their physical condition. It makes the clay more open, and the peat and sand more tenacious. A chemical as well as a mechanical change is effected. Oftentimes a soil is barren which contains all the elements of fertility, with a single exception. Thus some lands require lime, which they might secure

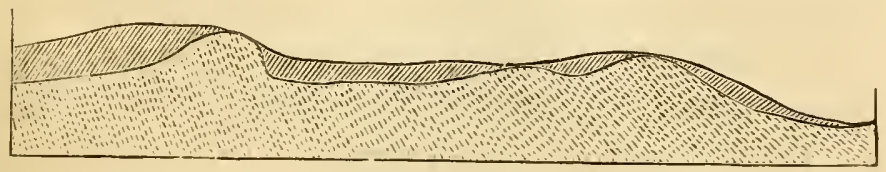

if the substratum should be mixed with the cultivated soil. Earths are often mixed by surface $13^{*}$ 
cultivation, as in the diagram before, when the porous substratum crops out; but where a stratum underlies the surface-soil at a regular depth it can only be incorporated with it by deep ploughing or digging.

4. The atmosphere is admitted to the roots, and consequently the fertility increased by deep cultivation. When a boy, I discovered a hole in which a woodchuck had residence, and commenced to dig him out of his intrenchment. The space dug over was about eight feet square and two feet deep. A handful of grass-seed was scattered upon the spot, that our sport might not injure the mowing the next year, and very little hay was expected; but it so far eclipsed the surrounding fields in the luxuriance and quality of its crop, that the whole field was treated in the same manner. This result must have been attained through admission of air to the soil, as no manure was applied. Prof. C. W. Johnson says M. Saussure has shown how essential a free access of air is to the roots of plants. He "found that oxygen gas was absorbed by the roots as well as by the leaves, and that it is there united with carbon, and transmitted to the leaves to be decomposed. It has been proved that vegetation is greatly increased by mourishing it with water impregnated with oxygen gas; hence, too, the superiority of rain-water. Some recent experiments were 'made by Mr. Hill, demonstrating the great benefit 
plants derive from oxygen gas applied to their roots. This is another reason for increasing the moisture of the soil by deep and complete ploughings; for M. Humboldt and M. Schubler have clearly shown that a dry soil is quite incapable of absorbing oxygen gas. Thus it must be evident to the most listless observer that the deeper and more thoroughly a soil is pulverized, and its earth made permeable, the greater will be the absorption by it of both oxygen and watery vapor from the surrounding atmosphere.

"It is, perhaps, needless - to prove that the roots of most cultivated plants will penetrate, under favorable circumstances, to a much greater depth in search of moisture than they usually do, on account of the hardened subsoil. Thus, the roots of the wheat plant in loose, deep soils have been found to descend to a depth of two or three feet, or even more. It is evident, if plants are principally sustained in dry weather by the atmospheric aqueous vapor absorbed by the soil, that at such a time their supply of water at the roots must be increased, by enabling the atmospheric vapor and gases, as well as the roots of plants, to attain a greater depth ; for the interior of a well-pulverized soil, be it remembered, continues steadily to absorb this essential food of vegetables even when the surface of the earth is drying in the sun. The free access of air to the soil adds to its fertility, by promoting the decomposition of organic substances in it." 
Prof. Voelcker, of the Agricultural Institution at Cirenchester, said, in a lecture on this subject:

"Into the composition of sandy soils but a very small amount of those substances enter which are food for plants. Clay soils contain insoluble silicates; and undecomposed materials, from which the clay is formed, furmish, on gradual decomposition, potash, which is one of the most fertilizing constituents. By working the land, fresh quantities of granite are brought under the influence of the atmosphere, and the felspar contained in it is gradually decomposed, and furnishes soluble potash. This benefit is not reaped from stirring a sandy soil. However much it is worked we camnot eliminate such a result from it, because there is not potash present in any considerable quantity; but in many clay soils the supply is almost inexhaustible; and they possess, to a remarkable degree, the power of absorbing moisture and fertilizing gases from the atmosphere. They also have the power of absorbing carbonic acid gas and ammonia, - two constituents which furnish the materials on which the plant builds up its organic structure.

"The more we plough the glebe, the more readily we give the atmosphere access to it, the more it is pulverized, the greater is the absorbing surface, and the more beneficial is the result. The advantages of deep ploughing, as a mode of improving clay soils, become more and more apparent from year 
to year. The nature of the subsoil must determine whether it is more advantageous to plough at once very deep, or gradually to improve the condition of the land by going a little deeper every year or two, or to allow it to remain in its natural position."

A gentleman in the vicinity of Boston commenced, about five years since, to prepare the ground for an orchard. The lot consisted of two acres. One acre and a half, which we will call (a), was trenched with the spade three feet deep, and the remaining half-acre was roughly ploughed to a depth of ten inches. 'The whole had been thoroughly drained, and was fertilized equally; part of the manure being mixed with the soil by spading and ploughing, and part applied upon the surface as a dressing. Pear trees were planted on the whole lot. The first year those upon (a) were covered with beautiful rich foliage, increased wonderfully in stock at the butt, and some made a growth of a few inches. Those upon the ploughed ground looked sickly and yellow the whole season, their foliage was small and malformed, and they increased neither in shoot nor stock. The owner became so dissatisfied with the shallow cultivation, that he could not wait to see the result of the experiment, and the next fall took up one-half of the trees upon the improperly prepared ground and trenched it thoroughly with the spade, thus leaving only one-quarter of an acre 
poorly cultivated. At the close of the second season, the trees upon (a) clothed themselves from top to bottom with rich shoots, and bore some fine fruit. Pears of the Winter Nelis variety weighed nine ounces, and several of them seven ounces, while some of his Duchesse d' Angoulene weighed from twenty-two to twenty-seven ounces. Those upon the second lot prepared had much the same appearance as those upon (a) the first year; and those upon (c), the ploughed land, continued to look sickly and slender, and throwing out but here and there a spindling shoot. In the fifth season the crop from (a) was sufficient to pay the original cost of the whole orchard. That upon the second, though one year behind (a), were yet very good; while the trees upon the ploughed soil were little larger than when they were transplanted.

How shall the soil be pulverized? The most thorough mode is that performed with the spade. A trench of the requisite depth, and two or three feet in width, is opened across the lower side of the

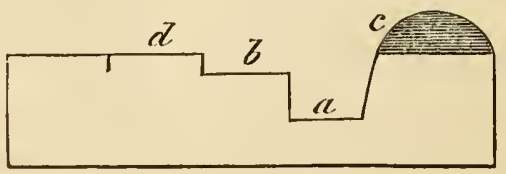

land to be worked. This is represented in the diagram by $(a)$, the earth being thrown out to $(c)$. Also the surface-soil of the next space $(b)$ is thrown 
to $(c)$. The subsoil at $(b)$ is then turned into the trench (a), at the same time being finely broken with the spade. The surface-soil at $(d)$ is thrown on the subsoil, spaded from $(b)$ to $(a)$, and so the work is continued, - the surface-soil being always in the same relative position as before.

The reason for this course, rather than to turn the surface-soil of $(b)$ into the bottom of the trench (a), and the subsoil above it, is readily found in the fact, that when the tree is first planted its roots reach but a few inches in depth into the soil, and they require fine earth about them, which has already been elaborated by the atmosphere and fertilized by rain and cultivation. When the roots find their way into the subsoil, it will have become tempered, purified, and fertilized. There are soils where the mixture of the two strata is, however, of decided benefit. Such is the case when a stratum of clay underlies a light soil, or the opposite. When peaty land has a subsoil of clay, their mixture has a remarkable effect. 'The Farmers' Encyclopedia says of such mixtures:

"There is, perhaps, no agricultural improvement in its immediate and permanent effects more important than the careful and judicious mixture of soils. This mode of improving the land was one which very early engaged the attention of the farmer. Nature herself, in fact, portrayed to him in very intelligible language the means of producing 
the richest of soils by the mixture of the strata. The solid matters brought down from the distant hills by the flood-waters, and deposited in the valleys where the waters rested, formed, by the mixture of the different strata, the rich alluvial soils of the old and new worlds."

The character of the subsoil must be considered before a mixture is allowed. A writer says: "By spade husbandry, extensive districts of blowing sand have been brought into cultivation in Flanders; while in various parts of England it has been equally successful; witness, as an example, the gardens of the cottages of the black, hungry sands of Bagshotheath, the poor chalks of Beachy Head, in Sussex, and the deep, trembling bogs of Lancashire. By many agriculturists the spade is considered the best instrument of fertilization, not only for gardens, but also for fields. The mere moving of the soil produces incalculable benefit. By the spade, and it only, some of the poorest, thinnest-skinned lands of Surrey have, by the deep trenching of the cottagers, been made to produce all the common vegetables. 'No gardener,' observed the late Dr. Fellowly, 'would think of planting potatoes, cabbages, or' carrots in ploughed land if he could get it dug; for the difference of produce would far more than compensate him for the increased cost." ",

The Hon. Marshall P. Wilder once performed an experiment for the purpose of determining the 
propriety of trenching with the spade for ordinary farm crops. The land was carefully pulverized to a depth of three fect, and was then planted with carrots. The result proved unquestionably the profit of a thorough preparation of the soil.

But under some circumstances, such as the scarcity of labor, some more economical method must be adopted. A common plough, with two horses or oxen, first turns as deep a furrow as possible, and the subsoil plough following immediately behind it with four cattle, loosens the earth to from eighteen to twenty inches more in depth. After this loosening of the subsoil has taken place, frequent pulverization of the surface by cross-ploughing tends to comminute the soil more perfectly. It is well to cultivate the ground for one season with some hoed crop before planting the trees, which loosens the earth still more, and gives time for the subsoil to become sweetened.

The season for pulveriation. The best time for subsoil pulverization is the autumn, because the frost will then penetrate the earth cluring the winter. In some localities insects nearly ruin the crops; these bury themselves in the soil which is not disturbed. If plonghing is performed in the autumn, these insects are exposed to the weather, and must nearly all perish; but if this is done in the spring, they are aided in their resurrection, 
appear in large numbers, and cause great havoc. Preparation in the fall is absolutely necessary when the land is to be planted the next spring; but to allow the ground to remain fallow, or to cultivate it with hoed crops during the season before planting, is productive of more satisfactory results.

The results of pulverisation. It is well in every important work to consider the effect to be produced. This, as relating to comminution of the soil, is -

1. The more ready destruction of weeds.

2. The decrease of the tenacity of heavy, and the increase of it in light, soils.

3. Greater fertility, on account of more rapid absorption of moisture.

This is a very important quality in pulverized earths, especially in warm and dry climates. Sir II. Davy observed that "the power of the soil to absorb water by cohesive attraction depends in a great measure on the state of division of its parts; the more divided they are, the greater is their absorbent power:"

4. The free admission of the air to the soil.

5. The enlargement of root-pasture.

6. The mixture of earths.

7. The destruction of insects.

8. Increase of heat at the season when it is desirable.

M. Alphonse de Candolle has admirably illustrated 
the effect upon vegetation of heat in the soil: "It has been proved, both by observation and experiment, that heat acts locally upon the organs of plants much more energetically than by transmission from one part to another. The best proof of this is afforded in the fact, that if the branch of a tree that is growing in the open air be protected, or introduced into a pit for exotic plants, its leaves will be developed before those upon the other branches. So, also, in the polar regions, the warmth of the air causes the plant to leaf and flower while the ground is still extremely cold. Nevertheless, since all plants pump up their sap from the ground, the temperature of the latter is an important element. During great heat, it is cooler than the air ; during great cold, it is warmer; and the more variable a climate is, the greater the importance to the gardener of this phenomenon. The heating or cooling effect of the soil will be most sensibly felt in those organs which are nearest the root, in those to which the sap flows rapidly and copiously, and in those which are bad conductors of heat. Thus the temperature of the interior of the cocoa-nut differs little from that of the earth around its roots, because of the thickness of the husk, which conducts heat badly; whilst, on the other hand, the young shoots and flowers of trees acquire the temperature of the surrounding air. Plants whose roots penetrate the earth deeply will resist vicissitudes in the surround- 
ing air better than those whose roots are superficial, because the temperature of the earth varies less the deeper we penetrate it.

"Many interesting observations have been made with regard to the heat of the soil at different depths; but, for our purpose, it is necessary only to consider such as extend to about three feet from the surface: for the roots of most plants penetrate no deeper; those which do, are generally such as affect a very light soil; and even great trees have more root-fibres near the surface than at the depth of three feet. It matters little to our investigations that, in our climate, a stratum of unvarying temperature exists at a depth of from twenty to thirty feet; that this stratum is found at three feet below the surface in some very uniform climates, and at much greater depth in such extremely cold countries as Siberia. We shall consider only the monthly variations in the upper three feet of the soil.

"That the temperature of the soil at this depth is less variable than that of the air, is proved by Mr. Muncke's observation at Heidelberg, which shows that the diurnal variations are not felt beyond three feet, nor the monthly beyond five. At Brusscls, M. Quetelet has shown that the annual variations present the following decrease, in descending from the surface to a depth of three and one-fourth feet : 
Degrees.

Air in the shade at the surface, . . . . . . 62

Air at a depth of eight inches, . . . . . . . 56

Air at a depth of two feet, . . . . . . . $54^{\frac{2}{2}}$

Air at a depth of two feet six inches, . . . . . $52 \frac{1}{2}$

Air at a depth of three feet three inches, . . . . $51 \frac{1}{4}$

It further took nineteen days for the maximum and minimum temperature of the year to penetrate three and one-fourth feet; or, in other words, its march to this depth was nineteen days behind that of the surface. Prof. J. Forbes has shown how much the rapidity of transmission, and the amount of heat transmitted, are modified by the nature of the soil ; and that, in the case of sand, the variation was three degrees greater, and five days more rapid, than in sandstone (terrain de grès).

"The roots of most plants are found within a foot of the surface; and it is the temperature at this depth that should be compared with that of the external air. The Brussels observations supply us with the necessary data for every month in the year, and the following table exhibits the differences between two thermometers, one hung in the shade two and one-half feet above the surface of the soil, and the other sunk a foot below the surface, - both on the south side of the observatory.

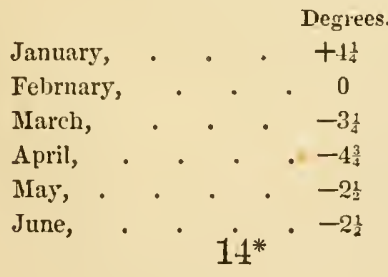

Degrees.

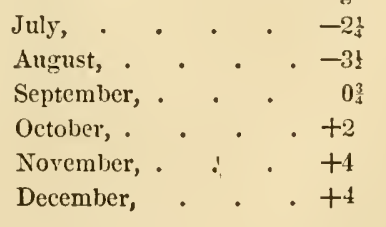




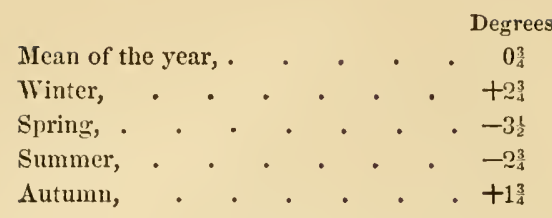

"Hence it appears that from the middle of autumn to the end of winter the temperature of the soil is warmer than that of the air at the mean depth of the roots; and that, on the contrary, at the season when the plant is at it greatest vigor, it is colder than the air. In the one case, the maximum difference between the soil and the air occurs in January, and in the other during one of the summer months. In no case does it exceed six and one-half degrees. At the end of winter and beginning of autumn, periods occur when there is no difference between the temperature of the air and soil. This fact, combined with that of the resuscitation of vegetable life in spring and its withdrawal in autumn, seems to indicate some direct adaptation of the cooler soil to the wants of plants at that season of the year. 'The difference is always greater in summer than in spring, and vegetation is not then more active than in April or May in the latitude of Brussels. During winter, a difference of four or five degrees can have but very little influcnce in diminishing the effects of cold; for the sap scarcely moves at that scason, and the effect of conduction from the roots to the branches must be extremely small. 
"During summer, a mean monthly difference of five and even six degrees is of considerable importance; and even supposing it to be reduced to half that amount by the time the sap has reached the leaves, it still lower's very perceptibly the temperature of the whole plant. This effect is increased by that evaporation from the leaves which results from the descent of the sap during the day; so that the hotter the air is, the greater are the resources which the plant finds within itself, and the earth in which it grows, for diminishing the effect of external heat."

The prevention of drought. Mr. John Sincham, in his work for the use of the engineer, thus enumerates the effects of pulverization: "It makes the drains efficient almost immediately and permanently. It enables the crop to be planted and harvested much earlier. It is the first and great step towards increasing the depth, and improving the condition of all light, bad soils. It allows the atmosphere to penetrate and circulate freely through the soil, and admits carbonic acid gas and oxygen to the roots of plants, to act upon the deleterious ferruginous compounds and secretions to be found in most soils. It secures also to them benefit from every drop of rain that passes through the atmosphere." 


\title{
CHAP'TER VI.
}

\author{
FERTILIZATION.
}

\begin{abstract}
SELECTIVE POWER OF PLANTS - FORM IN WHICH FOOD IS TAKEN UP EXCRETION - CIRCUlation OF tIIE SAP - ORganic SUBSTANCES : OXYGEN, HYDROGEN, CARBON, NITROGEN - IMORGANIC SUBSTANCES MANURES ADAPTED TO DIFFERENT SOILS: TO CLAYS, TO PEATY SOILS, TO SANDY LANDS - PLANTS TO BE USED IN GREEN-MANURING - APPLICATION OF MANURES.
\end{abstract}

PLAN'TS, like animals, show a preference in the selection of their food. They reject some substances, and elect others adapted to their nourishment.

Their food is supplied in two forms - liquid and gaseous. It has been stated by some writers that the former is absorbed by the roots, and the latter exclusively by the leaves. While this in the main is in accordance with observation, yet the roots do also absorb gaseous food, often in considerable quantities, especially in a well pulverized and thoroughly drained soil.

The cells through which the sap flows are, in their original and simplest form, cellulose, or parenchyma. Toward the root, the sap in these cells is thin; but at the leaves it becomes thickened by the decomposition of its water and the elimination 
of its oxygen. Thus there is constantly going on between the cells a process like that which may be observed if a membraneous bag containing a thick fluid should be immersed in water, - the thick becomes thinner by the absorption from the latter, or endosmose, while the water derives a small quantity of the former. Hofmeister discovered that this was the cause which produced the circulation of the sap from the root to the leaf, and that the little white fibres, styled spongioles by old writers, which were emitted during each season of growth, were formed of cells not covered by the thick skin or epidermis of the older roots, and that they absorb the thin fluid of the soil, which contains pabulum in solution. Thus a regular grade of elaboration, or thickness of the sap, is established from the leaf to the roots. These absorbing cells, after having performed their work for one season, become covered with the epidermis, and cease to provide for the growth of the tree. This should be borne in mind by the cultivator when he applies his manure to the ground about his trees. The feeding roots are at a considerable distance from the trunk of the tree, and if applied near it, scarcely any benefit will accrue.

Roots have been said to excrete substances absorbed, which were unnecessary or injurious. This was the belief of De Candolle, and others. It was formed from the fact that a plant will not succeed 
where one of the same species had been previously growing for any length of time, and that substances existed in that soil which were not to be found in other parts of the field. But this is by no means a sufficient proof, because we should expect that if the existing combinations were separated, others would be formed.

That the roots possess a general power of selection, we are led to believe from the fact that the ashes of various species differ so widely even when the plants are grown upon the same soil. It is probably confined to the combinations which the plant meets with in its indigenous soil, and does not apply to those artificial substances which are sometimes applied, nor to the tree when placed in an unnatural position. Thus, the application of a large quantity of iron to the roots of a plum tree, resulted in a dark-colored exudation from its bark; and the colors of flowers are often changed by the substances placed in the soil.

It will be well to examine more particularly the structure of those organs of the plant which perform the function of digestion. The upper surface of the leaves, and all green parts of other portions of the tree, exhale the oxygen contained in their sap, while the under surface of the leaves inhales carbonic acid and some other fertilizing gases from the atmosphere. The cells, on the upper surface, are therefore very close, to prevent excessive evaporation, 
while on the under surface they are placed loosely to admit gases freely. Thus this figure ${ }^{1}$ represents

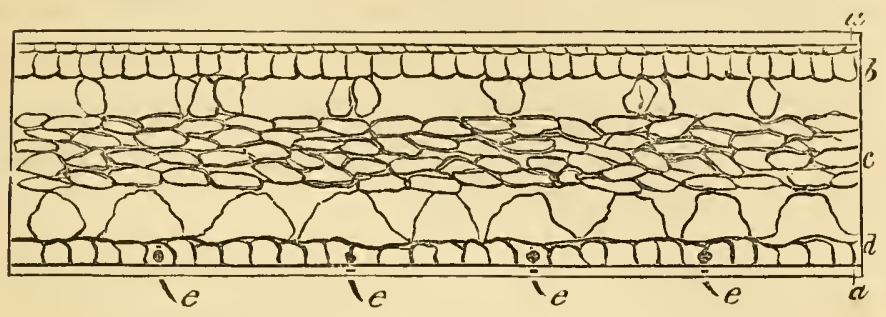

a cut made through the thickness of the leaf, exhibiting its edge highly magnified.

(a) denotes the epidermis;

(b) a close layer of parenchyma ;

(c) internal cells ;

(d) the cells of the lower surface;

(e) stomates, or valves through which the gases enter.

As the sap descends in the liber by gravitation, it causes the multiplication of cells between the bark and wood. Every cell contains within itself a nucleus, from which the sap flows toward the walls; this contains several nucleoli, or cytoblasts, which, when they have attained size, burst the nucleus, and each becomes like its parent. Consequently, if there are two nucleoli, each creates a current acting comnter to the other, and at their point of contact a membrane is formed which divides the old cell. This is very rapid work. We can

1 Dr. Lindley's Introduction to Botany. 
form very little idea of the wonderful mechanism, or the rapidity of its motion, which exists in the interior of a fruit tree. These cells are very minute, - many of them not more than one-thousandth of an inch in diameter, - and yet grape vines in a warm house often grow from one to two inches on the end of each shoot per diem.

It must be manifest to all that plants, as well as animals, require food. It remains for us to examine its nature and adaptation. When a plant is burned, a part escapes into the atmosphere, and a part remains in the ash. The first we shall call organic, and the latter inorganic.

\section{ORGANIC SUBSTANCES.}

1. Oxygen. Mr. Johnston thus states the sources of this gas: "The water which plants imbibe so largely consists of this gas in great part, being eightninths of its whole weight. In this form it is easily decomposed, and yields an inexhaustible supply.

"'The atmosphere contains twenty-one per cent., and the leaves of plants, in certain circumstances, are known to absorb it.

"Carbonic acid contains seventy-two per cent. of oxygen by weight, and this gas is known to be absorbed in large quantities from the atmosphere by the leares of plants; while in solution with water, it is absorbed by the roots. 
"From any one of these sources an ample supply of oxygen can readily be obtained; and it may be considered as a proof of the vast importance of this element to the maintenance of animal and vegetable life, that it is everywhere placed abundantly within their reach. It is from the first of these sources, however, - water, - that plants derive their principal supply.

2. IIydrogen. "This elementary substance is not known to exist in nature uncombined. Therefore it must, like carbon, enter plants in union with some other element.

"Water consists of hydrogen in combination with oxygen. In the form of vapor, this compound pervades the atmosphere, and plays among the leaves of plants; in the liquid state it is diffused through the soil, and is unceasingly absorbed by the roots of all living vegetation. In the cells of plants - at least during their growth - water is continually undergoing decomposition; and this is unquestionably the principal source of the hydrogen which enters into the constitution of their several parts. In explaining the properties of water, we have already referred to the apparent facility with which its elements are capable either of separating from or of reuniting with each other in the vascular system of animals or plants.

"In light, carburetted hydrogen, given off during the decay of vegetable matter, and said to be always 
present in highly-manured soils, hydrogen exists to the amount of nearly one-fourth of its weight. On the extent, therefore, to which this gaseous compound gains admission by the roots into the plant will depend the supply of hydrogen which they are capable of drawing from this source. Had we satisfactory evidence of the absorption of this gas by the roots or leaves of plants in any quantity, we should find no difficulty in admitting that plants might from this source easily obtain a considerable supply of both carbon and hydrogen. We could also explain how, that is, by what chemical changes, it is capable of being so appropriated; but the extent to which it really acts as food for vegetables is entirely unknown.

"Ammonia is another compound containing much hydrogen (one equivalent of nitrogen to three of hydrogen), which excrcises a manifest influence on the growth of plants. If this substance enters into their circulation in any sensible quantity, - if, as some maintain, it be not only universally diffused throughout nature, but is constantly affecting and influencing at all times the functions of vegetation, - there can be no doubt that the hydrogen it contains must, to an equal extent, be concerned in the production of the various organic substances which are formed or elaborated by the agency of vegetable life. The quantity of ammonia which actually enters the circulation of plants in a state of nature 
is too little known, and, making the largest allowance, probably too minute, to permit us to consider it as an important source of hydrogen to the general vegetation of the globe." Ammonia is, however, a powerful agent in hastening the fermentation of such materials as are to become plant-food. This it does, according to some authors, directly, and to other's, by acting as food to the little fungi which do the work. The value of this compound has, no doubt, been greatly exaggerated by some writers, who have estimated the worth of fertilizers according to the amount which they contained. It is true that it acts as a stimulant to plants, and perhaps as a solvent for humus. As a writer in the Gardeners' Magazine states: "Notwithstanding Liebig, Johnston, and Schlieden object to this, on account of the ease with which the humates are decomposed, yet this process may be going on constantly, and, being immediately absorbed by the roots of the plant, this may aid it in building up its structure. But while Liebig argues that ammonia is derived from the air, there seems to be abundant evidence that a portion is also received from the soil. Yet the fact, as stated by some, that ammonia is furnished exclusively from the soil, cannot be correct. Both supply it, probably in varying proportions, according to the necessities of the plant."

Therefore the cultivator should be careful to preserve this extremely volatile substance in his 
manure-heap; and this can be done only by giving it absorbents, such as peat, sawdust, tan, sods from headlands, loam, or gypsum. Urine is rich in ammonia, and should not be allowed to run to waste. Often the drainings from the manure-heap containing it are permitted to flow away unmolested. Unless the soil naturally contains a quantity of humus, or has been well manured, fertilizers containing this substance largely - such as nightsoil, guano, or urine - cannot be recommended for exclusive application in large quantities. Although experiments have been cited where land has permanently retained its fertility under an annual dressing of guano, yet the experience of most farmers has been to the eifect, that such treatment produces a certain want of life, and in the end barrenness, while if mixed with the compost-heap it is calculated permanently to increase growth. If it is desirable to stimulate the vigor of the tree, the application of such manures may be well, otherwise they should be withleld.

Mr. Johnston again says: "The soluble organic substances which enter the circulation of plants through the roots consist not only of carbon and water, but of combinations of hydrogen and oxygen in various proportions. From these substances, therefore, plants derive an uncertain and indefinite supply of hydrogen in a state already half organized, and probably still more easily assimilated or con- 
verted into portions of their own substance than when this element is combined with oxygen in the form of water.

"We may conclude generally, in regard to the source of the oxygen of plants, that though there are undoubtedly several other forms of combination in which this element may enter their circulation in uncertain quantity, yet that all-pervading water is the main and constant source from which the hydrogen of vegetable substances is derived.

3. Carbon. "We have reason to believe that carbon is incapable of entering directly, in its solid state, the circulation of plants. There are two sources from which it can be obtained, - the soil in which the plant grows, and the air by which its stem and leaves are surrounded. In most soils much vegetable matter is present, and large quantities are added by the manures used. It is true, however, that plants are really fed by the vegetable matter existing in the soil.

(a) "We know from sacred history, what reason and science confirm, that there was a time when no vegetable matter existed in the soil. The first plants must have grown withont the aid of either animal or vegetable matter; that is, they must have been nourished from the air.

(b) "It is known that certain marly soils, raised from a great depth beneath the surface, and containing apparently no vegetable matter, will yet, 
without manure, yield luxuriant crops. The carbon in such cases must also have been derived from the air. De Saussure found that two beans, when regetated in the open air on pounded flints, doubled the weight of the carbon which they originally possessed.

(c) "Some plants grow when suspended in the air without contact with the soil.

(d) "When lands are impoverished, we lay them down to grass, and the longer they lay undisturbed the richer: in vegetable matter does the soil become.

"In certain extreme cases, as in those of plants growing in soil perfectly void of organic matter, this conclusion" (that they draw all their carbon from the atmosphere) "must be absolutely true. But is it as strictly true of the more usual forms of vegetable life, or in the ordinary.circumstances in which plants grow spontaneously, or are cultivated by the art of man? Has the vegetable matter of the soil no connection with the growth of the tree? Does it yield them no regular supplies of nourishment? Is nature working in vain when preparing all this vegetable mould in the soil ?

"The consideration of one or two facts will show that our general conclusion must be moaified. Plants in certain circumstances will grow in a soil containing no sensible quantity of organic matter; but it is also true, generally, that they do not luxuriate, or readily ripen their seed in such a position. 
"It is consistent with almost universal observation that the same soil is more productive where organic matter is present than where it is absent; that if a crop be carried off the field, less organic matter is left in the soil than it contained when it began to grow ; that by constant cropping the soil is gradually exhausted of organic matter. The conclusion, therefore, seems to be reasonable and legitimate, that the vegetation which we remove from a field has not derived all its carbon from the air, but has extracted a portion of it immediately from the soil. It is to supply the supposed loss of carbon, as well as other substances, that the practical farmer applies manure to his land. Supposing it to be established that the whole of the carbon contained in plants has originally been derived from the air, we have only to inquire in what state this element exists in the atmosphere in order to satisfy ourselves as to the form of combination in which it is, and has been received into the circulation of plants. Carbonic acid, a compound of carbon and oxygen, is always present in the atmosphere, though in comparatively small quantities; yet it is everywhere to be detected, while no other compound of carbon is to be found there in any appreciable quantity. We must conclude that from this gaseous carbonic acid the whole of the carbon contained in plants has been primarily derived. But in what state or form of combination do they absorb carbon from the soil? 
"The most abundant product of the decay of vegetable matter in the soil is this same gas. In land replete with vegetable matter, therefore, the roots are surrounded by an atmosphere more or less charged with it. Hence, if they are capable of inhaling gaseous substances, this will enter the roots in the aeriform state; if not, it must enter in solution.

4. Nitrogen. "The question as to the form in which nitrogen enters the circulation of plants, at the present moment engages much attention.

"It is considered an essential part of good tillage to break up and loosen the soil, in order that the air may have access to the dead vegetable matter, as well as to the living roots, which descend to considerable depths beneath the surface. When thus admitted to the roots, some of the nitrogen of the atmosphere, as well as a portion of its oxygen, will undoubtedly be directly absorbed and appropriated by the plant. 'To what extent this absorption of nitrogen may proceed we have as yet no experimental results from which we can form an estimate; - whether it takes place at all or not, is wholly a matter of opinion.

"The leaves of plants absorb certain gaseous substances from the atmosphere, and we might therefore expect that some of the nitrogen of the atmosphere would by this means be admitted to their circulation. This view is not confirmed by any of 
the experiments hitherto made with the view to investigate the action and function of the leaves. We are not at liberty, consequently, to assume that any of the nitrogen which plants contain has been derived in this way directly from the air. It may be the case, but it is not yet proved.

"There is little doubt, however, that nitrogen enters the roots of plants in a state of solution, but the quantity they thus absorb is uncertain. When water is exposed to the air in an open ressel, it gradually absorbs oxygen and nitrogen, though in proportions different from those in which they exist in the atmosphere. The whole quantity of the mixed gases thus taken up, according to Humboldt and Guy Lussac, amounts to about four per cent. of the bulk of the water, and in rain-water about twothirds of this consists of nitrogen. One hundred cubic inches of rain-water will therefore carry into the soil about two and two-third inches of nitrogen gas."

These organic substances were all originally possessed by the air. The first forms of vegetation which existed upon the earth were those whose roots simply served to hold them in position, or to draw very slightly from the earth. All the organic elements of growth were to be easily absorbed by those which were aquatics from the water which surrounded them, and by land-plants from the atmosphere. These, by their death, imparted to the 
soil organic elements, and upon the remains of their decomposition sprung up what we call higher orders of vegetable life. These gave way to others; and at last, from the death of these numerous generations, the soil became supplied with organic elements, and then the fruit tree appeared; not according to the Darwinian theory, by development one from another, but by independent creations of the great Designer.

Barren sandy lands are unproductive because they do not contain these organic substances. We shall consider the method of supplying them in the proper place.

II. INORGANIC SUBSTANCES.

These are found only in the soil, and although many of them enter in very small quantities the organism of plants, they are none the less important. One link, however small it may be, is necessary to the completion of a chain; just so a onethousandth part of some inorganic substance is demanded by the plant to perfect its structure. The names of these inorganic substances are as follows :

$\quad$ Substance
Allumina,
Lime,
Chloride of Calcium,
Chlorides,
Iodides,
Oxides,

$\begin{array}{ll}\text { Oxyroduced by } & \text { Aluminum, } \\ \text { Oxygen, } & \text { Calcium. } \\ \text { Chlorine, } & \text { Caleium. } \\ \text { Mretals, } & \text { Chlorine. } \\ \text { Metils, } & \text { Iodinc. } \\ \text { Oxygen, } & \text { Iron. }\end{array}$


Substance

Sulphurets,

Magnesia,

Oxides,

Sulphurets,

Phosphoric Acid,

Potash,

Chloride of Potassium,

Silica,

Soda,

Chloride of Sodium,

Sulphurets,

Sulphuretted Hydrogen,

Sulphuric Acid,
Produced by combining

$\begin{array}{ll}\text { Sulphur, } & \text { Iron. } \\ \text { Oxygen, } & \text { Magnesium. } \\ \text { Oxygen, } & \text { Manganese. } \\ \text { Sulphur, } & \text { Manganese. } \\ \text { Oxygen, } & \text { Phosphorus. } \\ \text { Oxygen, } & \text { Potassium. } \\ \text { Chlorine, } & \text { Potassium. } \\ \text { Oxygen, } & \text { Silicon. } \\ \text { Oxygen, } & \text { Sodium. } \\ \text { Chlorine, } & \text { Sodium. } \\ \text { Metals, } & \text { Sulphur. } \\ \text { Hydrogen, } & \text { Sülphur. } \\ \text { Oxygen, } & \text { Sulphur. }\end{array}$

Alluminum ${ }^{1}$ is a very rare metal.

Allumina is very abundant, especially in clay soils.

It is soluble in acids, but not in water. The proportion of it which plants absorb is exceedingly small, and, from its abundance in the soil, would lead one to suppose that it possessed some more indirect and important quality, probably that of the absorption of ammonia.

Phosphate of alumina is present in the soil in very small amounts.

Sulphate of alumina exists in swampy, peaty soil.

Calcium, in its combination with oxygen, forms one of the most important of inorganic compounds.

Lime. Many substances proceed very slowly in their decomposition which is hastened by the application of lime.

Carbonate of lime forms a part of almost all plants, and is very important to their growth.

1 Johnston. 
Chloride of calcium also has a wonderful effect upon many crops.

Sulphuret of calcium is produced by the agency of heat acting upon calcium and sulphur.

Sulphate of lime. This compound of sulphur and lime is very valuable as a fertilizer, and has caused lands which before had defied all attempts to render them productive to bring forth fine crops. Besides its other properties, it possesses that of absorbing ammonia from the air.

Nitrate of lime is found in the soil, and is of considerable value, but is very soluble.

Phosphate of lime is the substance from which the bones of animals are formed, and is important as a manurial substance. It is soluble only in acids, when it becomes super-phosphate of lime.

Chlorine, in combination with hydrogen, forms muriatic acid, which dissolves many of those substances of the soil that are insoluble in water, and prepares them to become the food of plants.

Iodine is beneficial to vegretation when combined with sodium. It is soluble, and exists largely in the waters of the ocean.

Oxides of iron. Iron combines in two different proportions with oxygen. One is called prot-oxide, and possesses about twenty-three per cent. of oxygen. This is very injurious to plants; but by exposure to the air it assimilates with more oxygen, and becomes per-oxide, in which state it is a powerful absorbent of ammonia. 
Sulphuret of iron exists in some undrained soils, and although not itself injurious, yet, when exposed to the air, it produces the sulphate of iron, or green ritriol, which is decidedly hurtful to plant-life.

If the land is thoroughly pulverized and drained, this will become the per-oxide, which is so beneficial a compound.

Carbonate of magnesia exists in many soils, and has great powers of absorbing moisture.

Chloride of magnesium has been applied with benefit to lands, but great care must be exercised on account of its remarkable solubility.

Phosphate of magnesia is present in urine, and in many of our most valuable fertilizers.

Manganese resembles iron in its action and character, and in forming several combinations with oxygen.

Phosphorus, when combined with other substances, forms many valuable compounds - such as phosphate of lime, phosphate of potash, etc.

Silica produces many valuable substances in its combination with potash, soda, etc. It is present in all regetable matter, and is distributed very libcrally through the soil. It is insoluble in water, and dissolves very slowly in alkalies.

Carbonate of potash exists in the sap of almost all plants, and the good results following the application of wood ashes are produced by its presence.

Chloride of potassium is also found in the ashes 16 
of most plants, and its action upon them as a manure is beneficial.

Nitrate of potash. This is a most important substance in hastening the growth of plants. It is formed of nitric acid and potash, and is commonly known as saltpetre.

Chloride of sodium, or common salt, is found in all plants. It exists in largest quantities in lands which lie near the seacoast.

Sulphate of soda has a good effect upon many plants.

Carbonate of sola in its various forms, as sesquicarbonate, bi-carbonate, and in the simple form, is also beneficial.

Phosphate of soda is another important constituent of urine.

Sulphuric acid is rarely met with in the soil, except in union with other substances, forming sulphates with potash, lime, soda, etc.

These are the compounds which usually exist in the soil ; but land may have an abundance of some of them, while it is entirely destitute of others, or of the means of producing them. This should guide us in the consideration of the next division of our subject.

III. MANURES ADAPTED TO DIFFERENT SOILS.

Accurate chemical analysis can alone ascertain the exact substance which is wanting; but we doubt 
if this is always practicable. We can merely consider generally those manures which experience has proved to produce the best mechanical as well as chemical effect on a soil of a certain general character.

Clay earths. These have a great amount of fertility stored in them ; but they are often so tenacious as to prevent the entrance of the air, which is important to the production of valuable compounds. This is partially remedied, as we have seen, by thorough draining and pulverization; but a still further benefit can be realized by an application of sand to the depth of from one-half an inch to an inch mixed with the surface, thus not only producing a mechanical effect by loosening the soil, but inducing a chemical change by the introduction of air. In such cases very coarse sand is to be preferred; that which is rich in lime is the best, as by its fermentation it produces still greater porosity. Horse-manure, and others which ferment rapidly, lime, marl, etc., are best for such land.

Peaty soils are also bencfited by applications of sand or fine gravel. On such lands many plants fail to succeed because the carbon contained in the humus absorbs the oxygen as it enters the earth to form from it carbonic acid. By the increased porosity produced by sand, oxygen is not only presented to the roots, but the decomposition of the humus is hastened. Manures possessing vegetable 
matter would be superfluous, as such soils already contain a sufficiency; but an application of lime would be beneficial. That which is generally used for agricultural purposes contains carbonate of lime, with many other substances, which fact accounts for its varied effects upon different soils.

When it is caustic, or has disposed of its carbonic acid from burning, it is particularly desirable. To prolong this condition, and prevent its absorption of carbonic acid and other substances, it should be mixed with the surface-soil as soon as possible. Lime should not be applied in too large quantities, else the humus will be decomposed faster than the crop could use it, and the application would become in the end a means of impoverishing the soil. On very stiff clay soils as much as five thousand pounds has been applied to the acre with benefit, while light land would not be improved by more than three or four hundred pounds. On marshy land about twelve hundred weight is sufficient. It should be used in summer, as it can then be more intimately mixed with the surface-soil.

The cultivator should be warned against the use of lime, if he has not thoroughly drained his land, unless he desires to bring it to the consistency of mortar. The length of time in which it acts upon the soil varies according to the quantity used; but the average is from six to ten years. It should be first slacked in small quantities, by covering with 
earth ; then thoroughly composted with loam spread over the land; ploughed in at first only an inch or two, and then deeper, to mix it perfectly. The application should never be made in wet weather.

Dr. Dana states that the action of lime on soils is threefold: "First, it is a neutralizer" second, a decomposer; third, a converter. 1. There are certain acids which are free in the soil, such as phosphoric, acetic, or malic, which become neutralized by the lime. 2. There are certain substances which, for want of decomposition, are locked up, and are therefore useless to plants; but lime, by forming a combination with them, decomposes and retains them in a state in which they can be easily dissolved. 3. Lime also acts upon humus, to render it soluble plant-food, by converting it into acid. Therefore, if plants such as sorrel are produced by land, it is evidence that lime is needed to neutralize these free acids in the soil. The more humus a soil contains, the more lime will it need to convert the insoluble matter and undecayed vegetable fibre into decomposed and soluble food. When a great amount of lime is applied, manure must also be added, because the first is not the food itself, but the fuel which prepares it for use. Lime does not revive worn-out land, but gives it the means of using the manure."

Lime is often applied in a cheap form, as marl. This widely differs in composition; but that which 
crumbles is the most valuable. The effects are quickly seen, and of short duration; but this is no objection, for it is as important to the farmer as to the capitalist to receive quickly the returns from his investment.

Sandy lands are improved by mixture with substances containing humus, or vegetable matter. Chief among these is peat, which is so generally found in the temperate zone. 'Martin Doyle's Cyclopædia of Practical Husbandry gives Lord Meadowbanks's method of rendering peat a profitable manure. His suggestion is, to "form a layer of peat, which had been previously in a dry state, a little longer than the intended midden, six inches thick; and on this to lay fresh dung and peat, in alternate courses, diminishing each layer of dung from ten inches in thickness, until the compost is three or four feet high, when it should be covered from the ends (which should be formed to overlap for the purpose) and the sides with peat. His lordship's proportion is, one load of dung to three of peat, in mild or warm, and a little more dung in cold weather, so as to produce a full and generous fermentation, which in summer will be so rapid and violent as to require an additional application of peat. The heap should be turned upsicle down, thoronghly mixed, and all the lumps broken a few weeks before using, after which it ferments mod-

1 Gardeners' Chronicle of 1813, p. 39. 
erately a second time, and then presents the appearance of garden mould, and equals farm-yard manure."

One of the most economical methods of applying regetable matter to the soil is by the use of green crops. Sir Thomas A. Knight, in his experiments upon manures, found that seeds germinated and grew more rapidly which had been manured with green vegetable substances; and he argues from this that it was because the plant found there the substances suited to its nutrition in a state of elaboration nearer to that in which they existed in itself; and that it was upon the same principle that carniverous animals were nourished by the flesh of other animals more than by the materials which constituted the food of their prey.

Dr. Anthony Todd Thompson, in a review of the same in the Gardeners' Magazine, says that it is a question whether the sap of plants drawing their nourishment from vegetable matter is in any higher state of elaboration than those feeding upon decayed manures. But he finds the advantage of the use of the green manure, as in Mr. Kinight's experiments, to result from the difference in the degree of heat. Green regetable matter would, of course, ferment rapidly, and heat would be the consequence; so that the ground about such manures would be affected by it, the germination of seeds and the growth of plants would be hastened and increased. 
Prof. Sprengel, of Germany, published in the year 1842 a number of valuable papers in the Gardeners' Chronicle upon green manuring, from which we glean the following:

"It is the operation of growing certain plants merely for the purpose of ploughing them in as soon as they have reached a certain maturity (namely, are in blossom), which may be done either on the spot or by conveying them to another field. This is no modern discovery, for it was used even by the Romans, especially with the lupine. Although this sort of manuring has been extolled by some anthors beyond all measure, it cannot be doubted that it is a very advantageous operation, especially on light land with a pervious subsoil. Its advantages are that most of the plants grown for green manuring obtain from the subsoil, by means of their deep roots, those substances which are required as food by shallow-rooted plants, and which are thus brought back to the surface whence they were previously removed by rain; at the same time they convey substances to the surface which it never before possessed. These are the chief advantages derived from ploughing in green crops, which, however, have not been hitherto properly appreciated. Among the more useful substances thus brought up from the subsoil are potash, soda, chlorine, sulphuric and phosphoric acids, magnesia, and lime. The green crop, when ploughed in, enriches the 
land with carbon, which was absorbed from the atmosphere by the leaves of plants. That it supplies the soil with nitrogen is very important to corn plants, for they possess the power of attracting nitrogen (which is one of their chief sources of nutrition) from the air only in a very slight degree. Green crops, moreover, keep dry soils cool and moist, because the humus which is engendered by their decomposition not only absorbs much moisture, but retains it for a long time. Their strong herbage and woody roots act mechanically on heary land by loosening it. After manuring with a green crop, corn is never laid, although it grows as luxuriantly as after a dressing of dung. The reason is, that while the latter supplies the ground suddenly with a great amount of nitrogen, green manure affords it much more gradually, in consequence of the slowness of its decomposition, acting most powerfully when the plant requires most nourishment. Its effects will not last, however, more than two years, as the mass of herbage ploughed in is often not more than a third of the weight of the dung.

"This method of enriching land is very economical, not requiring more than one ploughing and harrowing, and the sced is generally very cheap. When fields are at a distance, it saves much carriage; and it prevents the soil from losing its humus by evaporation; because, as soon as the corn is gathered in, the field is plonghed and the crop for green 
manure sown. These advantages have led to the assertion that plentiful crops may be obtained without any other kind of manure, if, between every two corn crops, green manure is employed. It has been forgotten, however, that this itself will exhaust the subsoil in the long run. If the subsoil be very rich in fertilizing substances, the surfacesoil may be kept in full vigor for many years by green manures, without the assistance of dung; nevertheless, under any circumstances, it will be useful to manure occasionally, employing such substances as gypsum, common salt, bone-dust, wood ashes, etc., which will be useful both to the crop for manure, and to that which is to follow it.

" He who wishes to obtain all possible advantage from green manure must observe-first: those plants only must be used whose seed is very cheap. Second: those must be taken which are sure to succeed and grow very fast, in order that in the shortest time the greatest amount of herbage may be produced. 'Third: they must not contain substances which would be injurious to the succeeding crops. Fourth: they should be deep-rooted plants, for such will absorb the nourishing substances hidden in the earth, and convey them to the surface for the use of the shallow-rooted crops. We are not required, however, to confine ourselves to annual plants; on the contrary, it is much better (as will be seen hereafter) if perennial plants are sown, 
because in that case annual cultivation, and all the seed after the first, will be saved. Such plants cannot, as a matter of course, be ploughed in on the spot; but they must be cut down and carted on the ficld most in need of manure. For this purpose plants may be used that have not yet been much thought of. Fifth: those plants more especially are to be used for green manure which have many broad lcaves, because they most absorb aeriform substances (carbonic acid, hydrogen, and nitrogen). Spurry is an exception to this rule. Sixth: those plants must be selected which absorb from the subsoil those mineral substances in which the surface is deficient, and which are required for the nourishment of the future crop of corn; but whether those substances on which the success of deeprooted plants depend are to be found in the subsoil, can only be decided by a chemical analysis. Seventh: in order that the plants sown may yield the greatest amount of herbage, seed must be used abundantly. It may, therefore, be useful to sow different sorts together, so that if one does not succeed the other may. In all cases it is essential that the field should be clear of grass and other weeds ; because, as the land cannot be ploughed more than once, weeds may increase subsequently to such an extent that the failure of the corn crop may be apprehended. Deep-rootcd weeds are best destroyed by the closencss and shade of the green crop, and this 
is an additional reason for sowing a great deal of seed. Eighth: the land which is to be manured must itself be rich enough on its surface to sustain the green manure on its first development. All endeavors, by ploughing in green plants, to fertilize a soil which is deficient in all vegetable nourishment, will be vain. If land is very poor, such plants must be selected as need very little nourishment, like spurry. They should be ploughed in, and resown repeatedly, till the land is capable of bearing something better. This, of course, takes several seasons. In most cases, nature is the best nurse, and a field which is too poor to repay the outlay for cultivation, if left fallow, or used for pasturage, will by degrees produce a scanty vegetation. Grasses or clover may be sown, and then, if the field has been fed from three to five years, and is again ploughed, the soil will have received some nourishment from the roots of the grass, and will produce a tolerable crop. Ninth : all plants used for green mannre should be ploughed in at the very moment when they are in blossom; if it is done before this time, the herbage will not have attained its greatest growth; if later, the humus from the decaying leaves will needlcssly evaporate, and nitrogen be exhaled from the flowers."

Thus it is evident that green manure gives to the soil those organic substances which it has absorbed from the atmosphere, and the inorganic, derived 
from the subsoil. If their decomposition took place in the open air, many of the most valuable elements of the former would be lost; but by ploughing them in, they are absorbed by the soil as they are disengaged. The consumption of turnips on the land where they were grown, by feeding them to sheep, is well known to promote fertility; still it is an open question whether, if ploughed in, they would not have a more beneficial effect upon the soil. They gain nothing by passing through the sheep, but rather lose; for the animal requires their nourishment to sustain him. Whether this would be as profitable as to feed them to sheep, when the return from the mutton and wool is considered, we do not pretend to say, but only to call the attention of the cultivator, who has in his mind merely the fertilization of his land, to the principle involved.

The soil of the forest shows the effect of natural green manuring. It is continually dressed by the fall of the foliage; and, notwithstanding the growth of the tree, the soil gains by the crop, because the leaves contain organic substances derived from the atmosphere, which decompose and escape slowly on account of the shade of the forest. The crops principally used for artificial manuring are the vetch, buckwheat, rye, turnips, red clover, white lupines. These are adapted to various soils in their several conditions.

The vetch and white lupine are adapted to all 
soils except those which contain lime. The frost should be permitted to touch them before they are ploughed in.

Buckwheat is excellent upon sandy, poor land, if used while about knee high.

Rye is suited to sandy land, but is inferior to buckwheat.

Tumips are excellent on almost all soils.

Red clover is a very valuable crop for heavy land, as its roots penetrate deeply, and thoroughly loosen the earth.

Spury is valuable for sandy soils. It grows very fast, and two or three crops can often be secured in a season.

Some substances are applied as green manure which are not grown upon the soil; such as straw, muck, tan, sawdust, ctc. These should be partially decomposed before application ; some of them containing injurious qualities, in the crude state, as well as those that are beneficial. In the use of litter for the barn, those materials should be used which will produce the best result upon the land to which they are to be applied. Thus the cultivator. in the manufacture of his barn-yard manure, can combine those substances most needful to his soil, and to the life of the plant which he desires to cultivate.

The fruit-grower should not lose sight of the value of liquid manure, for it is particularly rich in 
organic substances. It is very valuable upon sandy soils, where its direct application is not attended with those injurious results which sometimes follow it upon heavy land. It stimulates the plant to produce an abundance of roots, as well as branches, and thus binds the soil together, making it more fertile for the succeeding crop. The urine of all animals is too valuable to be thrown away, as is the foolish practice of many farmers. It is particularly important to those who rely for their manure upon animals which work hard, as with such the liquid manure increases while the solid excrement decreases in value. Urine is very rich in nitrogen, which is supposed to be particularly valuable to grain crops, and would be necessary to a certain extent with orchards to sustain the draft which the seeds of the fruit make upon it. The application of liquid manure has been found to bake the earth, and prevent the free action of the air among its particles. This is easily overcome, while its good qualities are still retained, by so placing loam or some other porous material as to absorb it as it runs to the cellar from the animal.

The loss of the liquid manure of our animals is a most deplorable evil in the husbandry of our country, as it contains much more of those organic substances which are so valuable to vegetation than does the solid excrement. There are at least twenty millions of horses, cattle, sheep, and hogs 
in the United States; add to this thirty millions of human beings, and, at a low estimate, the value of their liquid manure is worth one hundred millions of dollars annually. It has been said that that of Great Britain would, if saved, pay her whole internal tax. What an addition would this be to the farming capital of our country !

The waste of valuable manurial substances in this country is enormous ; but, as it increases in population, more regard will probably be paid to it. The soil of China is forced to produce bread for such a teeming multitude, that no fertilizer is allowed to waste which can enrich the land. The Madras Almanac for 1841 says: "Most of the individuals met in the paths of the fields are provided with a basket and rake; and every evening the cottager brings home a certain quantity to add to the dungheap, which is a most important appendage to every dwelling. Having but few sheep and cattle, they are obliged to make the most of the stercoraceous stock of men and swine. This is carefully collected, and actually sold at so much per pound; while whole strings of scavengers may be seen cheerily posting into the country every successive morning with their envied acquisitions, little heeding the olfactory nerves of the less interested passengers. Every other substance likely to answer the end is anxiously collected, and carefully disposed, so as to provide for future exigencies. Decayed animal and 
vegetable matter, the sweepings of streets, the mud of canals, burnt bones, lime, and, what is not a little singular, the short stumpy hair shaven from millions of heads, every few days is industriously gathered, and sold for manure throughout the empire."

There are undoubtedly some lands, in the western portion of our country, where it would be injurious to manure for an orchard, because it would cause so free a growth as to induce blight $;^{1}$ but these are exceptional cases, for the majority of the soils of the world require the addition of manure; and twenty failures are made in this country, from want of sufficient fertility, to one where it too much abounds.

IV. APPLICATION OF MANURES.

The best time for applying manure is the fall, that its fertility may be washed into the soil by the rains and thaws of winter. If it is well decomposed, it can be applied just before ploughing. The condition desirable for manure, when applied, depends upon the mode of its application. Fresh manure should be placed on the surface, because its juices are absorbed by the soil before fermentation takes place; and this occurring in the soil, its volatile qualities are retained. But, for incorporation with the soil, decomposed manure is preferable, because it has already undergone that decomposition in

I See Chapter on Diseases. 
which the oxygen of the air was necessary, and of which it would have been partially or wholly deprived in the soil: fresh manure might have remained unfermented, and therefore useless under these circumstances.

M. Boussingault has an interesting paper on this point. He says: "If opinions are divided on the question whether manure should be used before or after fermentation, they are not less so as regards the manner of spreading it, and the proper season of carrying it into the field. Those who are convinced that the dung should be used as it comes from the stall, are quite indifferent as to the time of carting it; the most convenient time may be chosen, which is no small advantage, and this is our practice at Bechelbronn, where it is carried out as soon as possible. The fields to be fertilized for spring cultivation are manured in the winter, when the frost permits. The dung, at first laid in little heaps at regular distances, is afterwards spread as equally as possible, generally on the snow, - a practice in which we have never found any inconvenience. The method adopted by certain cultivators of keeping dung in great masses, with the view of spreading it when the tillage takes place, is certainly wrong; the spots in which the heaps are laid are too highly manured, and the plan is adapted for fresh dung only. The custom of leaving it for months, perhaps, spread on the land, and 
exposed to every variation of the season, has been criticized. It is said to lose its volatile parts; that rain washes out and carries away those which are soluble; and, induced by these fears, many do not spread the dung till the very moment when the land is ready for the plough. This difference of opinion in parties personally interested in making the most of their manure, ought not to be passed over lightly. In agricultural matters it is dangerous to generalize too much. The climate ought to be taken into consideration. In Alsatia, where the rain during the whole year amounts to twenty-seven inches, during December, January, and February, the quantity amounts only to four inches and thirtysix hundredths. The quality of the manure might, perhaps, be injured when the proportion in winter is greater. The quality of the manure itself must also be taken into consideration, as a heap which contains a large portion of carbonate of ammonia, and emits a very ciecided odor of volatile alkali, would certainly be deteriorated by prolonged exposure to the air; but this loss is scarcely perceptible where the manure contains but a small quantity of ammoniacal salts, as is the case with that which has been treated with gypsum. When the rains are not too heavy, the soluble part of the manure which is spread over the land penetrates it, and is retained in the upper stratum, exactly as when, instead of incorporating the manure with the soil, it is spread 
over crops in full vegetation, or before the germination of the seed. This practice of top-dressing is often profitable, and is proof enough of the little inconvenience there is in exposing the dung to the changes of weather. It arose in the first instance, perhaps, from necessity; but it has been found so useful that it has been much adopted. We have applied it with decided advantage to crops after hoeing - time being thus gained for the production of manure. In the district of Marck, it is daily gaining ground; the dung is spread when the plant has already appeared, and experience shows that the passage of the carts over the land is not sensibly injurious. It would be preferable, however, to choose a time when the surface is hard from frost. This method, according to Schwartz, is very useful in Switzerland for hemp, and indeed for almost every kind of crop. I regard it myself as a matter of convenience; but. Shaer assures us - and his authority is of great weight - that he has too often seen its good effects on leguminous crops not to be convineed of the excellence of this method on loose land in which grass has been sown late."

Thus green manure should be applied on the surface in the fall or winter. 


\section{CHAPTER VII.}

SELECTION OF VARIETIES.

EVILS OF IXDISCRIMNATE SELECTION - FRUITS SUITABLE FOR THE AMATEUR, FOR FAMILY USE, FOR THE MARKET - CATALOGUE OF THE DIFFEREXT VARIETIES ADAPTED TO THE DIFFERENT SECTIONS OF THE COUNTRY - THE BEST SIX, TWELVE, TWENTY, OR ONE HUNDRED SORTS, FOR EACH STATE.

§ I. THEIR ADAPTATION TO DIFFERENT LOCALITLES.

WE have already considered the influence of the atmosphere, the properties of the soil, and the various methods of improving it. 'The next subject to occupy our attention is the selection of varieties of fruit adapted to different conditions.

Much of the failure in the growth of fruit is to be attributed to an indiscriminate selection, in the belief that one variety is as well suited to a certain position as another. Both science and practice teach us that it is folly to remove a tropical plant to the polar regions, with any expectation of success; the climate is not adapted to it, and it soon perishes; vice versa, plants from cold regions become stunted and die in the tropics. To be sure, art sometimes overcomes these difficulties, and in- 
duces plants to flomish for a time; but, if left to nature, they soon become extinct, or produce an offspring suited to their present surroundings.

This law of adaptation is one which relates not only to the orders, genera, and species of the vegetable kingdom, but also to its varieties; and, as we descend the scale, this distinction becomes more nice. For instance, some varieties of the pear luxuriate upon a rich alluvial soil, while others become diseased and worthless.

But, as it would be impossible to form an isothermal map of any country in which the influence upon the temperature of every little elevation of the surface should be noted, so is it to form one exhibiting the proper varieties of fruit to be grown in every conceivable position. There is no universal law within our knowledge for the government of the cultivator in this respect, and all the data from which we have to judge are the results of experience.

We avail ourselves of the excellent catalogue of the American Pomological Society, to which we have been enabled to add one or two Southern States from documents in our possession.

As the United States possess such a diversity of climate, many of the most valuable fruits of one section will not arrive at maturity in another. This fact enhances the value of such a table as we insert, prepared by the able chairman of the General Fruit 
Committee of that society; but the cultivator must not lose sight of the more particular influences of soil and exposure.

The use to which the fruit is to be applied should influence the selection. If the amateur desires a collection of some one species to combine all the styles of growth, of beauty, or oddity of form and delicacy of flavor, the bearing properties will be a minor consideration. With such a man, a careful selection is not of importance; for the discovery of adaptation is a part of the study in which he delights.

For family use those varieties should be chosen which are of acknowledged worth, both for the table and the kitchen, and such as will afford a constant succession ; while beauty is unimportant compared with productiveness.

For the market we should have but few varieties. Many of our fruit-growers have erred in this respect; they lave multiplied their sorts, which gave them only a few trees, and so little fruit of each kind that it was difficult to market it. The most successful cultivators for the market have been those whose orchards contained but few varieties, and their crop of each was sufficiently large to induce them to make a business of selling it. The variety should also be of vigorous habit, because it is designed to tax its bearing properties as much as is consistent with safety. If, by accident, or the 
too sanguine disposition of the cultivator, some trees be permitted to bear a crop which exhausts their strength, such will generally recover themselves easily, while others become diseased and die. The variety should be prolific. This is such a selfevident condition of profitable culture, that it is needless to enlarge upon it. The fruit should be large and beautiful, even at the expense of quality. The importance of this fact is acknowledged by all cultivators for the market. The great popularity of the Bartlett Pear is owing, in a measure, to its size and beauty. The Windsor, or Summer Bell, is very large and handsome, but of poor quality; yet it sells in our market at a better price than many really superior varieties. The size of the fruit is of more importance to the producer than he may at first imagine, not only on account of his immediate profit realized from the sale, but also by reason of the exhaustion of his trees. On a superficial investigation, one might decide that the production of a larger fruit weakened the tree more than a small one. But that which expends the strength of animals and plants is the formation of the offspring. This is not the fruit, but the seeds contained in it; the flesh which surrounds them no more exhausts the tree in its growth than do the leaves; for until the ripening process commences they perform much the same functions. 'Those varietics, like the Vicar of Winkfield, whose fruit has hardly any or no 
seeds, can bear an almost unlimited crop without injury. Thus it will be evident that a little Seckel pear may exhaust the tree even more than a Bartlett. The Belle Lucrative, or Fondante d'Automne, is one of the most delicious of pears, as well as a great and regular bearer; and yet it will not bring more than two-thirds the price of greatly inferior sorts, on account of its green color.

$A$ list of varieties proved to be the best for orchards of different sizes, in various sections of the country, is added below. Some of the states are necessarily omitted. 
TABLE $L$.

The Colnmns indicate: 1st, the Name of Variety; $2 d$, the Seasou of Maturity; $3 d$, the in which the Varieties are recommended. A star (*) opposite a variety indicates two stars $\left({ }^{* *}\right)$ distinguisb those most highly recommended. The Itatics in the The Abbreviations are as follows: Seasons, S. summer; A. autumn; W. winter; E. as medium. Use, K. designates varieties recommended only for kitchen purposes; regarded as dessert or table sorts. M. desiguates the most valuable varieties for

\begin{tabular}{|c|c|c|c|c|c|c|c|c|c|c|c|c|}
\hline No. & NAME. & 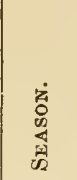 & 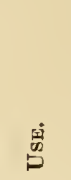 & $\tilde{E}$ & | & 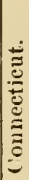 & 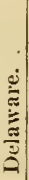 & 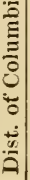 & 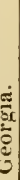 & تصغ & & 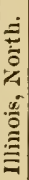 \\
\hline 1 & Ailes, ........... & W. & & & & - & .. & & & & & -- \\
\hline 2 & $\begin{array}{l}\text { Alexander, } \\
\text { Emperor Alexander. }\end{array}$ & E. A. & & - & & ... & -. & & & & & .. \\
\hline 3 & $\begin{array}{l}\text { American Summer Pearmain,...-. } \\
\text { American Summer. } \\
\text { Early Summer Pearmain. }\end{array}$ & S. & & & & -- & * & - & 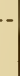 & * & * & * \\
\hline 4 & Astrachan Red, .......................... & E. S. & K. MI. & * & - & $*$ & - & * & * & $*$ & - & $*$ \\
\hline 6 & $\begin{array}{l}\text { Autumn Bongh, } \\
\text { Late Bough. } \\
\text { Sweet Bellflower. }\end{array}$ & A. & $\mathbf{T}$ & & & .. & & -. & & - & & $\begin{array}{ll}-- \\
--\end{array}$ \\
\hline 7 & Autumnal Swaar, .............. & A. & & & & -. & -. & - & & & - & * \\
\hline 8 & $\begin{array}{l}\text { Baldwin, } \\
\text { Stcele's Red Winter. }\end{array}$ & W. & M & * & & $* *$ & $*$ &.- & & $*$ & - & $\therefore$ \\
\hline 9 & $\begin{array}{l}\text { Bailey Sweet, } \\
\text { Edgerly's Sucet. } \\
\text { Patter'son's Sweet. }\end{array}$ & E. W. & & & & & & & & & & $*$ \\
\hline 10 & Baltimore Pippin, .................. & A. & & & & -. & & & & - & & -. \\
\hline 11 & $\begin{array}{l}\text { Belmont, } \\
\text { Gate. Waxen. }\end{array}$ & E. W. & MI & .. & & ... & - & $\ldots$ & & * & * & .. \\
\hline 12 & Bellefleur Yollow, & W. & M. & $\ldots$ & -. & * & - & $*$ & - & $*$ & $*$ & * \\
\hline 13 & $\begin{array}{l}\text { Benoni, } \\
\text { Beauty of Kent }\end{array}$ & S. & & - & & -- & - & $*$ & -- & * & $*$ & $*$ \\
\hline $\begin{array}{l}14 \\
15\end{array}$ & $\begin{array}{l}\text { Beauty of Kent, } . . \\
\text { Black Oxford, }\end{array}$ & IV. & & - & & ${ }_{-}$ & _ & -1 & 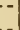 & - & - & -- \\
\hline 16 & Black's Annette, & S. & & & & 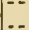 & $\ldots$ & - & & &.- & -- \\
\hline 17 & Blooming Orange, .............. & E.W. & & - & & -. &.- & .. & . & - & - & $\ldots$ \\
\hline 18 & Blue Pearmain, & W. & & & - & .. & -. & .. & - & - & - & -. \\
\hline 19 & $\begin{array}{l}\text { Bohannan, } \\
\quad \text { Buchannan. }\end{array}$ & S. & & & & .. &.- & $\ldots$ & & - & $*$ & -- \\
\hline 20 & Bowling's Sweet, .......... & WV. & K. & & & & & - & & 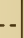 & - & -- \\
\hline 21 & 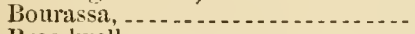 & IV. & & & - & $-\cdot$ & - & -. & . & - & -- & -- \\
\hline $\begin{array}{l}22 \\
23\end{array}$ & $\begin{array}{l}\text { Broadwell, } \\
\text { Brooke's Pippin, }\end{array}$ & $\begin{array}{l}\text { IV. } \\
\text { IV. }\end{array}$ & & & & & -. & * & & . & $* *$ & -- \\
\hline 21 & $\begin{array}{l}\text { Bullock's Pippin, } \\
\text { American Golden Russett. }\end{array}$ & W. & & & & & $*$ & $*$ & & * & $*$ & $*$ \\
\hline 25 & Buckinglom, ....... & A. & & & & & & $\ldots$ & & & & -. \\
\hline 26 & $\begin{array}{l}\text { Carolina lied June, .................. } \\
\text { Red June. }\end{array}$ & E. S. & & & & 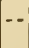 & - & $*$ & * & * & & $*$ \\
\hline 27 & Cannon Pearmain, & L. W. & MI. & & & & & * & & & * & -- \\
\hline 29 & $\begin{array}{l}\text { Cooper, } \\
\text { Beauty Red. } \\
\text { Lady IVushington. }\end{array}$ & A. & M. & & - & - & . & - & & & & -. \\
\hline
\end{tabular}




\section{APPLES.}

particular Use for which the variety is best adapted; and the remainder the Districts that such a variety succeeds well in the district named at the head of the column; column of Names donote synony mes.

early ; L. late. Those not designated as early or late of their season may be regarded C. those specially adapted for making cider. Those not marked $K$. or C. may be the market.

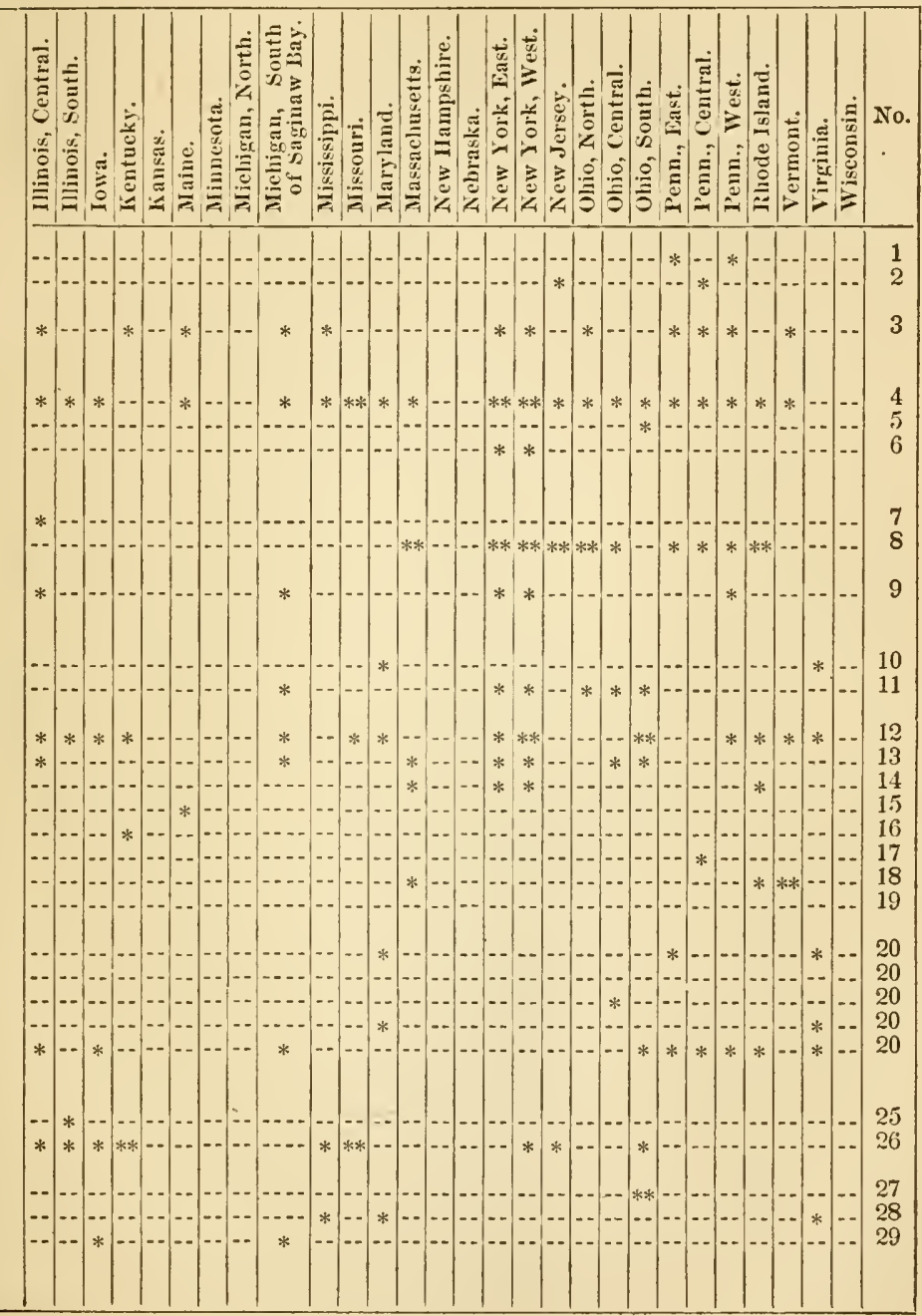




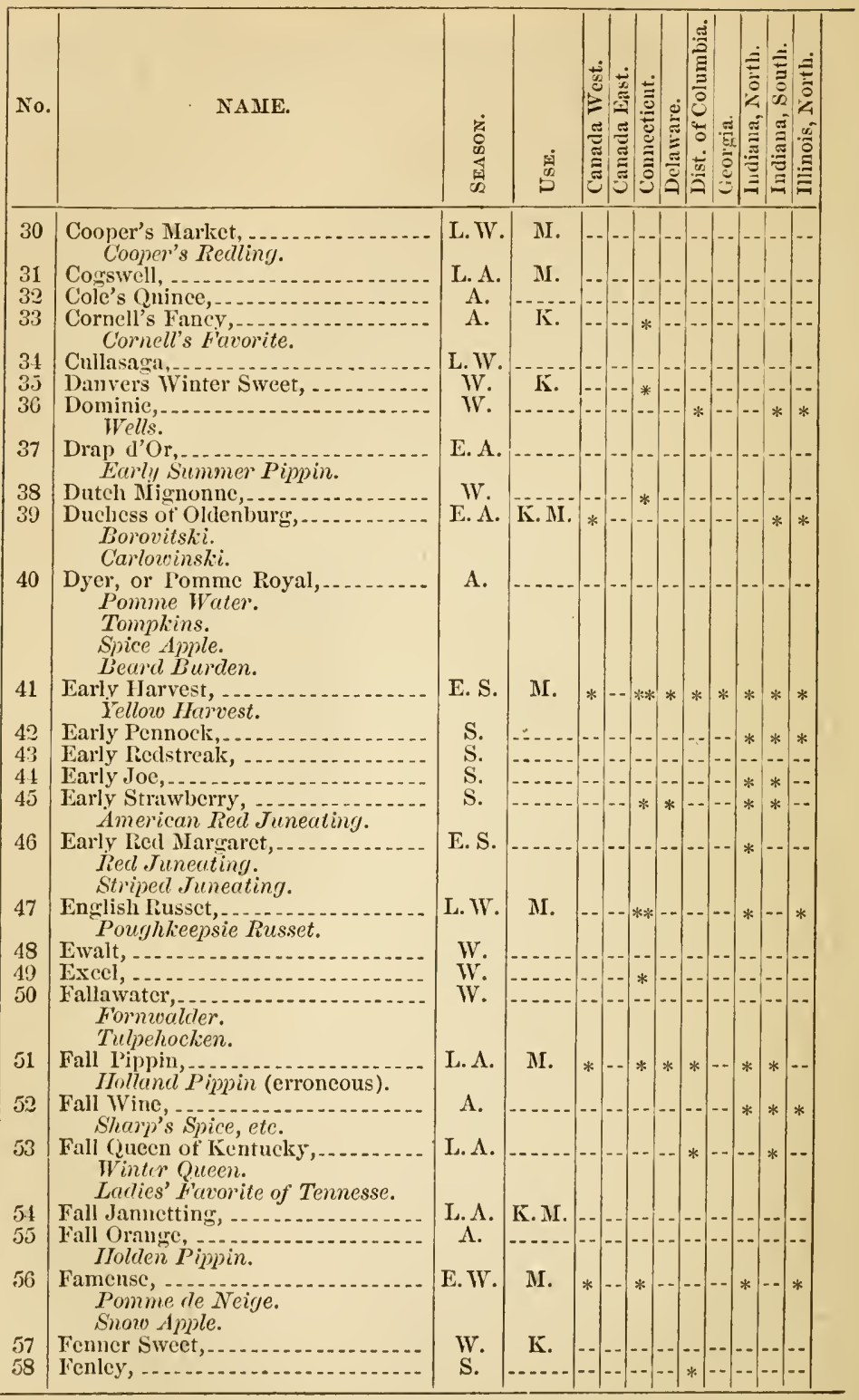




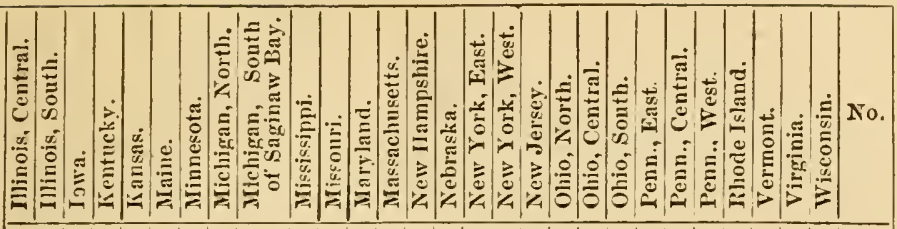

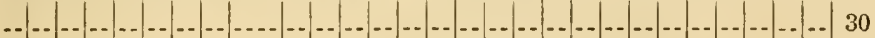

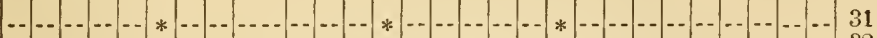

..

-

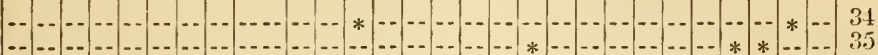

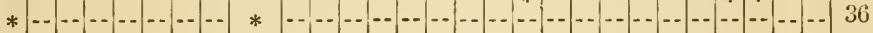

.

_.

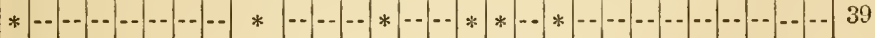

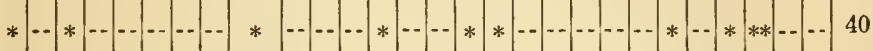

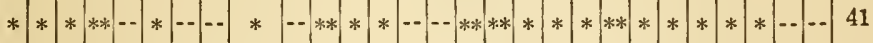

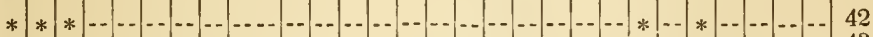

-.

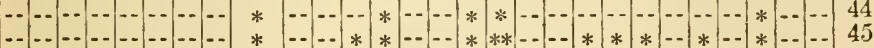

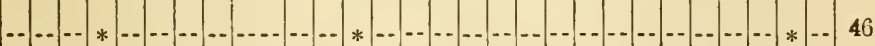

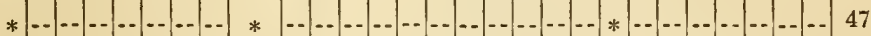

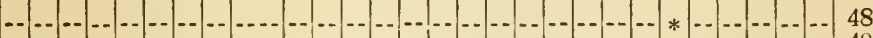

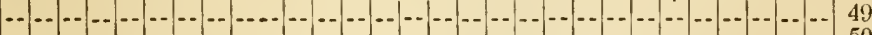

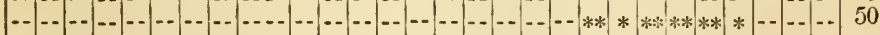

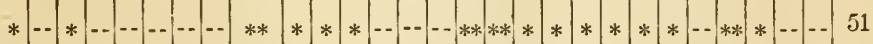

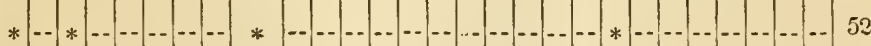

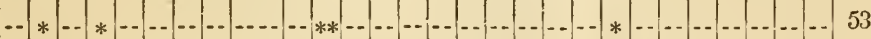

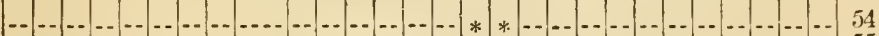

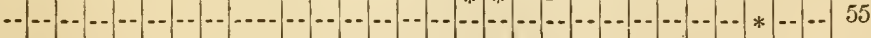

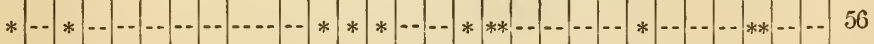

1..

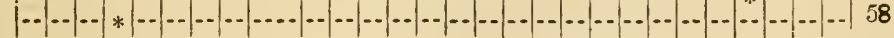




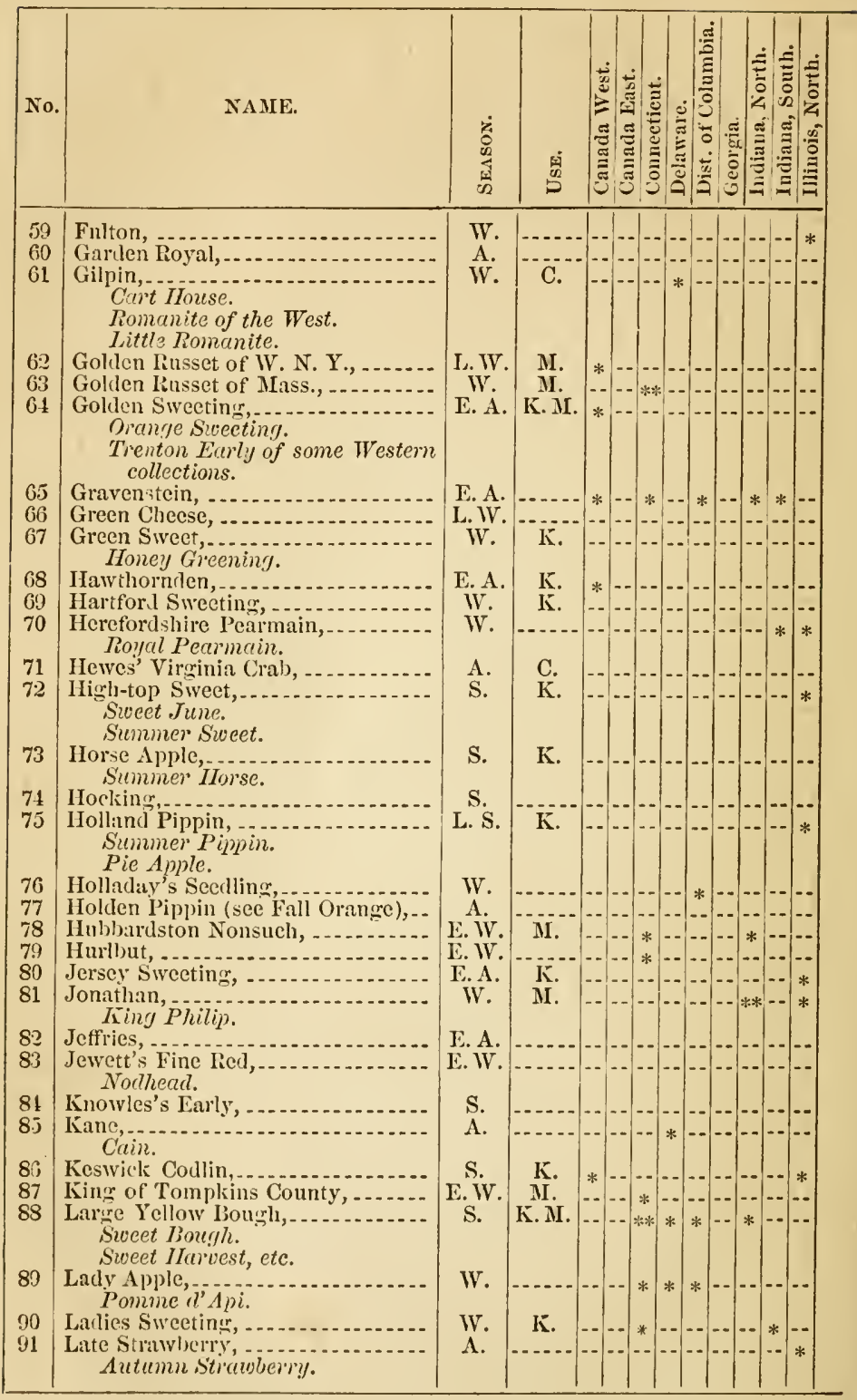




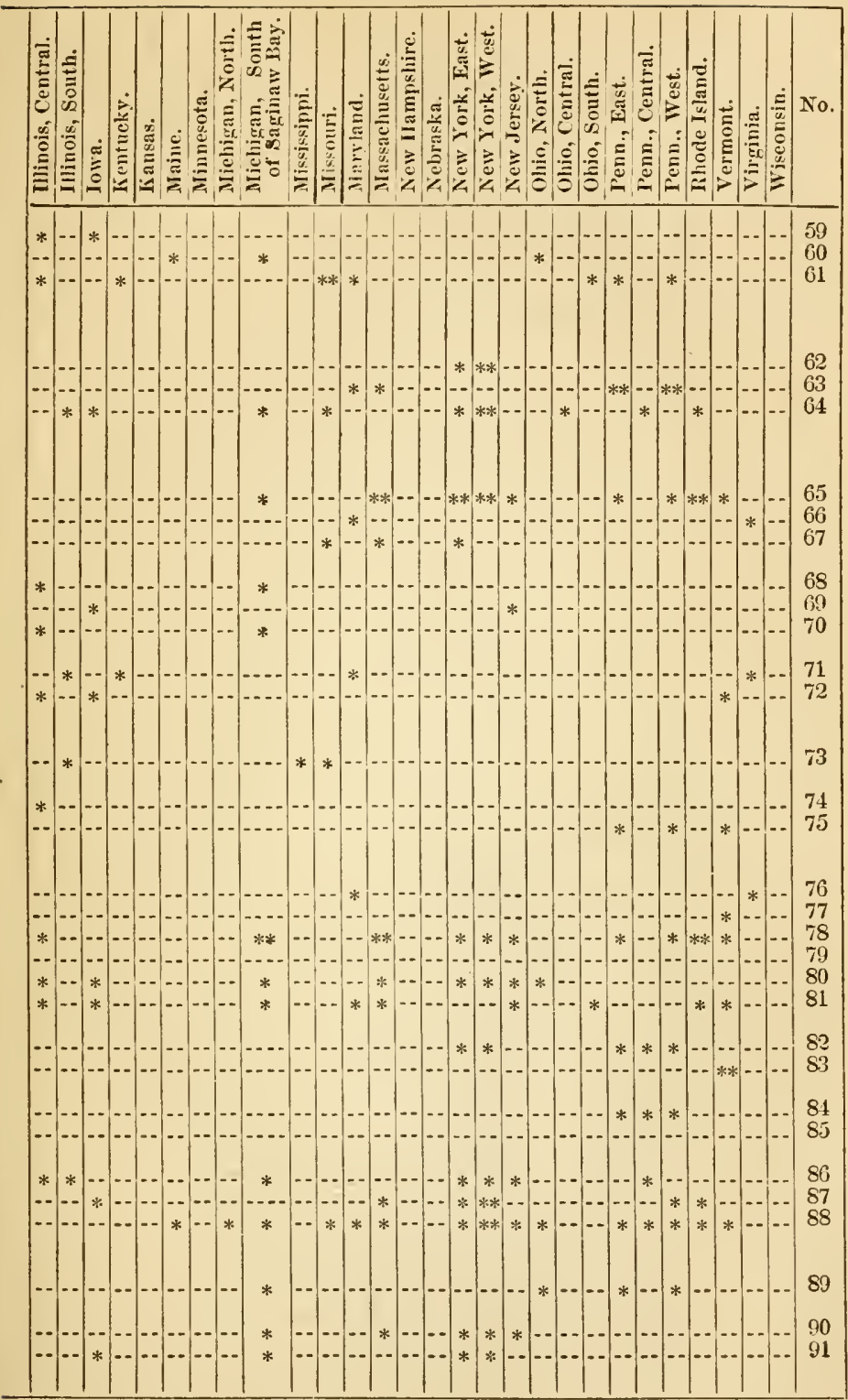




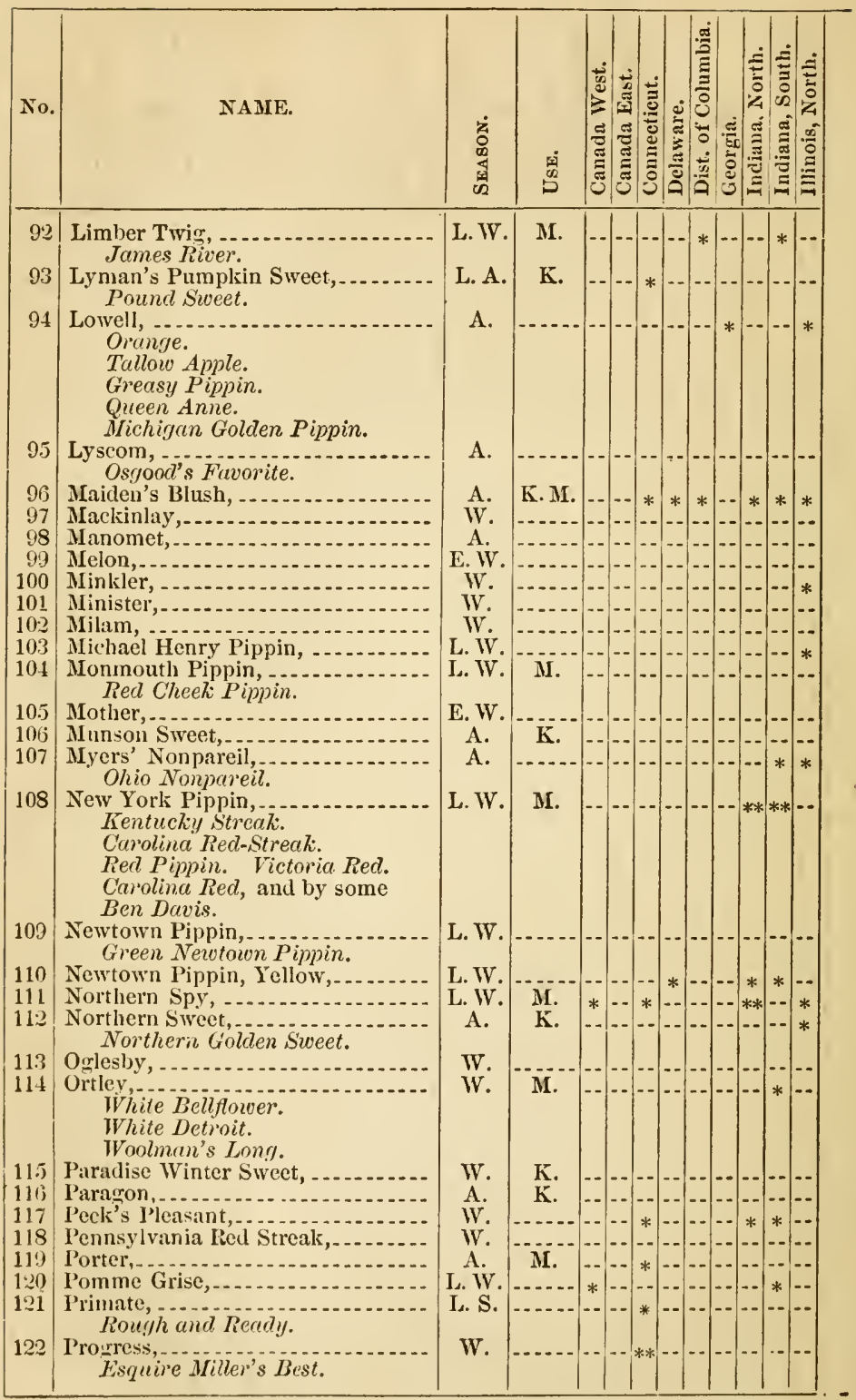




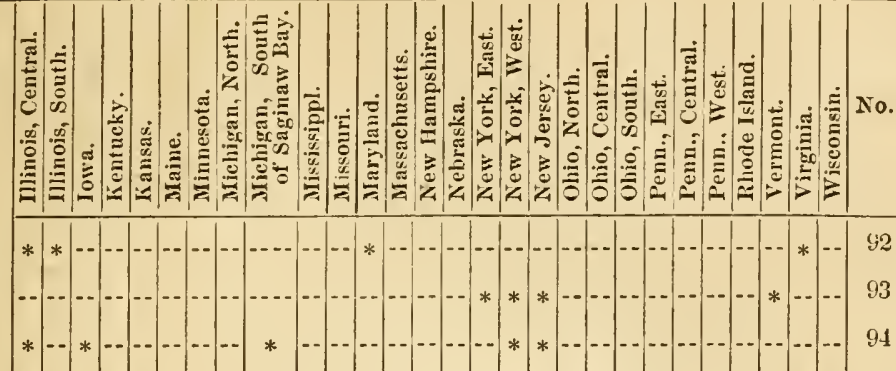

...

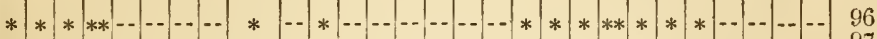

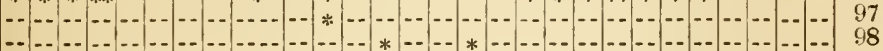

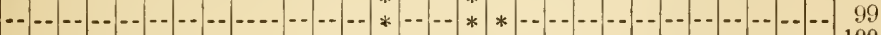
-

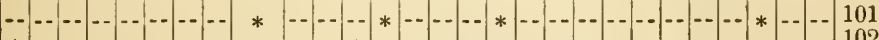

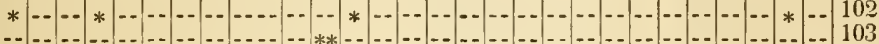

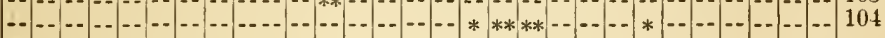

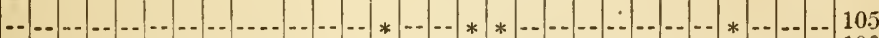
_.

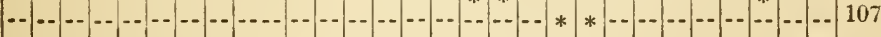

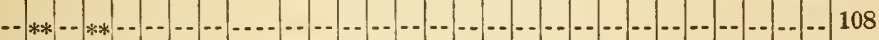

-

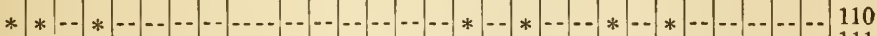

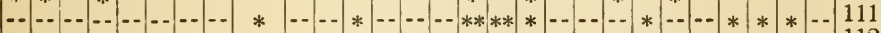

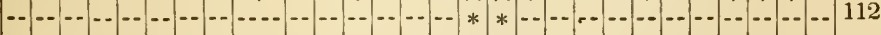
_.

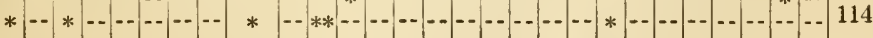

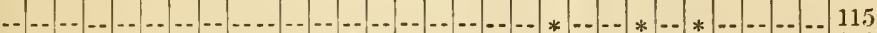

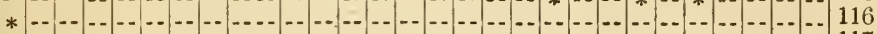

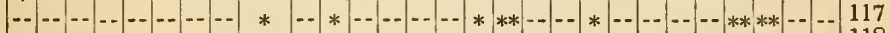
_. * - _ -

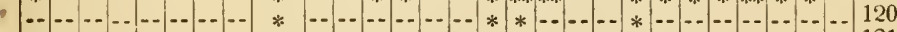

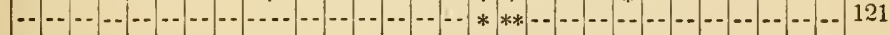

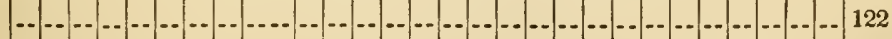




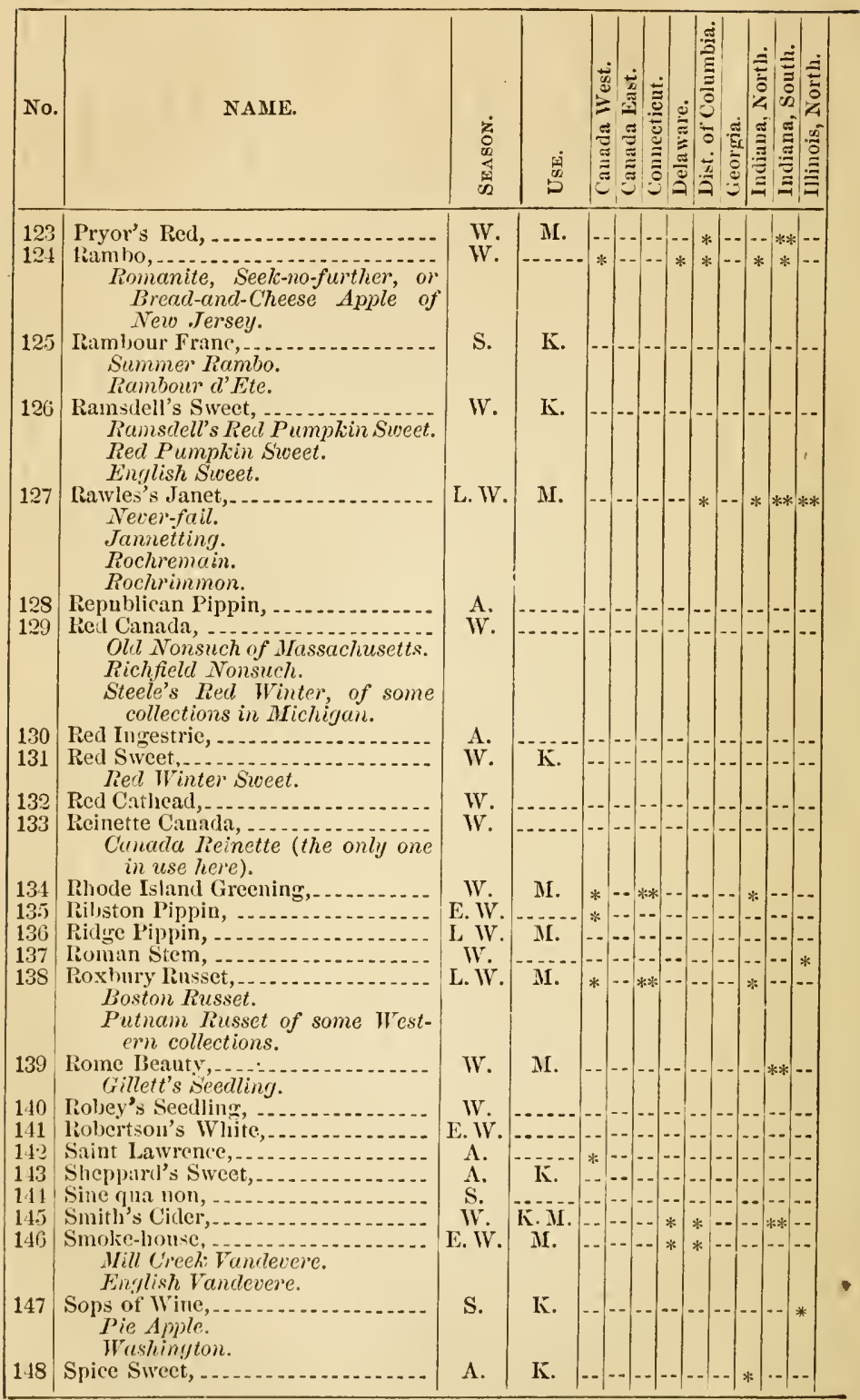




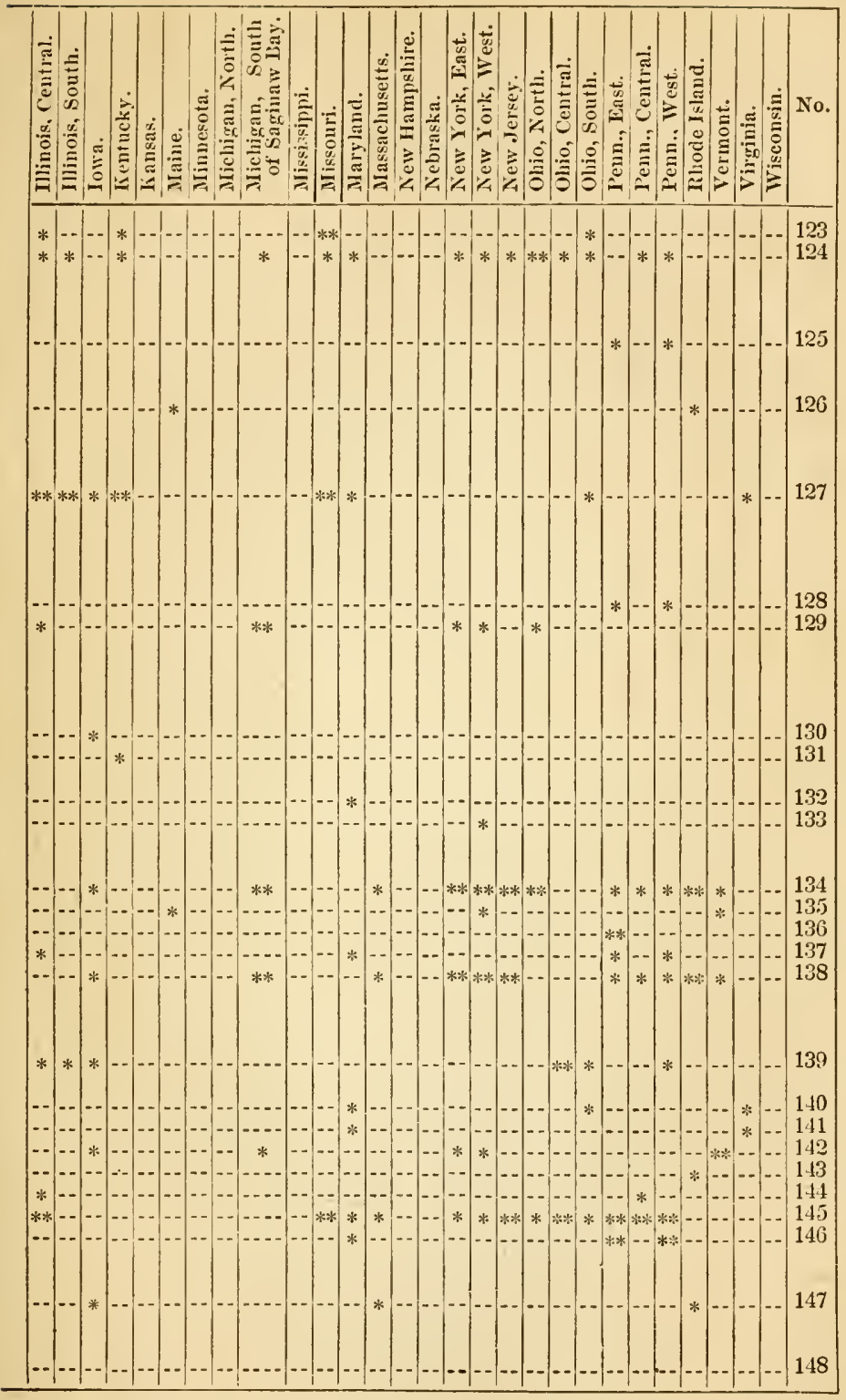




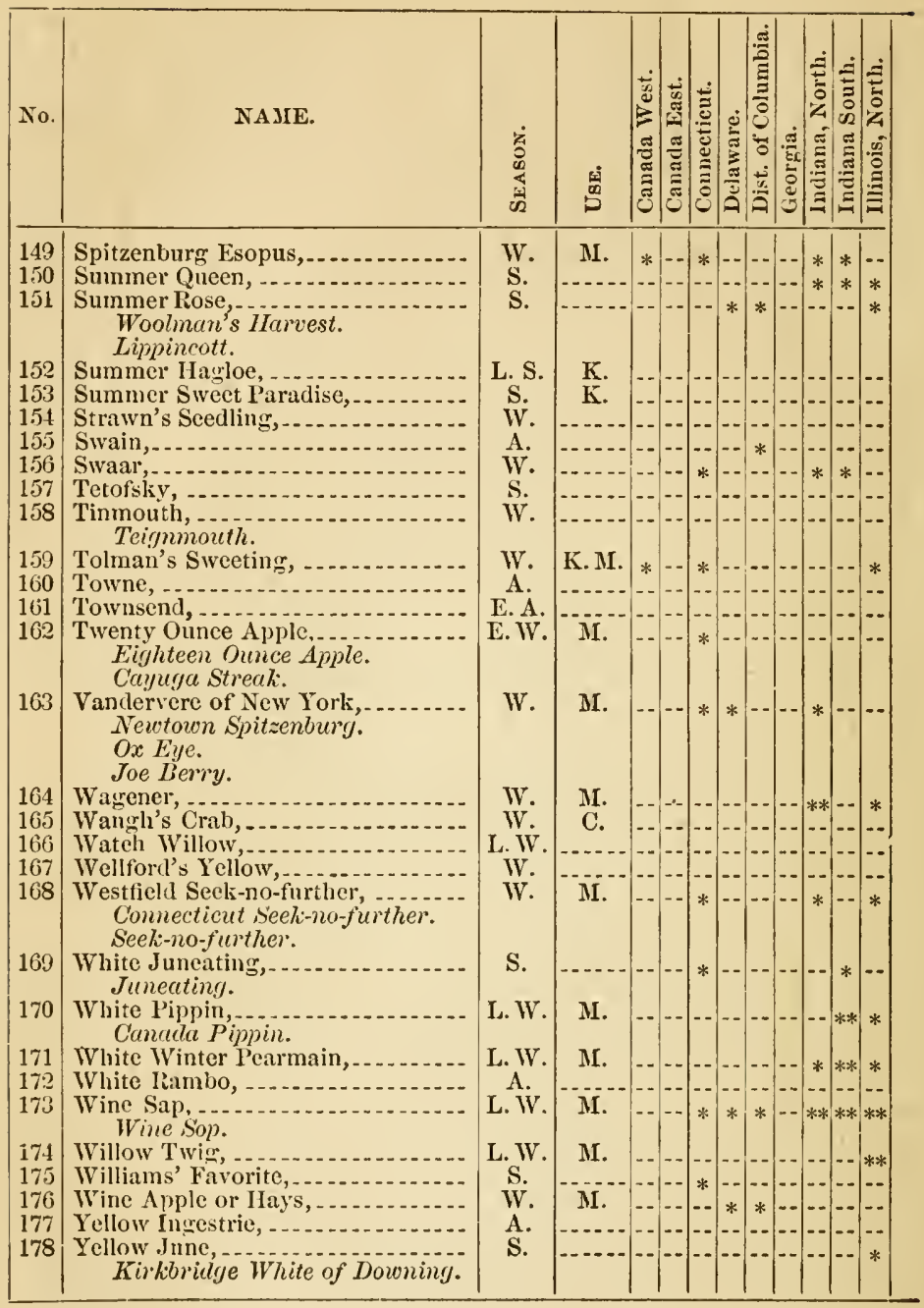




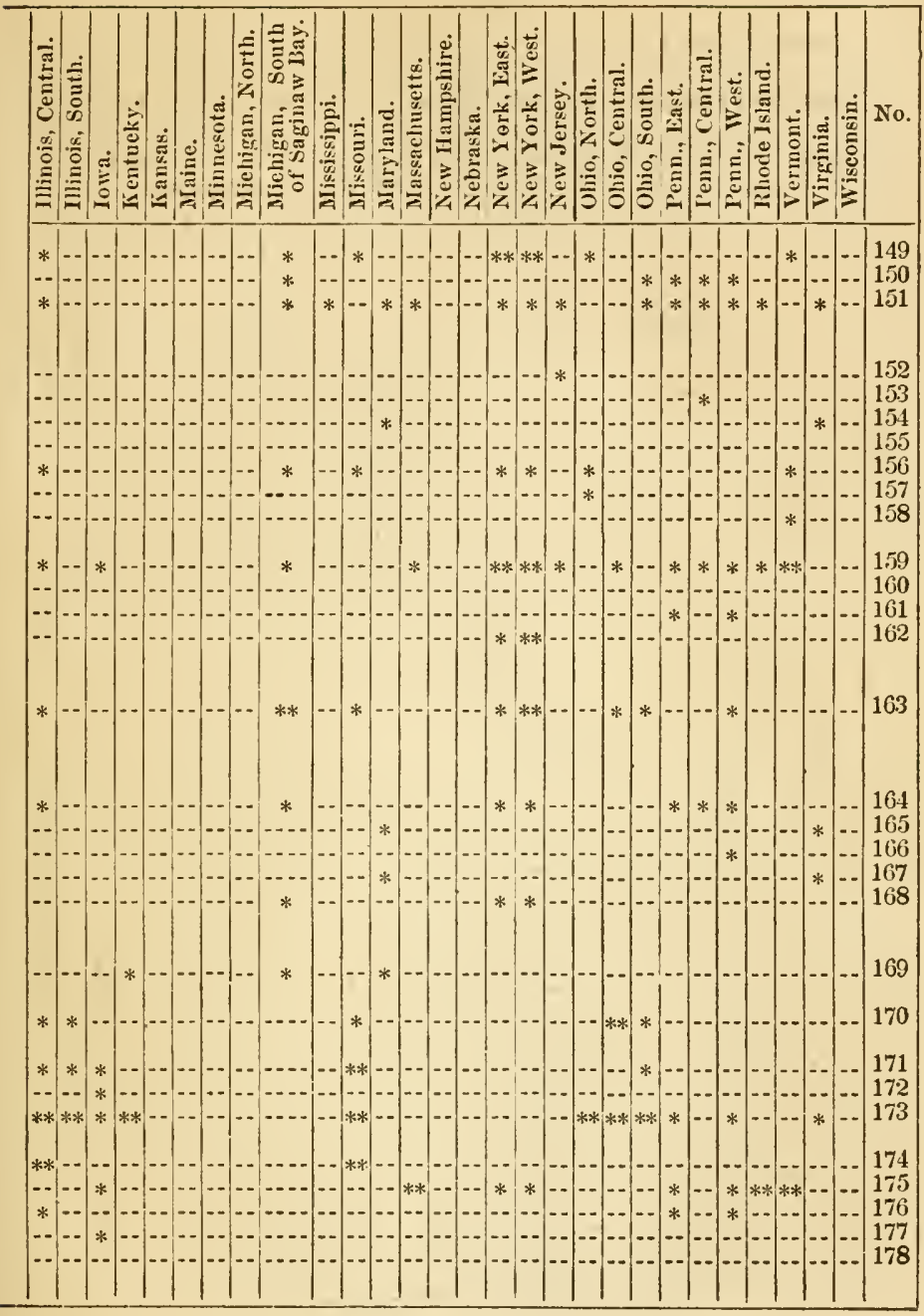


TABLE MI. -

The Columns indicate: 1st, the Name of Variety; 2d, the Season of Maturity; 3d, the the Distriets in which the Varieties are recommended. A star (*) opposite a of the column; two stars (**) distinguish those most highly recommended. The

The Abbreviations are as follows: Seasons, S. summer; A. autumn; W. winter; E. Those not marked Ki. may be regarded as dessert or table sorts. MI. designates are known to succeed well on the Quince stock, and are, consequently, specially

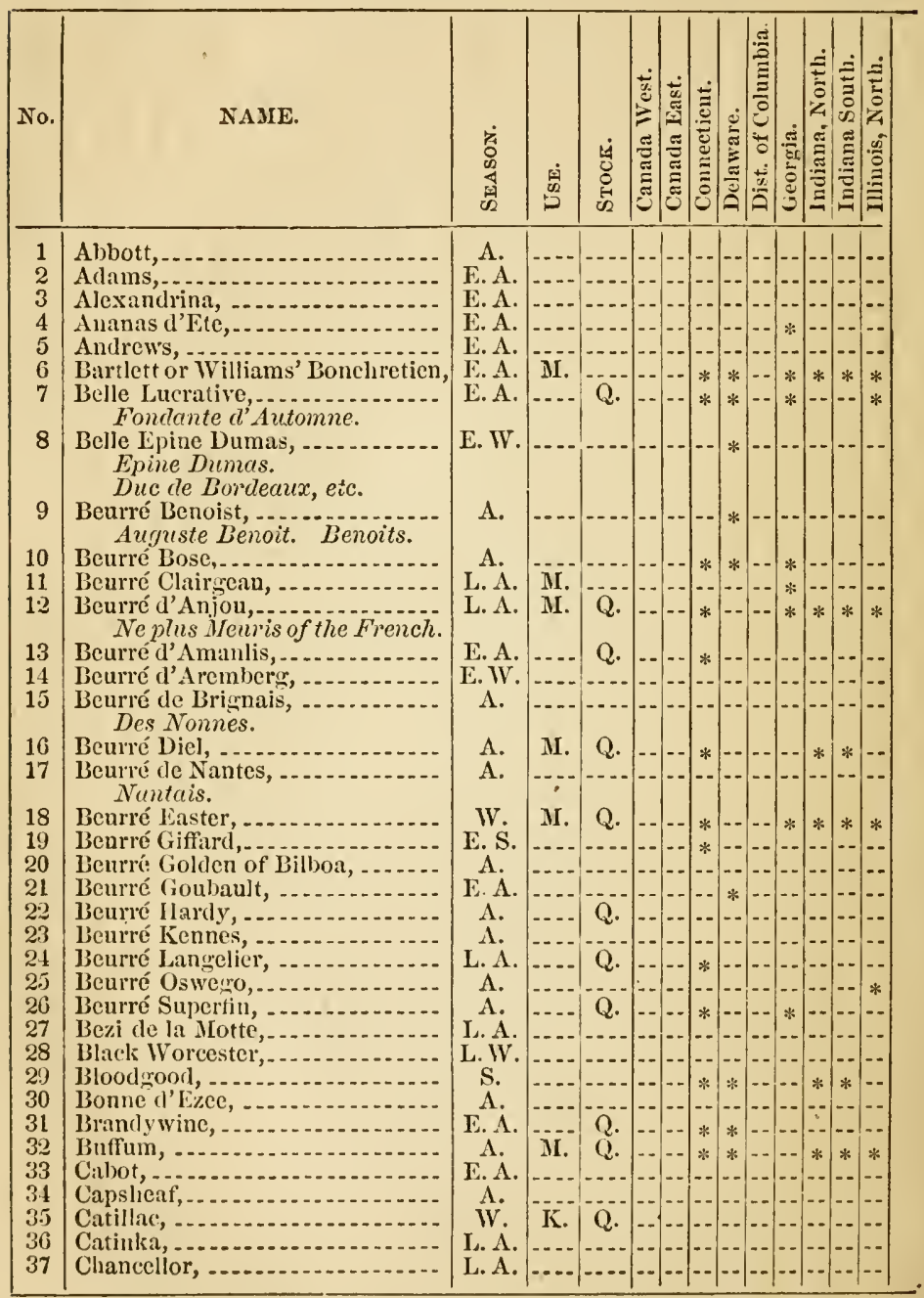


- PEARS.

particular Lse for which the variety is best adapted; 4 th, Stock; and the remainder variety indicates that such a variety succeeds well in the district named at the head Italics in the column of Names donote synonymes.

early; L. late. Use, K. designates varieties recommended only for kitchen purposes; the most valuable varieties for the market. Stock, $Q$. designates those varieties which adapted for small gardeas.

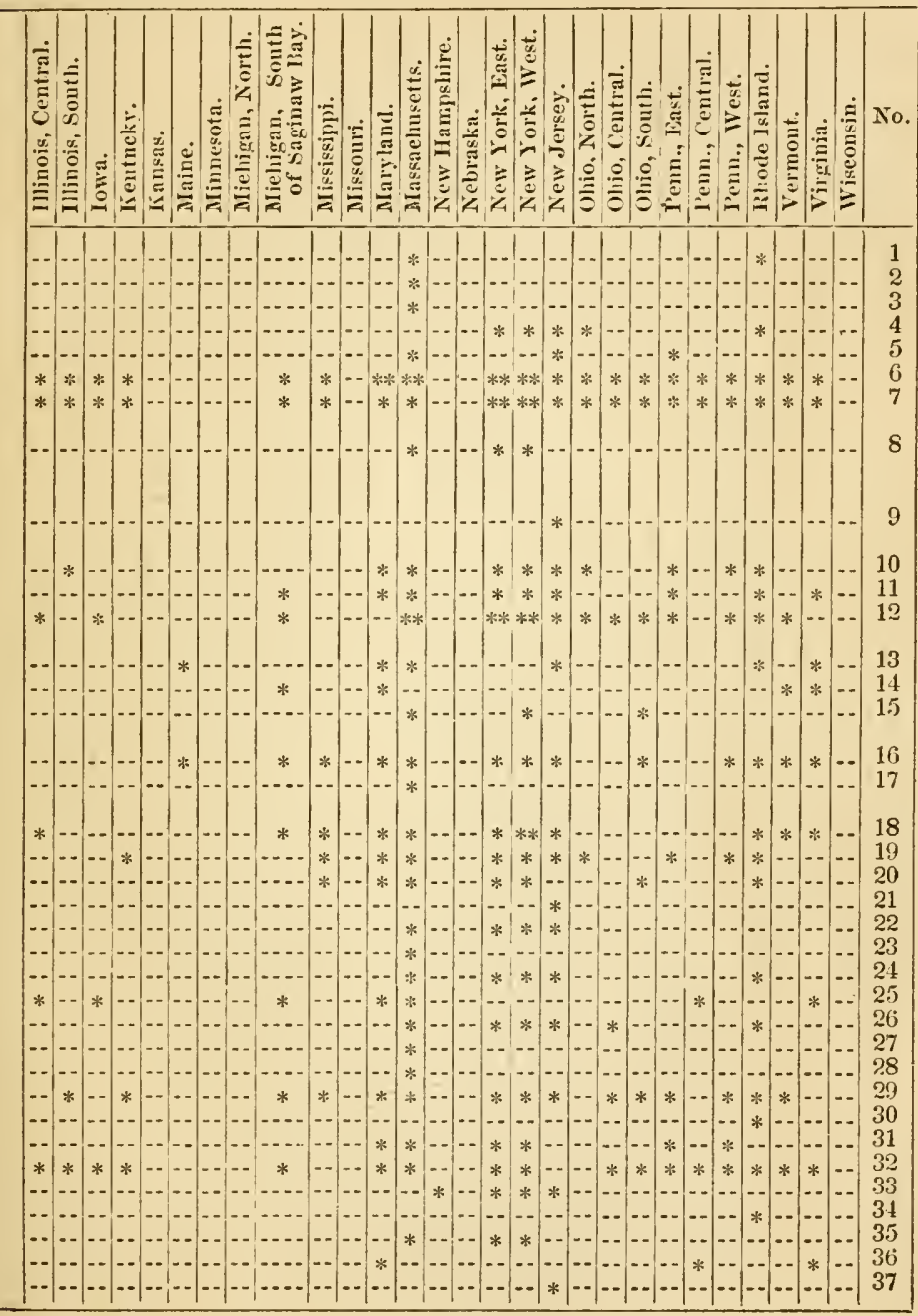




\begin{tabular}{|c|c|c|c|c|c|c|c|c|c|c|c|c|}
\hline No. & NANIE. & $\begin{array}{l}\text { 安 } \\
\text { 品 } \\
\text { 思 }\end{array}$ & $\begin{array}{l}\dot{9} \\
0 \\
\end{array}$ & 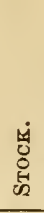 & : & 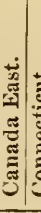 & 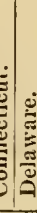 & 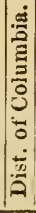 & $\mid$ & 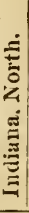 & & 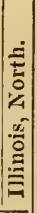 \\
\hline 38 & Chelmsford, & & . & & & & & & & - & -- & -- \\
\hline 39 & $\begin{array}{l}\text { Columbia, } \\
\text { Columbian Virgalieu. }\end{array}$ & E. W. & & & $\ldots$ & & & 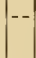 & - & $\ldots$ & - &.- \\
\hline $\begin{array}{l}40 \\
41\end{array}$ & Conseilleur de la Cour, & L.A. & & & - & & & & & - & . & -- \\
\hline $\begin{array}{l}41 \\
42\end{array}$ & D'Albret, & A. & & & $\cdots$ & $\because$ & --- & 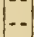 & - & - & - & -- \\
\hline 43 & Dcarborn's Seedling, & $\mathrm{S}$. & & & - & - & $*$ & - & & - & $*$ & $*$ \\
\hline 44 & Delices d'Hardenpont d'Angers, - & L. A. & & & - & & -- & - & - & - & 1 & -- \\
\hline $\begin{array}{l}45 \\
46\end{array}$ & $\begin{array}{l}\text { Dix, } \\
\text { Doyenne Boussock, - }\end{array}$ & A. A. & M. & & - & $\therefore$ & $*$ & - & -- & - & -- & --1 \\
\hline 47 & $\begin{array}{c}\text { Doyenne d'Alencon, } \\
\text { Doyenne d'Hiver Nouveau. }\end{array}$ & L. IV. & & Q. & - & & $-\left.\right|_{-1} ^{*}$ & $j^{-}$ & F & - & - &.- \\
\hline 48 & Doyenne du Comice, . ......... & I. A. & & & & & 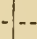 & & $=-$ & - & & - \\
\hline 49 & $\begin{array}{l}\text { Doyenue d'Lte, } \\
\text { Doyenne de Juillet. } \\
\text { Summer Doyenne. }\end{array}$ & E. S. & & & $\cdots$ & - & $* *$ & $*$ & $*$ & $*$ & $*$ & $*$ \\
\hline 50 & $\begin{array}{l}\text { Doyenne Gray, } \\
\text { Doyenne Gris. } \\
\text { Red Doyenne. }\end{array}$ & A. & & & $\ldots$ & & & - & & * & $*$ & - \\
\hline 51 & Doyenue Robin, ........ & A. & & & & & * & & & & -- & \\
\hline 52 & $\begin{array}{l}\text { Doyenne White, } \\
\text { St. Michael. Virgalieu. } \\
\text { Butter Pear. }\end{array}$ & A. & M. & Q. & -. & & & $\ldots$ & $*$ & * & $*$ & $*$ \\
\hline 53 & Duchesse d'Angouleme, - & L. A. & M. & Q. & - & * & $k-$ & -- & $*$ & $*$ & $*$ & -- \\
\hline $\begin{array}{l}54 \\
55\end{array}$ & $\begin{array}{l}\text { Duchesse de Berri d'Ete, } \\
\text { Duchese de Brabant }\end{array}$ & S. & & & -- & - & $\ldots$ & -- & .- & $\ldots$ & -- & $\because-$ \\
\hline 56 & $\begin{array}{l}\text { Duchesse d'Orleans, } \\
\text { Beurre St. Nicholas. }\end{array}$ & A. & & & 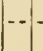 & & $-\ldots$ & -- & -- & - & -- & -- \\
\hline 57 & Dunmore, & A. & & & & & & & $\cdots$ & $\cdots$ & -- & -- \\
\hline 58 & $\begin{array}{l}\text { Early Rousselet, } \\
\text { Early Catherine. } \\
\text { Rousselet Ilatif. }\end{array}$ & S. & & & -. & & $-\ldots$ &.- & $\ldots$ & $\ldots$ & -- & -- \\
\hline 59 & Elizabeth, Manning's, - & S. & & & & & & & & - & - & -- \\
\hline 60 & Figue d'Áleneon,...... - & E. W. & & Q. & - & * & | $\mid-$ & -- &.- & -. &.- & $\ldots$ \\
\hline 61 & Flemish beauty, ....... & A. & M. & $\ldots$ & - & * & $*$ & -- & * & $*$ & $*$ & $*$ \\
\hline 62 & $\begin{array}{l}\text { Frederick of Wirtemburg, } \\
\text { Fulton, }\end{array}$ & A. & & & - & & -- & - & 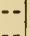 & $\cdots$ & -- & -- \\
\hline $\begin{array}{l}63 \\
64\end{array}$ & Fulton, & A. & & & -- &.- & $-1-$ & & $\begin{array}{l}-- \\
--\end{array}$ & -- & $\begin{array}{l}-- \\
--\end{array}$ & 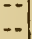 \\
\hline 65 & Glout Moreean, ..... & E. W. & & Q. & $\cdots$ & $--*$ &.- & -- & $*$ & * & $*$ & -- \\
\hline 66 & Hanners, ............. & A. & & & -- & - & -- & - & $\cdots$ & -- & -. & -- \\
\hline 67 & $\begin{array}{l}\text { Heathcot, } \\
\text { Gore's IIeathcot. }\end{array}$ & A. & & & & & & & & & & $*$ \\
\hline 68 & Henkel, & A. & & & & & & & $*$ & - & & -- \\
\hline 69 & $\begin{array}{l}\text { Henry the Fourth, } \\
\text { Ananas. } \\
\text { Poire Ananas, etc. }\end{array}$ & A. & .. & Q. & -. & & & & 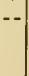 &.- & & 1 \\
\hline $\begin{array}{l}70 \\
71\end{array}$ & $\begin{array}{l}\text { Hovey, Dana's, .............. } \\
\text { Howell }\end{array}$ & L. A. & & & & & & & & & & -- \\
\hline 71 & $\begin{array}{l}\text { Howell, } \\
\text { Hull, } \ldots \ldots \ldots\end{array}$ & A. & M. & & & & & & * & & & -- \\
\hline 73 & Jalousie de Fontenay, & A. & & - & - & $*$ & - & - & - & & --1 & -- \\
\hline 74 & Jaminette, & W. & & Q. & -- & & 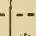 & & & & -. & $\ldots$ \\
\hline $\begin{array}{l}72 \\
76\end{array}$ & $\begin{array}{l}\text { Jean de Witte, } \\
\text { Jolionnot, }\end{array}$ & $\begin{array}{l}\text { E. W. } \\
\text { A. }\end{array}$ & & & 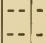 & & * & & & & & -- \\
\hline
\end{tabular}




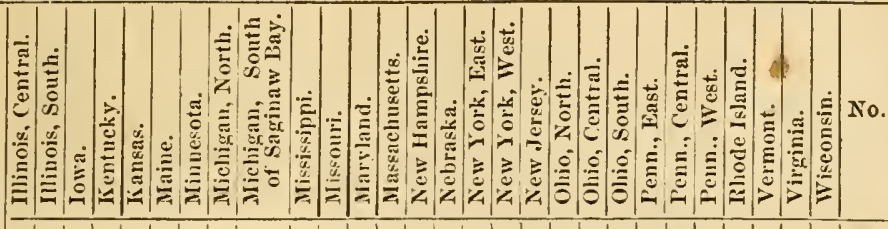
\begin{tabular}{|c|c|c|c|c|c|c|c|c|c|c|c|c|c|c|c|} 
& \\
\hline
\end{tabular}

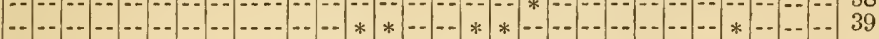

_.

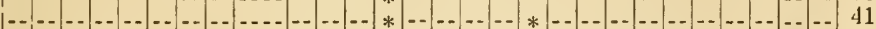

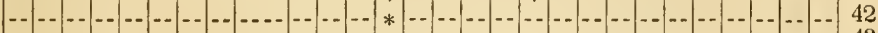

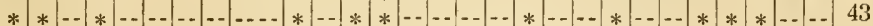

_.

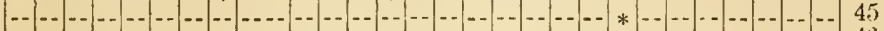

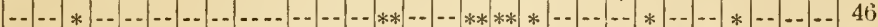

_.

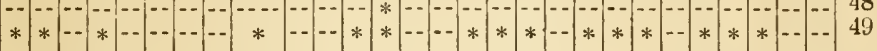

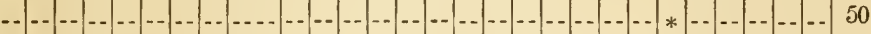

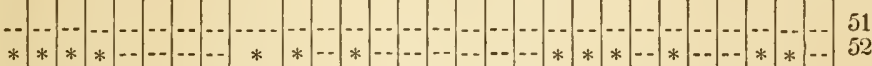

-. - - - $*$ -

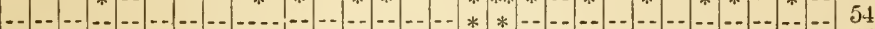

_.

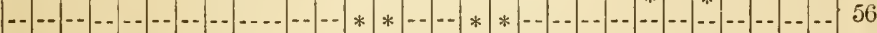

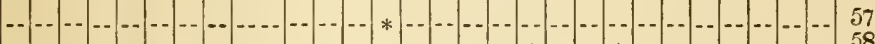

58

_.

_.

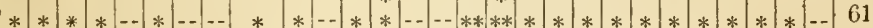

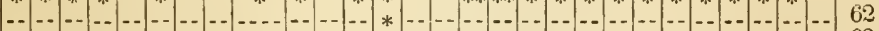

_.

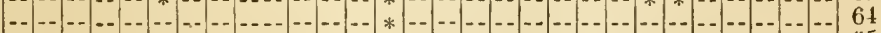

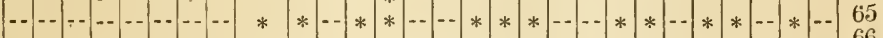

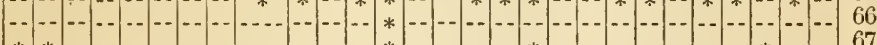

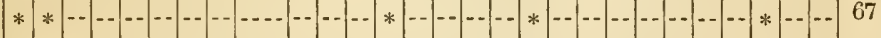

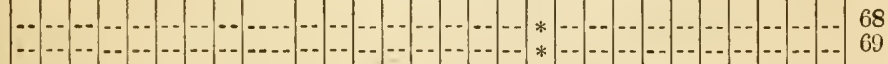

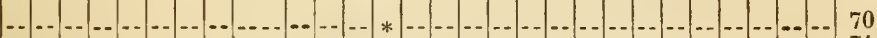

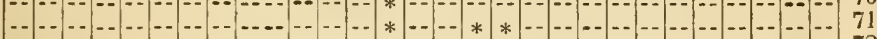

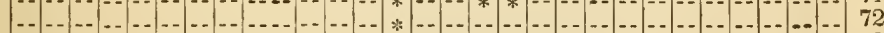

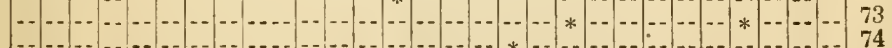

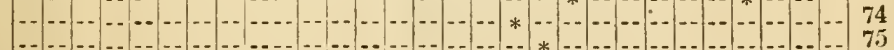

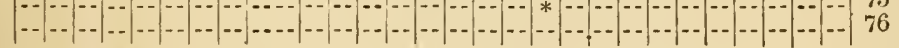




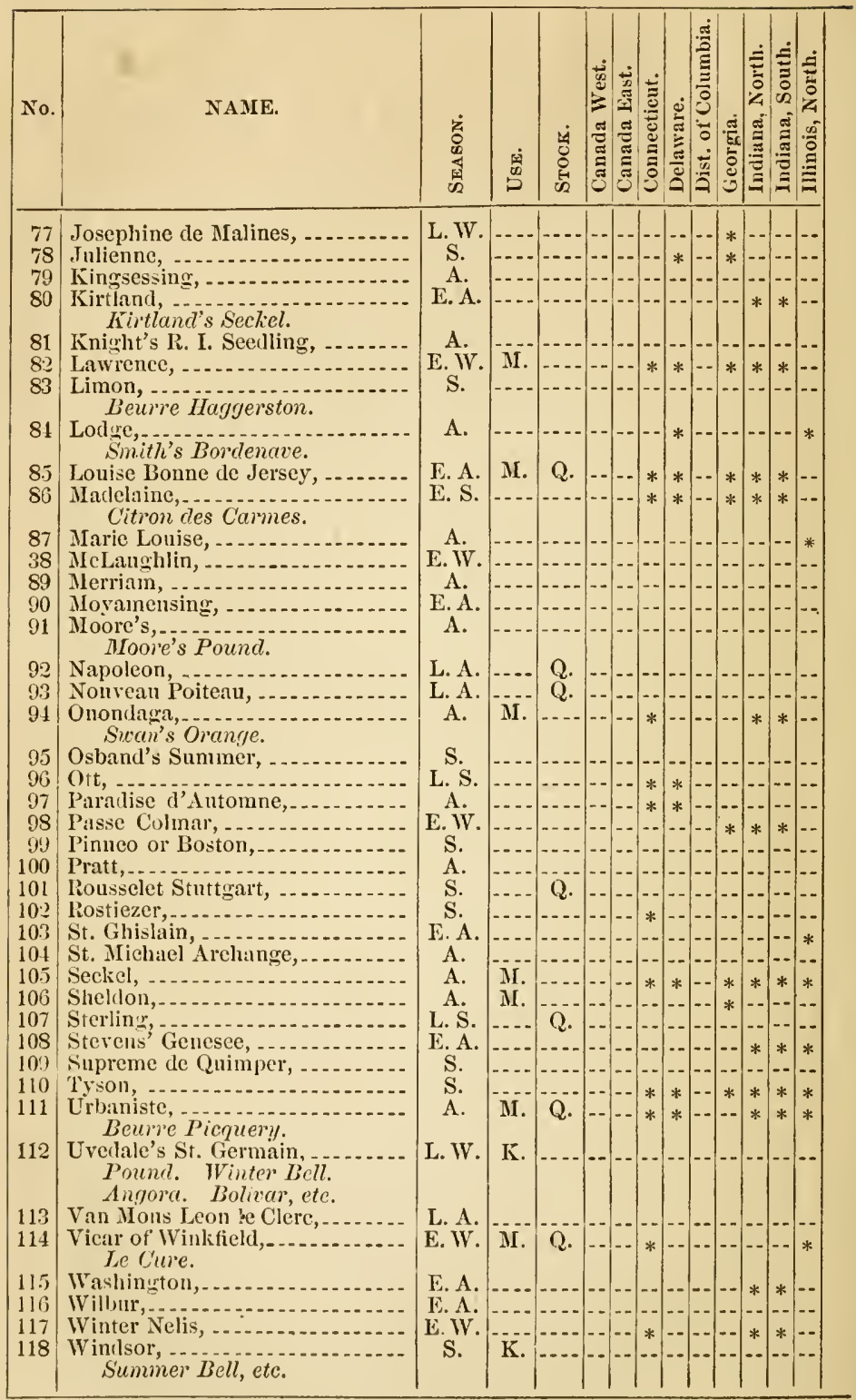



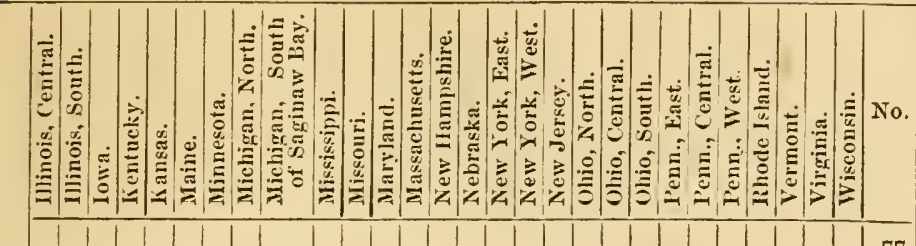

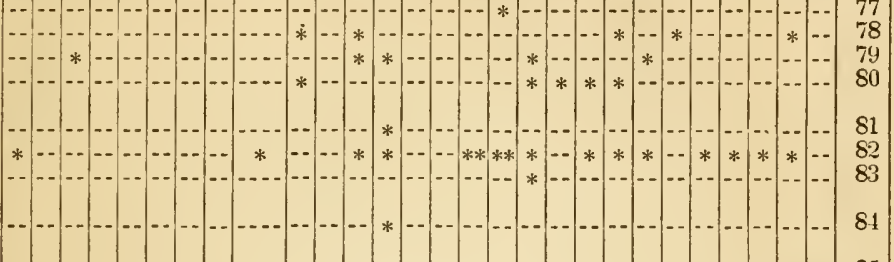

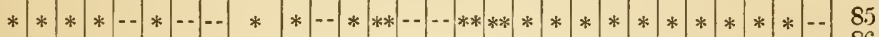

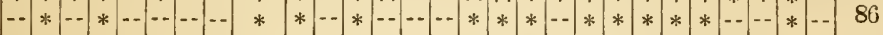

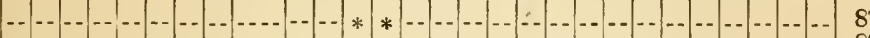

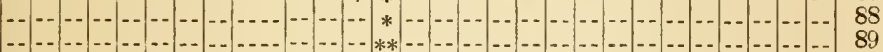

_.

_.

_.

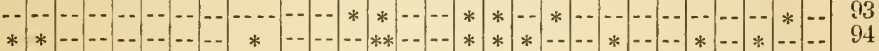

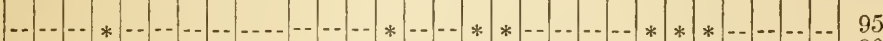

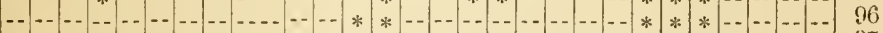

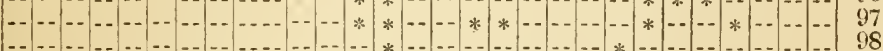

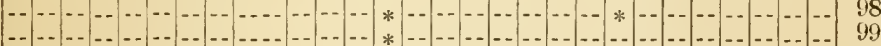

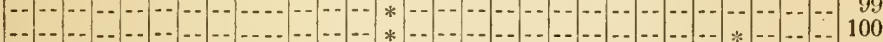

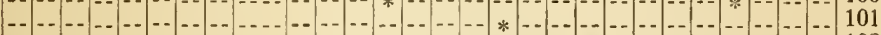

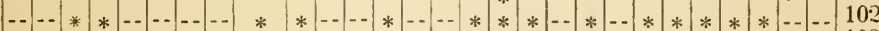

*

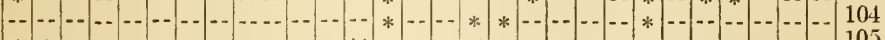

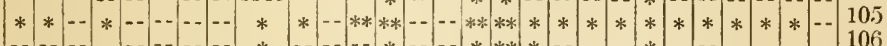

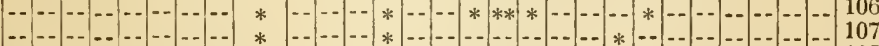

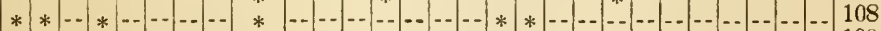

_.

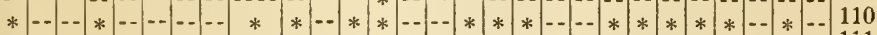

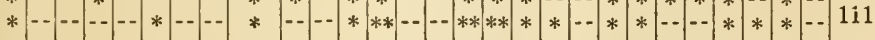

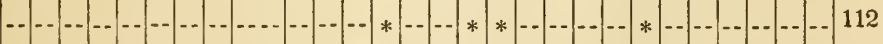

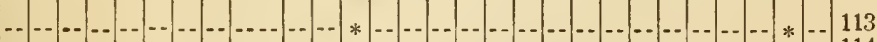

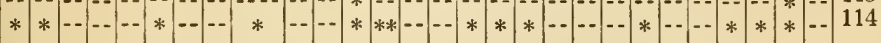

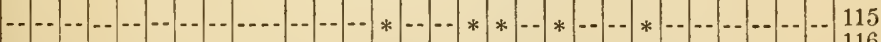

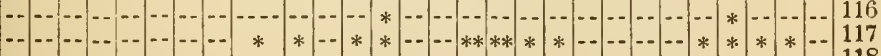

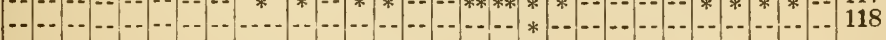


TABLE N.

The Columns indicate: 1st, the Name of Variety; 2d, the Season of Maturity; 3d, the

Varieties are recommended. A star (*) opposite a variety indicates that it succeeds The Abbreviations are as follows: Seasons, E. early, as Early Purple Guigne, etc., to the season; MI. medium season, those ripening between the 20th of June and tender-fleshed, sweet Cherries, such as Black Heart, Governor Wood, etc.; B. having more or less acidity, as May Duke, etc.; M. Morellos, having generally

\begin{tabular}{|c|c|c|c|c|c|c|c|c|c|c|c|c|}
\hline No. & NAME. & 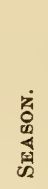 & 恋 & 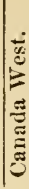 & 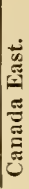 & 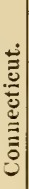 & : & 8 & & 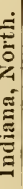 & 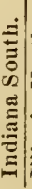 & 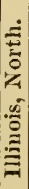 \\
\hline 1 & American Amber, ..... & M. & H. & - & $1 .$. & - & & & & & & \\
\hline 2 & American Heart, ..... & M. & $\mathrm{H}$. & -. & - & $\ldots$ & $\ldots$ & & & &.- & - \\
\hline 3 & $\begin{array}{l}\text { Bauman's May, } \\
\text { May Bigarreau. }\end{array}$ & E. & H. & .. & .- & -. & $\ldots$ & - & & & - & - . \\
\hline 4 & Belle d'Orleans, ........ & E. & H. & $\cdots$ &.- & -. & - & * & & & & \\
\hline 5 & Belle de Choisey,..... & $\mathrm{MI}$. & D. & 1 & -- & - & $\ldots$ & * & & * & $*$ & * \\
\hline 6 & Belle Magnifique, & $\mathrm{L}$. & D. & -- & $-\cdot$ & - & - & * & 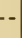 & * & * & $*$ \\
\hline 7 & $\begin{array}{l}\text { Bigarrean, or Graffion, } \\
\text { Yellono Spanish. } \\
\text { White Bigarean, of some. } \\
\text { Black Bimarreau (new) }\end{array}$ & MI. & B. & - & & & & * & & * & * & -- \\
\hline 9 & Black Eagle, & M. & H. & .. & |. & * & - & & & * & * & $\because$ \\
\hline 10 & Black Heart, ........ & II. & H. & $\ldots$ & .. & 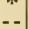 & .. & & & &.- & -- \\
\hline 11 & Black Tartarian, ... & M. & H. & $\ldots$ & -. & * & -1 & $*$ & & & - & .- \\
\hline 12 & Buttner's October Morello, & L. & II. & $\ldots$ & -. & -- & - & * & $\ldots$ &.- & $\ldots$ & $\ldots$ \\
\hline 13 & Carnation, ........ & L. & MI. & $\ldots$ & .. & $\ldots$ & $\ldots$ & - & & * & $*$ & -- \\
\hline 14 & Champagne (Downing), & MI. & II. & - & ... &.- & 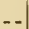 & & & & F & -. \\
\hline 15 & Cleveland Bigarreau (K.),... & M. & H. & -. & -- & .. & .. & - & & - & $\cdots$ & -- \\
\hline 16 & Coe's Transparent, ......... & M. & H. & $\ldots$ & .. & * & -1 & $*$ & &.- & -- & .- \\
\hline 17 & Donna Maria,....... & L. & MI. &.- & -. & $\ldots$ & $\ldots$ &.- & - & * & $*$ & -- \\
\hline 18 & Downer's Late, ....... & $\mathrm{L}$. & H. &. & .. & $*$ & $\ldots$ & & & $\ldots$ & $\therefore$ & -- \\
\hline 19 & Downton, & M. & H. &.- & -- & $\therefore$ & 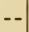 & & & - & $\ldots$ & -- \\
\hline 20 & Early Purple Guigne, & E. & II. & -- & - & - & 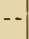 & 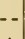 & & * & * & * \\
\hline $\begin{array}{l}21 \\
22\end{array}$ & Elton, & M. & H. & -. & -. & $\because$ & -- & * & & * & * & -- \\
\hline 23 & Guigne Noir Luisante, .......... & L. & $\mathrm{D}$. & -- & -- & $\ldots$ &.- & & & - & $\ldots$ & -. \\
\hline 24 & 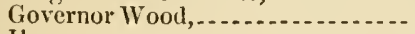 & M. & H. & - & - & $*$ & - & $*$ & & * & * & - \\
\hline 2.5 & Ilovey, & M. & B. & $\ldots$ & $\because$ &.- & 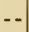 & & & & - & .. \\
\hline 26 & $\begin{array}{l}\text { Jeffrey's Duke, } \\
\text { lioyale. }\end{array}$ & $\mathrm{M}$. & D. & $\ldots$ & 1 & .. & - & & & & 6. & -- \\
\hline 27 & $\begin{array}{l}\text { Kentish, } \\
\text { Early Richimond. } \\
\text { Viryinian May. }\end{array}$ & E. & M. &.- & -- & - & & & & & * & $*$ \\
\hline 28 & Knighlit's Early Black,... & M. & II. & & -. & & & * & & * & * & .. \\
\hline 29 & Iate Duke, & L. & D. & & - & & & & & & $\therefore$ & $*$ \\
\hline 30 & Lonis I'lilippe, & I. & M. & $\cdots$ & - & 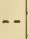 & & & & & - & .. \\
\hline $\begin{array}{l}31 \\
32\end{array}$ & Mlay Duke, & MI. & D. & -. & - & * & - & $*$ & & * & * & $*$ \\
\hline 32 & $\begin{array}{l}\text { Monsirense de Mezel, } \\
\text { Great Bigaryeau, of Mezel. } \\
\text { Bigarrecul Goublais, etc. }\end{array}$ & M. & B. & & & & & & & & & \\
\hline 33 & $\begin{array}{l}\text { Morello, } \\
\text { English Morello. } \\
\text { Lurge Morello, etc. }\end{array}$ & L. & M. & - & - & & & & & & * & $*$ \\
\hline
\end{tabular}




\section{- CHerRIEs.}

Class to which the Variety belongs; and the remainder the Districts in which the well in the district named at the head ot the column. The Italics donote synonymes. which usually ripen at liochester (lat, $43^{\circ}$ ) from the 10 th to the 20 th of June, according the 20th of July; and L. late, those ripening after that time. Class, H. llearts, or Bigarreau, or firm-fleshed, sweet Cherries, like Graffion, Napoleon, etc.; D. Dukes, acid fruit, used chiefly for kitchen or confectionary purposes.

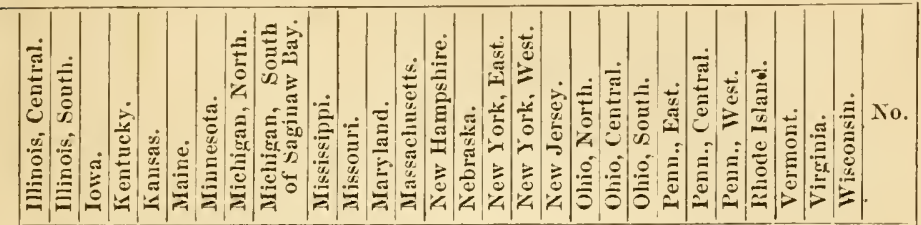

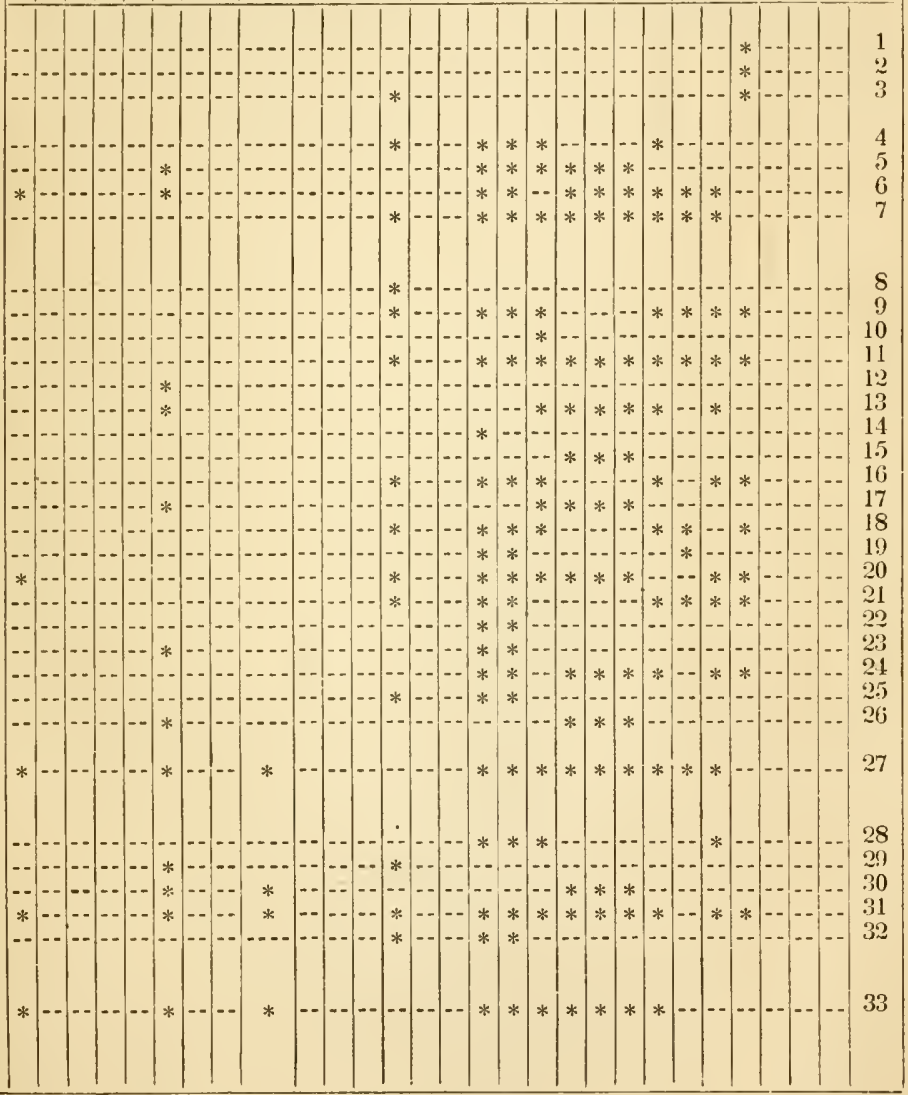




\begin{tabular}{|c|c|c|c|c|c|c|c|c|c|c|}
\hline No. & NAME. & $\begin{array}{l}\dot{3} \\
\text { 品 } \\
\frac{3}{3}\end{array}$ & $\sum_{\substack{\infty \\
\dot{n}}}^{\dot{0}}$ & 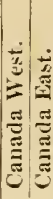 & & 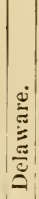 & 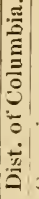 & 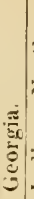 & 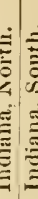 & 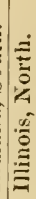 \\
\hline 34 & $\begin{array}{l}\text { Napoleon Bigarreat, } \\
\text { Holland Bigmreau. } \\
\text { Biqurreau d'Esperin. }\end{array}$ & M. & B. & - & * & & $*$ & & & -- \\
\hline 35 & Oseeoli, & M. & B. & - & & & & & & .. \\
\hline 36 & Plumstone MIorello, & $\mathrm{L}$. & M. & -- & & & $\cdots$ & & 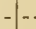 & * \\
\hline $\begin{array}{l}37 \\
39\end{array}$ & Red Jacket (K.), & M. & H. & - & & & -- & & & - \\
\hline $\begin{array}{l}35 \\
39\end{array}$ & $\begin{array}{l}\text { Reine Hortense, } \\
\text { Rockport Bigareau (K.), }\end{array}$ & II. & li. & & & & $*$ & & $* *$ & $*$ \\
\hline 40 & Sparhawk's Honey, ............. & & & & & & & & & $\ldots$ \\
\hline 41 & Teeumseh (K.), & L. & II. & & & & .. & & & -. \\
\hline 42 & $\begin{array}{l}\text { Trarlescant's Black Heart,........ } \\
\text { Elkhorn. } \\
\text { Large Black Bigarreau. }\end{array}$ & L. & L. & -. & & & 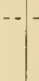 & & & - \\
\hline 43 & White French Guigne,............ & M. & II. & & & & & & & \\
\hline
\end{tabular}




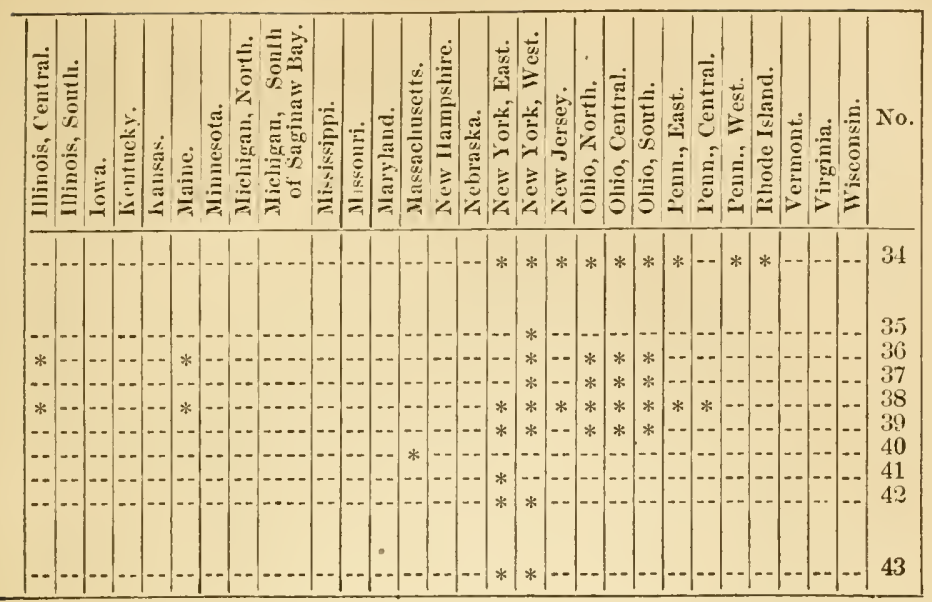




\section{TABLE 0 .}

The Columns indicate: 1st, the Name of Variety; 2d, the Class (Freestone or ClingIaturity; and the remainder the Districts in which the Varieties are recomin the district named at the lead of the column. The Italics in the column of

The Abbreviations are as foilows: Class, F. Freestone; C. Clingstone. Color of Flesh, (in lat. $43^{\circ}$ ) previous to or about the 1 st of September; V. E. very early; II. meafter that period; V. L. very late. A few only of the very early and very late

\begin{tabular}{|c|c|c|c|c|c|c|c|c|c|c|c|c|}
\hline No. & NAME. & 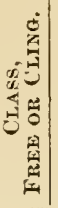 & 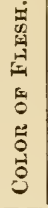 & 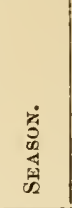 & 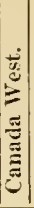 & | & 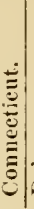 & & 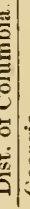 & . & 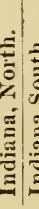 & $\stackrel{4}{a}$ \\
\hline 1 & $\begin{array}{l}\text { Barnard, } \\
\quad \text { Early Barnard. } \\
\text { Yellow Barnard. }\end{array}$ & F. & $\mathbf{Y}$. & M. & -- & & -. & & & & & * \\
\hline 2 & Barrington, ............ & & & & & & & & & & & \\
\hline 3 & Bellegarde, - & F. & W. & MI. & .. & . & & & & & & \\
\hline 4 & Bergen's Yellow, & F. & $Y$. & $\mathrm{MI}$. & - & & & & & & & \\
\hline 5 & Cambridge Belle, & F. & W. & M. & -- & - & .. & & & & & \\
\hline 6 & Carpenter's White, & F. & WV. & L. & $\ldots$ & & .. & - & 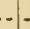 & 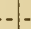 & .. & . \\
\hline 7 & Cole's Early Red, . & F. & W. & E. & -- & - & 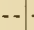 & . & * & -. & -- & * \\
\hline 8 & Columbia, . . . & F. & Y. & M. &.-- & . &.- & . & - & * & -. & $\ldots$ \\
\hline 9 & Cooledre's Favorite, & F. & W. & E. & -- & $\ldots$ & -- & - & * & - & - & $*$ \\
\hline 10 & Crawford's Early Melocoton, & F. & Y. & E. &.- & - & -- & * & * & * & * & * \\
\hline 11 & Crawtord's Late Melocoton,- & F. & Y. & L. & -. & - & -. & $*$ & * & .. & $*$ & * \\
\hline 12 & 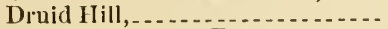 & F. & W. & I. & -. & & .- & .. & * & 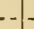 & $\ldots$ & \\
\hline 13 & Early Newington Freestone, .... & F. & W. & E. & -- & - & .. & 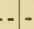 & -. & . & .- & $\ldots$ \\
\hline 14 & Early Slocum, & F. & WV. & li. & - & $\cdots$ & -. & - & -. & -. & -- & .. \\
\hline 15 & Early Tillotson, ........... & F. & W. & V. E. & $\ldots$ & 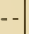 & -- & - & - & * & * & - \\
\hline 16 & $\begin{array}{l}\text { Early York } \\
\text { Serrate Early York. } \\
\text { Early Purple. }\end{array}$ & F. & W. & V.E. & .. &.- & - & * & & * & $* *$ & - \\
\hline 17 & Fay's Early Aun, & F. & W. & V.E. & 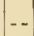 & - & -- & - & .- & * & -- & - \\
\hline 18 & George the Fourth, & $\mathrm{F}$. & WV. & E.. & .. & - & -. & * & * & * & * & - \\
\hline 19 & Grand Admirable,..- & C. & W. & L. & -. & .. & -. & $\therefore$ & & * & * & - \\
\hline 20 & Grosse Mignonne, - & F. & $\mathbf{W}$ & E. & -- & - & -- & $\cdots$ & * & 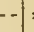 & * & - \\
\hline 21 & Haines' Larly Red, - & F. & W. & E. & -- & 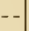 & - & - & * & - & -- & .. \\
\hline 22 & Hales' Early (from Ohio), ... & F. & WV. & V. E. & -. & 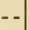 & $\cdots$ & $=0$ & & 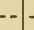 & & \\
\hline 23 & Heath Cling, & C. & WV. & 1. & -- & + & -- & * & * & - & -- & * \\
\hline 24 & $\begin{array}{l}\text { Hill's Madeira, } \\
\text { Madeira Freestone. }\end{array}$ & F. & Y. & MI. & 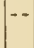 & 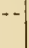 & -. & & & & - & 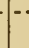 \\
\hline 25) & IIyslop Cling, ............. & C. & $\mathbf{W I}$. & V. L. &.- & & & & 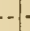 & - & $\ldots$ & \\
\hline 26 & Jacques, & F. & Y. & 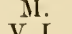 & - - & - & - & & - & & - & \\
\hline 27 & $\begin{array}{l}\text { Kenrick's Heath, } \\
\text { Heath Freestone. }\end{array}$ & F. & W. & V.L. & -- & - & - & & * & & - & - \\
\hline 28 & La Grange, .... & F. & IV. & V.L. & - & & -. & 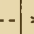 & * & - & -. & - \\
\hline 29 & Large Jarly York, & F. & WV. & E. & -- & - & -. & * & * & . & 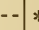 & * \\
\hline 30 & Larige White Clingstone, ........ & C. & IV. & M. & $-\cdot$ & & - & 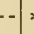 & * & & 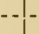 & - \\
\hline 31 & Late Red Rareripe, & F. & W. & M. & -- & - & - - & * & & & * & - \\
\hline $\begin{array}{l}32 \\
33\end{array}$ & $\begin{array}{l}\text { Lemon Clingstone, } \\
\text { Leopold Clingstone, }\end{array}$ & C. & Y. & L. & -- & & & & & & $\begin{array}{c}* \\
*\end{array}$ & - \\
\hline 34 & Mal $a, \ldots . . . . .$. & $\mathrm{F}$. & WV. & M. & $\because$ & & & & & 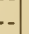 & $*$ & 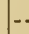 \\
\hline 35 & Molden's White, ... & F. & W. & L. & -- & - & $\ldots$ & & & . & -. & \\
\hline 36 & Morris's White, & F. & WV. & M. & -- & - & - & * & * & - & $*$ & * \\
\hline 37 & Noblesse, . . & F. & WW. & M. & -- & & & & & & - & \\
\hline 38 & Old Mixon Free, - & F. & $W$ & L. & & & & & & * & * & * \\
\hline
\end{tabular}




\section{PEACHES.}

stone) to which the Variety belongs; 3d, the Color of the Flesh; 4th, the Season of mended. A star $\left({ }^{*}\right)$ opposite the name of a variety indicates that it succeeds well names donote synonymes.

W. White or pale-colored; Y. Yellow or yellowisl. Season, E. early, those ripening dium, those ripening from the 1st to the 15 th of September; L. late, those ripening have been so designated.

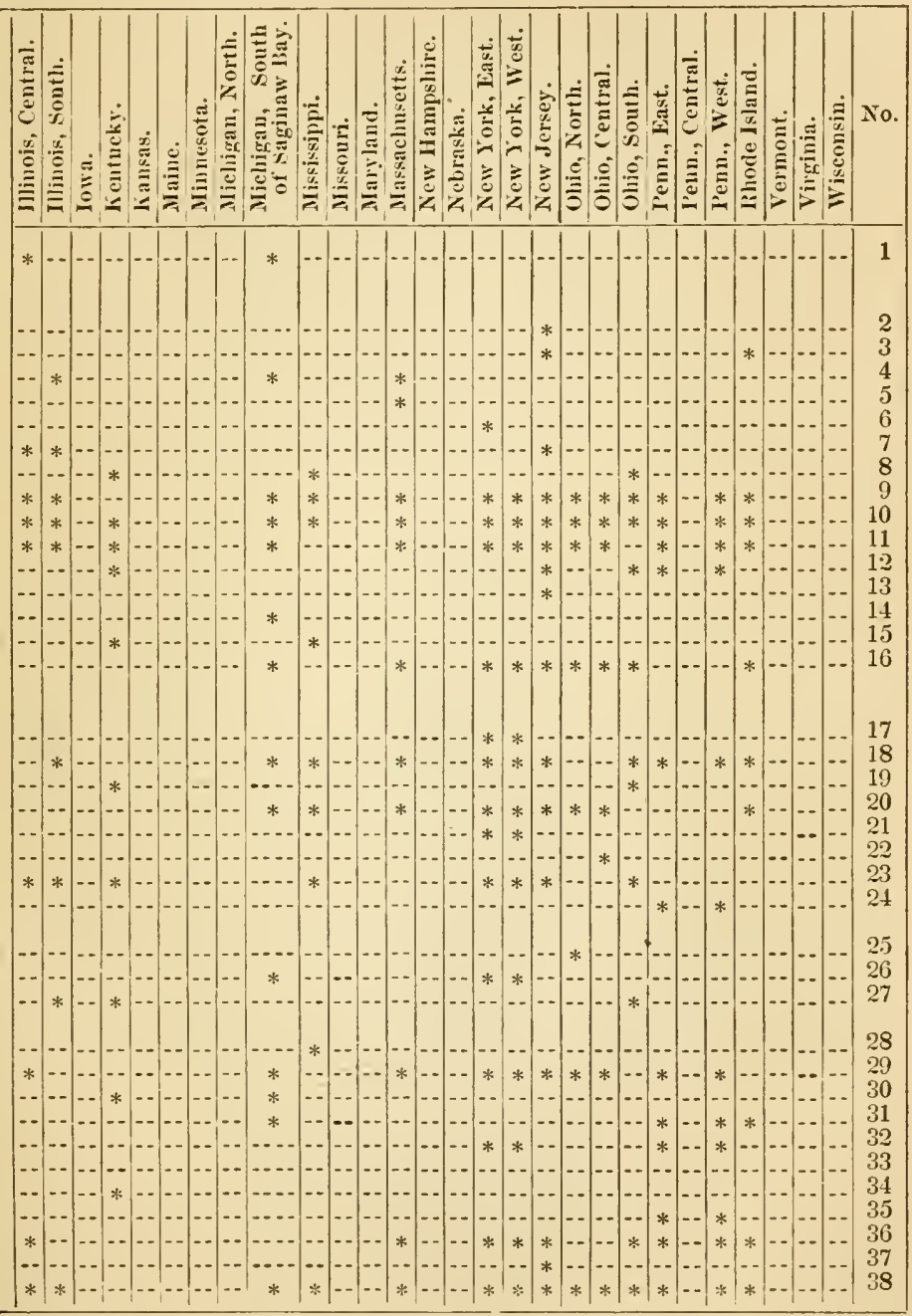




\begin{tabular}{|c|c|c|c|c|c|c|c|c|c|c|c|c|c|}
\hline No. & NAME. & 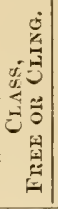 & $\begin{array}{l}\text { 章 } \\
\text { 量 } \\
0 \\
0 \\
0 \\
0 \\
0 \\
0 \\
0 \\
0\end{array}$ & $\begin{array}{l}\text { 㟔 } \\
\text { की } \\
\text { 톄 } \\
\text { क }\end{array}$ & & 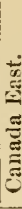 & 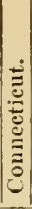 & 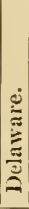 & 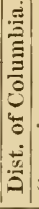 & 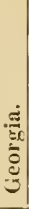 & 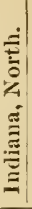 & & 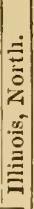 \\
\hline 39 & Old Mixon Cling, & C. & W. & L. & & & & $*$ & $*$ & & $*$ & $*$ &.- \\
\hline 40 & $\begin{array}{l}\text { Rodman's Cling, } \\
\text { Red Cling. }\end{array}$ & C. & W. & V.L. & & & & $*$ & $\therefore$ & & $*$ & $*$ & -- \\
\hline 41 & Royal George, & F. & W. & E. & & & &.- & - & & & - & -- \\
\hline 42 & Scott's Nonpareil, & F. & Y. & L. & & & & .. & * & & & - & -- \\
\hline $4: 3$ & Smock Freestone, ........... & F. & Y. & L. & & & - & * & *. & - & - & .. & - \\
\hline 44 & Snow, & F. & W. & M. & & & & & $\pi$ & & - & - & $\ldots$ \\
\hline 4.5 & Stump the World, & F. & $\mathrm{W}$. & $\mathrm{L}$. & & & & & - & & & . & $*$ \\
\hline 46 & Sturtevant (of Ohio), & F. & $Y$. & $M$. & & & & -- & -- & & & - & -- \\
\hline $\begin{array}{l}47 \\
48\end{array}$ & $\begin{array}{l}\text { Susquehanna, } \\
\text { Tippecanoe Cling }\end{array}$ & li: & Y. & M. & & & & $\because$ & -- & & & - & -- \\
\hline 49 & Troth's Early, & $\mathrm{F}$ & WV. & E. & & & & & $*$ & & & - & $*$ \\
\hline 50 & Van Zandt's Ślperb, & F. & W. & E. & & & & &.- & & .. & -1 &.- \\
\hline 51 & Ward's Late Free, & F. & W. & V. L. & & & & * & -- & & $*$ & $*$ & -- \\
\hline $\begin{array}{l}52 \\
53\end{array}$ & Ware, $\ldots$ & 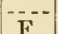 & $T$ & & & & & * & & & & & 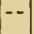 \\
\hline 54 & Yellow Alberge, & $\mathrm{F}$. & Y. & l. & & & & & & & & & 1 \\
\hline 55 & Yellow Rareripe, ................. & $\mathrm{F}$. & $\mathrm{Y}$. & M. & & & & & & & & & $\therefore$ \\
\hline
\end{tabular}

TABLE $O$.

The Explanation of the Columns and the List of Abbreviations

\begin{tabular}{|c|c|c|c|c|c|c|c|c|c|c|c|c|}
\hline No. & NAME. & 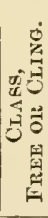 & 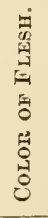 & 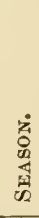 & $\mid$ & 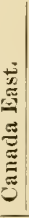 & 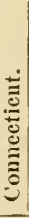 & & & : & & 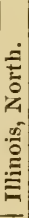 \\
\hline 1 & Boston & $\mathrm{F}$. & $\mathrm{Y}$. & Mr. & & & & & & & & \\
\hline 2 & Downton, & F. & IV. & M. & - & - & - & & & - & & - \\
\hline 3 & Early Newington, & C. & W. & $\mathrm{M}$. &.- & - &.- & & & -- & & -- \\
\hline 4 & $\begin{array}{l}\text { Early Violet, } \\
\text { Violette Hative. }\end{array}$ & F. & Y. & E. & -. & - & & & & * & * & -- \\
\hline 5) & Elrnge,,$-\ldots \ldots$ & F. & W. & $\mathrm{MI}$. & - & & - & & & * & * & -- \\
\hline 6 & Stanwick, & F. & W. & L. & & & & & & & & . \\
\hline
\end{tabular}




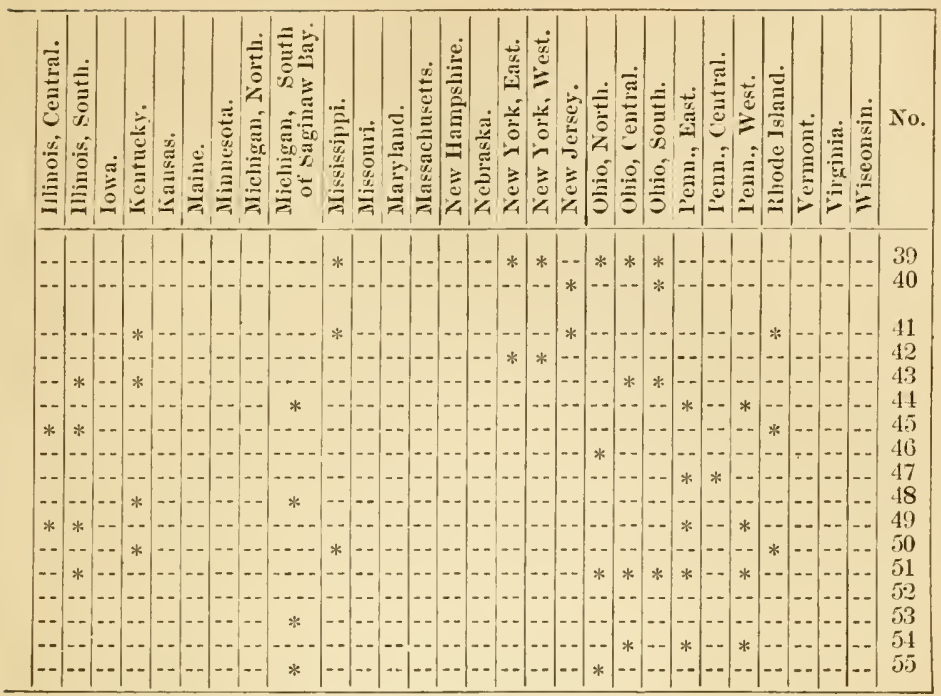

\section{NECTARINES.}

given under the head of Peaches are applicable also to this Table.

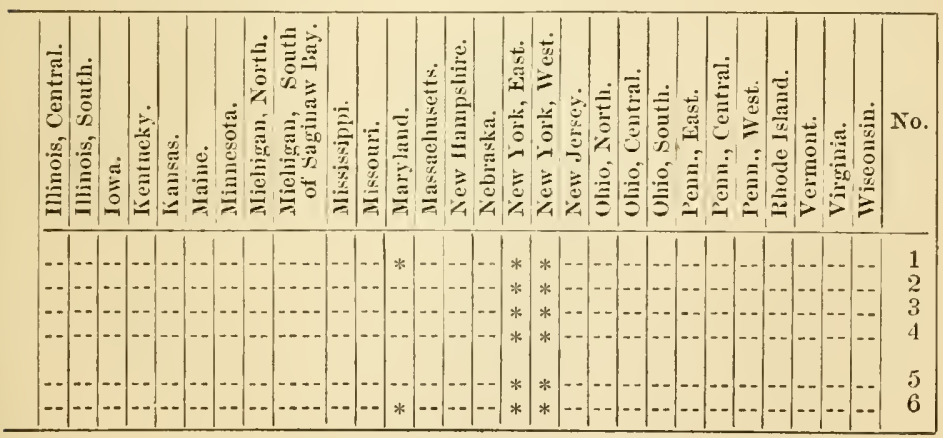


TABLE Q.

The Explanation of the Columns and the List of $\Lambda$ bbreviations

\begin{tabular}{|c|c|c|c|c|c|c|c|c|c|c|c|c|}
\hline No. & NAME. & 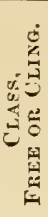 & $\begin{array}{l}\dot{1} \\
0 \\
0 \\
0 \\
0 \\
0 \\
0 \\
0 \\
0 \\
0 \\
0 \\
0 \\
0 \\
0\end{array}$ & 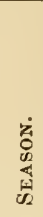 & 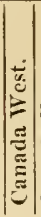 & 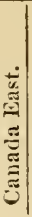 & | & 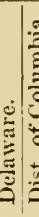 & 荛 & & & 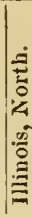 \\
\hline 1 & Breda, & F. & 0 . & M. & $\ldots$ & . & - & $\ldots$. & & $*$ & $*$ & 1-- \\
\hline 2 & Early Golden, ... & $\mathrm{F}$. & Y. & E. &.- & & - &.- & & & & .. \\
\hline 3 & Large Jarly, & F. & O. & E. & $\ldots$ & - & - & $\ldots$ & & & . & -- \\
\hline 4 & Lilire liod, & F. & O. & M. & $\ldots$ & & 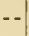 & & & & & 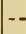 \\
\hline 6 & $\begin{array}{l}\text { Latiygeite, } 1,10 \\
\text { Moorpark, }\end{array}$ & F. & 0 . & MI. & & & & * & & $*$ & $*$ & $\because$ \\
\hline 7 & Orun fe (Royal Orange), & C. & 0. & $\mathrm{Ii}$ & - & & & 20 & & & - & $\cdots$ \\
\hline 8 & Peach, & F. & Y. & M. &.- & & - & -..- - & & $*$ & * &.- \\
\hline 9 & lied Masculine, ................... & F. & $\mathbf{Y}$. & E. & -- & & - & $*$. & & & & - \\
\hline 10 & St. Ambroise, & F. & Y. & E. & - & & & & & & & \\
\hline 11 & Turkey, , .......... & F. & Y. & L. & $-\cdot$ & & & & & & & \\
\hline
\end{tabular}

TABLE R.

The Columns indicate: 1st, the Name of Variety; 2d, the Color of the Fruit; $3 d$, the best adapted; 5th, the Season of Maturity; and the remainder the Districts in indicates that it succeeds well in the district named at the head of the column.

The Abbreviations are as follows: Color of Fruit, D. dark, including all red, purple, F. Freestone; C. Clingstone. Use, T. Table; K. Kitchen; D. Drying; M. those V. L. very late. The dirisons of the season for Peaches apply also (in lat. $43^{\circ}$ )

\begin{tabular}{|c|c|c|c|c|c|c|c|c|c|c|c|c|c|}
\hline No. & NAME. & 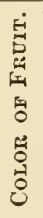 & 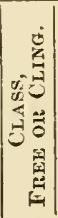 & 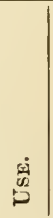 & 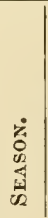 & 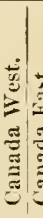 & E. & 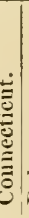 & 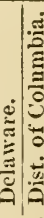 & 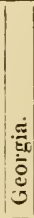 & 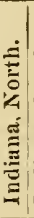 & 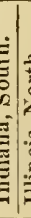 & 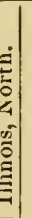 \\
\hline 1 & Blecker's Gage, ....... & & & & & & & & & & & & \\
\hline $\begin{array}{l}1 \\
2\end{array}$ & Bradshaw, -..... & 1. & C. & II. & E. & - & & - & -. & & - & * & $*$ \\
\hline 3 & Coe's Golden Drop, & P. & C. & $\cdots$ & L. & - & & * & * & & * & $*$ & $*$ \\
\hline $\begin{array}{l}4 \\
5\end{array}$ & $\begin{array}{l}\text { Columbia, } \\
\text { Damson, }\end{array}$ & $\mathrm{D}$. & $-\cdots$ & $\mathrm{K}$. & L. & - & & & & & & - & - \\
\hline & $\begin{array}{l}\text { Common Damson. } \\
\text { Black Damson. } \\
\text { Blue Damson. }\end{array}$ & & & & & & & & & & & & \\
\hline 6 & $\begin{array}{l}\text { Duane's l'urple, } \\
\text { Purple DIegmim Bonum. }\end{array}$ & D. & C. & & MI. & .. & & 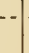 & & & - & & $\ldots$ \\
\hline 7 & Early livvoritc (livers'), .... - & D. & F. & & VE. & - & & & & & & & . \\
\hline 8 & $\begin{array}{l}\text { Fellember.r. } \\
\text { Ilalumin Prune. } \\
\text { Quetsche r'Italie. } \\
\text { Prune d'Italie. }\end{array}$ & D. & F. & D. & MI. & $\ldots$ & & & & & & & -- \\
\hline 9 & $\begin{array}{l}\text { German P'rune, } \\
\text { ((Quetsche) }\end{array}$ & D. & F. & K.D & MI. & & & & & & & & * \\
\hline 10 & General Iand, ... . & P. & F. & & M. & & & & & & & & \\
\hline
\end{tabular}




\section{- APRICOTS.}

given under the head of Peaches are applicable also to this Table.

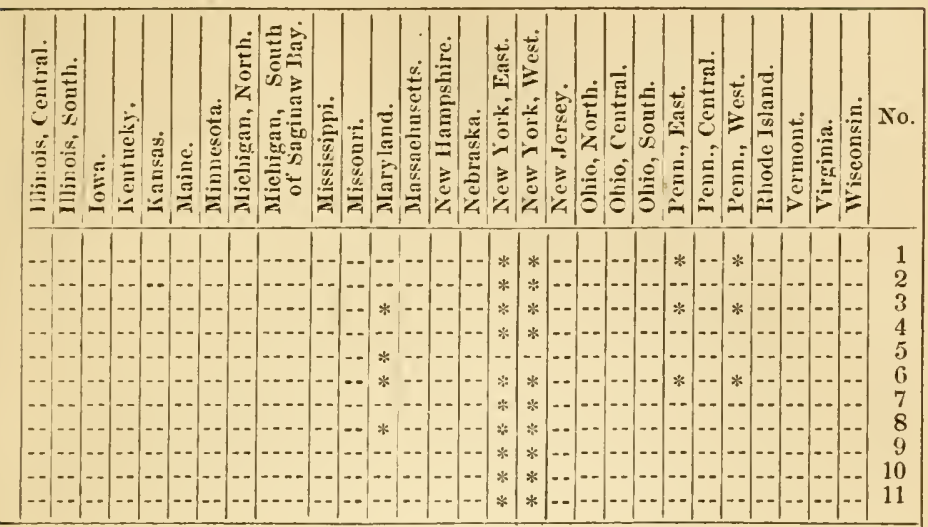

\section{PLUMS.}

Class (Freestone or Clingstone) to which the Variety belongs; 4th, the Uses to which which the Varieties are recommended. A star (*) opposite the name of a variety The Italics in the column of names donote synonymes.

blue, and other dark-colored varieties; P. pale, including green, yellow, etc. Class, most profitable for market. Season, E. early; II. medium; L. late; V. E. very early; to Plums

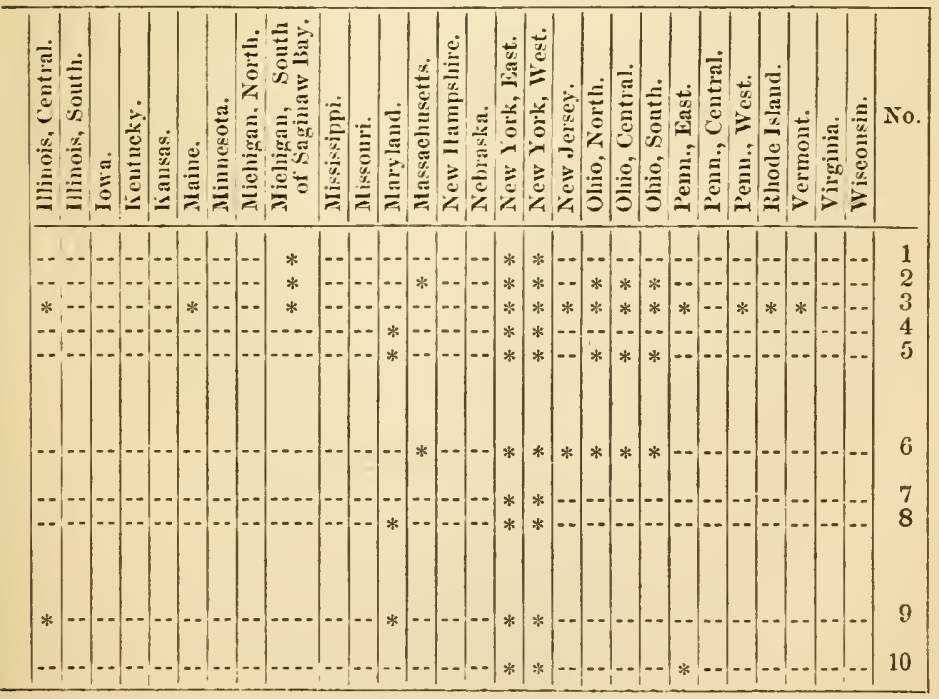




\begin{tabular}{|c|c|c|c|c|c|c|c|c|c|c|c|c|c|}
\hline No. & NAME. & $\begin{array}{l}\dot{E} \\
5 \\
0 \\
0 \\
0 \\
0 \\
0 \\
0 \\
0 \\
0 \\
0 \\
0\end{array}$ & 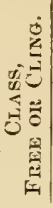 & 密 & $\begin{array}{l}\text { 落 } \\
\text { 离 } \\
\text { 露 }\end{array}$ & 位 & | & 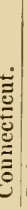 & 芦 & 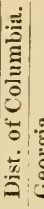 & 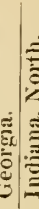 & 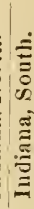 & 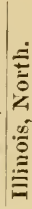 \\
\hline 11 & $\begin{array}{l}\text { Green Gage, } \\
\quad \text { Reine Clatide. }\end{array}$ & P. & F. & & E. & & & $*$ & $*$ & & $*$ & $*$ & -. \\
\hline 12 & $\begin{array}{l}\text { Goliath, } \\
\text { Caledonian. } \\
\text { Nectarine (by error). }\end{array}$ & D. & C. & K. & M. & 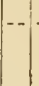 & & & - & . & & & -- \\
\hline 13 & IInling's Superb, & P. & C. & & E. & & & . & $*$ & -- & $*$ & * & -- \\
\hline 14 & $\begin{array}{l}\text { Imperial Gate, } \\
\text { Prince's Tmperial Gage. } \\
\text { Flushing Gage. }\end{array}$ & P. & F. & & MI. & -- & & & - & & $* *$ & $*$ & $*$ \\
\hline 15 & Jefferson, , - & $P$. & F. & & M. & -- & & * & . & $--\mid-$ & - $*$ & * & - \\
\hline 16 & $\begin{array}{c}\text { Lawrence's Favorite, } . . . . . . . .- \\
\text { Lawience's Gage. }\end{array}$ & P. & F. & & M. & 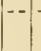 & & & & & $*$ & * & - \\
\hline 17 & $\begin{array}{l}\text { Lombard, } \\
\text { Beckman's Scarlet. } \\
\text { Bleeker's Scarlet. }\end{array}$ & D. & C. & & M. & -. & & $*$ & & & * & * & * \\
\hline 18 & McLaughlin, ........... & P. & C. & & I. & & & $*$ & & & - & -- & -- \\
\hline 19 & $\begin{array}{l}\text { Monioe, } \\
\text { Nonioe Ga!ge. }\end{array}$ & P. & F. & & M. & $\ldots$ & & $\ldots$ & & & $*$ & $*$ & - \\
\hline $\begin{array}{l}20 \\
21\end{array}$ & $\begin{array}{l}\text { Orleans, Smith's, } \\
\text { Peach Plum, }\end{array}$ & $\mathrm{D}$. & C. & & II. & & & * & & - & * & * & $*$ \\
\hline 22 & $\begin{array}{l}\text { Prume d'Agren,................ } \\
\text { D'Agen. }\end{array}$ & D. & $\mathrm{F}$. & ... & II. & -- & & & & & & - & - \\
\hline 23 & $\begin{array}{l}\text { Robe de Sergent. } \\
\text { Purple Gare, } \\
\text { Reine Cluide Violette. }\end{array}$ & D. & F. & & M. & & & & & & & & -- \\
\hline 21 & Purple Favorite, & D. & F. & & E. & $\cdots$ & & - & & & . & $\cdots$ & -. \\
\hline 2.5 & $\begin{array}{l}\text { Reine Claurle de Bavay, } \\
\text { Royal IIative, }\end{array}$ & P. & C. & & L. & 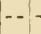 & & * & $=$ & 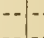 & - & -- & $*$ \\
\hline 26 & $\begin{array}{l}\text { Rioyal IIative, } \\
\text { Royal de Tours, }\end{array}$ & D. & C. & & E. & - & & & & & & 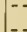 & $\ddot{r}$ \\
\hline 28 & St. Catharine,........... & P. & C. & & L. & |-. & & . & & & & $\therefore$ & $\begin{array}{l}* \\
--\end{array}$ \\
\hline 29 & St. Martin's Quetsche, ... & 1. & $\mathrm{F}$. & & V L. & 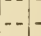 & & * & & $\because$ & & . & - \\
\hline 30 & $\begin{array}{l}\text { Victoria, } \\
\text { Alderton. } \\
\text { Denyer's Victoria. }\end{array}$ & D. & F. & K. & II. & L & & & & & & & -- \\
\hline 31 & $\begin{array}{l}\text { Washinigton, } \\
\text { Bolmar's. }\end{array}$ & P. & F. & & E. & -. & & * & * & & * & * & $*$ \\
\hline 32 & $\begin{array}{l}\text { White Magnmm Bonum, -...- } \\
\text { Yellow Magmum Bonum, } \\
\text { Yellow Eg.. }\end{array}$ & P. & C. & K. & M. & & & & & & * & * & - \\
\hline 33 & Yellow Gage (Prince's),...... & P. & F. & & E. & & & & & & & & \\
\hline
\end{tabular}




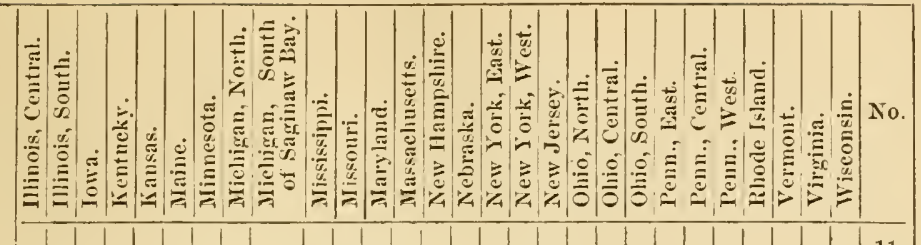

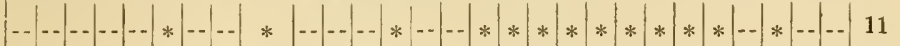

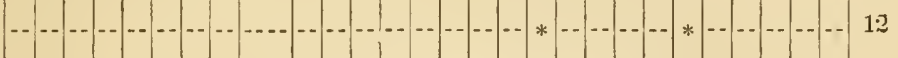

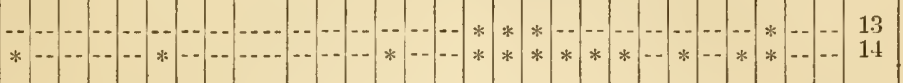

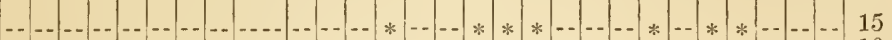

-

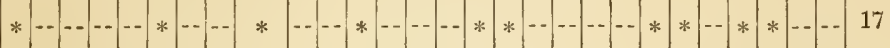

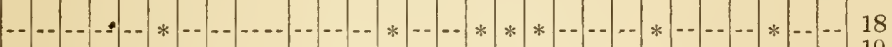

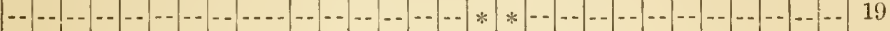

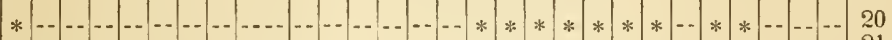

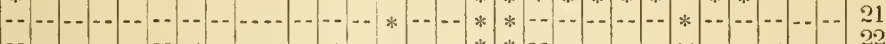

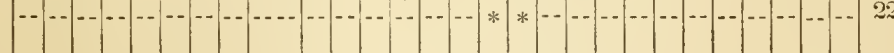

-

$\ldots$.

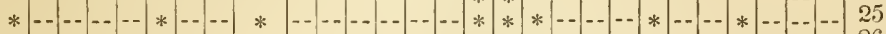

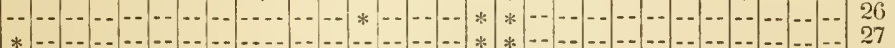

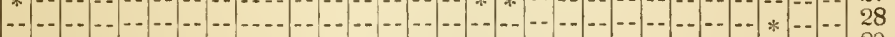

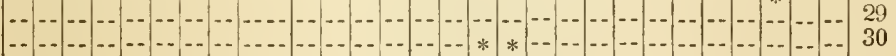

*

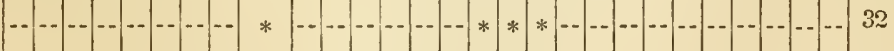

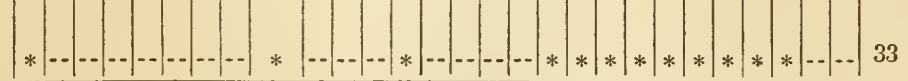


TABLE S.

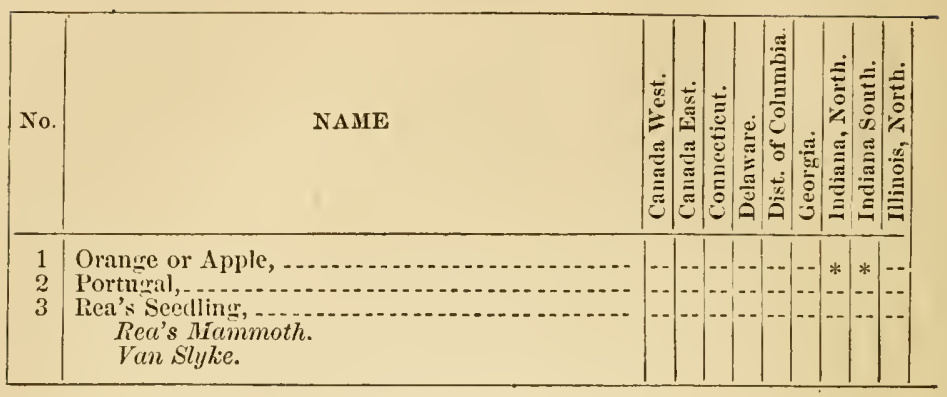

TABLE T.

The Cuiumns indicate: 1st, the Name of Variety; 2d, the Season of Maturity; 3d, recommended. A star (*) opposite the name of a variety indicates that it succeeds The Abbreviations are as follows: Secason, E. Early; M. Medium; L. Late. Color,

\begin{tabular}{|c|c|c|c|c|c|c|c|c|c|c|c|}
\hline No. & NAME. & 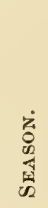 & 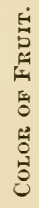 & 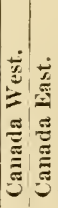 & 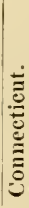 & & 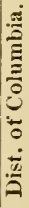 & & & & 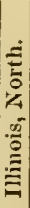 \\
\hline 1 & Bland's Madeira, & & & & & & & $*$ & & - & -- \\
\hline 2 & Brinckle, ......... & & & & & & 1 & * & & $\cdots$ & -. \\
\hline 3 & Catawba, ....... & L. & R. & 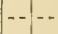 & .. & $*$ & - & * & * & $*$ & -- \\
\hline $\begin{array}{l}4 \\
5\end{array}$ & $\begin{array}{l}\text { S(uppernong, } \ldots \ldots \ldots \ldots \\
\text { Clinton. }\end{array}$ & & & & $\ldots$ & & & * & & -- & -- \\
\hline 6 & Concord, $\ldots . .$. & E. & 13. & * & $\because$ & * & -- & * & $*$ & $*$ & * \\
\hline 7 & Cuyahora, . & $\mathrm{I}$. & WV &. & $\pi$ & & & - & 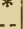 & ... & $\ldots$ \\
\hline 8 & Delaware, & E. & li. & -. & $*$ & $*$ & & $*$ & * & * & .. \\
\hline 9 & Diana, . . . . . . & M. & li. & $\ldots$ & $*$ & & & $\ldots$ & * & $*$ & .. \\
\hline 10 & Elsingburer, & I. & 13. & -- & -- & & & & & & -- \\
\hline 11 & Ilart ford l'rolific,,$\ldots$ & E. & 13. & - & -- & & & * & & $\cdots$ & -- \\
\hline 1.2 & Hybritl (Allen's), $\ldots \ldots \ldots$ & M. & W. & -- & 1* & 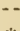 & & & 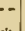 & -- & 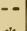 \\
\hline I4 & $\begin{array}{l}\text { Is:1bella, } \\
\text { Lenoir, }\end{array}$ & II. & B. & & $*$ & $*$ & & & & $*$ & $*$ \\
\hline 1.5 & .............. & E. & B. & .. & & & & & & & -- \\
\hline 16 & Maxatawny, & L. & W. &. & | & & & & & & -- \\
\hline 17 & Norther'u Muscadine, & E. & R. & - & & & & & & & - \\
\hline 18 & Oporto, $\ldots \ldots \ldots$ & MI. & B. & - & & & & & & & - \\
\hline $\begin{array}{l}19 \\
20\end{array}$ & 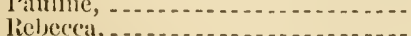 & I. & $\bar{w}$ & - & 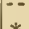 & & & & & & \\
\hline 21 & 'To Kalon, ... . . . . & L. & B. & .. & & & & & & 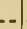 & \\
\hline 22 & Union Village, & L. & B. & 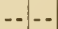 & & & & & & & . \\
\hline
\end{tabular}




\section{QUINCES.}

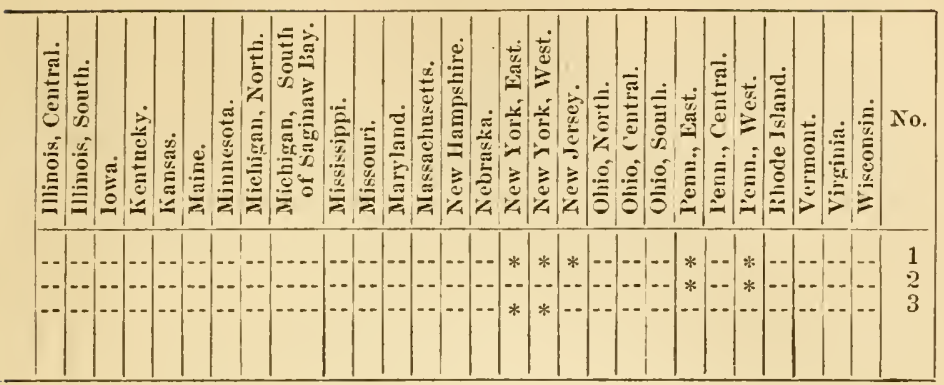

\section{NATIVE GRAPES.}

the Color of the Fruit; and the remainder the Districts in which the Varieties are well in the district named at the head of the column.

B. Black; R. Red; IW. White.

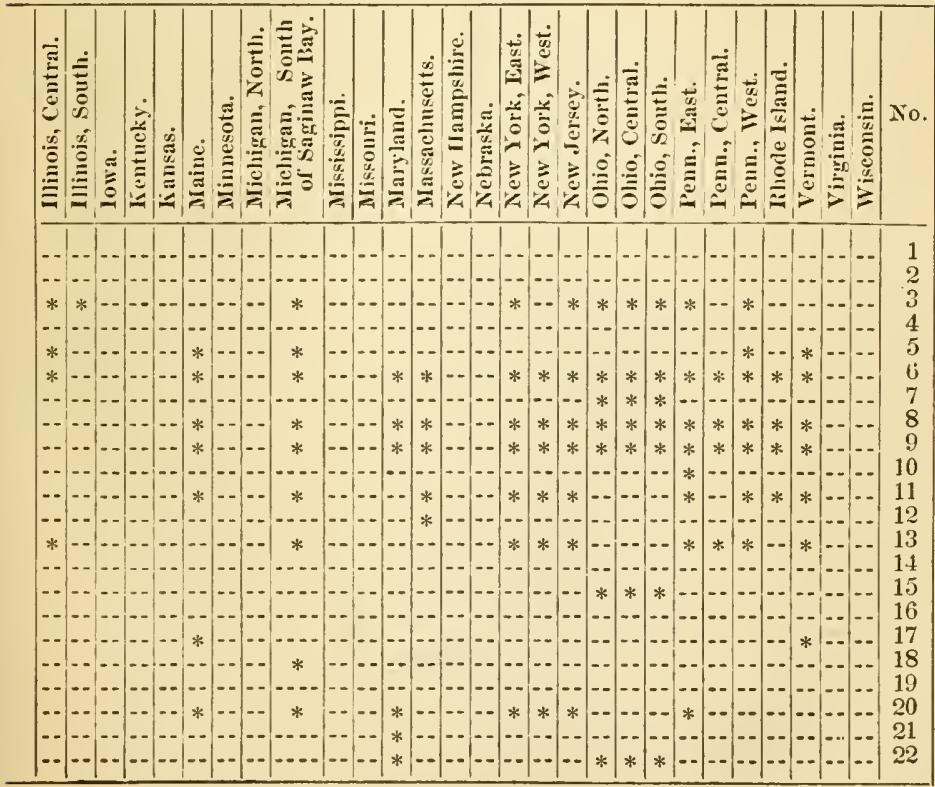


TABLE U.

\begin{tabular}{|c|c|c|c|c|c|c|c|c|c|c|c|}
\hline No. & NAME. & 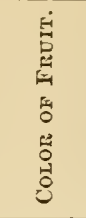 & $\mid$ & 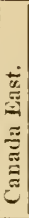 & $\mid$ & 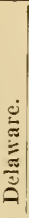 & 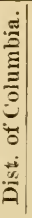 & $\begin{array}{l}0 \\
0 \\
0\end{array}$ & & & 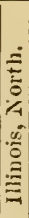 \\
\hline 1 & Attractor, & White. & & & & & & & & & \\
\hline 2 & Black Naples. & Black, & . & 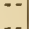 & 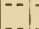 & & 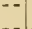 & & & & \\
\hline 3 & Champagne, .. & Flesh, & .. & 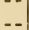 & - & & .. & & & & -. \\
\hline 4 & Cherry, ...... & Red, & * & .. & * & - & * & & * & & .. \\
\hline 5 & Commón lHack (Black English), ...... & Black, & $*$ & & & & .- & & & & -- \\
\hline 6 & Feriile de Palluau, ................ & lied, & $\therefore$ & -- & $*$ & - & * & & & & -- \\
\hline 7 & Fertile d'Angers, & Rienl, &.- & .. &.- & $*$ & * & & & & -. \\
\hline 8 & Gondouin Red, & Red, & - & - & $\ldots$ & $\%$ & $*$ & & & & -. \\
\hline 9 & Gondonin White, & White, &.- & - & -- & & $*$ & & & & - \\
\hline $\begin{array}{l}10 \\
11\end{array}$ & $\begin{array}{l}\text { Kuight's Large Red, } \ldots \\
\text { La Versaillaise }\end{array}$ & lied, & 1 & D & $\because$ & 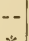 & $\therefore$ & & & & - \\
\hline 12 & May's Victoria, & Red, & * & - & $*$ & $\ldots$ & $\ldots$ & & & & $\ldots$ \\
\hline 13 & Prince Albert, & lied, & - & - & $\therefore$ & & $\ldots$ & & & & $\ldots$ \\
\hline 14 & Rell Dutch,... & Rerl, & * & - & $*$ & & -1 & & * & * & -- \\
\hline 15 & Fed Grape, & lierl, & 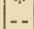 & 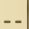 & $*$ & & 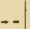 & & & & 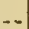 \\
\hline 16 & Transparent White, & White, & .. & - &.- & -. & * & & & & .. \\
\hline 17 & White Duteh, ..................... & White, & * & $\cdots$ & * & & $*$ & & & & -. \\
\hline 18 & White Grape, & White, & * & & * & & & & * & * & 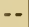 \\
\hline
\end{tabular}

TABLE $V$.

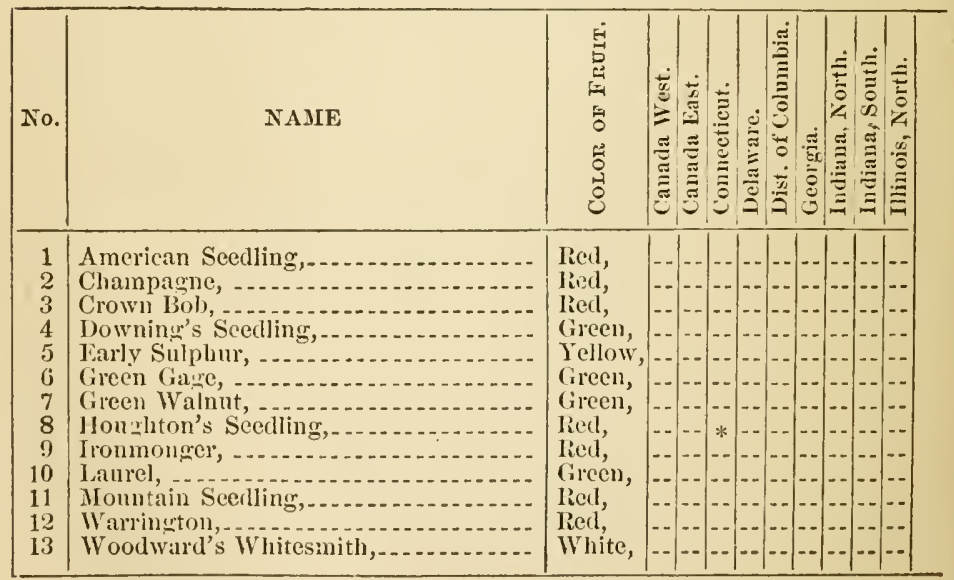


- CuRRants.

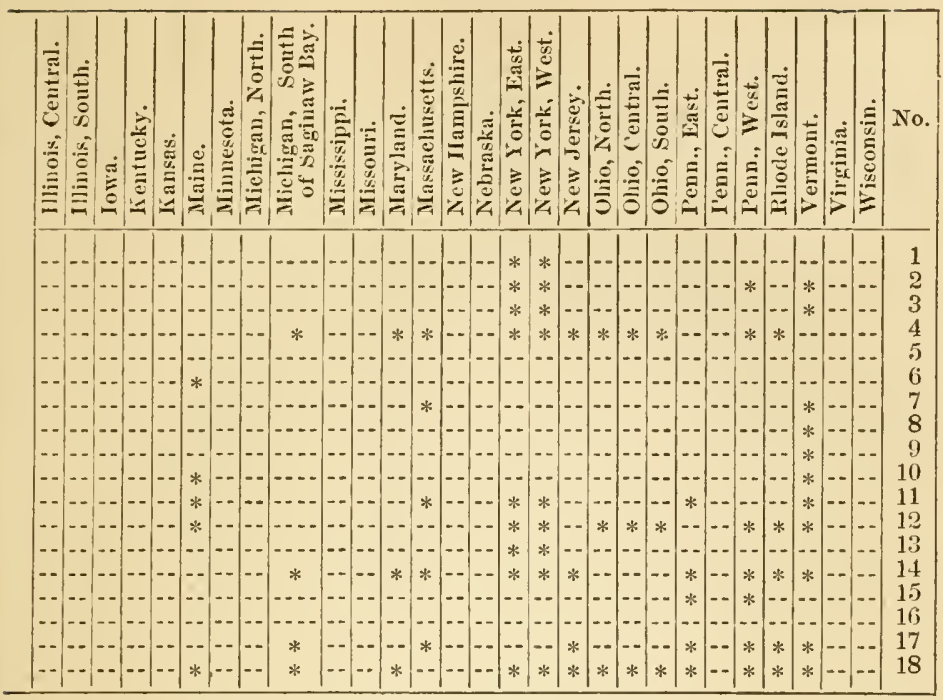

GOOSEBERRIES.

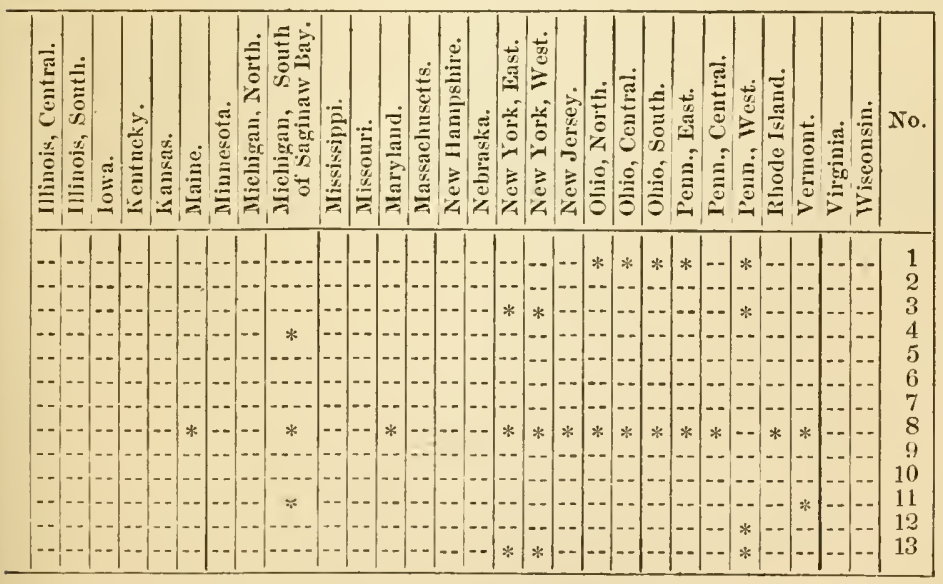


TABLE $\mathbf{X}$

\begin{tabular}{|c|c|c|c|c|c|c|c|c|c|c|}
\hline No. & NAME. & 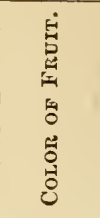 & 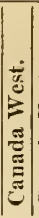 & 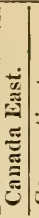 & 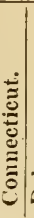 & 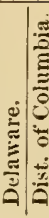 & $\frac{\pi}{80}$ & 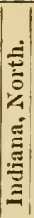 & 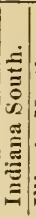 & 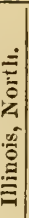 \\
\hline 1 & American Black, & Black, & & & & & & & & \\
\hline 2 & Antwerp Red of Hudson River. & Red. & 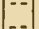 & - & & & & & & \\
\hline 3 & Antwerp Yellow, & Yellow, & $*$ & |-- & $\ldots$ & .. & & - & $\ldots$ & $\ldots$ \\
\hline 4 & Belle de Fontenay, & Red, & -- & -. & - & ..... & - & 1- & -1 & - \\
\hline 5 & Catawissa, ............. & Ried, & -- & -- & * & $--*$ & - & - & - & \\
\hline 6 & Fastolff, & Ried, & - & $-\cdot$ & * & $-\cdot-\cdot$ & -. & * & $*$ & -. \\
\hline $\begin{array}{l}7 \\
8\end{array}$ & Franconia, ...... & Red, & $*$ & [- & $*$ & $\cdots$ & & $*$ & $*$ & --1 \\
\hline & Vice-President French. & & & & & & & & & \\
\hline 9 & Knevitt's Giant, & Red & & & $*$ & & & & & \\
\hline 10 & Merveille de 4 Saisons, ...... . . & Red, & & & & & & & & , \\
\hline 11 & Orange, Brinckle;s Orange. & Yellow, & & & * & & & $*$ & * & -- \\
\hline 12 & Ohio Everlasting, ....... & Black, & & & & & & & $*$ & \\
\hline
\end{tabular}

TABLE Y.

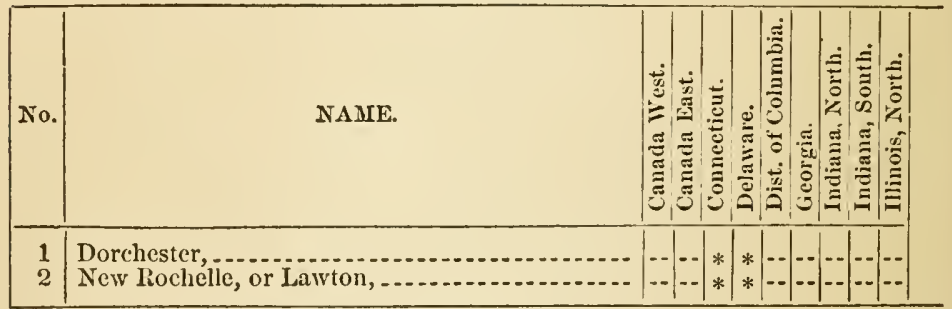




\section{RASPBERRIES.}

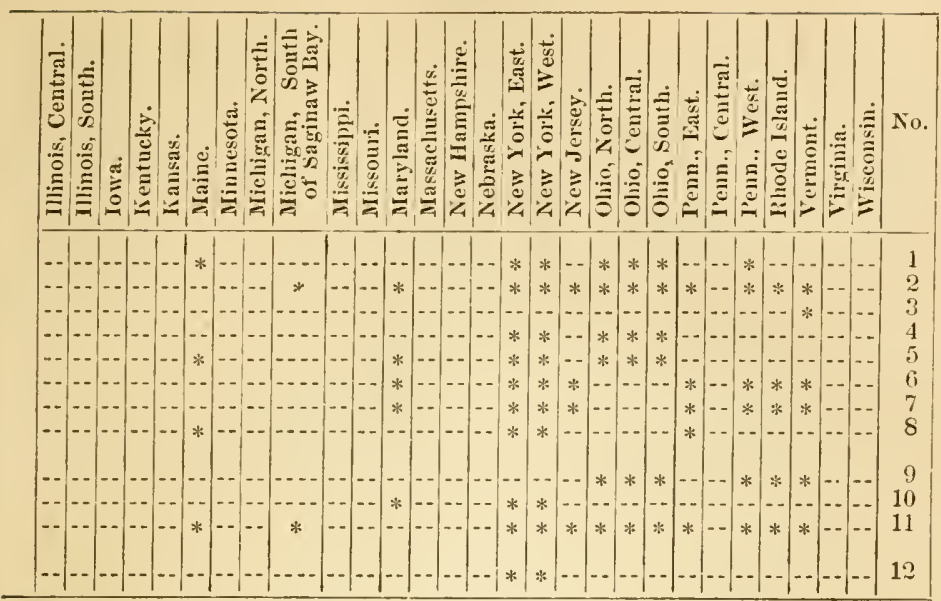

IULACKBERRIES.

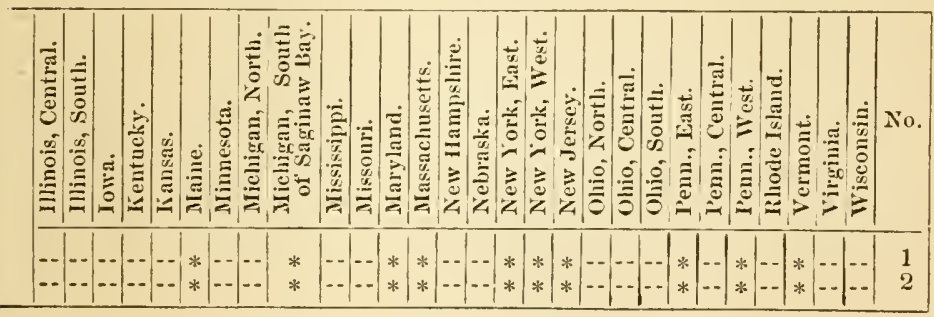




\section{TABLE Z.}

The Columns indicate: 1st, the Name of Variety; 2d, the Sex (Hermaphrodite or which the Varieties are recommended. A star (*) opposite the name of a variety The Abbreviations are as follows: Sex, P. Pistillate; all others are Hermaphrodite;

\begin{tabular}{|c|c|c|c|c|c|c|c|c|c|c|c|c|}
\hline No. & NAME. & 祻 & 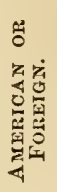 & لِ & 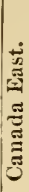 & & & 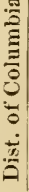 & 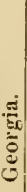 & & 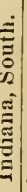 & 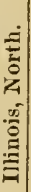 \\
\hline 1 & Alice Maude,. & & F. & & & & & $*$ & & & & --1 \\
\hline 2 & Brighton Pine, - & & A. & -- & & & & & - & & &. \\
\hline 3 & British Queen, ...... & & $\mathrm{F}$. & - & -- & & & $\cdots$ & - & & & -- \\
\hline 4 & Boston Pine, & $\mathbf{P}$ & A. & -- & & & &.- & & 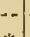 & & -- \\
\hline $\begin{array}{l}5 \\
6\end{array}$ & $\begin{array}{l}\text { Burr's New Pine, } \\
\text { Crimson Cone, }\end{array}$ & P. & A. & & & & & - & - & * & & -- \\
\hline 7 & Downer's Prolifie, - & & A. & -- & & & & $*$ & & & & 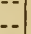 \\
\hline 8 & 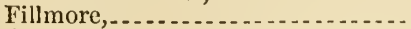 & - & A. & .- &.- & & & -- & .- & - & & 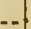 \\
\hline 9 & Genesee, ........... & & A. & .. & & & & .. &. & -. & & -1 \\
\hline 10 & Hooker, & & A. & -- & 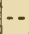 & & & * & -- & * & &.. \\
\hline 11 & Hovey's Seedling, .......... & P. & A. & -- & & * & & * & -- & $*$ & & -- \\
\hline 12 & 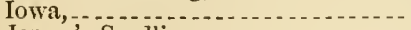 & 0 & A. & & & & & -- & -. & - & & -- \\
\hline 13 & Jenny's Seedling, & P. & A. & -- & & & & - & - & & &.- \\
\hline 14 & Jenny Lind, ........ & -..... & A. & * & $\ldots$ & * & & * & * & - & & -- \\
\hline 15 & La Constante, .....-. & & $\mathrm{F}$ & $\ldots$ & & & & -. & -- & 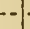 & & -- \\
\hline 16 & Larre Early Scarlet, & & A. & - & & & & - & -- & & & \\
\hline 17 & Longworth's Prolific, .... & & A. & -. & & & &.- & * & * & & $\ldots$ \\
\hline 18 & McAroy's Superior, & P. & A. & - & & & & - & $\cdots$ & * & & - \\
\hline 19 & Monroe Scarlet, - & $P$ & A. & -. & & & & .. & I & & & 1 \\
\hline 20 & Moyamensing, .. & P. & A. & & & & & $\cdots$ & -- & & & -- \\
\hline 21 & Scott's Seedling, & -- & A. & & & * & & - & 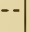 & , & & -01 \\
\hline $\begin{array}{l}22 \\
23\end{array}$ & $\begin{array}{l}\text { Triomphe de Gand, - } \\
\text { Trollope's Vietoria }\end{array}$ & & F. & $*$ & & & * & $\cdots$ & - & * & & \\
\hline 24 & Walker's Seedling, - & & A. & -. & & * & & $*$ & . & .. & & -. \\
\hline 25 & Wilson's Albany,..- & & A. & * & & & & .1 & 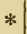 & $* 1$ & & 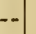 \\
\hline
\end{tabular}




\section{STRAWBERRIES.}

Pistillate); 3d, the Origin, American or Foreign; and the remainder the Districts in indicates that it succeeds well in the district named at the head of the column.

Origin, A. American; F. Foreign.

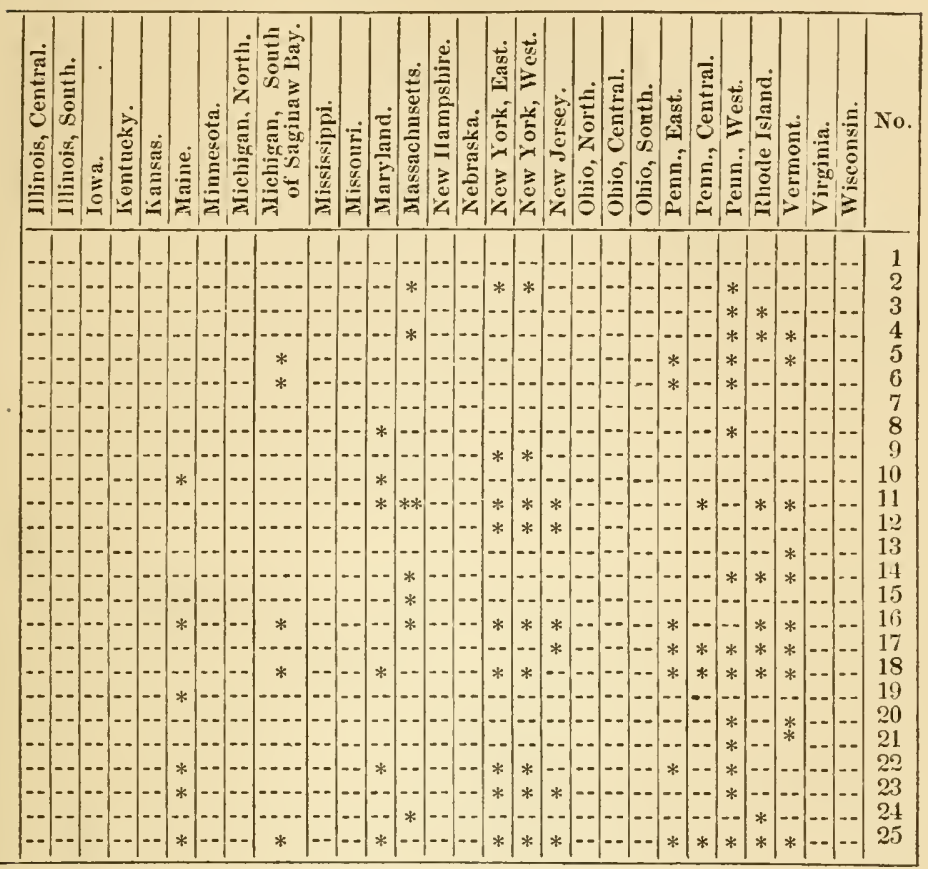


§II. BEST SIX, TEN, TIVELVE, OR TWENTY VARIETIES.

It is of great importance to the practical fruitgrower to know not only what varieties will flourish well in his locality, as set forth in the preceding pages, but also in what manner those varietics should be combined so as to secure him an orchard of the greatest value for domestic use and for the market. To teach the latter lesson, we have collated, from the issues of the American Pomological Society, and from other authentic sources, the following results of the experience and observation of the best cultivators in a number of the states of the American Union.

It has been our aim to obtain full reports on this point from every part of the country. But this has been in a measure prevented by circumstances beyond our control. WVe have classified these results geographically, so that cultivators, in states from which we have no returms, can form their judgment as to the combination of varieties, so as to secure the best reward of labor and expenditure from an inspection of returns from other states in their vicinity. As reliable data may be received by us from other states and territories, and from the $\mathrm{Pa}$ cific coast and the British provinces, we shall add them to these specifications, in the hope of accumulating ultimately the ripe experience of American fruit-growers. 


\section{NET ENGLAND STATES.}

1. FOR MAINE.

BEST VARIETIES OF APPLES.

Ramsdell's Sweet,

Red Astrachan,

Sreet Bough,

Early Harvest,

Urbaniste,

Fulton,

Beurré Clairgeau,

Doyenne Boussock,

Imperial Gage,

MeLaughlin,

Green Gage,

IVaslington,
R. I. Greening,

Black Oxford,

Cogrgswell,

Ribstone Pippin.

PEATS.

Winter Nelis,

Onondaga,

Dearborn's Seedling,

Lawrence.

PLUMS.

Lombard,

Reine Claude de Bavay,

Coe's Golden Drop.

cherries.

Only the Dukes and Morellos.

2. FOR MASSACHUSETTS.

BEST SIX VARIETLES OF APPLES.

Williams,

Early Bough,

Gravenstein,

Fameuse,

IIubbardston,

Baldwin.

BEST TWELVE VARIETIES ADD:

Red Astrachan,

R. I. Greening,

Ladies' Sweet,

Roxbury Russet,

Suith's Cider,

Talman's Sweet. 
BEST VARIETIES OF PEAR, ON PEAR STOCK, FOR ONE HUNDTED TREES.

Bartlett,

Urbaniste,

Vicar of Winkfield,

Buffum,

Beurré d'Anjou,

Lawrence,
Rostiezer,

Merriam,

Flemish Beauty,

Belle Luerative,

Doyenne Boussock,

Onondaga.

ON QUINCE.

Louise bonne de Jersey, Urbaniste,

Duchesse d'Angouleme,

Vicar of Winkfield, Beurré d'Anjou,

Glout Morceau.

BEST VARIETIES OF STRAWBERRIES.

Early Scarlet,

Hovey,

Boston Pine,

Jenny Lind,

Brighton Pine.

BEST VARIETIES OF GRAPES FOR OUT-DOOR CULTURE.

Delaware,

Diana,

Concord, Hartford Prolific.

3. FOR RHODE ISLAND.

BEST SIX VARIETIES OF APPLES FOR ONE HUNDRED TREES.

Early Harvest . . . . $10 \mid$ Baldwin . . . . . . 25

William's Favorite . . . . 10 R. I. Greening . . . . 25

Porter . . . . . . 15 Roxbury Russet . . . . 15

BEST TWELVE.

Early Harvest . . . . . . $4 \mid$ R. I. Greening . . . . . 20

Early Sweet Bough . . . . 4 Peck's Pleasant. . . . . . 5

William's Favorite . . . 6 Baldwin . . . . . . 20

Porter. . . . . . . 10 Hubbardston Nonesuch . . 10

Gravenstein . . . . . . . 4 Sheppard's Sweet . . . . 3

Beauty of Kent. . . . . 4 Roxbury Russet . . . . 10 
BEST TWENTY.

Early Harvest . . . . . . 3/ Fall Pippin . . . . . . . 4

Golden Sweet . . . . 2 Hubbardston Nonesuch . . 4

Red Astrachan . . . . . . 2 Peek's Pleasant. . . . . . 4

William's Favorite . . . . 3 Yellow Bellefluer . . . . . 3

Early Bough . . . . . . 2 Talman's Sweet . . . . 2

Porter . . . . . . . 6 R. I. Greening . . . . 20

Pomme Royale . . . . . . 2 Baldwin . . . . . . 20

Dartmouth Sweet. . . . 3 Sheppard's Sweet . . . . 4

Beauty of Kent. . . . . . 2 Northern Spy . . . . . 3

Gravenstein . . . . . $3 \mid$ Roxbury Russet . . . 8

BEST SIX VARIETIES OF PEARS FOR ONE HUNDRED TREES ON PEAR STOCK.

Dearborn's Seedling . . . $10 \mid$ Pratt . . . . . . . 20

Beurré Giffard . . . . . 10 Fondante d'Automne . . . 15

Bartlett . . . . . . 30 Lawrence . . . . . 15

BEST TWELVE.

Bloodgood . . . . . $5 \mid$ Pratt . . . . . . 15

Beurré Giffard . . . . . 5 Flemish Beauty . . . 10

Dearborn's Seedling . . . 5 Seckel . . . . . . 5

Doyenne Boussock . . . . 5 Buffum . . . . . . . . 5

Bartlett . . . . . . 20 Lawrence . . . . . 10

Belle Lucrative. . . . . $10 \mid$ Easter Beurré . . . . . 5

BEST SIX VARIETIES OF PEARS FOR ONE HUNDRED TREES ON QUINCE STOCK.

Beurré Giffard . . . . . $15 \mid$ Beurré Diel . . . . . 10

Louise bonne de Jersey . . . 35 Urbaniste . . . . . . 10

Duchesse d'Angouleme . . 20 Glout Moreeau . . . . 10

BEST TWELVE.

Beurré Giffard . . . . . $10 \mid$ Urbaniste. . . . . . . 5

Doyenne d'Ete . . . . . 5 Louise bonne de Jersey • . 20

Rostiezer. . . . . . 5 Duchesse d'Angouleme . . 10

Beurré d'Amaulis . . . . 5 Beurré Diel . . . . . 10

Belle Luerative . . . . 10 Glout Moreeau . . . . . 6

Beurré d'Anjou . . . . $10 \mid$ Easter Beurré . . . . . 4 


\section{FOR CONNECTICUT.}

BEST SIX VARIETIES OF APPLES FOR ONE HUNDRED TREES.

Early Harvest . . . . . 2 Talman's Sweet . . . . 8

Golden Sweet . . . . . 10 R. I. Greening . . . . . 50

Cayuga Red Streak . . . 10 Roxbury Russet . . . .20

BEST TWELVE VARIETIES FOR ONE HUNDRED TREES.

Early Harvest . . . . . 2 Fall Pippin . . . . . 5

Early Bough . . . . . . 1 Talman's Sweet . . . . . 5

Spice Apple . . . . . . . 1 Peck's Pleasant. . . . . . 10

Golden Sweet . . . . . 5 Esopus Spitzenberg . . . . 10

Cayuga Red Streak . . . 10 R. I. Greening . . . . . 30

Ýellow Bellefleur . . . . . 1 Roxbury Russet . . . . 20

PEAIS ON PEAR STOCK. BEST TWELVE VARIETIES FOR ONE HUNDRED TREES.

Bartlett . . . . . . 25 Gansel's Bergamotte . . . 2

Fondante d'Automne . . . 2 Beurré Diel . . . . . . . 2

Paradise d'Automne . . . . 2 Vicar of Winkfield . . . 25

Seckel . . . . . 10 Lawrence . . . . 10

Flemish Beauty . . . . . 8 Winter Nelis . . . . . 2

Louise bonne de Jersey . . . 10 ( Buffum . . . . . . . . 2

BEST TEN VARIETIES OF TEAIS ON QUINCE STOCK.

Louise bonne de Jersey,

Belle Lucrative,

Urbaniste,

Flemish Beauty,

Beurré Diel,
Duchesse d'Angouleme,

Beurré d'Anjou,

Glout Morcean,

Vicar of Winkfield,

Easter Beurré,

BEST SIX VARIETIES OF PEACIES.

Early York,

Cooliclge's Favorite,

George IV.,
Morris' White,

Late lied Rareripe,

Bergen's Yellow. 


\section{MIDDLE STATES.}

1. FOR NEW YORK.

BEST SIX YAIIETIES OF APPLES FOR ONE HUNDRED TREES.

Red Astrachan .

Baldwin . . . . . . 24

Fall Pippin . . . . . 12 Talman's Sweet . . . . 20

R. I. Greening . . . . . 24 lioxbury Russet . . . . 10

BEST TWELVE.

Early Ilarvest . . . . . . $4 \mid 20$ oz. Pippin . . . . . . 8

Red Astrachan . . . . . . 4 R. I. Greening . . . . . 24

Sweet Bough . . . . . . 4 King Tompkins Co. . . . . 4

Primate . . . . . . 4 Talman's Sweet . . . . 10

Gravenstein . . . . 4 Baldwin . . . . 18

Fall Pippin . . . . . . $6 /$ Roxbury Russet . . . . 10

BEST TWENTY.

Early Harvest . . . . . . $4 \mid 20$ oz. Pippin . . . . . . 8

Red Astrachan . . . . . 4 R. I. Greening . . . . 12

Early Joe . . . . . . 2 King Tompkins Co. . . . . 6

Primate . . . . . . 2 Fameuse . . . . . 4

Sweet Bough . . . . . . 2 Mother . . . . . . . 4

Jersey Sweet . . . . . 2 Talman's Sweet . . . . 8

Porter . . . . . . . 2 Ladies' Sweet . . . . . 4

Fall Pippin . . . . . 4 Baldwin . . . . . . 10

Gravenstein . . . . . 4 Northern Spy . . . . . 4

Belmont . . . . . . 4 Roxbury Russet . . . . 10

BEST VARIETIES FOR MARKET, FOR ONE THOUSAND TREES.

Red Astrachan . . . . 60 R. I. Greening • • . 200

Golden Sweet. . . . . 60 Talman's Sweet . . . . 100

Duchesse of Aldenburgh . . 80 Baldwin . . . . . . 200

20 oz. Pippin . . . . $200 /$ Roxbury Russet . . . . 100

BEST SIX VARIETIES OF PEARS ON PEAR STOCK.

Benrré Giffard,

Bartlett,

Tyson,
Seckel,

Sheldon,

Lawrenee. 
FON BEST TWELVE ADD:

Bloodgood,

Flemish Beauty,

Duchesse d'Orleans,
Beurré Clairgeau,

Winter Nelis,

Vicar of Winkfield.

BEST SIX VAIIETIES OF PEARS ON QUINCE STOCK.

Beurré Giffard,

Brandy wine,

Belle Lucrative,
Duchesse d'Angouleme,

Louise bonne de Jersey,

Vicar of Winkfield.

FOR BEST TWELVE ADD:

Beurré Langelier,

Beurré Diel,

Urbaniste,
Easter Beurré,

Glout Moreeau,

Beurré d'Anjou.

FOR THE MAREET.

Duchesse d'Angouleme, Louise bonne de Jersey, Glout Morceau,

Easter Beurré,

Vicar of Winkfield.

best tWelve VARIeties of PEAChes.

Early York,

Senate,

Early Newington,

Crawford's Early,

Coolidge's Favorite,

Walter's Early,

Morris' White,
Old Mixon Free, Old Mixon Cling,

Red Cheek Melocoton.

George IV.,

Crawford's Late, or

Langworthy's Late Rareripe.

FOR ONE HUNDRED TREES.

Early York Scrrate . . . 25| Old Mixon Cling . . . 10

Crawford's Early . . . . 20 Red Cheek Melocoton . . 15

Old Mixon Free . . . . 20 Langworthy's Late . . . 10

\section{FOR NEW JERSEY.}

BEST sIX VARIETIES OF APPLES fOR ONE HUNDRED TREES.

Yellow Harvest • . . . . $5 \mid$ R. I. Greening . . . . . . 25

Maiden Blush . . . . . 10 Baldwin . . . . . . 25

Fall Pippin . . . . . 10 Roxbury Russet . . . . 25 
BEST TWELVE

Yellow Harvest

Maiden Blush . . . . . 8

Hubbardston Nonesuch . . . 8

Sweet Bough . . . . . . 5

Fall Pippin . . . . . 8

\begin{tabular}{|c|c|c|}
\hline & & \\
\hline Yellow Bellefleur & & \\
\hline Monmouth Pippin & & \\
\hline isopus Spitzenberg & & \\
\hline ewt & & \\
\hline oxbury $R$ & & \\
\hline
\end{tabular}

R. I. Greening

10 Roxbury Russet

BEST TWENTY.

Yellow Harvest . . . . . $3 \mid \begin{aligned} & \text { Monmouth Pippin . . . . } 8 \\ & 8\end{aligned}$

Sweet Bough . . . . . . 2 Yellow Bellefleur . . . . . 5

Summer Hagloe . . . . . 3 Newtown Pippin . . . . . 5

Maiden Blush . . . . . . 5 Talman's Sweet . . . . 5

Fall Pippin . . . . . . 5 Dominie . . . . . . 5

Gravenstein . . . . . . 5 Seeknofurther (Westfield) . . 5

Jersey Sweet . . . . . 2 Esopus Spitzenberg . . . 5

Ilubbardston Nonesuch . . . 5 Roman Stem . . . . . . 5

R. I. Greening . . . . . . 10 Roxbury Russet . . . . . 5

Baldwin . . . . . . . 8 Lady Apple . . . . . 4

BEST VARIETIES FOR ONE THOUSAND TREES.

Yellow Harvest . . . . 30, Esopus Spitzenberg • . . 50

Sweet Bough . . . . . 25 Newtown Pippin . . . . 50

Maiden Blush . . . . . 50 Monmouth Pippin . . . 75

Fall Pippin . . . . . 50 Roxbury Russet . . . . 75

Gravenstein . . . . 50 Dominie . . . . . 50

Jersey Sweet . . . . . 25 Lady Apple . . . . . 25

Hubbardston Nonesuch . . 50 Snith's Cider . . . . . 50

R. I. Greening . . . . 100 Seeknofurther . . . . . 50

Baldwin . . . . . . 60 Roman Stem . . . . 25

Yellow Bellefleur . . . 60 Wine. . . . . . . 25

Talman's Sweet . . . . 25

BEST SIX VARIETIES OF PEARS ON PEAR STOCK.

Beurré Giffard,

Bartlett,

Seckel,

Madeleine,

Belle Lucrative,

St. Ghislain,
Beurré d'Anjou,

Winter Nelis,

Glout Morceau.

FOR BEST TWELVE ADD:

Vicar of Winkfield,

Beurré Diel,

Easter Beurré. 
BEST FOR ONE HUNDRED TREES.

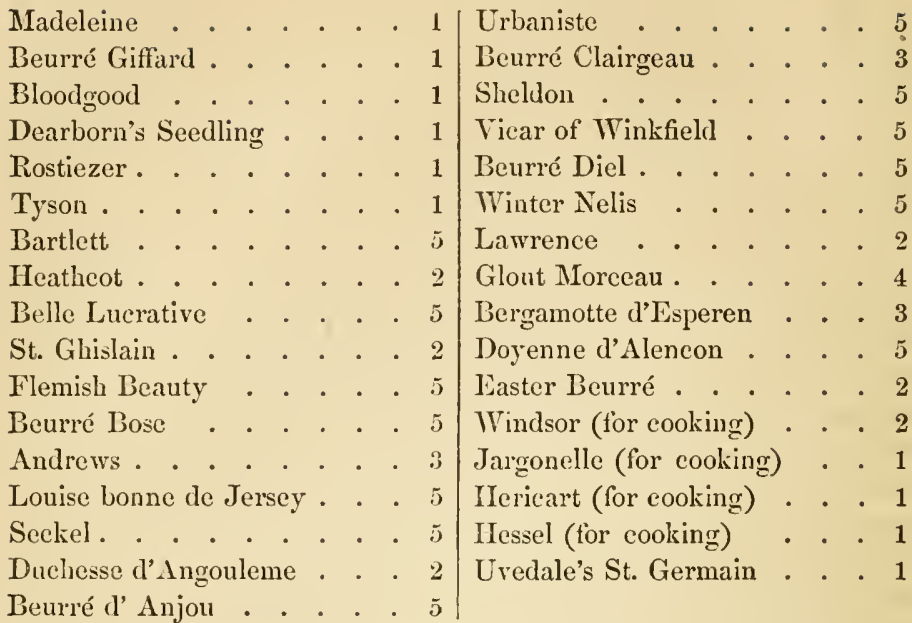

BEST FOR ONE THOUSAND TREES.

\begin{tabular}{|c|c|c|c|c|c|c|c|}
\hline ine & & & & & & & \\
\hline Beurré Giffard & . & . & . & . 10 & Beurré Clairgeau & . & \\
\hline$d$ & & & & 5 & Sheldon. & & \\
\hline n's Seedl & ing. & & & 5 & Vicar of Winkfield . & & \\
\hline $\mathrm{er}$ & & & & 5 & Diel . . . & & \\
\hline yson . & & & & 5 & Winter Nelis . . . & & \\
\hline $\mathrm{t} .$. & 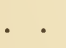 & & & .100 & nee . . . & & \\
\hline ot . & . & & . & . 20 & orceau & & \\
\hline crative & . & & & . 25 & tte d'Esperen & & \\
\hline in & & & & . 20 & d'Alencon. & & \\
\hline Beauty & & & & 50 & 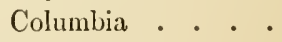 & & \\
\hline 3ose & & & & . 50 & eurré. & & \\
\hline 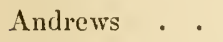 & & & & 20 & . . . & & \\
\hline onne de & & & & 50 & He . . & & \\
\hline & & & & . 50 & Ilericart. . . & & \\
\hline d'Ango & & & & . 10 & & & \\
\hline euré d'Anjou & & & & . 50 & Uvedale's St. Germ & & \\
\hline
\end{tabular}

BRST TWELVE VARIETIES ON QUINCE STOCK.

Rostiezer,

Belle Lucrative,
Beurre d'Anjou,

Beurré Diel, 
Duchesse d'Angonleme, Louise bonne de Jersey, Vicar of Winkfield, Bergamotte d'Esperen,
Glout Morceau, Doyenne d'Ete, Doyenne d'Alencon, Easter Beurré.

\section{FOR ONE HCXDRED TREES.}

Doyenne d'Ete . . . . . 3 Louise bonne de Jersey . . 10

Rostiezer. . . . . . . 3 Urbaniste . . . . . . 5

Bartlett . . . . . . 5 Beurré d'Anjou . . . . 10

Duchesse d'Angouleme . . . 5 Vicar of Winkfield . . . . 5

Bon d'Ezee . . . . . . . 2 Beurré Diel . . . . . . 5

Belle Lucrative . . . . 5 Columbia . . . . . . . 3

Beurré Superfin . . . . 2 Glout Morceau . . . . . 5

Andrews . . . . . . 2 Benrré Langelier . . . . 3

Stevens' Genesee . . . . 2 Bergamotte d'Esperen . . . 3

Henry IV. . . . . . . . 2 Doyenne d'Alencon . . . . 2

Doyenne Boussock . . . . $3 \mid$ Easter Beurré . . . . . . 1

Kirtland's Beurré . . . . . 2 Catillae . . . . . . . . 2

Buffum . . . . . . . 2 Uvedale's St. Germain . . 2

Kingsessing . . . . . . 2 Epine Dumas . . . . . . 2

Flemish Beauty . . . . 2

FOR ONE THOUSAND TREES.

Doyenne d'Ete . . . . . $10 \mid$ Louise bonne de Jersey . . 100

Rostiezer . . . . . 10 Urbaniste . . . . . 50

Bartlett . . . . . . 35 Beurré d'Anjou . . . . 75

Duchesse d'Angouleme . . 100 Vicar of Winkfield . . . . 75

Bon d'Ezee . . . . . 25 Beurré Diel . . . . 65

Belle Lucrative . . . . 25 Columbia . . . . . . 50

Beurré Superfin . . . 25 Glout Moreeau . . . . 75

Andrews . . . . . 25 Beurré Langelier . . . 25

Sterens' Genesee . . . . 25 Bergamotte d'Esperen . . . 30

Henry IV. . . . . . . . 5 Doyenne d'Alencon . . . 25

Doyenne Boussock . . . 25 Easter Beurré . . . . . 10

Kirtland's Beurré . . . 10 Catillac . . . . . . 10

Buffum . . . . . . 25 Uvedale's St. Germain . . 10

Kingsessing . . . . 10 Epine Dumas . . . . 20

Flemish Beauty . . . 25

beSt Six VARIETIES OF PEAChes.

Farly Newington, Early Crawford, Late Crawford,
George IV., Old Mixon Free, Morris' White. 
FOR BEST TWELVE ADD :

Early York,

Old Mixon Cling,

Noblesse,
Grosse Mignonne,

Late Heath,

Royal George.

\section{FOR PENNSYLVANIA.}

BEST SIX VARIETIES OF APPLES FOR ONE HUNDRED TREES.

Larly Harvest . . . . . 5 Baldwin . . . . . . 20

Fallawater . . . . . 20 Smoke House . . . . . 25

Townsend . . . . . 10 Golden Russet of Mass. . . 20

BEST TWELVE.

Early Harrest . . . . . 2 Baldwin . . . . . . . 15

Jeffries . . . . . . 3 Lady . . . . . . . 10

R. I. Greening . . . . . 10 Benoni . . . . . . 2

Roman Stem . . . . 10 Smoke House . . . . . 20

Townsend . . . . . 4 American Golden Russet . 10

Holland Pippin . . . . . . 4 English Golden Russet . . 10

BEST TWENTY.

Knowles' Early . . . . 1 | Fallawater . . . . . 10

Benoni . . . . . . 1 American Golden Russet . 5

Maiden Blush . . . . . . 4 Smith's Cider . . . . . 5

Rambo . . . . . . 5 English Golden Riusset . . 10

Baldwin . . . . . . 6 Townsend . . . . . 3

Wine Sap . . . . . . 5 Jeffries . . . . . . 2

Pennoch . . . . . . 5 Smoke House . . . . 15

Early Ilarvest . . . . . 2 Paradise . . . . . . 5

American Summer Pearmain . 2 Roman Stem . . . . . 5

Ilolland Pippin . . . . . 4 Ailes . . . . . . . . 5

BEST FOR ONE THOUGAND TREES.

Early Redstreak . . . . 25|Lady . . . . . . . 100

Maiden Blush. . . . . . 25 American Summer Pearmain 25

Smith's Cider . . . . 100 Fallawater . . . . . 100

Townsend . . . . . 25 Golden Russet . . . 100

Smoke House . . . . . . 500 
BEST SIX VARIETIES OF PEARS ON PEAR STOCK.

Beurré Giffard . . . . . . $5 \mid$ Seckel . . . . . . . . 15

Bartlett . . . . . . 10 Belle Luerative . . . . 10

Tyson . . . . . . . 10 Lawrence . . . . . . 10

BEST TWELVE VARIETIES FOR ONE THOUSAND TREES.

Doyenne d'Ete . . . . . $25 \mid$ Belle Lucrative . . . . 50

Rostiezer . . . . . . 25 Duchesse de Brabant . . 25

Washington . . . . . 25 Tyson . . . . . . 50

Seckel . . . . . . 100 Bartlett . . . . . . 500

Beurré Giffard . . . . 50 Beurré Bose . . . . 25

St. Ghislain . . . . 25 Lawrence . . . . 100

BEST SIX VARIETIES OF PEARS ON QUINCE STOCK.

Rostiezer,

Louise bonne de Jersey,

Brandywine,
Duchesse d'Angouleme, Belle Luerative, Glout Moreeau.

BEST SIX VARIETIES OF PEACHES FOR ONE HUNDRED TREES.

Troth's Early Red. . . . . $15 \mid$ Ward's Late Free . • • . 20

George IV. . . . . . . . 15 Coolidge's Favorite . . . . 10

Large Early York . . . . 20 Molden White . . . . . 20

BEST TWELVE VARIETIES FOR ONE THOUSAND TREES.

Troth's Early Rerl . . . 150 Crawford's Late . . . . 100

Coolidge's Favorite . . . . 50 Warl's Late Free . . . 100

Old Mixon Free . . . . . 25 Red Rareripe . . . . . 50

Molden White . . . . 100 Morris'White . . . . 25

Large Early York . . . 200 Druid Hill . . . . . . 50

George IV. . . . . . 50 Late Heath . . . . 100

\section{SOUTHERN STATES.}

\section{FOR VIRGINIA.}

BEST YARIETIES OF APPLES FOR ONE HUNDRED TREES,

Mary . . . . . . . 5 | Red Cathead . . . . . 5

Stripe June . . . . . . . 5 Brooke's Pippin . . . . 10

Carter. . . . . . . 5 Holady's Seedling. . . . 10 
Summer Golden Pippin . • . 5 Rawle's Janetting • . . . . 10

Porter. . . . . . . 5 Northern Spy . . . . . 5

Baltimore Pippin . . . . . 5 Wine Sap . . . . . . 10

Robey's Seedling . . . . . 5 Limber Twig . . . . . 10

Winter Cheese . . . . . . 5

BEST FOR ONE THOUSAND TREES.

Mary ... . . . . . . $20 \mid$ Brook's Pippin . . . . . 50

Stripe June . . . . . . 20 Holady's Seedling . . . . 50

Carter . . . . . . . 20 Rawle's Janetting . . . . 50

Summer Golden Pippin . . . 20 . Northern Spy . . . . . 50

Benoni . . . . . . 20 Wine Sap . . . . .50

Spice . . . . . . . 20 Limber Twig . . . . 50

Porter. . . . . . . 20 Waugh's Crab . . . . 50

Red Cathead . . . . 20 Strawn's Seedling. . . . 50

Baltimore Pippin . . . . 20 Welford's Yellow . . . . 50

Robey's Seedling . . . . 20 Oglesby . . . . . . 50

Robertson's White . . . 20 Milan . . . . . . .50

Y'ellow Bellefleur . . . . . 20 Long Island Russet . . . . 50

Bowling's Sweet . . . . 10 Nicker Jack . . . . . 50

Winter Cheese . . . . . $50 /$ Calasaga . . . . . .50

BEST TWENTY VARIETIES OF PEARS ON PEAR STOCK FOR ONE HUNDRED TREES.

Bartlett,

Julienne,

Beurré d'Amaulis,

White Doyenne,

Nouveau Poiteau,

Seekel,

Viear of Winkfield,

Hawes' Winter,

Taylor's Winter,

Lawrenee,
Catinka,

Nadeleine,

Belle Luerative,

Tyson,

Benrré Diel,

Oswego Beurré,

Urbaniste,

Flemish Beauty,

Winter Nelis,

Buffum.

BEST TWENTY VARIETIES OF PLARS ON QUINCE STOCK

Madeleine,

Julienne,

White Doyenne,

Belle Lucrative,

Bartlett,
Seekel,

Viear of Winkfield,

Beurré Easter,

Glont Morceau,

Lawrence, 
Rouselet de Stutgart,

Beurré Diel,

Duchesse d'Angouleme,

Oswego Beurré,

Lonise bonne de Jersey,
Taylor's Virginia, Winter Nelis, Bezi de la Motte, Beurré Clairgeau.

2. FOR GEORGIA.

BEST SEVENTEEN VARIETIES OF APPLES FOR ONE HUNDRED TREES.

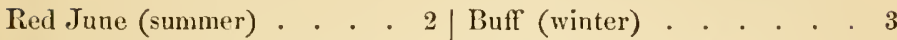

Cane Creek Sweet (s!ımmer) • 2 Camak's (winter sweet) . . 10

Julien (summer) . . . . . 2 Calasaga (winter) . . . . 5

Sweet Paradise (summer) . . 2 Cullawkee . . . . . . 3

Bachelor (autumn) . . . 8 Equinetley (winter) . . . 20

Disharoon (autuun) . . . 4 Hoover (winter) . . . . 10

Chistalee (autumn, for cooking) 2 Maverick's Sweet (winter) • 10

Rome Beauty (autumn) . . 2 Nickerjack (winter) . . . . 9

Berry (winter) . . . . 6

BEST TWLLVE.

Red June (summer) . . . . $2 /$ Nickerjack (winter) . . . 10

Julien (summer) . . . . . 2 Equinetley (winter) . . . 20

Cane Creek Sweet (summer) . 2 Canak's (winter sweet) . . . 20

Bachelor (autumn) . . . 10 Calasaga (winter) . . . 10

Disharoon (autumn) . . . 5 Junaluskee (winter) . . . 10

Rome Beauty (autumn) . . . $5 /$ Winter Queen (winter). . . 4

BEST EIX.

Julien . . . . . . . 6 | Equinetley . . . . . 26

Bachelor . . . . . . 6 Camak's Sweet . . . . 26

Nickerjack . . . . . 26 Hoover . . . . . . 10

BEST SIX VARIETIES OF PEARS ON PEAR STOCK.

Doyenne d'Ete,

Beurré Bosc,

Bartlett,
Winter Nelis,

Seckel,

Beurré Gris d’ Hiver nouveau. 
FOR BEST TWELVE ADD:

Bloodgood,

Sterling,

Belle Lucrative,
White Doyenne,

Lawrence,

Compte de Flanders.

BEST SIA VARIETIES OF PEARS ON QUINCE STOCE.

Doyenne d'Ete,

Duchesse de Berri d'Ete,

Louise bonne de Jersey,
Glout Morceaul,

Duchesse d'Angouleme,

Easter Beurré.

FOI BEST TWELVE ADD:

Beurré Diel,

Rostiezer,

Soldat Laboreur,
Lawrence,

White Doyenne,

Belle Epine Dumas.

FOR AN ORCHARD OF ONE HUNDIED OR ONE TIOUSAND TREES, WITH THE ABOVE ALSO INCLUDE :

Buffum,

Manning's Elizabeth,

Camok's,

Beurré d'Anjou,

Delices d'Harden pont,

Columbia,

Flemish Beauty,

Beurré Langelier,

Neighbors,
Van Asche,

Beurré Clairgeau,

Henry IV.,

Tyson,

Heatheot,

Kirtland,

Rivers' Winter Beurré,

Sheldon.

\section{BEST SIX VARIETIES OF PEACHEg.}

Early Tillotson,

Stump the World,

Heath Cling,
Large Early Tork,

La Grange,

Bough.

FOR BEST TWELVE ADD:

Serrate Ispahan,

Washington Rareripe (of Parsons),

Washington Cling,
Chinese Cling,

Elwards' Late White, IIull's Athenian. 
FOr AN ORCHARD OF ONE HUNDIED OR ONE THOUSAXD TREES, WE SHOULD ADD TO THE AEOTE, OF CLINGSTONES:

Georgia Cling,

Tippecanoe,

Large White Cling,

Donohue,
Old Miron Cling, IIorton's Delicious, Blonton.

OF FREESTONES:

Serrate Early York, Druid Hill, Van Zandt's Superb, Smock Free, Fay's Early Ann, Montgomery's Late, Coolidge's Favorite,
Harker's Seedling, Crawford's Early, Camok's Serrate, Crawford's Late, Lady Perham, Late Admirable, Baldwin's Late.

FOR SHIPPING:

Early Tillotson, Fay's Early Ann, Columbus June,

Heath Cling.
Early Chelmsford, Crawford's Early.
FOR DRYIXg:

\section{FOR MIISSISSIPPI.}

BEST SIX FARIETIES OF APPLES FOR OXE HUNDIED TREES.

Carolina Red June . . . 10 , Camenser . . . . . . 10

Horse Apple . . . . . 10 Shockley . . . . . . 20

Summer Red . . . . . 10 Poole . . . . . . . 40

BEST TWELFE.

\begin{tabular}{|c|c|c|c|c|c|c|c|c|c|c|}
\hline & & & & 5 & er & & & & & \\
\hline arolina June & . & . & & 5 & Sweet Russet & 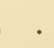 & & & & \\
\hline Innt & & & & 5 & Colley. . & & & & & \\
\hline Iorse Apple & & & & 5 & $\mathrm{Co}$ & . & & & & \\
\hline & & & & 5 & Shockley & . & & & & \\
\hline ov & & & & & Poole & & & & & \\
\hline
\end{tabular}


BEST TWENTY.

\begin{tabular}{|c|c|c|c|c|c|c|c|c|c|c|c|}
\hline May & & & & & 2 & Wonder & & - & & & \\
\hline Carolina June & & & & & 4 & Camenser. & - & . & & & \\
\hline Red Astrachan & & & & & 2 & Sweet Russet & . & . & . & & \\
\hline Sweet Bough & & & & & 2 & Fall Pippin . & . & . & 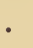 & & \\
\hline John Hunt & & • & & & 4 & Buff & • & . & - & & \\
\hline Horse Apple & & & & & 3 & Carter. & • & - & • & & \\
\hline Summer Red & & & & & 3 & Colley . . & . & . & & & \\
\hline Covington & & & & & 4 & Cooner . & . & . & & & \\
\hline Summer Pearmai & & & & & 4 & Poole . . & . & . & • & & \\
\hline ulian . . . & & & & & 4 & Shockley . & . & . & - & & \\
\hline
\end{tabular}

BEST VARIETIES FOR ONE THOUSAND TREES.

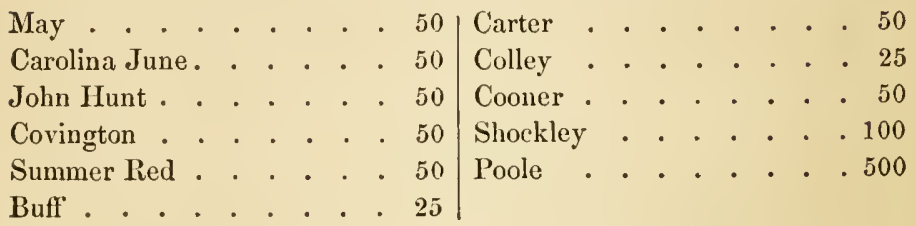

BEST SIX VARIETIES OF PEARS ON PEAR STOCK.

Madeleine,

Belle Lucrative,

Dearborn's Seedling,
Beurré Diel,

Bartlett,

Winter Nelis.

FOR BEST TWELVE ADD:

Bloodgood,

Seckel,

White Doyenne,
Rostiezer,

'Tyson,

Doyenne d'Alencon.

FOR ONE HUNDRED TREES.

Madeleine . . . . . . 5

Doyenne d'Ete . . . . 5

Beurré Giffard . . . . . 5

Bloodgood . . . . . . 5

Dearbon's Seedling . . . 5

Julienne . . . . . . . 5

Golden Beurré . . . . . 5

Bartlett . . . . . 5
White Doyenne $\cdot$. . . . 5

Seckel . . . . . . . 5

Belle Luerative . . . . 5

Beurré d'Anjou . . . . . 5

Doyenne d'Alencon . . . 20

Beurré Diel . . . . . . 10

Winter Nelis . . . 10 
FOR ONE THOUSAND TREES.

Madeleine . . . . . $100 \mid$ Flemish Beauty . . . . 50

Doyenne d'Ete . . . . 50 Seckel . . . . . . . 25

Beurré Giffard . . . 100 White Doyenne . . . . 25

Bloodgood . . . . . . 25 Belle Lucrative . . . . 25

Dearborn's Seedling . . 25 Beurré Diel . . . . 100

English Jargonelle . . . 25 Doyenne d'Alencon . . . 50

Rostiezer . . . . . 25 Winter Nelis . . . . 100

Tyson ". . . . . . 25 Beurré d'Anjou . . . 25

Washington . . . . . 25 Kirtland's Beurré . . . 25

Golden Beurré . . . . 25 Julienne . . . . . 50

Bartlett . . . . . 100

BEST SIX VARIETLES OF PEARS ON QUINCE STOCK.

Beurré Giffard,

Duchesse d'Angouleme,

Tyson,

Beurré Diel,

Rostiezer,

Easter Beurré.

FOR BEST TWELVE ADD:

Seckel,

Louise bonne de Jersey,

Glout Morceau,

Bartlett,

Belle Luerative,

White Doyenne

BEST VARIETIES OF PEACHES FOR ONE HUNDRED TREES.

Early Tillotson . . . . . $20 \mid$ Van Zandt's Superb . . . 4

Coolidge's Favorite . . . 10 Lagrange . . . . . . 4

Crawford's Early . . . . 10 Columbia . . . . . . 2

George IV. . . . . . 5 Ray . . . . . . . . 4

Royal George . . . . . 5 Bermuda Cling . . . 4

Grosse Mlignonne . . . . . 4 Heath . . . . . . . . 4

Skinner's Superb . . . . . 4 Hubbard Cling . . . . . . 4

Lovejoy Cling . . . . . 4 Burford's October Cling . . 4

De Soto Cling . . . . . 4 Baldwin's Late . . . . . 4

\section{THE WESTERN STATES.}

\section{FOR KENTUCKY.}

BEST SIX VARIETIES OF APPLES FOR ONE HUNDRED TREES.

Early Harvest . . . . . . 5 Small Romanite . . . . . 10

Maiden Blush . . . . . . 5 |Wine Sap . . . . . . 30

Rambo . . . . . . $10 /$ Rawle's Janet . . . . .46 
BEST TWELVE.

Early Harvest . . . . . . 5 Yellow Bellefleur . . . . . 4

Maiclen Blush . . . . . . 5 Milan . . . . . . . 15

Carolina Red June . . . . 3 Wine Sap . . . . . . . 15

American Summer Pearmain . 3 New York Pippin . . . 15

Rambo . . . . . . 5 Small Romanite . . . 10

Pennsylvania Red Streak . . $5 /$ Rawle's Janet . . . . . 15

IBEST TWENTS.

White Juneating . . . . 2 1 Yellow Bellefleur . . . . . 3

Early Harvest . . . . . . 5 Milan . . . . . . . . 2

Carolina Red June . . . . 3 New York Pippin . . . . 10

Black's Annette . . . . . 2 Wine Sap . . . . . 10

Fenley . . . . . . 3 Red Winter Sweet . . . 5

American Summer Pearmain . 3 Pryor's lied. . . . . . 2

Maiden Blush . . . . . . 5 Newtown Pippin . . . . 5

Fall Queen . . . . . . 3 liawle's Janet . . . . 20

Rambo . . . . . . 5 Small Romanite . . . . 5

Pennsylvania Red Streak . . $3 /$ Carolina . . . . . . 4

BEST FOR ONE THOUSAND TREES.

Early Harvest . . . . $100 \mid$ Pennsylvania Red Streak . . 50

Carolina Red June . . . . 100 Wine Sap . . . . . . 100

Maiden Blush . . . . . 50 New York Pippin . . . 150

Red Astrachan . . . . . 50 Rawle's Janet . . . . . 200

Fenley . . . . . . . 50 Carolina. . . . . 100

Fall Pipipin . . . . . . 50

Best VATIETIES OE PEARS ON PEAT. STOCK.

Madeleine,

Bloodgood,

Tyson,

Bartlett,

Seckel,

Buffum, •

Belle Lucrative, White Doyenne,

Flemish Beauty.

BEST VARIETIES OF PEARS ON QUINCE STOCK.

Duchesse d'Angouleme,

Belle Lucrative,

White Doyenne,
Louise boune de Jersey, Tyson, Seckel. 
BEST VARIETIES OF PEACHES.

Early Tillotson,

Crawford's Early,

Old Mixon,

Crawford's Late,

Grand Admirable,

Large White Heath, Hill's Superb Jersey,

Leopold,

Early lied Rareripe,

Royal George,

Malta,
New York Cling,

Van Zandt's Superb,

Catharine,

Columbia,

Freestone Heath,

Smoek's Late,

Druid Hill,

Tippecanoe,

George IV.,

Hobbs' Seedling.

2. FOR NORTHERN OHIO.

BEST SIX VARIETIES OF APPLES FOR ONE HUNDRED TREES,

Yellow Harvest . . . . . 10 R. I. Greening . . . . . . 25

Garden Royal . . . . . . 5 Baldwin . . . . . . . 25

Belmont . . . . . . $25 /$ Rambo . . . . . . 10

BLST TWELVE.

Garden Royal . . . . . 3 Early Harvest . . . . . 5

Belmont . . . . . . 15 R. I. Greening . . . . . 15

Baldwin . . . . . . 17 liambo . . . . . 10

Red Canada. . . . . . . 10 Red Astrachan . . . . . .4

Myers' Nonpareil . . . . 5 Sweet Bough . . . . . 3

Jersey Sweet . . . . . $3 /$ Wine Sap . . . . . 10

BEST TWENTY.

Garden Royal . . . . . . 2 Esopus Spitzenberg . . . . 5

Belmont . . . . . . 10 Early Harvest . . . . . 3

Baldwin . . . . . . 10 R. I. Greening . . . . 10

Red Canada. . . . . . 5 Rambo . . . . . . 10

Myers' Nonpareil . . . . 4 lied Astrachan . . . . . 3

Jersey Sweet . . . . . 3 Sweet Bough . . . . . . 2

Fall Pippin . . . . . . . 3 Wine Sap . . . . . . 5

Westfield Seeknofurther . . 5 American Summer Pearmain . 2

Coggswell . . . . . . . 5 Swaar . . . . . . . . 5

Paradise Winter Sweet . . . $3 /$ Lady Apple . . . . . . . 5 
FOR THE MARKET.

Letofsky . . . . . . 5 Maiden Blush . . . . . . 5

Red Astrachan. . . . . 5 Baldwin . . . . . . 20

Early Harvest . . . . . . 5 R. I. Greening . . . . . 20

Duchesse of Aldenburgh . . . 5 Rambo . . . . . . . 20

Myers' Nonpareil . . . . 5 Wine Sap . . . . . 10

BEST SIX YARIETIES OF PEARS ON PEAR STOCK.

Zoar Beauty,

Bartlett,

Kirtland,
Beurré Bose,

Flemish Beauty,

Winter Nelis.

FOR BEST TWELVE ADD:

Beurré d'Anjou,

Washington,

Stevens' Genesee,
Ananas d'Ete,

Seckel,

Nonvean Poiteau.

BEST TWELVE VARIETIES OF PEARS ON QUINCE STOCK.

Beurré Giffard,

White Doyenne,

Louise bonne de Jersey,

Urbaniste,

Jalousie de Fontenay Vandee, Kirtland,
Beurré d'Anjou, Stevens' Genesee, Nouveau Poiteau.

Zoar Beauty, Belle Lucrative, Bon Chretien Fondante.

FOR THE MAIKET.

Louise bonne de Jersey, Bartlett,

Duchesse d'Angouleme, Beurré d'Anjou

BEST TWELVE VARIETIES OF PEACHES.

Early York,

Coolidge's Favorite, Sturtevant,

Grosse Mignonne,

Large Early York, Old Mixon Free,
Old Mixon Cling, Ward's Late Free, Yellow Rareripe, IIyslop's Cling, Crawford's Early, Crawford's Late. 
BEST FOR ONE HUNDRED TREES, AND THE SAME PROPORTION FOR ONE THOUSAND.

Hale's Early . . . . . . $20 \mid$ Yellow Rareripe . . . . . 20

Crawford's Early . . . . 20 Ward's Late Free . . . 10

Crawford's Late . . . . $20 /$ Hyslop's Cling . . . . . 10

\section{FOR CENTRAL OHIO.}

BEST SIX VARIETIES OF APPLES FOR ONE HUNDRED TREES.

Benoni

Maiden Blush . . . . . 10 Smith's Cider . . . . . 20

Belmont . . . . . . 10 White Pippin . . . . 25

BEST TWELVE.

Farly Harvest . . . . . . 2| Fallawater . . . . . 10

Benoni . . . . . . 6 Rome Beauty . . . . 10

Maiden Blush . . . . . . 6 Smith's Cider . . . . . 12

Ohio Nonpareil. . . . . 6 Newtown Spitzenberg • • 8

Rambo . . . . . . 10 Baldwin . . . . . . 12

Talman's Sweet . . . . . $6 /$ White Pippin . . . . . 12

BEST TWENTT.

Early Harrest . . . . . . $2 \mid$ Talman's Sweet . . . . . 3

Benoni . . . . . . . . 3 Peck's Pleasant. . . . . 3

Early Strawberry . . . . . 3 Rome Beauty . . . . . . 10

Red Astrachan . . . . . 3 Fallawater . . . . . . 10

Golden Sweet . . . . . 2 Smitl's Cider . . . . 10

Maiden Blush . . . . . 4 Newtown Spitzenberg . . 3

Fall Pippin . . . . . . 2 Baldwin . . . . . . 6

Chio Nonpareil . . . . 4 Yellow Bellefleur . . . . 6

Belmont . . . . . . 4 White Pippin . . . . 10

Rambo . . . . . . 4 Wine Sap . . . . . 8

BEST SIX VARIETIES OF PEARS ON PEAR STOCK.

Madeleine,

Bartlett,

Flemish Beauty,

White Doyenne,

Seckel,

Lawrence.

FOR, BEST TWELVE ADD:

Bloodgood,

Belle Lucrative, Buffum,
Louise bonne de Jersey,

Kirtland,

Doyenne d'Alencon. 
FOR MARKET.

Madeleine,

Doyenne d'Ete,

Bloodgood,

Bartlett,
Flemish Bèuty,

Louise bonne de Jersey

White Doyenne,

Seekel.

BEST SIX VARIETIES OF PEARS ON QUINCE STOCK.

Doyenne d'Ete,

Belle Luerative,

White Doyenne,
Louise bonne de Jersey, Duchesse d'Angouleme, Doyenne d'Alencon.

FOR REST TWELVE ADD:

Bartlett,

Rostiezer,

Kirtland,
Buffum,

Beurré Superfin,

Beurré d'Anjou.

BEST TWELVE VARIETIES OF PEACHES FOR ONE HUNDRED TREES.

Iale's Early . . . . . $10 \mid$ Old Mixon Free . . . 10

Early York . . . . . . 8 Smock's Free . . . . . . 8

Coolidge's Favorite . . . . 8 Crawford's Late . . . . . 12

Yellow Alberge . . . . . 8 Old Mixon Cling . . . . . 12

Large Early York . . . 8 Lemon Cling . . . . . 3

Crawford's Early . . . . 12 Ward's Late Free . . . . . 3

\section{FOR SOUTHERN OHIO.}

BEST SIX VARIETIES OF APPLES FOR ONE HUNDRED TREES.

Early Harvest . . . . . . 5 Yellow Bellefleur . . . . 25

Benoni . . . . . . 5 Jonathan . . . . . 25

Fall Pippin . . . . . 15 Cannon Pearmain . . . 25

BEST TWELVE.

Early Harvest . . . . . . 5 Rambo . . . . . . . 5

Red $\Lambda$ strachan . . . . . . 5 Yellow Bellefleur . . . . 10

Benoni . . . . . . 5 Broadwell . . . . . 10

Fall Wine . . . . . . 5 Jonathan . . . . . . 15

Aslmore . . . . . . . . 5 Rawle's Janet . . . . . 15

Maiden Blush . . . . . . 5 Cannon Pearmain . . . . 15 
BEST TWENTY.

Early Harvest . . . . . $3 /$ Ameriean Golden Russet . . 3

Red Astrachan . . . . . 3 English Golden Russet . . . 5

Benoni . . . . . . 3 Pomme Gris . . . . . 5

Ashmore . . . . . . . 4 Broadwell . . . . . . 5

Fall Pippin . . . . . . 5 White Winter Pearmain . . 5

Maiden Blush . . . . . 5 Wine Sap . . . . . 10

Fall Wine . . . . . 3 Rawl's Janet . . . . . 8

Yellow Bellefleur . . . . . 8 Newtown Pippin . . . . . 8

Ortley . . . . . . 4 Cannon Pearmain. . . . 8

Fall Queen . . . . . 5

BEST SIX VARIETIES OF PEARSON PEAR STOCK.

Early Catharine,

Bloodgood Julienne,

Bartlett,
Seckel,

Glout Moreeau,

Passe Colmar.

FOR BEST TWELTE ADD:

Early Butler,

Golden Beurré,

Flemish Beauty,
Onondaga,

Beurré Diel,

Dix.

BEST SIX VARYETIES OF PEARS ON QUIXCE STOCK.

Doyenne d'Ete,

Bloodgood,

Tyson,
Seekel,

Lonise bonne de Jersey,

Vicar of Winkfield.

FOR TEST TWELTE ADD:

Poire des Nonnes,
Onondaga,
Buffum,

Lawrence,

Napoleon,

Soldat Laboreur.

BEST SIX VARIETIES OF PEACHES.

Large Early York,

George IV.,

Crawford's Early,
Old Mixon Free, Rodman's Red, IIeath Cling.

FOR BEST TWELVE ADD:

Coolidge's Favorite, Serrate Early Iork, Columbia,
Ward's Late Free, Grande Admirable, Heatlı Free. 


\section{FOR ILLINOIS.}

BEST SIX VATIETIES OF APPLES FOR ONE HUNDRED TREES.

Red June (summer) . . . . 10 Donine (winter) . . . . 20

Summer Pennock (summer) . 10 TVagner (winter) . . . . . 20

Snow (fall) . . . . . $15 \mid$ Willow Twig (winter) . . 25

\section{BEST TWELVE.}

Red June (sunmer) . . . . $10 \mid$ Domine (winter) . . . . . 15

Sops of TVine (summer) . . . 5 Wagner (winter) . . . . 15

Summer Pennock (summer) $\quad 10$ Willow Twig (winter) • . . 15

Tompkins (autumn) . . . 5 White Bellefleur (winter) . . 5

Snow (autumn) • . . . 5 Yellow Bellefleur (winter) . 5

Cloth of Gold (autumn) . . . 5 New York Pippin (winter). . 5

\section{BEST TWENTY.}

Red June (summer) . • . . $5 \mid$ Sweet Wine (autumn) . . . 2

Sops of Wine (summer) • . 2 Cloth of Gold (autumn) . . . 2

Summer Pennock (summer) . 5 Domine (winter) . . . . 10

lied Astrachan (summer) . . 3 Wagner (winter) . . . . . 10

Cooper's Early White (summer) 2 Willow Twig (winter) • . . 10

Leicester Sweeting (summer) . 2 White IBellefleur (winter) • . 2

Tompkins (autumn) . . . 3 Yellow Bellefleur (winter) . 2

Snow (autumu) . . . . . 5 New York Pippin (winter) . 10

Fall Wine (autumn) . . . . 2 Red Seeknofurther (winter) $\quad 10$

Hawley (antumn) . . . $3 /$ Swaar (winter) . . . 10

BEST VARIETIES FOR MARKET, FOR ONE THOUSAND TREES.

Red June (summer) • • . $200 \mid$ Wagner (winter) • • . 150

Summer Pennock (summer) . 100 Willow Twig (winter) • . . 200

Snow (autumn) . . . . 50 New York Pippin(winter) . 200

Domine (winter) . . . . 100

\section{FOR MICHIGAN.}

BEST SIX VARIETILS OF APPLES FOR ONE MUNDRED TREES.

Early IIarvest . . . . . 5| Fall Pippin . . . . . 20

Red Astrachan . . . . . . 5 R. I. Greening . . . . . 30

Michigan Golden Pippin . 10 Red Canada. . . . . 30 
BEST TIVELVE.

Early Ilarvest . . . . . . $3 \mid$ Fall Pippin . . . . . . . 5

Red Astrachan . . . . . . 3 Yellow Bellefleur . . . . . 5

Large Yellow Bough . . . . 2 R. I. Greening . . . . 10

Miehigan Golden Pippin . . 4 Roxbury Russet . . . . . 20

Gravenstein . . . . . . 4 Red Canada . . . . . 30

Keswick Codlin . . . . . 4 Ladies' Sweeting . . . . 10

BEST TWENTY.

Early Harrest . . . . . . $3 \mid$ Belmont . . . . . . . . 2

Red Astrachan . . . . . . 2 Yellow Bellefleur . . . . . 5

Large Yellow Bough . . . . 2 Roxbury Russet . . . . . 10

Early Joe . . . . . . . 2 R. I. Greening . . . . 10

Ameriean Summer Pearmain . 3 Esopus Spitzenberg . . . . 5

Gravenstein . . . . . . 3

Fall Pippin . . . . . . 2

Pomme de Neige . . . . . 2

Vandevere . . . . . . 4

Hubbardston . . . . . $5 /$ Red Canada . . . . . 20

BEST FOI ONE THOUSAND TREES WHERE THE MARKET IS NEAL.

Early IIarvest. . . . . . $25 \mid$ Hubbardston . . . . . 50

Red Astrachan. . . . 25 Vandevere . . . . . 50

Sweet Bough . . . . 25 R. I. Greening . . . 100

Miehigan Golden Pippin . . 25 Baldwin. . . . . . 50

Gravenstein . . . . 50 Jonathan . . . . . 50

Fall Pippin . . . . . . 50 Roxbury Russet . . . . 150

Talman's Sweet . . . 25 Red Canada . . . . 300

Ladies' Sweeting . . . . 25

DEST WHERE THE MARKET IS REMOTE.

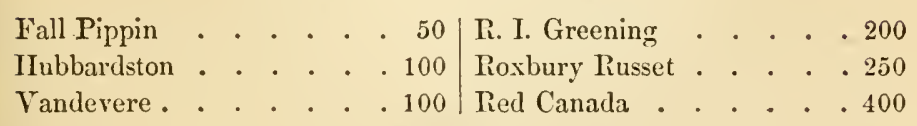

BEST SIX VARIETIES OF TEARS ON PEAR STOCK FOR ONE HUNDRED TREES.

Bloodgood . . . . . . $5 \mid$ Onondaga . . . . . . 15

Bartlett . . . . . . . 20 White Doyenne . . . . 25

Belle Lucrative . . . . $10 \mid$ Winter Nelis . . . . . 25 


\section{BEST TWELVE.}

Macleleine . . . . . 3, Flemish Beauty . . . 6

Bloodgood . . . . . . 3 Onondaga . . . . . 10

Rostiezer . . . . . 3 White Doyenne . . . . 20

Sterling . . . . . . 5 Oswego . . . . . . 5

Bartlett . . . . . . 10 Lawrence . . . . . 15

Belle Lucrative . . . . . 5 Tinter Nelis . . . . . . 15

BEST VARIETIES ON QUIXCE STOCK.

Belle Lucrative,

Vicar of Winkfielk,

Louise bonne de Jersey,

Beurré Diel,
Duchesse d'Angouleme,

Glout Morceau,

Doyenne d'Alencon.

BEST SIX VARIETIES OF PEACHES FOR ONE HUXDRED TREES.

Serrate Early York . . . . 5 Early Slocum . . . . . 10

Coolidge's Farorite . . . 15 Early Crawford . . . . 25

Barnard's Seedling . . . 20 Late Crawford . . . . . 25

DLST TWELVE.

Serrate Early York . . . 5 5 Early Slocum . . . . 10

Coolidge's Favorite . . . . 5 Thite Imperial $\bullet . . .55$

Barnard's Seedling . . . 10 Early Crawford . . . . 15

Large Early York. . . . . 5 Late Red Rareripe . . . 5

Jacques Rareripe . . . . . 10 Old Mixon Free . . . 10

Poole's Late Yellow . . . 10 Crawford's Late . . . . . 10

FOR TRANSPOR'TATION TO NORTHERN MAREETS.

Barnarl's Seedling . . . $300 \mid$ Crawford's Early . . . . 400 White Imperial . . . . $100 /$ Crawford's Late . . . . 200

It is very evident, to one who considers the difference in these lists for the various portions of the country, that it would be impossible for a nurseryman to have them all in his possession. Some varieties are confined to very limited districts, and the demand for them is not sufficient to warrant his 
keeping a stock; others are of such poor growth from the bud, that it is difficult to procure a good tree, and the proportion of them which would be salable would be small. Therefore the producer is obliged to limit his attention to a few stronggrowing varieties. When this is the case, the cultivator should plant these, and graft after one season's growth. This will not postpone their bearing, as he might expect; but it is a great question whether it is not better to obtain strong trees, and graft upon them those which are weaker, than to procure them immediately from the bud. 


\section{CHAP'TER VIII.}

SELECTION, ARRANGEMENT, AND TRANSPLANTATION.

§ I. SELECTION OF TIE TREE : TIIE APPLE - ROOT-GRAFTED TREES IIEIGIT OF THE TREE NO CRITERION OF ITS VALUE - WHERE THEY SHOULD LIMB - THE PEACI - THE VINE - TIE CURRANT AND GOOSEBERRY - TIE STRAWDERRY, IIASPBERRY, AND BLACKBERRY. §II. ARRANGement : INTENSIVE PLANTING - a Garden OF ONE SQUARE ROD - a GaRden of SIXTEen SQUARE RODS - APPLE ORCHARDS - SQUARE PLANTING FOR THE PEAR - QUiNCUNX - DISTANCES, AND NUMBER OF TREES UPON AN ACRE. §III. TIIE TRANSPLANTATION: SEASON OFCONDITIONS MOST FAYORABLE TO - DEPTH OF - THE DWARF PEAR MANNER OF OPERATION - THE MOVEMENT OF LARGE TREES BY MACHINERY.

§. SELECTION OF THE TREE.

TERE it is generally best to confide in the judgment of a trustwortly nurseryman. Above all, avoid purchasing cheap trees, which drag out a miserable existence for a few years, only in the end to waste the capital and to disappoint the reasonable expectations of the cultivator who spends time and money in the preparation of the soil. Many persons, on account of the purchase of inferior stock, become disgusted with fruit-culture, and conclude that it requires more experience than they possess. A good tree will always command its full value, and those which are sold at a cheap rate are, para- 
doxically, the most expensive. A reliable nurseryman has his reputation at stake, and, when it is left to his judgment to select, will send to his customers only trees of good quality, and those which are properly labelled. But, as all dealers are not of this class, it will be well for all to know the general points of exccllence in a tree.

For apples we should prefer those of four or five years' growth from the bud: they then have uniformly sufficient strength to succeed. It is a great trial of patience to find that a few, which are growing rapidly, are shading and crowding out their poor neighbors. A certain proportion will always be feeble and sickly, which results, probably, from the seed from which the stock was raised. This is not so apparent in infancy as after three or four years, as the strong tree gains over the wcak a little every year. Thus one tree, which at two years seems scarcely inferior to another, often at the latter age requires a year or two more of nursing before planting in the orchard. The profit to the producer is, of course, greater to dispose of them while young; but that does not subserve the interest of the purchaser.

Many apple trees are sold which are grafted at the root. These may or may not be valuable, according to the method in which the work has been performed. Every seedling plant has a root, or descending axis; and a stem, or ascending axis. 
Where these meet at the surface of the ground, there is a swelling, called a collar, which is perhaps, more than any other part, the seat of life. The maintenance of its proper position is of vital importance. Perhaps one-half of the trees which fail, after transplanting, do so because this collar is placed beneath the surface; and this stifles the tree. This swelling is only possessed by seedlings, and never by layers, or otherwise artificially-produced plauts. Some years ago it was the custom to cut the long taproot of a yearling into three or four parts, into each of which a scion was inserted. In this way several plants were produced from one. That upon the upper cut, or collar, would, of course, form trees equally as good as those which were budded. The next picce, on account of its strength, might make a good tree; yet it would be of more dwarfish habit than the former. Those grafted upon the remaining portions of root would be nearly, if not altogether worthless, sometimes never coming into fruit. They may grow in the nursery lines until large enough to sell, but, compared with a budded tree, or one grafted properly, they are only calculated to disappoint and discourage the beginner.

But why are such practices encouraged by purchasers? In the cndeavor to buy at a cheap rate the cultivator has driven nurserymen to this only remaining expedient for obtaining remuneration for his labor. In this manner he can raise several 
plants, where by the old and better method he could produce but one; and the labor can be performed at a season of leisure. Only the experienced few will purchase the first class of trees, and pay a corresponding price for them. We believe, with the lamented William Reid, of New Jersey, that many apple trees which have been sold, especially in the Western country, will not be likely to attain a bearing condition. Such is the demand for cheap apple trees, that the rery best nurserymen are obliged to licep those of this class.

If such trees are examined critically, it will be discovered that their roots are a mass of fibres, like a head of hair, and possessing very few, if any, large roots. After the most careful transplanting in excellent soil, or in that which was barren, it is impossible to induce them to throw strong roots. Under such circumstances they will be sensitive to the least wind, and there is nothing to prevent their being blown to the ground. The tree is merely a cutting, and the little piece of root into which it is grafted scrves to keep the scion alive only until it is established.

While the use of the third or fourth cut as a stock for grafting should be discountenanced, that of the second may be of use in some cases. As its effect is to dwarf the tree, it may bring some of the late-bearing varieties to an earlier maturity. Such has been the repeated effect upon the Northern 
Spy. Still, even such are better confined to a small garden; and, if I judge not too harshly, they will often want propping to guard them against the wind. When the root is used entire, the tree is as valuable in every respect as one which has been budded.

Some naturalists have argued that all the plants of any variety are parts of one individual, which is the original seedling; that every layer, cutting, and offshoot which have been rooted and dismembered, are not separate individuals, but only parts of the parent. Cthers, among whom have been some of the most renowned, state, with equal persistence, that each is a perfect individual in itself. But do not the latter overlook the fact that these layers and parts were made independent by artificial means? that they must be noticed scientifically, as they would exist in a natural state? An individual plant must be one which has passed through all the periods of growth, from infancy upwards ; originally, directly from a seed; having, or having had, cotyledons, a plumule, an ascending axis, a descending one, and a collar. Artificial plants have none of these but the ascending axis.

The fact that some discases will attack a certain variety at once, or nearly so, - some locations being so favorable as to ward it off for a time, - shows that varieties grow old and die, as they would have done 
if confined to the original plant. The supporters of the opposite theory argue against this, by saying that the family becomes diseased and extinct through the influence of something analogous to scrofula in the human family. But, can this be the ease, when their offspring from seed are often perfectly free from infection? Thus some pears, which were once very fair and fine in growth, become uniformly cankered and cracked, and finally disappear, while plants from their seed are entirely free from both.

An eminent gentleman of this country has said that "the plant which springs from a bud is as really a new plant as that which springs from a seed." No seedling is exactly similar to its parent. It differs either in the flavor, form, or size of its fruit, or in the habit of its growth. There is some point by which we can instantly determine that it is an entirely different individual. Is such the case with the plant derived from the bud? Must they not be the same, when their fruit and habit are exactly alike? Can it be said to be a distinct individual? The same author adds, that "if the feebleness of a tree be general, its functions languid, its secretions thin, then a bud or graft will be feeble; and so will be its seed." Although the former is generally true, are not the seeds of such trees often unusually plump and fine? and is not this feebleness often caused by expenditure of strength in forming them? But, while the seed does often 
escape the diseases of its parent, and accommodate itself to the influences which affect it in its new position, - as a tender variety produces from sced one perfectly hardy, - does a plant from a bud ever escape, unless through those artificial means which only influence it for the time? It retains the diseases (perhaps undeveloped and latent), the form, flavor, and texture of fruit, and the habit of growth of the original scedling; and would always have been a part of it, had it not been for art. No bud of the Bartlett pear, wherever or however inserted, ever produced anything but a Bartlett; and no seed of the Bartlett ever originated a tree which was the same as that variety.

Some authors have recommended planting pear trees of one year oldi, because then they might be formed as desired. While this may be best in the grounds of those gentlemen who employ professional gardeners, and have walls to which they wish to adapt an espalier, ${ }^{1}$. yet, in our country, such persons of skill are rare, and our standard method of pruning does not render it important. Trees of two years old, also, are much better in the nursery lines; but, after thrce ycars, or, still better, if transplanted the second, and set in the orchard the fourth, they will have a strength of constitution which, compared with a tree of one or two years from the 
bud, would be like that of a man in his prime to a tender infant. They will become less liable to injury in winter, as thcir wood is more firm, or to remain stunted for several seasons, as the former are likely to do.

The height from the ground at which the lower limbs of the standard pear should grow is about two and one-half to three feet, and with varieties of weeping habit, perhaps a little more. 'The old method was to train them much lower; but it was found that these limbs trailed upon the ground, and rendered their fruit almost worthless. Most inexperienced persons ask for trees limbed so high that a horse can cultivate under them. The admittance of such cultivation into an orchard of pear trees, planted as near together as we should advise, is of very doubtful propriety. Even if the trees were sufficiently far apart for such an operation, the danger of scalding the trunk from the sum should not be risked for a matter of so little convenience.

The height is too often considered as a criterion of the value; so that, for a certain class of purchaser's, the strength must be sacrificed to satisfy them: but the true value of a tree should be estimated by the size of the butt, or trunk, at the ground. To produce a stocky plant, the top is kept pruned back, which makes the tree very sturdy; while, for 
a tall tree, the top is allowed to run, and its growth is obtained in nearly half the time, but results in a slender, withy whipstick.

The value of transplanting the tree before setting in the orchard, is, that the roots are brought into a limit where they can nearly all be retained.

This diagram exhibits the roots of a tree as they lie in the ground, and the circle the proportion of roots which would be retained by the tree as it is usually dug. (a) represents a root with the little spongioles through which the

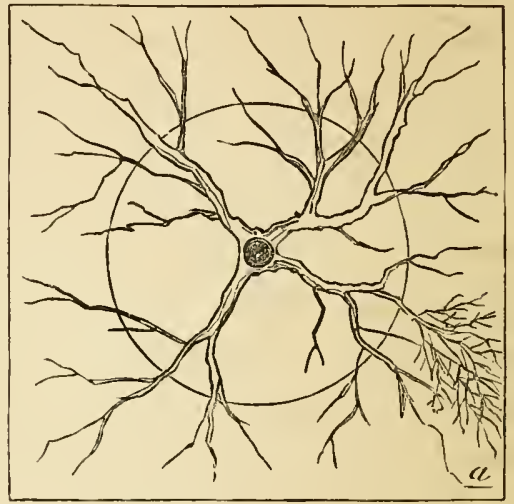
tree feeds. These are very soft and tender, and, in transplanting, it is almost impossible to retain them alive. But this is of no great importance; for if there is a good supply of the small roots, of the size of a pipe-stem, or of even half that, they will readily supply themselves with feeders. But it will be seen that most of these small roots are outside of the circle, and are, consequently, lost. To be sure, the large roots will supply themselves also, but not so readily as the former; and therefore this transplanting more properly takes place in the nursery, where 
the trees will have better care than they generally receive in open culture.

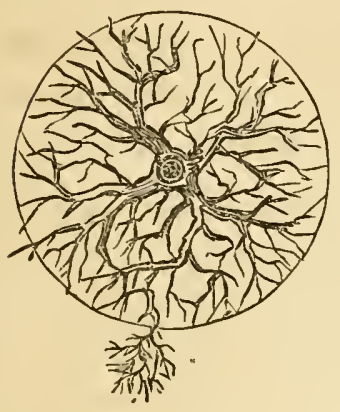

The result of transplanting will be seen to be, in the third or fourth year, or the first or second after the operation, that in this circle a large number of these small roots have been formed, and consequently the strength of the tree greatly increased after moving. If the tree was to be carried but a little distance, the spongioles might be kept fresh by wrapping a moist cloth about them; but even then they would be likely to be bruised in sifting the soil into the hole, however carefully performed.

The limbs of the dwarf pear, or that upon the quince stock, are much stiffer than those of the standard, and can be allowed to grow much nearer to the ground. The nearer the limbs are to the earth, the less height shall we allow to the tree, and therefore the wind will have less effect upon it, and will blow off its fruit much less. Several years ago the pear was budded on the quince, some inches above the surface of the ground. When the present practice was introduced of placing this junction entirely under ground (the reason for which will be explained in the directions for planting), the point of union was so high that it was impossible 
to fix it in its proper place without plunging the roots into the cold soil below. Now, all skilful nurserymen bud their trees as low as possible; but, should they be of the former description, they ought to be placed at the proper depth, even at the risk of losing the lower roots, as the quince furnishes itself easily from any part of its stem.

Peach trees are of very rapid growth, and bear transplantation easily; so that a tree of one year is preferred, and a crop will be realized quite as soon as from an older one. The limbs upon the yearling peach are of no importance, as they are cut off at planting.

In general, grape vines of two or three years are better than those younger. The most common method of propagating them is by layers. If they have not been cut and transplanted, those of two years are no better than those of one; yet, if they have been, they are much more valuable; although those of one year may be used for vineyard planting where the land has been skilfully prepared. A yearling vine, grown in a pot, has a great quantity of very fine roots, which it is difficult to preserve fresh during the winter. If not in dry, barren soil, the fibres decay, and disease seems to extend to the larger roots, so that it is doubtful whether it is of much more value than a cutting. Therefore, if such vines are used, they should not be planted in the autumn, nor until the time arrives in the spring 
when they will immediately grow. Much the best way is to trim oif these fibres entirely; and if they are diseased, the roots should be cut to the sound part. After it has been transplanted another year in the nursery it is in better condition for general planting.

A great mistake is made by the purchase of large and old vines. The roet is, like the top, a great ranger, and it can hardly be imagined what an exceeding small proportion of its roots can be obtained by the most careful attention in transplanting. Besides, it is a useless expenditure, for such will seldom acquire a healthy habit, and will certainly never succeed as well as young vines. Those who buy are often disappointed, upon receiving their vines, to find that the top has been nearly all cut off, and only a foot or two remains. Unlike a tree, if it possesses three or four sound eyes, the rest is useless. Even a single eye is all that is absolutely requisite.

Currant and goosebervy bushes should be of the old fashioned form, or bush-shape, and not treeformed. When there is but one stem, a single attack of the borer may destroy the whole top, while if there are several, such an occurrence would only give the remaining parts more strength.

Plants of the strawberry should be rumers; those of the blackiberry and raspberry suckers of the previous summer. 


\section{\& II. METHODS OF ARRANGEMENT.}

If one has a limited tract of land, it is a question which naturally suggests itself, how can he plant it to the best advantage? 'This inquiry is pertinent where large tracts are possessed. In this country, land lias been of so little value that our cultivation has been too extensive. The liability has been to spread over a large area, cultivate superficially, and obtain only that from two or three acres which should have been produced from one. The aim should be more intensive, - to place upon one acre the number of trees often planted upon several, and to give it as much care and as good treatment as the larger tract would have received. This will undoubtedly be productive of better returns. The farmer who possesses one or two hundred acres of land, and designs becoming a fruit-grower, will do well to retain but ten or twenty, and invest the amount received from the sale of the remainder in stock to be placed upon what he retains, and in bringing the same to the highest possible state of tillage. If we mistake not, his profits will be very much increased.

There is hardly any one who does not possess land enough, accessible to the sum, to raise some fruit. Supposing he has but one rod square, let us see how he may use it for a fruit-garden, and what 
results it will be possible for him to obtain. 'This diagram represents such a plat.

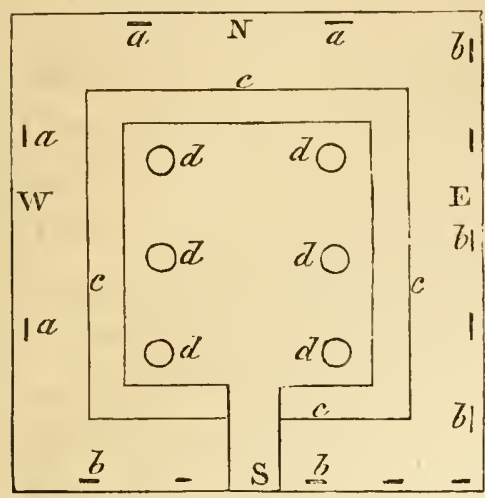

(a) denotes the spot where four grape vines are placed, which are eight feet apart, and against the north and west wall or fence, where they receive the sun from the opposite direction.

(b) represents currant bushes, planted about three feet distant from one another, on the south and east.

$(c)$ is a line of strawberries, one foot apart, extending entirely around the apparent interior of the border, but really, however, over the whole rod, thus affording a fine field for the roots of the vines to roam. Its superficial boundary, as shown in the plan, is three feet from the outside.

(d) represents pots of eighteen inches in diameter, each containing a peach trec, which is dwarfed by pruning; the pot being plunged to the rim in the earth of the border, to prevent too rapid evaporation of moisture.

Now, what may we expect, as the practical result from such an orchard, if kept in good heart by annual manuring and a judicious use of the knife? The four grape vines should bear, at least, fifteen 
pounds each, making sixty pounds. The ten currant bushes would yield one-half a bushel. The strawberry bed should produce, at least, thirty boxes of fruit. And the six peach trees, two dozen each. Let us extend the tract to sixteen square rods.

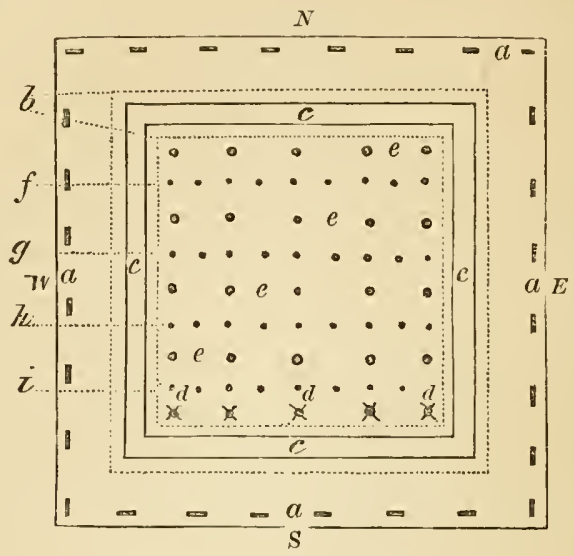

A border is constructed all around the plat, of cleven feet in width, but a walk is laid over the interior three feet, which is represented in the diagram by $(c)$. In this border grape vines are planted, eight feet apart, all around the plat. These are distinguished by $(a)$. On the north and west should be a fence nearly tight, but not wholly so, as it is desirable that the air should pass through it. The vines are to be trained on stakes, or on a trellis, at least a foot in front of it. On the south and east should be, if any, only a light slat or wire fence, through which the sun may shine. 
(b) upon the plan denotes a line of strawberries, one foot distant from each other, cxtending around the outside and inside borders on both sides of the walk.

(d) is a line of peaches, reaching across the inside border, eight feet apart, pruned into a dwarfish habit.

(c) represents four lines of dwarf pears, of the same distance from each other as the peaches, and containing a selection of varieties which shall afford a supply for the whole season.

$(f)$ is a line of summer-bearing raspberries, four feet distant, three plants being set in a hill.

$(g)$ is a row of currants.

(h) a line of fall-bearing raspberries, planted like $(f)$.

(i) is a row of gooseberries.

By this plan we have, upon one-tenth of an acre, thirty-two grape vines, four hundred strawberry plants, five peach trees, sixteen pear trees, eight lills of summer raspberries, the same number for the autumn, eight currant bushes, and an equal number of goosebcry plants. This is a sample of the intensive cultivation which should be more $e x$ tensively practised. One often hears it said that such cultivation becomes a garden, but is not adapted to the orchard. But this should be a garden ; and, until it is so considered and treated, it will not yicld all the profit of which it is capable. 
The Clapp Brothers, of Dorchester, Mass., have well illustrated the profit of intensive cultivation in their orchard of thirteen acres. The general plan is somewhat like the following.

(a) represents the apple trees.

(b) peaches planted between them; but these become so tender in this locality

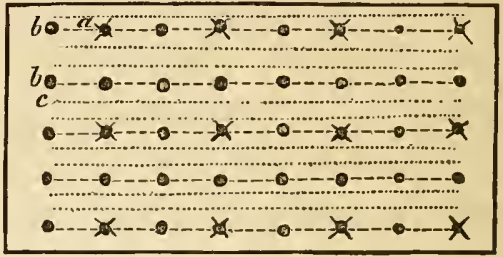
that many of them have been killed.

(c) denotes lines of currants, three feet distant each way.

This plan has an advantage in the fact that the whole ground must be kept in cultivation, which is very necessary to the best results; and the annual manuring which the currants receive also enriches the trees, and that at the extremities of their roots, where the spongioles are placed; and it is therefore more available than immediately about the trunk, as gencrally applied, where there are no roots to make use of it. Dwarf pears may be used instead of peaches, where the latter are not hardy; and they will yield many fine crops before the apples require the room. An excellent plan, practised by many apple-orchardists, is to plant four times as many trees upon the land as they design to have remain there. If it is proposed that in the end they be forty feet distant each way, another line would be 
planted between them in both directions. By this method, when the trees commence to bear fruit, and during the first fifteen years, they receive four times the quantity which they would have done in the old method, which often amounts to a full crop from an established orchard. When they begin to interlock, the superfluous trees are cut out.

The old method of planting the pear intensively may be seen in the figure below.

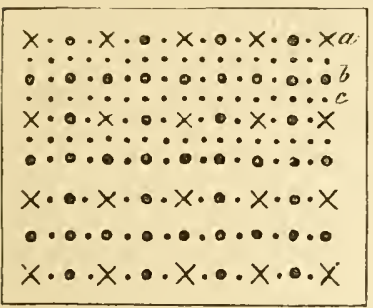

(a) denotes the standard pears, sixteen to twenty feet distant.

(b) the dwarfs.

(c) small fruits; such as currants, raspberries,or strawberries.

The beauty of the orchard, as well as its utility, is a point to be considered by the cultivator, when the latter is not sacrificed to the former, and the quincunx is therefore generally preferred.

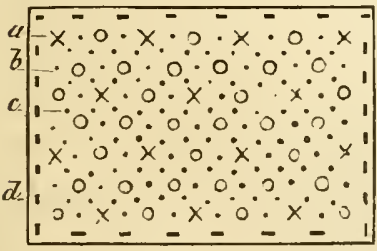

$(a)(b)$ and $(c)$ correspond to the same numbers in the preceding diagram, and $(d)$ represents a line of grape vines, extending around the whole. The manner of laying out this plan upon the ground may confuse the planter, and we therefore give a more simple method. On examination, it will be found that the 
distance from one tree or bush to another is just four or five feet, according as the standard pears were placed sixteen or twenty feet apart. The whole is laid off in squares of four or five feet with a line, and marked upon the ground by nicking with the spade. Stakes are then easily driven down, representing the standard, dwarf or shrub. In this way the trees will be set exactly in line, which adds greatly to the attractiveness of the whole.

NUMBER OF TREES OR PLANTS ON AN ACRE, WHEN PLANTED AT THE FOLLOWING DISTANCES APART, IN FEET.

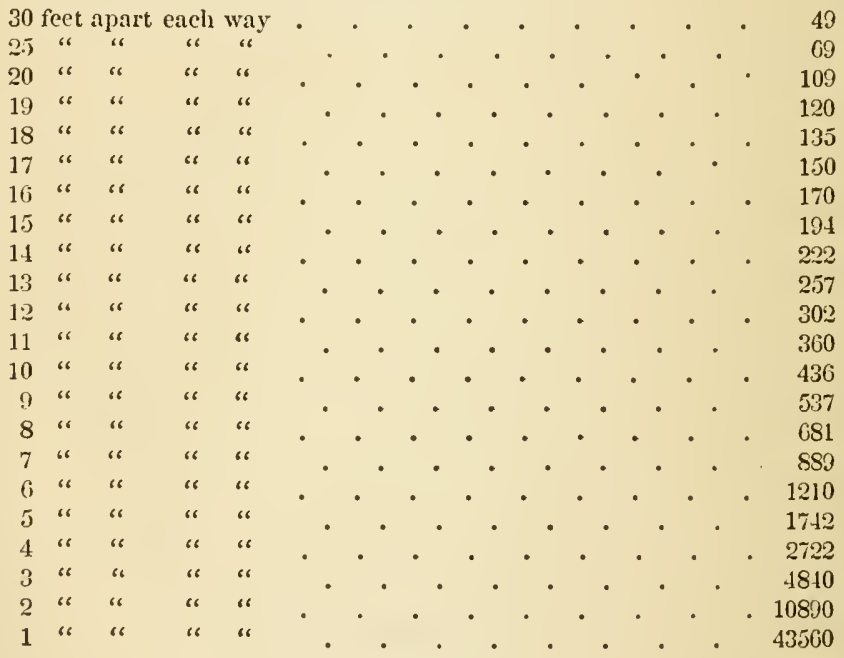

DISTANCES FOR PLANTING.

Standard Apples

- 24 to 30 feet distant each way.

Standarl Pears

Standard Cherries'

Standard l'lums and Peaches . . 12 to 16

Pyramid Pears on Pear roots . . 10 to 12

Pyramid Pears on Quince roots . . 8 to 10

Currants, Gooseberries, and Rasplerries. 3 to 4

Strawberries

$2 !$ to 3

or 1 foot in the row, and the rows 3 feet apart. 
§III. TRANSPLANTATION.

When the trees arrive at the orchard they should be carefully unpacked, and the moss or other material about the roots removed, as otherwise it may promote decay. A deep trench should be dug, in dry, gravelly soil, and the roots set in properly to a considerable depth, that they may remain fresh. If, from any accident, the top has become shrivelled, the trees shonld be buried root and branch until they become plump.

The best time for the purchase of trees, even if not to be planted until spring, is undoubtedly the autumn. Between the sale in the fall and that in the spring, there is no season of growth, and those disposed of at the latter time have been left over from the former. Therefore the order should be given as early as possible in the summer previous, if the cultivator designs that the nurseryman shall make a wise selection. If these trees are to be heeled in until the spring planting, the earth should be finely shaken about the roots, that no recesses be left for retaining the water or sheltering mice. After the earth has been banked up about them to a considerable height, it should be stamped hard. The trench must be, of course, where no water will stand about the trees, and not in the vicinity of heaps of weeds, old turf, or any other rubbish from which the mice can make a sally. 
The best season for transplanting most trees is, no doubt, the autumn. The earth is then in good condition - dry, friable, and still containing much of its summer heat. This latter circumstance is of much importance. It encourages the wounded parts of the roots to heal over, and to throw out numberless rootlets, which fix the tree in the ground, and enable it to start quickly and healthfully into growth with the first opening of spring. As we approach mid-winter, this terrestrial heat diminishes; therefore, the earlier the process can take place the better. At the same time, it should not be before the tree has shed its leaf; for then the evaporation from the top would be more than the shortened root could sustain; it would not find a recompense in the absorption at the root, and the top would shrivel. This same rule is of application after the buds have begun to swell in the spring, except that then the vital functions are just commencing, and the roots, being thus stimulated, are more liable to furnish spongioles, and sustain the draft.

Altogether, autumn planting is on these accounts to be preferred; yet it is somewhat dependent upon the age and style of tree to be set. Those which are young and succulent, or those varieties which are tender, might be injured by immediate exposure from the nursery to the vicissitudes of winter. Such should be heeled in, in some sheltered situation, for use in the spring. The aspect, too, may be such as 
would forbid the work being performed in the autumn. If strong winds prevail, the newly-planted tree will be thrown about, loosening the roots in the soil, and preventing the formation of rootlets by the constant strain which is made upon it in maintaining its position. Trees planted at this season should always be protected by a mound of earth around their base, made hard by the foot or spade ; and if a stake is added, it will afford a still better support.

The condition of the soil most favorable to planting, is when it is not wet, so as to be clammy or adhesive, but dry and friable. If the sky should be overcast, so much the better, as the roots will not be as likely to become dry. Strong wind is very unfavorable, as it dries the fibres, and hinders the plinter from performing his work thoroughly. If the soil is wet, it cannot be placed suitably between the roots.

No matter what care the nurseryman may exercise, it will be impossible to retain all the roots, as in the preceding diagram, as well as in the chapter upon fertilization, it is shown to what length they grow. When they are to be set, therefore, the ends of the roots and all bruised parts should be pared with a sharp linife, that the wound may be smooth. 'The cut should, if possible, be made from beneath, so that it will rest upon the earth when the tree is upright. The benefit of this operation is, that the 
fresh wound will send out roots immediately, while, if not pared, the ragged parts would decay, which would prevent the production of rootlets, and perhaps produce death in the whole root. The hole should be dug of sufficient diameter to allow all the roots to be spread easily in their natural positions, and several inches deeper than was originally required by the tree. The fine surface-soil may then be placed in the bottom until the hole is of the proper depth. If the roots are dry, they may now be sprinkled with a rose-pot, that the earth may cling to them more compactly. One person should hold the tree, while the other carefully places the roots, as the earth is finely sprinkled in. The person spreading these cannot be too particular in their arrangement. If possible, the tree should be set, at first, about the height at which it is to stand, so that it will not require lifting after the setting is completed, which disturbs the position of the roots, and often breaks their tissue. But it must not be left too deep on this account, for the latter evil would be greater than the former.

The tree should be set as deep in the ground as it was in the nursery. If the collar is below the surface, the tree will never thrive. The pear upon the quince is an exception to this rule. The quince stock is raised from a layer or cutting, and has no collar, and the ease with which it throws out roots from any part of its stem permits it to 
accommodate itself to any depth of planting. 'The union of the pear with it is not so perfect as it would be with its own species; therefore, if this point of junction is above the surface, a great strain is brought upon it by the wind, which sometimes results in its parting. This, of course, ruins the tree. The borer is very fond of the quince, and he makes his attacks at the surface of the soil. By placing the junction three inches below the level of the soil, it is beyond his attack, and the pear stock, like a cutting, soon throws out roots, which strengthen the hold of the tree at the same time that they lengthen its longevity. If the quince decays, the pear roots maintain the tree in fruitfulness.

The question may arise, What is the advantage of placing the pear tree upon the quince stock at all, if it is to be on its own roots in the end? The union between the two has been said not to be perfect, because the pear is naturally a much more vigorous grower than the quince. Being united with the latter, it must receive nourishment only as fast as the quince would give it to its head. By this the pear is to a degree stunted or matured, and that slow circulation of the sap is induced which is promotive of fruitfulness. This may be encouraged to an extreme, and the cultivator who argues against dwarf pears, and complains of their stunted growth, want of productiveness, and yellow leaf, will be able, 
probably, to remember a time, it may be years before, when the tree brought on this ill health by a too large crop. The addition of the pear roots give the tree greater strength, and consequently increased power of production. The period of barrenness before maturity in the pear on free stock is cut short by the quince, and the life extended nearly as long as the standard, if cropperl judiciously. The life of pear's upon the quince independently, has, I believe, been understated. Where blight or other diseases have attacked them, or exhaustion has followed overbearing, their life will not probably exceed fifteen or twenty years at the most; but an observation of those from thirty to forty years of age, in the gardens of my esteemed partner, Hon. Marshall P. Wilder, which are still bearing crops, and the large number, of fifteen to twenty years of age, apparently in full health and productiveness, must lead one to extend this period.

Some one may ask why these trees are not rooted from the pear. Formerly the importance of such deep planting of the dwarf was not rightly estimated, and the necessity of it has become impressed by the results of the experience of the cultivator, although it was taught theoretically more than two centuries ago.

If manure has been applied broadcast, according to the preceding directions, there will be little need of using it at the time of planting; but if not, a 
gool quantity of old rotten manure should be placed at each hole, and finely composted with the loam to be sifted in at the setting. If the dung used is not well rotted, or at least a year old, it must not on any account be placed with the loam, as it will greatly injure the roots of the tree, but must be used on the surface as mulching, which will be explained hereafter. When the tree is set, the ground should be made as firm as possible by treading.

The fibrous roots of a grape vine should be spread out carefully; and it is well if the cane is laid down carefully. Each eye, in this case, will throw out a bunch of roots, and strengthen the vine.

Strawberries, of old, were planted in beds, and were permitted to remain for several seasons; but the care required to keep out the weeds was very great, and a remunerative crop was seldom realized after the second year. Among the best growers, strawberries are now planted in rows two and a half to three feet in width, and about one foot distant in the rows. The ground is prepared as directed, and the runners of the preceding year, not plants which have borne fruit, are dibbled out like cabbage plants in cloudy weather in the spring. During the whole of this season they can be kept clean with a horsecultivator and a hand-hoe. After producing one crop the second year from planting, they are permitted to make runners for a new patch, and then ploughed in, to make way for the plants the next 
spring. It scarcely ever proves to be good practice to let them remain another summer. By some they are grown in hills, and not allowed to extend; but the former method is productive of greater results.

A variety of strawberry may produce blossoms, however, which are destitute of stamens, or the male element; or they may be so sessile as not to perform their office of throwing the yellow pollen upon the stigma of the pistil, so as to impregnate it, and the consequence will be utter or partial barrenness. Such plants are called pistilate, or female. Others there are where the pistil is imperfect, while the stamens are fully developed. These are called staminate. When the former are planted, every fourth or fifth line should be of the latter class, when the whole will be productive. But they must be of the same species; a haubois must be fertilized with one of the same. There are some varieties which have both sexes well developed. These are called hermaphrodite; but they are not generally as great bearers as the pistilate sorts.

The movement of large trees is accomplished with great labor. Mr. Stewart McGlashen, of Great Britain, invented, a few years since, a wonderful machine for digging and removing those of almost any size. An account was published of the first experiment in the journals of the day. We do not know whether it has been brought much into use, but give a description of it that it may perhaps lead 
to something else, which shall be of general utility. This machine was applied to a tree fifty feet in height, and of more than five feet in circumference at the trunk.

"The first process of Mr. McGlashen, is to lay down a frame of T-iron - in this case, ten feet square. He then takes cutters, made of malleable iron, one foot broad, and three feet deep, or, including the head and neck, four and one-lialf feet. These cutters are driven, by a wooden mallet, into the soil to the depth of three feet all around, and being inserted sloping inwards, they give to the enclosed mass the form of a square blunted wedge. A rod of iron is then laid along the top of the four rows of cutters, and extensive rods going across the frame force the heads of the cutters apart as far as possible, and, consequently, cause the point to converge at the bottom. A clasp or gland is then put around the trunk of the tree, with a mat under it to preserve the bark. Two parallel beams are then laid across the frame, and fastened to it with chains. The above constitutes the frame to be raised. The means of elevating it is a carriage (which also serves the purpose of transportation), consisting of two strong conmon carts, one at each end, with bolsters raised above the axletree of both, and on which bolsters rest two massive parallel beams secured to them with strong bolts. The height of the beams from the ground is about six feet. They, of course, 
enclose the tree. The process of lifting is exceedingly simple, the whole being accomplished by the power of the screw. The screws are four in number, and so arranged as to make them lift equally. They are made fast to the beams of the frame, and are worked by men standing on planks across the beams of the carriage. The frame and enclosed mass are slowly raised, and the tree, with gentle oscillation, moves erectly upwards. The tree may, it is evident, be raised without the use of any ropes, - the solid mass of earth effectually balancing the trunk and branches, - but they were used on this occasion as an extra precaution. After about twenty minutes' working of the screws, the tree was completely raised from the pit, the operation having been effected in an easy and gradual manner, and amidst tributes of admiration from all around. It was not the intention to remove the tree experimented upon; but the means of removal being exhibited and explained, all seemed satisfied with the feasibility of the apparatus provided for the purpose. A strong case was shown for the enclosure of the ball of earth when the tree is to be renoved to any distance. In moving, the tree still maintains its erect position. The propelling power, when horses cannot be used, is by a winch in front of the foremost cart, and block and tackle; but when the way is clear and the road good, horses will do the work safely, and more expeditiously. 
The tree is lowered into the pit prepared for it, on the same principle.

"It is calculated that, in this instance, the weight lifted was thirteen or fourteen tons; but the inventor and patentee states that, by an enlargement of the apparatus, he could lift almost any tree."

26 


\section{CHAPTER IX.}

PRUNING AND TRAINING.

THE AMPUtation OF the LIMLS OF A TREE BASED UPON SCIENTIFic PRINCIPLES - FACTS NECESSARY TO BE KEPT IN MIND: IMPORTAXCE

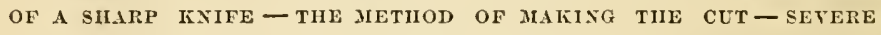
PRENING PRODCCTIYE OF VIGOR AND STERILITY - TIIE REMOYAL OF A PART OF TIIE WOOD OF A WEAK PLANT STReNgtilexs tile REmainder - inportaxce of sunsilye to all parts of the treeCIRCClation OF AIR-Distinguising TIE PECUliarities of tile VARIETY - THE PREVENTION AND CURE OF DISEASE - TIIE SEASON : SPRING AND SUMJER - PRUNING AFTER TRANSPLANTING - TRAINIXG

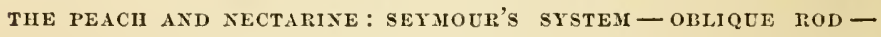
OBLIQUE DOUBLE ROD - DOUBLE OELIQUE ROD - STANDARD - IIORIZONTAL TRELLIS-TRAINING - TIE APRiCOT - THE PEAR - STANDARD, QUexotille, WiNeglass, etc. - THE CHerry - THE VINE - THE SYSTEM OF TIE IONIAN ISLANDS - SIMPLE CANE - SIMPLE THOJERT, PLAN PRACTISED IN OHIO - THE CURRANT - THE GOOSEBERTY - THE FASPBERRY - THE BLACKBERRY - THE STRAWBERRY - ROOT-PRUNING.

THE amputation of the limbs of a tree is based upon scientific principles; and when it is done indiscriminately, or at variance with these, discase or death may be the consequence. The wild tree is naturally of strong growth, at the expense of fruitfulness. The designs of pruning are to check undue luxuriance, and induce the immediate production of fruit; to reduce the size of the tree to such an extent that it is manageable with ease; to 
enable it to sustain itself from injury while bearing heavy crops; and to adapt it to the peculiarities of climate, soil, or position.

The facts which are to be kept in mind as necessary to good pruning are -

First, the importance of a sharp knife, with which to perform the operation. The wood of all plants is composed of cells and of woody fibre. If a keen instrument separate these, the neighboring parts are not materially disturbed, and their action will be continued, and the wound healed; but if the knife is dull it tears these one from another, and disarranges the tissue surrounding, so that, unless the plant is very vigorous, the outer parts decay, and the wound becomes an unsightly scar.

Second, the method of making the cut. ${ }^{1}$ So many instances occur of ugly knots disfiguring the tree from an utter disregard of this, that the following plates are inserted.
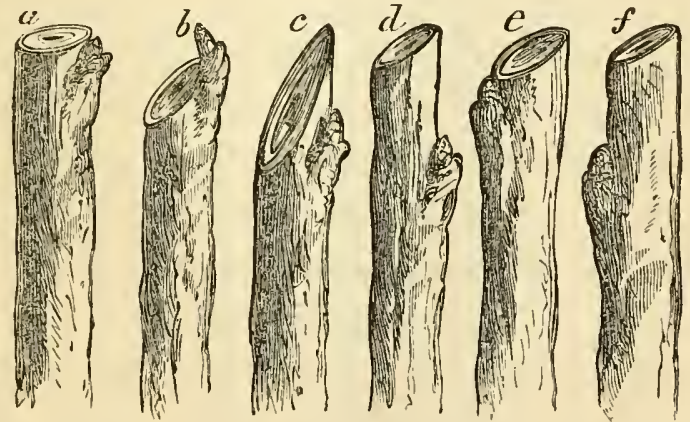

1 The remarks under this head were suggested by an artiele in the Gardeners' Chronicle of 1817 , and the plates are thence derired. 
(a) represents the proper cut, at an angle of about forty-five degrees, with the bud at the back. As the bud grows, the bark is thrown over the wound, and it becomes scarcely distinguishable.

(b) is a cut in which the bud is left so much exposed that drying winds or accident may destroy it. In either case the next one below will push, and the intermediate space become an ugly linot.

(c) represents the wound usually made in pruning by beginners or women, resulting from a dull knife or want of strength to make a firm stroke. The disadvantages are evident, as the surface to be healed is more than double that of $(a) . \quad(d)(e)(f)$ are cuts made at hap-hazard; in which the bud is not liable to take so straight a direction; and an unsightly joint is left above it.

Third, severe pruning produces vigor, but stevility. There is a certain balance which is to be maintained between the roots and the branches of a tree; and if this is disturbed, it seeks to restore the equilibrium before it will produce fruit. Therefore, if the branches are continually cut while the roots remain the same, the whole force of the tree will be spent to accomplish this by increased vigor. If a tree already possesses a quantity of fruit-spurs, and the knife be used severely, this force may transform them into wood-buds, and the tree be filled with spray-wood in consequence.

Fourth, the removal of a part of the wood, when the 
plant is weak, strengthens that which remains. This was made so patent under the last head, that it requires no additional remark.

Fifth, it is important that the sunshine reach every part of the tree. If a close, thick head is formed, the leaves are crowded together, and none of them act as freely as they might. Consequently, they are weak, light-colored, sickly, and produce debility in the whole tree. But if a part of the limbs is removed, or never allowed to form, so that each leaf can expand independently in the sunshine, the foliage becomes active and healthy. Although the number of leaves is diminished, yet their superficial area is increased, and the strength and longevity of the tree augmented.

The pear tree naturally grows to a considerable height, having a bare stem of several feet, and a spreading top, upon the exterior of which the fruit is produced, when it has access to the sunshine. One of the objects of pruning is to dispose of this bare stem, and keep the tree in such limits as will be within reach of the operator, and so low as to be protected from winds which would otherwise throw off the fruit. But as the tendency of the plant is always upward, it will soon go beyond the boundary unless we prune it. If this be merely the cutting back of those shoots which exceed the limit prescribed, the tree will soon become filled with brush, to the exclusion of sunshine and of worthy fruit. 
Some plan must be pursued from infancy which shall provide against these evils; this will be detailed hereafter.

Sixth, the importance of a circulation of air through the head of the tree is closely associated with that of light. As the latter is composed of rays of different colors, acting chemically upon vegetation, some absorbing one ray and some another, so the rustling of every leaf is necessary to secure to it those atmospheric substances which aid it in the elaboration of its sap. To produce this the same means are employed as with the last, - a loose, open head.

Seventh, the formation of an equal system of branches. All trees throw most of their vigor into a strong central shoot. This is while they are young; with increased age it is generally lost in the mass of vertical branches which form the head. The horizontal limbs, which were produced at the outset, receive so small a share of sap, that they become insignificant. By pruning, this energy and vigor should be equally distributed. The tendency upward is so great that in those trees which have been trained horizontally for a long time, a single bud, if allowed to escape the knife of the gardener, would soon turn the balance of strength in its favor. All systems of pruning contain this principle to a greater or less extent.

To accomplish it one must be aware of the nature of the buds upon a shoot, and the difference in 
result to be obtained from cutting to a bud near or at a distance from the base of a shoot. On account of this tendency uprwards, if unmolested, the eyes near the terminus of the last season's growth would burst and grow, while those at the base would remain dormant. But if the shoot is cut off to these latter, they are stimulated and produce stronger growths than those at the terminus would have done. 'The fruit-bearing buds are scarcely ever those at the base, but are generally about two-thirds of the length of the shoot from it, although sometimes terminal. Therefore, these dormant buds at the base produce shoots which will not fruit so quickly, but continue to elongate. Horizontal limbs grow slowly; and it is of importance to secure buds from the base of the shoot to form them. If the limbs are of equal strength, and light and air are admitted freely, they will be clothed with fruit-spurs to their very base, where they are capable of sustaining ten times as much weight as at the terminus, and where the risk of loss by winds is very small.

Eighth, the importance of distinguishing the peculiarities of the variety to be operated upon. Some sorts are very vigorous in their character; others weak; and some of decumbent or weeping habit. In pruning them the plan should be conformed to these peculiarities rather than to a uniform system.

Ninth, the prevention and cure of disease. If the subject has become exhausted by overbearing, and 
throws out nothing but sickly foliage, the removal of a part of the top, with judicious manuring, strengthens the remaining parts. Canker and other diseases are often formed by too close pruning when the roots are very strong. Withholding the knife entirely will help to stay it, although a more effectwal cure is wrought by root-pruning.

The season of pruming. This depends upon the end to be attained. As a general rule these seasons are two, - winter and summer.

If the winter pruning is done in the autumn, as soon as the growth is ripe there is danger from a warm season following that the tree would push forth a soft growth, on account of the stimulus given by severe cutting. When done in early winter, the end of the shoot which is cut does not heal, because the energies of the tree are dormant, and it becomes an unsightly black knot, requiring a pruning in the spring to remove it. If the invigoration of the tree is the object, this should be performed in the spring before the buds have started, and after all danger from severe frost is past. If it is desired to check undue luxuriance, it should be done after the buds have well started, or are even in leaf. The plum is very stout in its growth, and the more it is cut, the more luxuriant does it become. When it is necessary to use the knife, it should be when the buds are swollen, or the tree is coming into leaf. As it 
has then expended considerable strength in bursting these forth, and is deprived of some foliage, it weakens the remaining parts, and induces that condition which is favorable to fruitfulness. If it had been performed earlier, all the force of spring life, which would have been distributed through all these buds, is concentrated in those remaining, and the result would have been still greater vigor and less fruitfulness.

No precise time can be assigned for summer pruning. It must extend through a great part of the season of growth. It should be used in reference to the winter pruning. All gourmands, or watery shoots, which are taking a wrong direction, should be pinched before they have become so strong as to draw necessary nourishment from other parts. All stone-fruits are liable to exude gum from their wounds after severe pruning, so that summer pruning with them should be only the prevention of the formation of shoots by disbudding them before actually grown. If some should escape attention, it will be better to permit them to remain until the winter pruning, when the sap is moving sluggishly, and the wound will heal readily. With those fruits which bear upon the growth of the last season, as the peach, the laterals, which are designed for production, should not be disbudded or shortened to the proper length until the winter pruning, else they would burst all the eyes upon them, and fill 
the tree with soft shoots, which would be likely to injure it, by inducing late growth, which would be hazardous during the winter.

The season for pruning the vine will be considered particularly hereafter.

Pruning after transplanting. In transplanting, the majority of the roots will under any circumstances be lost. We have seen before that the tree while growing maintains a certain equilibrium between the roots and the top, and that the growth of the latter results from that of the former. Therefore, after transplanting we must so prune the top as to secure the balance, which had been broken in the removal of the tree. They should therefore be cut back very severely, when they will develop a few healthy leaves which will aid the tree in establishing itself, much more than the weak foliage which would be thrown out if they were not pruned. Trees planted in the autumn need not be cut as closely as those set in the spring, because they will be in a condition to throw out new roots immediately to support a larger top.

This figure represents a peach tree at planting, and the transverse lines indicate where it should be cut. The main stock is left at not more than eighteen inches in height, and all the

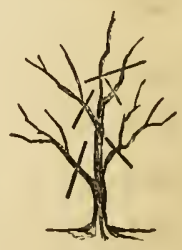
limbs are trimmed to an inch or two from the stem. 
Training the peach and nectarine. Many methods of espalier training are in use in Europe, but among them that recommended by Mr. Seymour seems to be, perhaps, particularly desirable.

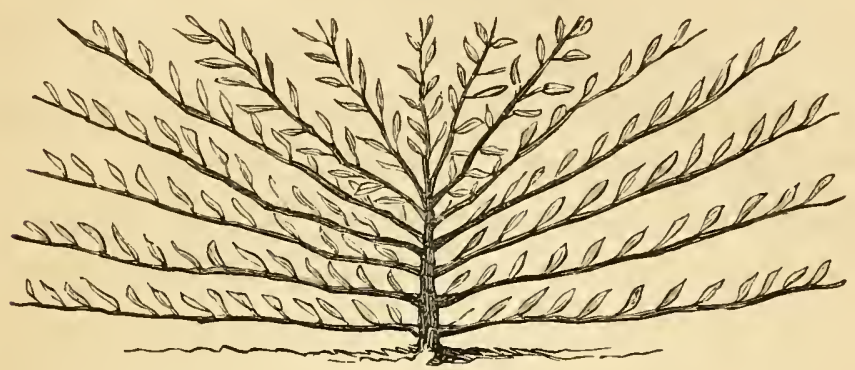

The arms which form it are, of course, permanent, and are kept in position by tying to the trellis, at proper distance from each other. The laterals, represented above, start from these. It is intended that each shall bear a single fruit, which is allowed to grow about midway from its base to terminus.

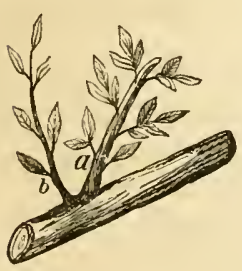

(a) represents where the fruit is to be borne. (b) the lateral for the next year. The buds which push are also pinched after making three or four leaves, with the exception of that at the terminus, which is allowed to grow a little longer, and the lower bud, which extends to form a lateral for the succeeding year. At the winter pruning the old lateral is cut as close to the main limb as possible without injuring the new shoot. 
Oblique rod training. This system has recently been introduced into our country as applied to the pear. In Europe it was found to be a simple and expeditious method of growing the peach, and without doubt might be applied to other fruits. It is claimed that it is superior to the other styles of trellis or wall-training, on account of the ease with which the rod can be replaced. It has been practised in the vicinity of Paris since about 184().

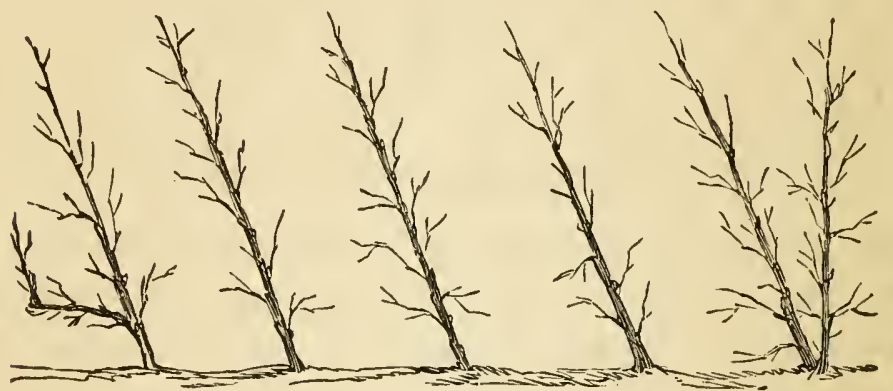

The trellis should be about ten feet high, and the trees trained at an angle of nearly forty-five degrees. After planting, the rod is cut to about eighteen inches in height. The buds bursting must be pinched and treated like those upon the arms of an espalier, in order that they may produce fruit, with the exception of that at the terminus, which is allowed to grow. If the shoot be strong, it may be retained for three feet, and so carried up by degrees until it reaches the proper height. On the left it will be seen that there is a vacancy to be filled. 
This is done by bending down the growth at the end of the first year, and permitting the uprights to proceed from it. On the right, after the rod has become formed the lower bud is allowed to burst, and throw up the remaining shoot.

Oblique double rod training. This is practised in

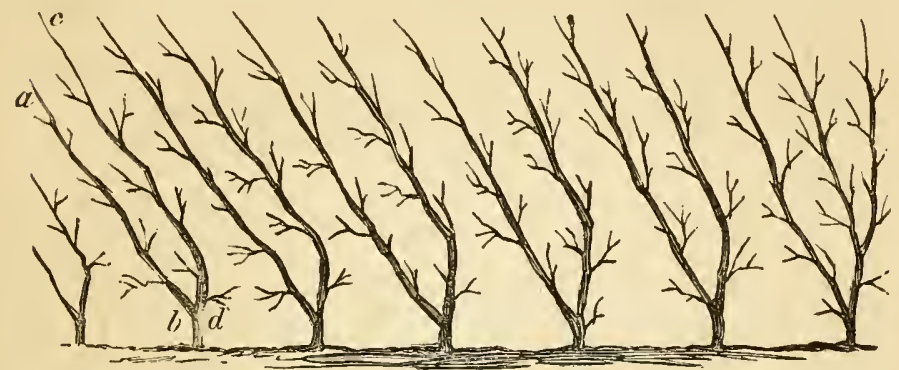

some parts of France, and is somewhat similar to the simple rod-training. 'The trees are four feet and four inches apart. A single limb is first grown, and when it is strong enough, is bent to the angle (a) $(b)$, and the lowest bud at the point where it bends is allowed to make another arm, which is afterwards placed as in $(c)(d)$. All these inclined methods of training the branches have for their object the improvement of the fruit in quality and quantity; the bend causes a staguant flow of sap, which is favorable to that object.

Double oblique rod training. This differs from the simple method only in the fact that the branches are placed at one foot apart instead of three, and that it is composed of a single tree. Great care 
should be observed that one side does not become stronger than the other.

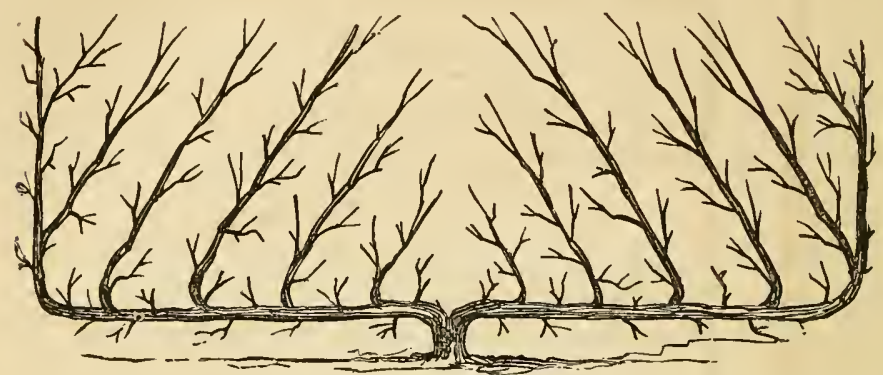

A style of training practised by M. Lepere, near Paris, is given on page 315 as figured in the Gardener's' Chronicle for 185\%, page 233.

All these styles, it will be perceived, are designed for the trellis or wall, because, in the countries where they originated the sun is not as powerful as in the United States, and by means of these helps they receive an increased amount of heat by radiation. This is not necessary here, and therefore the standard is the more favorite form of growing all fruits. The peach is not so short-lived a tree, when properly cared for, as some would have us believe; but, with the neglect which it too often receives, it soon falls a prey to disease.

Standard training. By reference to the first part of this chapter, under the head of "Pruning after transplanting," it will be found that it was recommended to cut down the yearling tree to a few inches. This is to encourage the branches to start 


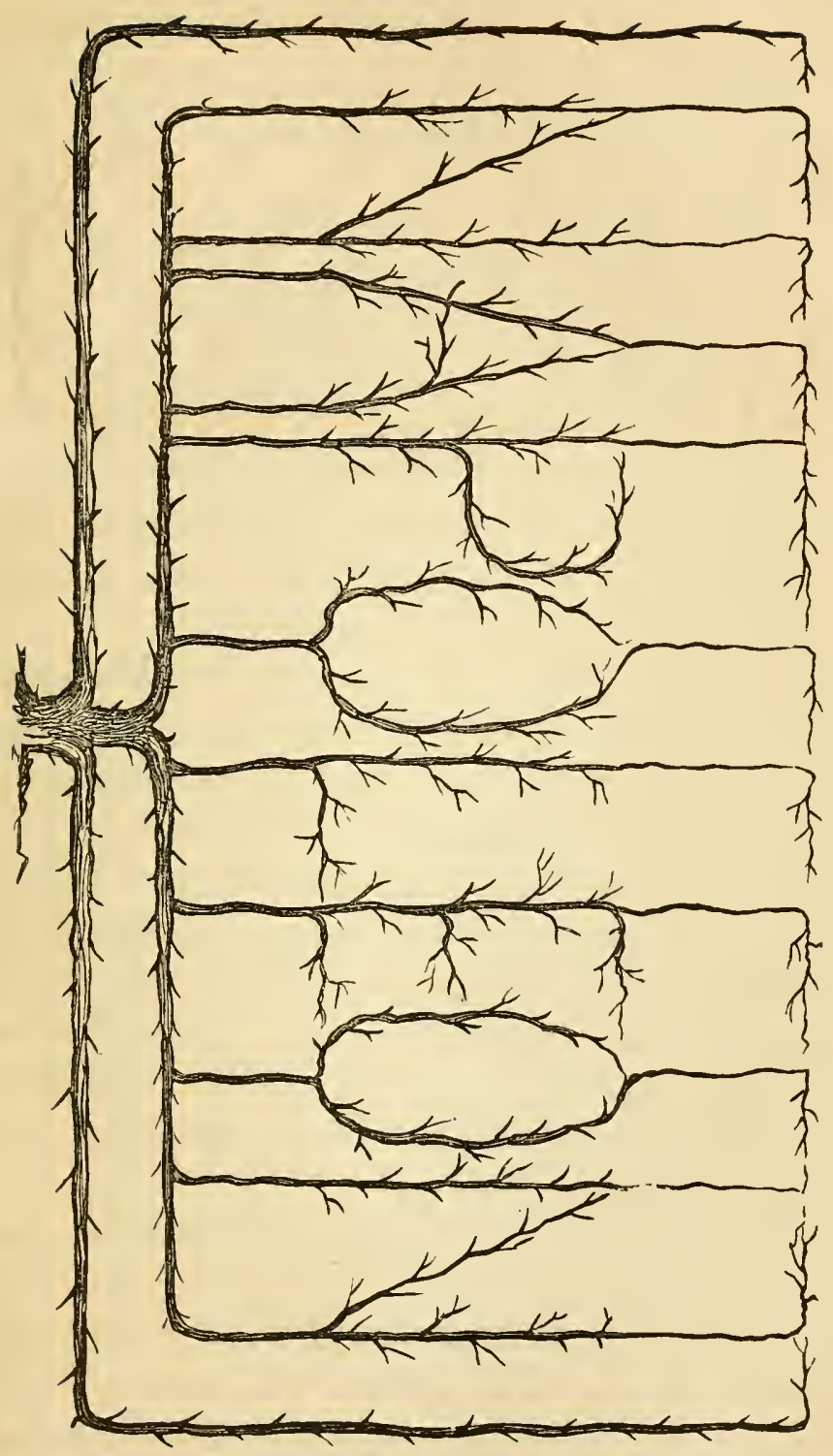


near the ground. The majority of neglected trees are broken down during the production of their fruit, by its weight on the end of very long limbs.
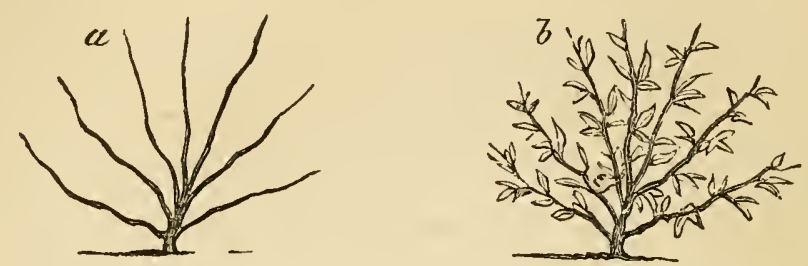

(a) represents the peach tree at the end of the first year, the arms having been formed, which show the skeleton of the tree. These are cut back at the winter pruning to one or two feet, according to their strength, and laterals are allowed to form and bear fruit at every bud, except that at the terminus, which is to grow. After two or three years the tree presents the appearance of $(b)$, and is to be pruned so as to keep it within its prescribed limits, which should be less than ten feet in height.

But in many of our northern districts the peach is injured seriously by the vicissitudes of climate. In such positions it is evident that the standard tree would not succeed, nor the espalier unless covered in winter, which its size and form preclude. The fact, which has been repeatedly observed, that limbs near the ground fruit when others do not, even when there is no snow of consequence to cover them, has suggested the following diagram.

Figure 1 represents the tree after the growth of 
the first year ; it having been cut down at planting to one foot. The second year the limbs are drawn

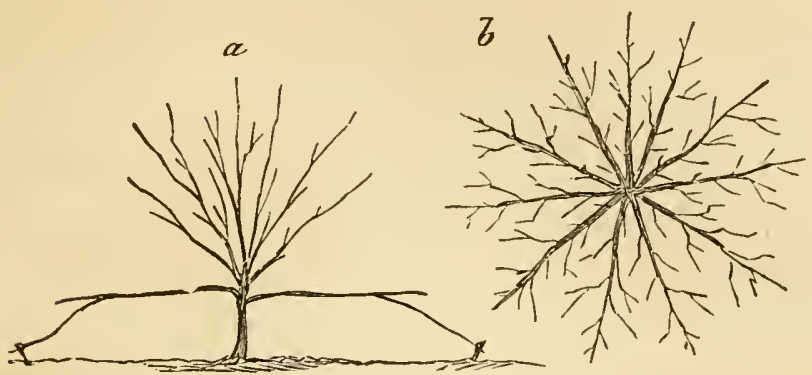

down horizontally and tied; the branches having the appearance of a wheel laid upon its side, which, when clothed with spurs, and seen from the top, is like figure $b$.

But, in certain sections, even this is attended with uncertainty, and still more precaution is necessary. In such cases, the cultivator should resort to the inclined trellis. Posts about one foot in height are set in the ground for the front of the trellis, and those for the back are two feet. Rails are then laid from post to post, and slatting across them. The tree having been planted before the trellis, is cut to about a foot in height, and at the end of the season

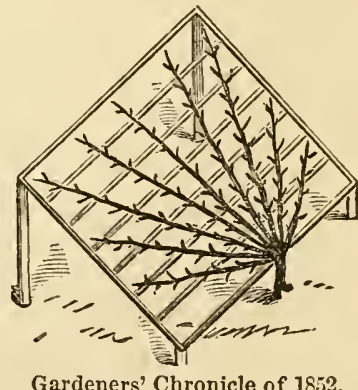

Gardeners' Chronicle of 1852. the arms are laid in their proper position upon the slats, the after pruning being the same as that of 
an espalier. That they may be protected from the winter's sun, which is the cause of their injury, straw, seaweed, or some other light material should be shaken over them in so small a quantity as not to afford shelter to mice; or a second trellis may be constructed over the first which shall be covered with such materials, or with loose boards.

The Apricot. This is trained by the espalier or standard methods, in the same forms as those applied to the peach and nectarine. The standard is always to be preferred where it is hardy. The remarks of Mr. Loudon, in his "Encyclopedia of Gardening," upon the pruning of the apricot, are given at length.

"The winter pruning should either be performed at the fall of the leaf, or at mild intervals from that time to the beginning of March" (in northern latitudes just before the swelling of the bud). "If it is deferred until the buds begin to swell, the promising shoots can be better distinguished. This pruning comprehends a general regulation both of the last year's shoots and of the older branches. The apricot bears upon the wood of the previous year, and upon spurs arising from that which is older.

"A general supply of the most regularly-placed young shoots, must be everywhere retained for successional bearers the ensuing year. Cut out 
some of the most naked parts of the last two years' bearers, and old branches not furnished with a competent supply of young wood or with fruit-spurs; cut, either to their origin, or to some well-directed lateral, as most expedient to make room for training, a new supply of the young bearers retained; and cut away all decayed wood, or old stumps. Generally observe in this pruning to retain one leading shoot at the end of each branch; either a naturally placed terminal, or, where a vacancy is to be furnished, one formed into a proper leader by cutting to it. Let the shoots retained for bearers be moderately shortened; strong shoots being reduced the least - one-fourth or less of their length; from those which are weak take away one-third, and sometimes half. This will conduce to the production of a competency of lateral shoots the ensuing summer, from the lower and middle placed eyes. As small fruit-spurs, an inch or two long, often appear on some of the branches of two or three years, these spurs should generally be retained for bearing, and thick clusters of spurs, which are apt to be formed upon aged trees, should be thinned."

The Pear. This fruit does not, like the preceding, bear upon the wood of the previous season, but on permanent spurs; and the method of treating them is important. The accompanying figure from the Gardeners' Chronicle, represents " $(a)$ as pro- 
gressing a blossom bud, while $(b, b)$ are already

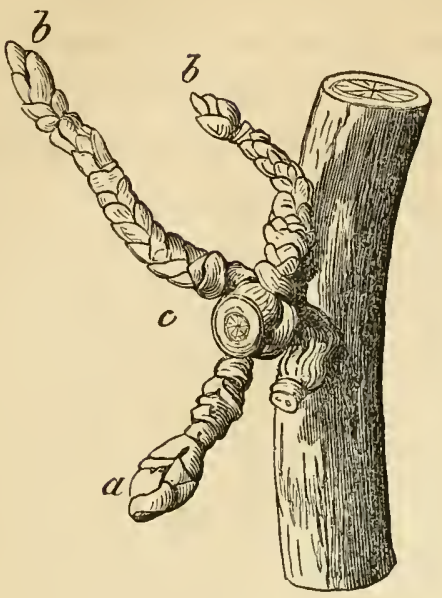
such, known by their plumpness, and from early spring these buds exhibit signs of active vegetation; but in $(a)$ the surrounding scales remain undisturbed until late. The scar at $(c)$ is where a portion of the spur which bore fruit has been cut back, at the winter pruning; after $(b, b)$ have produced, they also are cut back to buds likely to form at their bases, as did those at that of $(c)$." Unless this was done, decay would commence in the old spur, and spread among the tissue of the wood, until the whole spur was destroyed.

The causes which render it necessary to train the pear against walls in England, are not of force in this country. The summer is of such warmth as to perfectly mature the fruit without the aid of artificially radiated heat, and the standard is generally preferred.

Standard training. A bud of one year's growth will, of course, be a straight shoot, having buds from the base to the extremity. As the sap always seeks the highest point, those buds which are at 
the terminus will grow most rapidly. If the shoot has been strong, this would carry the limbs of the tree too high, and leave the stem very slender; therefore it is cut back to the height from which it is desired to have the highest limbs start, which should be from two and a half to three feet.
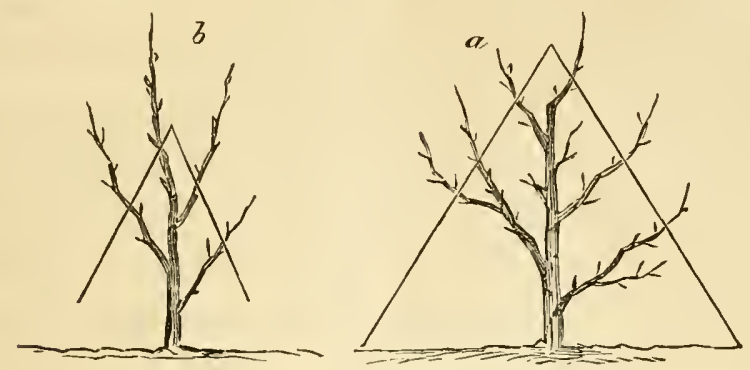

At the close of the second year the young tree will present the appearance of figure $b$. Then four shoots have been formed, the central leader being the highest. At the next winter's pruning the tree is cut at the point indicated by the transverse lines. The lower branches are left the longest, because the force of the sap tends upwards, and these will elongate slower. The next summer the buds upon these limbs are pinched to three or four leaves, except two at the terminus, which are allowed to grow. At the end of the third year the tree appears as in figure $a$. The transverse lines show when the third winter's pruning is to be performed. The same course should be pursued until the tree has attained about ten feet, when these terminal 
shoots, which are allowed to grow during the summer, to draw up the sap into the fruit-buds below them, are cut back to one eye every year.

It may be suggested, how can such a course be pursued with a tree thirty or forty feet in height? The answer is that a good cultivator will not allow his trees to attain that height. While summer pruning generally holds the vigor of the tree in check, yet it is sometimes necessary to resort to root-pruning, which will be described in another part of this chapter. After the tree has arrived at full size, all the pruning which is essential, is, cutting back the growths upon the end of each limb, and trimming the spurs.

The method of pruning the dwarf pear is the same as that upon the free-stock. By proper training the latter can be planted as near as dwarfs, and will succeed as well as when at a greater distance.

Quénouille training. This system is founded upon

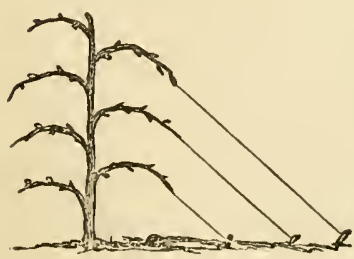
the fact that the fruitfulness of a tree is augmented by placing its limbs horizontally, or in a weeping position. They are tied to stakes driven in the ground, and made to assume the form represented in the figure. By the same means, the balance can be restored to an espalier, when one side has gained an advantage over the other, by depressing the thrifty limbs. In this 
way refractory trees can be forced to become fruitful. With these exceptions the style has no practical value, as all bearing trees assume this habit, more or less, with age.

Wineglass training. The permanent arms, which are five, start from a point about eighteen or twenty inches from the ground. These are not allowed to make any minor branches. The shoots, as they make their appearance, are shortened back to three or four leaves, to encourage the formation of fruit-buds. 'The terminal

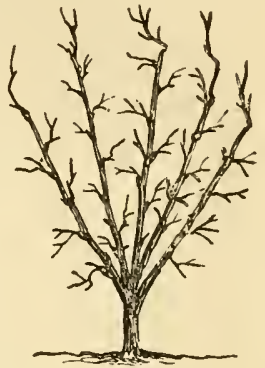
eyes are allowed to extend at will, and are cut back at the winter pruning to one or two eyes - sufficient to secure one for a shoot the next summer. If the tree is very vigorous, the shoots should not be pinched too severely, else it will cause the fruitbuds to become transformed into wood-buds, and grow; but they are permitted to extend, and are then shortened at the winter pruning. It is urged in favor of the above, that in violent winds the branches have full sweep to swing without interfering with each other, and the spring given from so long a limb gives so easy a motion as to hold the fruit fast, while it combines all the advantages of the pyramidal or standard pruning. On the other hand, it is contested that the weight of the fruit upon the terminus of these limbs, at such a distance 
from the fulcrum or base, is often so great as severely to strain, if not to break, the branch. This argument is easily overthrown on two grounds, and it therefore resolves itself into a mere matter of taste. 1. Each limb should not possess more than from twelve to eighteen pears. 2. If the branches should by neglect or bad judgment be allowed to produce more, the elasticity of so long a branch is so great that the end of the limb could almost touch the earth with its weight of fruit without injury. The standard is, however, more natural, simple, and more beautiful.

There are some positions where an espalier, or wall tree, may be grown where a standard could not, and it is therefore proper that we enter more largely into those plans which are most practised in those countries where they are favorites.

Mr. Loudon, in his valuable Encyclopedia, publishes the following forms, which are used in England for small trees (see page 325).

The Cherry. This fruit is so uncertain a crop when left to itself, and yet so delicious, that it is well to devise some methor of pruning which shall, if possible, remove the obstacles to its culture. It is of very vigorous habit, even upon poor soils, and in northern climates does not always ripen its wood sufficiently to escape unscathed the vicissitudes of the winter. While the tree is forming, the young 


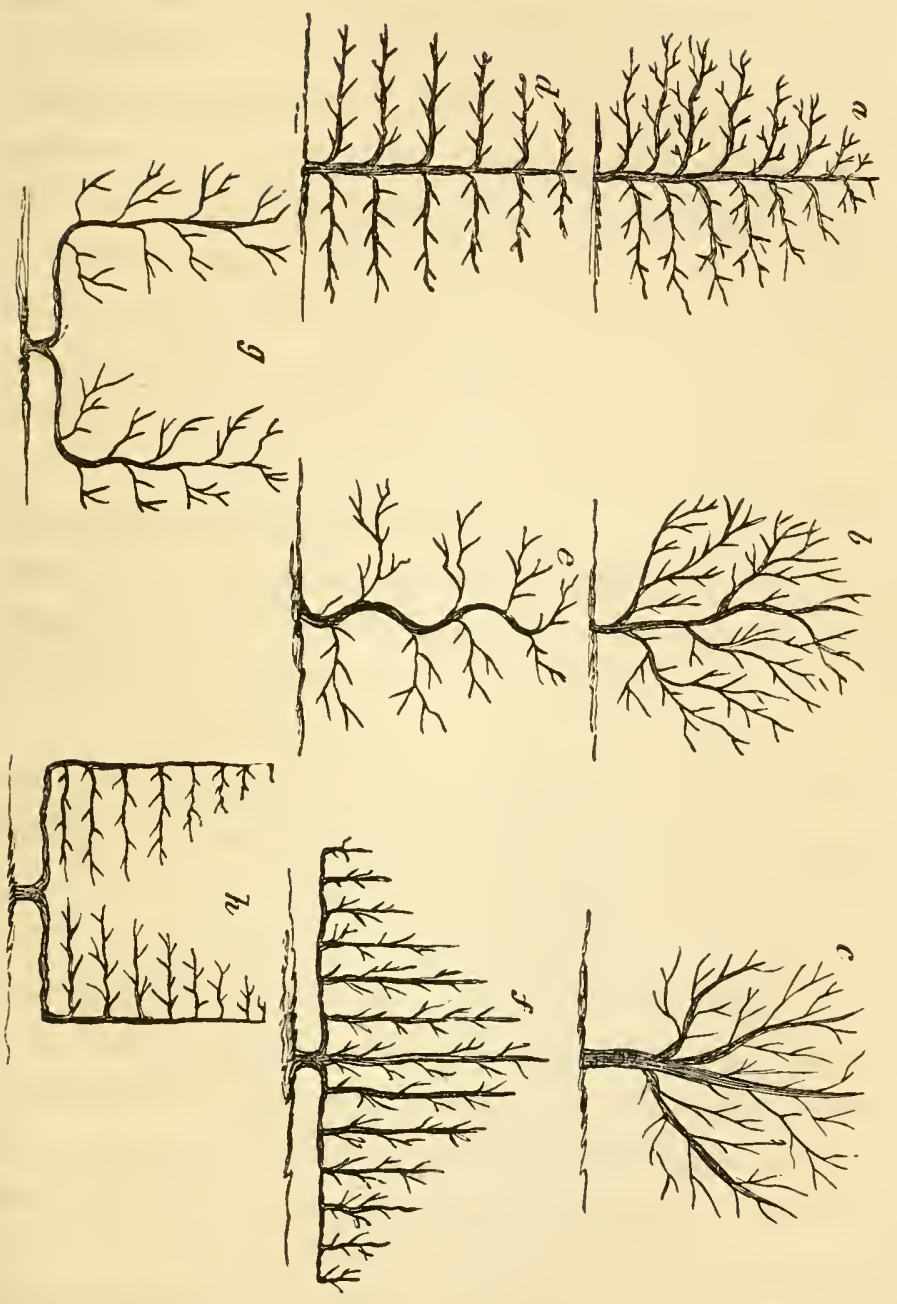


shoots should be directed properly, and the winter pruning should not be performed until all danger of cold weather is past. When it has attained the height which we desire (not more than fifteen feet), the pruming should be done in a way to check its luxuriance. Root-pruning will accomplish this, but a more mild operation may be attempted first, and the former used as the next resort. This tree pushes its buds with great force in the spring, and expends considerable strength in the process. Therefore if pruning is done after the buds have well swollen, we shall probably arrest its undue vigor. The morello varieties bear fruit upon the wood of the previous season, and regard should be had to a constant supply of young wood, and that which has produced should be cut out.

The Vine. Totally different from that of any of the plants to which we have referred is the pruning of the vine. It produces its fruit on wood of the same season's growth, and its vigor is therefore to be encouraged. As the size and quality of the bunch and berry are influenced considerably by the strength of the canc, it is evident that, for constant fruitfulness, a succession of young wood must be secured. Almost as many methods of training the vine have been recommended as men who grow it, each having advantages, yet all being similar in the endeavor to keep the trellis covered with bearing wood. 
When the vine is planted, it should be cut down so as to leave one eye to grow. Some accident might destroy this, however, and two or three should therefore be left at the fall pruning, when those which are superfluous should be destroyed. The first season this bud should throw a straight shoot of several fect. During November it should be cut back to five eyes; if it is delayed until spring, the wound will bleed, weakening the vine, and causing the shoots to start with less vigor. This stump will throw five branches, which are spread out on the trellis like a fan. At the next fall pruning, these arms are shortened, learing two eyes upon each, and the next summer the vine possesses ten arms. The vine has now attained it stature. At the next fall pruning, beginning at the bottom, the first limb is cut within two eyes, so as to sccure one, and the next to nine, and so on alternating two eyes and nine. The next summer, the five arms which have nine buds will fruit from each, and the lateral should be pinched within two joints of the bunch of fruit; the other five limbs throw five strong shoots, for fruiting the following season. At the next fall pruning the bearing arm or branch should be cut back to grow, while the other is left with nine eyes to fruit; thus each arm fruits on alternate years.

Sir Humphrey Davy, in his Notes and Observations on the Ionian Islands, says that the pruning of the vine is such as would be pronounced severe even in 
the wine regions of France. The value of the produce is so small that the cultivator cannot afford to use manure, or stakes to support the vines. The poorer the soil, the more vigorous do they prune. "In the rocky situations of the district of Erisso, in Cephalonia, where the vine is planted in the crevices of the rocks, only one or two of the last year's branches are preserved, and of these the greater part is removed, only two or three buds being allowed to remain." This practice is proved to be beneficial. It is urged that the branches of the vine extend further than the roots, and unless severe pruning is practised in poor soils the branches will exceed in proportion, and the vine become weak in consequence.

Simple cane training. The vine produces fruit

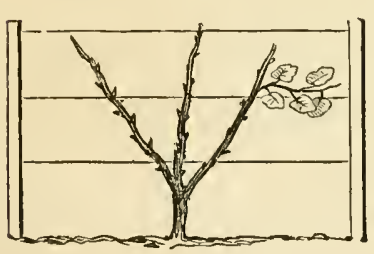
upon the new wood, and consequently a succession of it must be secured. A very simple method is that represented in the figure. The first year the vine is kept to a single cane. At the winter pruning, which takes place after the fall of the leaf, and the ripening of the wood, the cane is shortened back according to the strength of the growth, and the next season the terminal bud is allowed to extend, and one of the lower buds to start also, to make the cane upon the left. As soon as the strength of the vine will per- 
mit, the cane upon the right is carried up, and the vine is ready to produce fruit. This is borne upon the laterals which start from the buds on these canes, and which are pinched off after forming two leaves beyond the bunch of grapes. At the winter pruning these laterals are cut back to the lowest bud, which is to cast that for the next year.

Simple Thomery. This, although not so easily covered as the preceding, is well for cold or extreme latitudes; as it is for all others. The permanent arms, being so near the surface of the ground, are not very liable to suffer from extrenies. For if the temperature becomes suddenly cold after extreme heat, to such a degree as would be ruinous to canes higher from the ground, yet these receive radiation of heat from the earth, which enables them to cool off more gradually. The first season the vine is trained to one cane, and at winter pruning is cut back to two eyes; each of these will make a new cane, which is cut the next winter to about three feet, or rather pruned to the same number of sound eyes. These canes are bent down, and

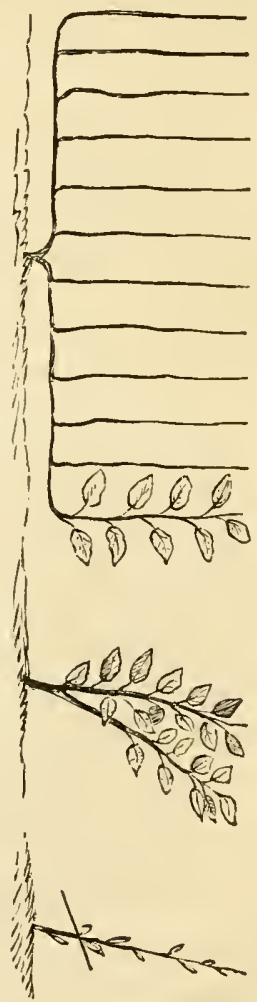
make the permanent arms, from which the canes 
will grow the next summer. These canes are then cut back to two eyes, and each eye may be allowed to bear one or more bunches of fruit, and produce a cane of about three feet in length. Care should be taken that the shoots are of equal length, as if one gains the ascendancy it will rob the others.

Systems to be practised where there is no need of winter protection. 'The training of vines upon Kelly's Island, Ohio, seems to be more or less peculiar to the locality, and as few failures have occurred, it is well to investigate it. Mr. George C. Huntington, one of the vignerons of that island, gives a description of the trellises used. They are constructed of posts set in the ground, eighteen feet distant in the lines; on these is stretched No. 9 annealed iron wire, weighing about one pound per rod, and therefore, if the rows are eight feet distant, requiring about one thousand pounds for the acre. In placing it a cylinder is used of the proper size to take a coil of wire. This is set upon a horse, like a grindstone, when it uncoils much smoother, and with less twist than if laid flat upon the ground. It has been found that the strain of the whole trellis comes upon the posts standing at each end, where the intermediate ones are bored to admit the wire through them, but by straining each length as the work procecds, and fastening it with a staple driven hard, the strain is more equally distributed. Three lines of wire are made to each trellis. The end 
posts have a brace inside to support them. A better and more permanent, although more expensive method of sustaining the posts, is to fix a stone under ground outside the end-post, with a rod reaching from it to the top of the former, which is tightened at pleasure by means of a coupling iron. Figure $(a)$ represents this, and $(b)$ the old methods.

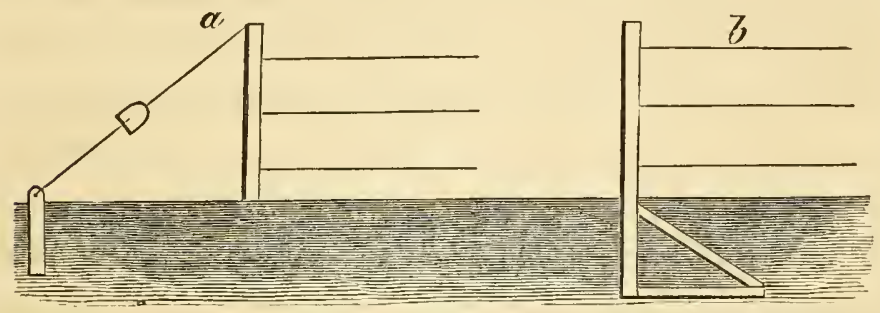

Mr. Huntington says that the plan of training is one of three canes in the form of a fan. These are cut back after bearing, to single eyes, which produce others, while the young canes that have been made at the same time are retained for fruiting the next year.

Plan practised in Ohio. This is thus described by Mr. Buchanan, in Elliott's American Fruit Grower's Guide. "In the spring" (at planting) "cut the young vine down to a single eye at first; if two are left for greater safety, take off one afterwards, drive a stake six or seren feet long firmly to each plant. Locust or cedar is preferred, but oak or black walnut, charred at the end, or coated with coal tar, and driven into the wood, will, it is said, last nearly as 
long. Keep the young vine tied neatly to the stake with rye or wheat straw; pick off all suckers, and let but one cane grow.

"'The second spring after planting, cut down to two or three eyes, and the third to four or five, pinching off all laterals, and tying up the vines. The third year they will produce a few grapes. Train two canes to the stake this year, and take off laterals. Pruning the fourth year requires good judgment, as the standard stem has to be established. Select the best cane of last year, and cut it down to six or eight joints, and fasten it to the adjoining stake in a horizontal position; tie to the stake at the top, or bend it over in the form of a hook or bow, and tie it to its own stake. This is the bearing wood. The other cane, cut down to a spur of two or three eyes, is to make bearing wood for the next season. Give the shoot the first tie to the stake,

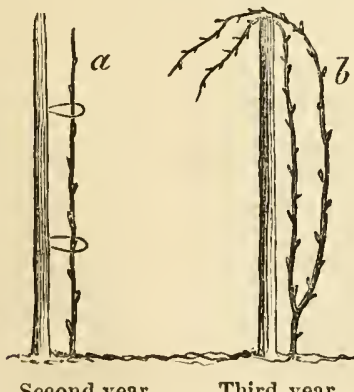

Second year, Third year, before pruning. before pruning.

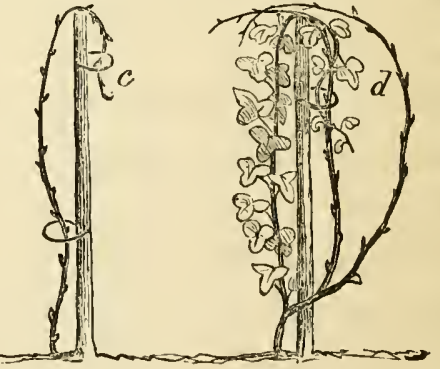

Fourth year, pruned.
Fourth year, summer training.

nine inches from the ground, and the second nine inches above this. 
"In the succeeding, and all subsequent years, cut away the old bearing wood, and form the new bow, or arch, from the best branch of the new wood of the last year, leaving a spur as before to produce bearing wood for the coming season, thus keeping the old stalk of the vine down to within eighteen to twenty inches of the ground. The vine is thus within reach and control."

Some grape-growers prune according to a renewal system, in which only two canes are used. Thus while the cane at the right is bearing a crop, that on the left has been growing to take its place the next year; when the former will be cut to one bud, and make a new cane for the alternate year. Those who practise this urge that strong buds are formed, which

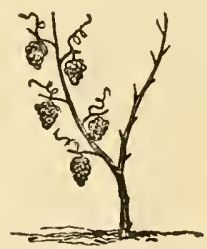
produce the finest fruit, and although this may be, and is, true to some extent, yet, as Mr. Charlton has said in his work upon the vine, the cutting off such a large proportion, and leaving so little perennial, structural base is of very doubtful economy. It must keep the plant in constant excitement, which is likely to result in disease and premature debility.

The following is the same principle applied in a more complex form. The first year the central cane was allowed to grow to half its present height. Upon that is produced fruit the second year, while 
it added as much more to its height, and the cane

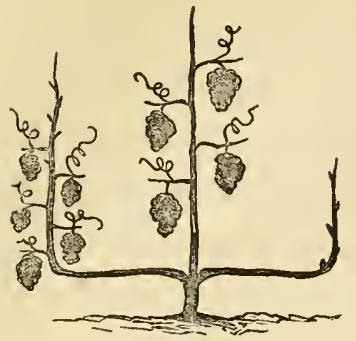
on the left also in the second year grew to half its present length. The third ycar the vine had the appearance of the figure. The top of the central cane, and the lower half of the left, produce fruit ; and the latter adds to its length, while that upon the right forms itself, as in the above representation, upon which to bear the next season.

An easier system of renewal is represented by the following. Every alternate bud upon the arm makes a cane while the other bears grapes. The next year the former bear,

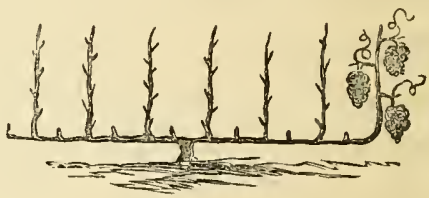
and these are cut back to one eye to push a cane for the next season.

'The celebrated Thomery system is thus given. A wall is erected about seven feet high, and before it a trellis is placed.

When vines are trained upon poles brought together at the top, a hoop should be inserted, to give opportunity for a free circulation of air.

The Currant. This fiuit should receive an oversight in the summer to see that no inproper or unnecessary growths are made which shall interfere 
with the limbs that are designed to remain; and also that suckers, which make their appearance, may be checked. This latter should not be done by simply cutting them off, which would only induce a more vigorous growth; but they should be twisted off, and then the tissue of the wood will be so far destroyed as to prevent its throwing a new shoot. The bush should not be restrained to one stem, because in the frequent attacks of the borer the plant would be entirely destroyed; but two or three stems may be allowed. The currant bears fruit on spurs from the old wood, as well as upon the new ; therefore if any of the superfluous shoots of the last year are cut back, an inch or two should be left on which spurs may be produced. All the old wood which has become unfruitful should be cut out, to make room for some of the young limbs. Very many successful growers of this fruit in England have cut back the growth to a few inches, when the berries begin to color, and have thought that it greatly improved the quality of the fruit; but in this country such treatment would be far from judicious, as our sun is so powerful that it would cause them to shrivel and dry, as do the common Dutch varieties under ordinary treatment. The shade afforded by the young shoots is not as injurious here as the deprivation would be, as affecting the length of the season. 
The Gooseberry. Maher states that if the gooseberry bush is crowded with superfluous shoots of the present season, they should be thinned so that the fruit will not have want of light and air; but this pruning must be moderate. At the winter pruning, in early spring, all the unnecessary growths can be removed, together with those which bend too low and drag upon the earth. The finest specimens of this fruit are produced upon the young wood of the preceding year. In general the shoots may not be prumed at all, except when they extend beyond the limits, when they may be cut back to eight or ten inches, but not shorter, for it would induce a superfluity of wood. The gooseberry bush is seldom retained in bearing for many years in the gardens of the most successful growers. It bears its best fruit during the fourth or fifth year, after which it depreciates each season. The gooseberry is the pride of some gardeners, and great pains are taken to make the bush beautiful as well as productive. 'Those varieties which are naturally upright in their growth should be planted at a distance of five feet. A central stem is carried up, and from it the branches proceed, which are cut back so as to form the bush like a pyramid. The limbs are not allowed to start within a foot of the ground. When the plants have completed their growth, they will be about six feet ligh. The weeping sorts do not reach more than half that. 
The Raspberry. At planting, the cane is cut down to six inches, and will throw up shoots which are to bear fruit the next year. These are sometimes fastened to stakes driven in the ground, or a trellis is built on which the canes are laid. The latter is not upright, but generally at an angle of about sixty degrees. This encourages the buds to burst every eye, and to throw the little shoots upon which the fruit is produced. Some tie one-half of the tip of one plant to that of another, and the remainder to that on the opposite side, which answers the same purpose. The summer pruning consists in cutting out the old canes after they have finished fruiting, and the superfluous and weak young shoots. This strengthens the buds upon the new canes. By a judicious winter pruning the season of bearing can be extended through six weeks.

Dr. Warder, of Ohio, published an excellent article upon this subject in the report of the Agricultural Department. He thought it a great mistake to leave the canes so long as they are generally seen. The tendency of the sap is always upwards, and therefore the weak buds at the top are those which push, producing inferior fruit compared with that below, which would have been borne on those had they not been smothered. The finest raspberries are always borne by the laterals which start from the strong buck at the base. The black-cap varieties should be pruned to three feet at least, and 
our common sorts to twenty or thirty inches, depending, of course, upon the strength of the shoot. As the buds at the top of the cane bear the earliest fruit, the scason may be extended if some are left unpruned, others cut as directed for the main crop, and some as low as one foot, for the latest supply.

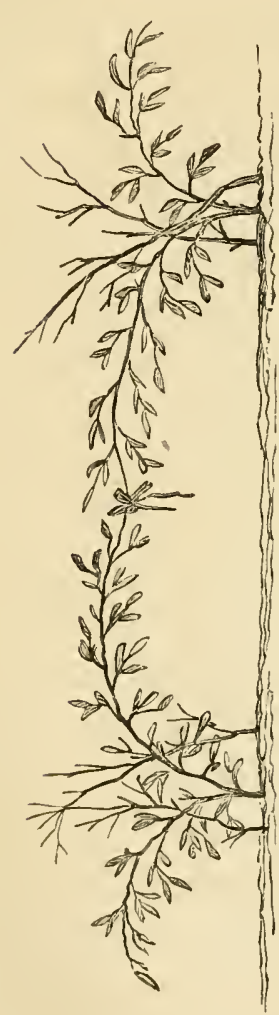

During one season the frosts held off, and quarts of berries of the Belle de Fontenay were gathered on the sixth of November, in the vicinity of Boston.

The Blackberry. This is such a delicious and beautiful fruit for the dessert that it is surprising it has been permitted to be only a nuisance in most gardens. If they are pruned properly, they can be as easily cultivated as any other fruit, and with little care yicld wonderful returns. When the plants have been set at regular distances, the suckers which are allowed to grow should be liept as near as possible to these places, and only a sufficient number grown to replace those which are to be cut out after producing a crop. If an unnecessary number are allowed to start, they draw away the sap, and prevent the production of 
fruit. The berries are borne on the young spurs arising from the buds, and, by bending over the canes and tying them together, as seen in the figure, all the buds will be encouraged to throw these spurs.

One of the most beautiful as well as successful methods of pruning the blackberry is to pinch out the terminal bud when the cane has grown about two feet and one half in height, when side branches will be thrown out, on which the fruit will be borne.

The Strawberry. In this country the cultivation of the strawberry is beginning to attract more attention than formerly, and various plans of training them have been proposed, to reduce the necessary amount of labor. The old style was to grow them in beds, and renew them once in a few years; but the expense of weeding them was so great that it made fearful inroads upon the profit. It was

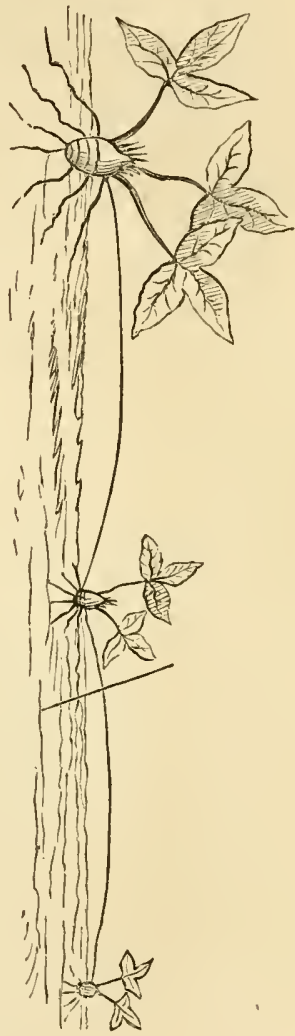
soon ascertained that it was scarcely profitable to allow them to bear more than one crop before renewal, when grown in beds. The rumners of the year previous are planted in the spring, cultivated 
during the first season with the horse-hoe, and ploughed in the next summer, after producing the crop and growing enough rumners to reset the plat. By this method every alternate season is left blank, while the plants are becoming established. Some plans unite the advantages of constant renewal with a yearly crop. After the fruit has become mature, the plant commences to make runners; on each of these, three or four plants may be formed. When the first has been produced upon the runners, if its roots are covered with a little- loose earth, and all further extension of the runners prevented, the plant will very speedily become strong, and, if transplanted about the first of August, a crop may be obtained the first year, and one season's umprofitable cultivation saved. If they are planted in hills, the cultivation can be done i almost entirely with a horse, and the plants can be renewed each year, as shown in the diagram, and the old plants destroyed.

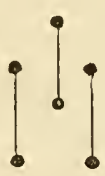

The strawberry plant is very fond of moisture, and irrigation at the time of the growth of the fruit produces an astonishing increase in its size. Many methods have been attempted to secure this benefit with the least labor. Mr. Loudon gives an account of the practice of a gardener in the 
neighborhood of Chatham. The beds were upon level ground, each of them being about one yard in width. Between each of these beds was a trench nine inches wide. The beds were kept in place by three heights of brick without mortar,

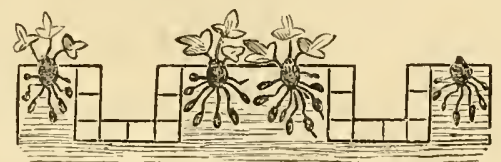
leaving the trench two bricks in width at the bottom. When the plants were in fruit, if the ground became dry, these trenches were filled with water from a pump near at hand. The result was an improvement in quantity and quality, and the extension of the season.

Root-pruning. By cultivation the roots are encouraged to extend, while the top is pruned and produces such a disturbance in the flow of sap, and the top not being able to dispose of the large amount of sap in circulation, that various diseases, such as canker, are induced. The addition of fertility to the soil increases the difficulty, while transplanting, which is virtually root-pruning, restores the equilibrium. Therefore, by this method of cutting the roots, undue luxuriance may be checked.

It encourages the formation of fruit-spurs, which takes place in unpruned trees after the luxuriance of growth has expended itself, and the cool weather of the autumn commenced. Root-pruning hastens this maturity, and consequently develops these buds 
more fully. For the same reason it prevents late growth, which so often leads to frozen-sap blight. Thus it may be said to render the tree more hardy, and it is probable that in the more northern parts of this country and the Canadas this would insure them many fruits which do not now succeed.

The operation should be performed with some regard to the variety of the firuit, and the present vigor of the tree. If it is just furnishing itself with blossom-buds, one pruning may prove sufficient, as all that is required is to induce the habit of fruitfulness. A tree of great vigor would be injured if pruned so severely as the former, and must be operated upon gradually, or by cutting only a part of the circumference of the ball of roots annually. Root-pruning, as productive of fertility, was originally suggested by the fact that mutilation of plants is often followed by prematurity. This can be observed upon those trees which have been girdled or severely injured in the stem, or whose roots have become bared. 'The practical application of this principle in gardening was made about the first of the present century, and fruit growers are largely indebted to Mr. 'Thos. Rivers, of Sawbridgeworth, England, for his demonstration of its advantages as applied to the different fruits. He thought it particularly adapted to those persons who had small tracts of land, and wished to realize the greatest returns; although the practice was by no means 
inexpedient for large orchards. He thus describes the method of performing the operation:

"A trench should be dug around the tree, about eighteen inches from its stem, every autumn, just after the fruit is gathered, if the soil be sufficiently moist; if not, it will be better to wait until the autumnal rains have fallen. The roots should be carefully examined, and those which are inclined to perpendicular growth cut with the spade, which must be introduced quite under the tree on all sides, ${ }^{1}$ so that no root can possibly escape amputation, and all the horizontal roots, except those that are very small and fibrous, shortened with the knife to within a circle of eighteen inches from the stem, and ail brought as near to the surface as possible, filling in the trench with compost for the roots to rest on. This should be well-rotted dung, and the mould from an old hotbed, in equal parts, which will answer exceedingly well. It may be found that after a few years of root-pruning, the circumferential mass of fibres will have become too much matted, and that some of the roots are bare of fibres towards the stem of the tree; in such cases, thin out some of the roots, shortening them at nine inches or one foot from the trunk. This will cause them to give out new fibres, so that the entire circle of three feet or more around the tree will be full of fibrous roots

1 This part of the work may be entirely avoided, if the bottom of the hole is floored with tile-brick or stones, when the tree is planted. 
near the surface, waiting with open mouths for the nourishment annually given to them by surfacedressings and liquid manure."

If a branch be lost from accident or disease, and it be necessary to produce another, the method adopted by M. Jamin may be useful.

(a) represents the position of a dormant bud, which will not burst naturally, because the force of the sap tends toward the highest portions of the tree. A cut is made through the bark, across the top and down the sides of the bud, which causes it to start and grow. 


\title{
CHAP'TER X.
}

\author{
SUMMER CULTIVATION.
}

REMOVAL OF MOSS AND DECAYED BARK - LOOSENING TIIE SOIL - MULCHING - THINNING TIE FRUIT - RINGING - WATERING, TYING, SUPPORTING, AND GATHERING THE FRUIT - PRESERVATION.

TIIE labors demanded of the fruit-grower during the summer are varied, and will be considered in the order in which they will necessarily require his attention.

The removal of moss and decayed bark. The presence of moss or lichens is not itself injurious to trees, exeept as providing a shelter for insects; but it is generally an index to a bad state of health in the tree. They are among the agents which nature employs to restore vegetable substances to earth, after life has left them. 'They never attack any part of the tree which is still alive, but only those which are in a state of decay. A tree which is in full vigor, as it grows and its trunk increases in size, bursts its old covering, and it peels off. When it is persistent it shows that the health of the tree is bad, on account of the barrenness of the soil, or, more frequently, the want of drainage.

The evils resulting from such a state, are that the 
tree is stifled or hidebound, and that this old bark affords shelter for myriads of insects, which ravage the crops the next summer. To restore the tree, the remedy must be applied to the primary cause, in the form of manure to increase the fertility of the land, or by draining to regulate its moisture. The tree should then be scraped so that the moss and old bark shall be entirely removed; but the instrument used for this purpose must not be too sharp, else it will mutilate the tree by exposing unduly the liber, or live bark. It is very well to wash the trunk with a very weak dilution of potashwater, to destroy the larvae which may be present. A great many orchards are treated so severely in removing the old bark as really to wound the tree, and the operation is generally rendered fruitless by the scrapings being left upon the ground, in which case the larvae can crawl upon and attack the trees almost as well as if they had never been touched. 'The bark which is scraped off should always be gathered up and burned, when the destruction of the insects will be certain.

Loosening the soil. The constant pulverization of the surface-soil, particularly by the use of the hoe, greatly promotes its fertility. By this means it is kept porous, and in a condition to absorb fertilizing gases, as well as moisture, from the atmosphere. It will readily be seen that deep ploughing or spading is injurious. 'The little fibres which 
produce and sustain fruitfulness are near the surface; they are almost invisible, and drink in the fertility of every shower, and that of the morning dew. The strong roots, which penetrate immediately to the subsoil, sustain the vigor of the tree, and it is the object of root-pruning, as has been seen, to prevent their formation, or to destroy them when in existence. 'Thus by this operation extreme vigor' is checked, and maturity gained. The same results are often obtained by encouraging the roots to come to the surface. This does not follow deep cultivation, for by it the little root-fibres in the surfacesoil are destroyed, or prevented from forming. It can, therefore, be understood why orchards deeply cultivated refuse to bear fruit, and still exhibit a luxuriant growth; they are receiving a constant pruning, which is discouraging fruitfulness, and promoting vigor. A fork, with tines only two or three inches in length, or a horse-cultivator, used judiciously, will answer all the good ends, without the evil results which follow the use of a deeper instrument.

The frequency of this operation camnot be governed by any fixed rule; the state of the weather, the condition of the soil, and the presence of weeds must decide it. The land should not be stirred when wet. The object in moving the soil is to so increase its porosity, by the separation of each particle from its neighbor, that the air may penetrate 
through to the subsoil, and aid in the decomposition and recombination of those substances which furnish nutriment to vegetable life. If the earth is wet when it is worked, it will lie even more close than before, and assume that condition which is described by the farmers as "baked," and thus the very object aimed at be lost.

Mulching. This consists in covering the earth, to the depth of an inch or two, with some porous material. It is always, and under almost all circumstances, attended with beneficial, and sometimes with remarkable, results. It is indispensable to the most successful production of fruit. Many of our best fruit-growers consider it so necessary that, should they be obliged to omit any of the important operations of cultivation, this would be among the last. It prevents, to a great degree, the cracking of fruit, and causes those varieties which are generally spotted and defaced, to become clean, and covered with a rich bloom.

The material to be used is not of so much importance; yet it is well that it be some substance which contains fertility, as thus a double object is gained in its application. Stable-manure, tan, sawdust, peat, or anything of this nature, will answer the purpose. Such as the second and third should not be fresh, for the gases generated might be unfavorable, or positively injurious. The time of application must be determined by the end which 
it is designed to accomplish. If it is protection from vicissitudes of temperature during the winter, which is given by the shade, it should be applied late in the fall, after the ground has frozen. If to prevent the ground from becoming too dry, and encouraging the roots to the surface, then in early spring.

The depth of the material should not exceed two inches. This maintains a regular degree of moisture in the soil, and it is thus always in a condition to absorb gases from the atmosphere, which is done more frequently in moist than in dry earths. The experiments of chemists have proved that air, passed through a long tube containing moist earth, loses entirely its ammonia. It also keeps the soil at an equal temperature, and prevents those sudden influxes of sap which cause many species to gum; the roots derive more fertility, both from their nearness to the surface, and on account of its porosity. In the autumn it lengthens the season, which the tree requires to thoroughly ripen its wood, and to perfect its fruit-buds; which it does when the flow of the sap has become sluggish. The soil does not lose its warmth so quickly; but, when it has once become frozen, the mulching prevents those thawings which stimulate the roots, and which often cause the death of the tree. As the sun has not so much power upon the soil in the spring, the frost comes out slowly, and the buds do not start until all danger 
is past; but, when they do vegetate, they progress with great rapidity. This is of so great importance that the balance of success often turns upon it, and yet it is the very operation which is generally most neglected.

The gooseberry is very sensibly affected by changes in the amount of aqueous vapor in the atmosphere, as well as in temperature, which produce mildew upon its fruit. If some material, such as has already been named, or charcoal dust, be spread upon the ground about the bushes, it will often prevent these discases. The annual application of these substances will produce a mould very favorable for the perfection of this berry. Tan has a peculiar value, as it throws off an effluvia which is destructive to insects, or prevents the deposit of their larvae.

If once commenced, it should be continued. If omitted for a season, the tender fibres, which have been encouraged to come to the surface, will be destroyed by exposure to the parching rays of the sun, or by the severe cold of the winter, intermitted by thaws. It should be either constant, or neglected altogether. When trees have attained sufficient size to shade all the ground, it will not be so necessary, as this answers the same purpose, at least during the summer. Its value is very clearly scen in the culture of the strawberry. This originally received its name from the fact that straw was placed under the vines for the purpose which we have stated, and to keep the fruit clean. 
Thiming fruit. Cultivators often speak of the "bearing ycars" of their trees, or the season when they produce a full crop. 'These fruitless years are the results of the exhaustion produced by the crop of the year previous; and the tree or plant has not strength enough, after maturing the fruit, to produce fruit-buds for the next season. This is particularly true with regard to late varieties. In the chapter upon pruning, it was stated that the fruitbuds wcre formed during the cool weather of the autumn, and this is the very time when the tree is taxed, in the producing year, in maturing the fruit. Summer varieties feel this strain upon their energies at an earlier part of the season, and recuperate before the time for the growth of the blossom-buds, and the consequence is that such sorts usually bear annually. If art can lessen the debility produced by the bearing year, and result in a full crop annually, it will be a triumph; and yet so it is.

The flesh of the fruit is formed like any other green part of the tree; its cells are similar, as is the duty it is called on to perform in the elaboration of the sap. This portion, therefore, which we desire for food, is rather a strengthening than a weakening ally to the foliage. It is the production of offspring, which exhausts the strength of plants as well as of animals; and this reproducing germ in fruit is formed in the seed. As soon as the annual has matured its seed, it droops and dies. It 
is evident that the seeds of an inferior specimen exhaust the energies of the tree as much as those of a superior quality. It is therefore important that the plant should be rid of all poor specimens, and that the good fruit should be so reduced in number that the tree can easily produce its burden without losing its vigor. Although the number of the fruits will be thus diminished, their measure or weight will be increased, their beauty improved, and their flavor made more delicious.

The extent to which this thinning of the fruit should be carried has, however, a limit. A single fruit conld not receive all the size and flavor which would have been expended in the production of those which were plucked, for it would not furnish a sufficient field to satisfy the tree's habit of fruitfulness, and gourmands or supply-shoots would soon make their appearance. Thie proper extent to which this operation should be carried will be readily determined by the good judgment of each cultivator, according to the power of his soil, and the thoroughness of his cultivation.

It is important that the orchardist should know which fruit to remove. Some varieties bear in clusters, and the rule should generally be to take off all but one in cach of these; but with regard to this a suggestion is necessary. If the pruning has been conducted as it should have been, the spurs, and consequently the fruit, will be distributed over the whole 
length of the limb. If this is not so, but the tips of the branches are provided with a large portion of the fruit, the thinning should be free upon that part, so that the strain upon the limb shall be equalized.

Ringing. This process is sometimes resorted to, in order to obtain fruit of extraordinary size; but although allowable in certain cases, it cannot be recommended for general use. It consists in cutting a ring of bark off, of about one-half an inch in width, and scraping the alburnum which lies immediately under it, so as to make an obstruction to the backward flow of sap, which is through this liber or newly-forming bark. The sap having reached the leaves, by means of the woody ducts, is elaborated, and, finding its downward passage checked, is precipitated into the fruit which lies above the girdle, which is thus greatly increased in size. It is better that this operation should be performed upon several small shoots, each of which has a fruit or two, than upon one which is common to all. The limb above this ring is of course destroyed after the first year. Some cultivators produce this same result by tying a string tightly about the limbs.

Mr. Knight accounts for this phenomenon by the hypothesis that the part below, being deprived of descending sap, ceases to grow, so that it does not impel the descending current with the usual force. 
'Thus the effect produced is like that of a drought which hastens its maturity; and, consequently, if persisted in, it will weaken and eventually destroy the plant.

Watering. Fruit is increased in size, when it is growing, by a good supply of water; and if extraordinary specimens are desired, it is necessary to apply it artificially. The effect of irrigation upon the strawberry has been illustrated in the chapter upon pruning. It has been stated by some strawberry growers that it is profitable to keep one man watering every half-acre while the fruit is green. This should be done before it begins to color, for this indicates that the saccharine fermentation has commenced, after which the berry ceases to grow. Irrigation, of course, detains the maturity of the fruit, as the time is spent in growing which would otherwise be occupied in fermentation, but the berry is much larger and finer. In producing specimens of other fruits for exhibition, irrigation will increase the size very perceptibly. The water is poured by means of a little trough scraped with the hoe at some distance from the trunk of the tree, so that it may reach the fibrous roots through which the tree is nourished. If it consists of diluted sewerage water, with a small proportion of urine, the effect is still more obvious. Mulching answers the same purpose, while it has the superiority of kecping the supply of moisture constant. 
Tying and staking the limbs. Sometimes the branches are so laden with fruit as to bend almost to the earth, and to give the cultivator great anxiety lest they should break and disfigure his trees. Although there is not much to be feared when a proper regard has been paid to the rules of pruning, which would so distribute and develop the limbs that each would be stiff and strong, also to the thimning which would regulate the strain, yet it is to be expected that some cultivators will neglect them. Such will be apt to find their fruit is all upon the tips of the branches, while the stronger portions, which are best able to bear the strain, are entirely free from fruit. This is owing to the amount of superfluous wood which was allowed to grow, which caused a want of light, and of proper circulation of the air. Such limbs evidently need support. This necessity is not always the result of bad cultivation, for trees are often taxed beyond the strength of endurance, especially those which have brittle wood. Support can be given them either by strings fastened to some higher portions of the tree, or by the use of stakes fixed in the ground. The latter is much the better way. If strings are used, they should be of very soft material, and should not be fastened tightly about the tree, but abundant room should be left for a free circulation of the sap. The usual method of support is illustrated in the figure : 
(a) represents the tree.

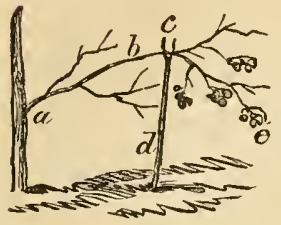

(b) the limb loaded with fruit.

(c) the point of attachment.

(d) the stake to support the limb.

(e) the weight of the fruit.

This method entirely defeats the object in view, and increases the danger of breaking the limb. While the strain was distributed through the whole branch before the support was used, it is thus concentrated at $(c)$, which becomes the fulcrum, while that part of the limb beyond the stake acts as the lever.

The proper plan is the following:

(a) again represents the tree.

(b) the limb.

(c) the point where the strain is felt after being equally distributed through the whole branch.

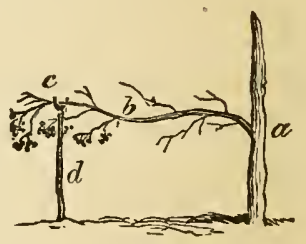

(d) is the stake.

In the first instance, when sufficient force is applied at (e) by the growth of the fruit, the limb will break, while in the latter mode of treatment the porver must be enough to pull asunder the very tissue of the wood before any damage can be done.

With some varieties the point of junction between the stem of the fruit and the spur is not firm; and when these are cultivated so that they attain a much larger size than they would naturally, it is 
very well to aid the stem by tying a string around it and then over the limb or the spur. This little work will reward the grower with still larger fruit. But what is better, is a bag made of gauze, drawn over the specimen and tied to the limb. This will not only give it support, but will catch it if broken off, defend it from birds, and to a considerable extent, too, from mischievous boys, who would seldom take off the bags, while others immediately at hand remained unprotected.

Gathering. This is generally esteemed a matter of little importance, but it is really one of great consequence. If fruit is gathered during a hot day, when the leaves have begun to wilt, and rapid evaporation is going on both from them and from the fruit, the flavor will be less desirable than in the morning when it is full of juice, which it has absorbed during the cool, moist hours of the night. But fruit should never be gathered during rain, or when wet, because this extreme is as bad as the other, and the fruit will be comparatively flavorless. The fact can be easily ascertained by permitting a fruit to remain in water for a few hours, and then tasting it. If picked in the heat of the day, when almost deprived of juice, it will absorb the flavor of almost anything near it, provided the atmosphere is moist. On this account fruits from a damp room, which is finished with pine, often taste of that wood. 
The proper time for gathering a fruit is when the saccharine fermentation has begun, and before it has become tender to the touch. If the fruit be permitted to remain upon the tree until ripe, the young cells, which were full of active sap, become lined with woody matter, and are farinaceous, or mealy, to the taste. If plucked as directed, this process of the production of woody tissue is stopped, because the supply from the roots is cut off, while the fermentation goes on, sugar is elaborated, and the flesh becomes tender.

The mamer of gathering should not be by shaking the tree, and permitting the fruit to fall to the ground. In that way the fruit-spurs are broken, and the fruit itself is bruised by the limbs and soil, and will consequently decay much sooner than if it had sustained no injury. By examination of the stem of the fruit it will be seen that the point of attachment with the spur is clearly defined. It is at this place that the separation should be made in gathering. 'The reason that so many orchards bear' only on alternate years is often owing, not so much to their over-bearing as to the careless manner in which the fruit was gathered. The spurs are thus destroyed, and the energies of the tree are required the next year to refurnish itself with them.

'The fruit, after being gathered, should be carefully lriel in the basket or barrel, and not thrown in, as is the custom with many. If it is bruised, the tissue 
of the cells is broken by the blow, the juice is liberated and runs about the healthy cells, and soon its decomposition takes place, which is speedily communicated to the whole.

Preservation. 'The proper ripening of fruit is owing in a considerable degree to the influences to which it is exposed after gathering. The fruit is still green, and therefore as active as ever in converting the water contained in its juice into wood, and as this is the very end to be avoided, all conditions, such as light and heat, which stimulate vegetative action, should be withdrawn. The shrivelling of fruit is owing to evaporation caused by the presence of these and similar agents.

The fruit should be handled as little as possible, as all are covered more or less, according to the variety and the soil upon which they were grown, with a waxen substance called "bloom," which prevents, to a great extent, the evaporation of juice. Therefore washing, wiping, or handling are injurious, because they deprive the fruit of this natural covering.

Several plans of rooms for the preservation of fruit have been recommended, and been practised upon with more or less success. Among the most prominent was that of Mr. Schouler, which was thought to be of great promise. The following is a description of one built according to his plan:

'The sides of the fruit-room proper are double, 
and the space between these, about eighteen inches,

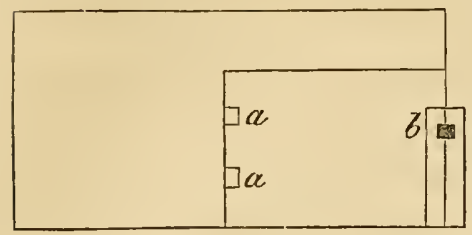

proper, and at its back. is stuffed with tan, sawdust, and shavings. The outer room, which is filled with ice, is just above the fruit-room which receive the cold air as it falls from the ice, and $(b)$ is another in the door of the room which governs the current of air, and therefore the melting of the ice. The water is discharged from the floor of the apartment into the open air, by means of a pipe, which should be provided with a faucet, and the water let off at stated times; otherwise a strong current of air would be created, like that circulating through the room. The top of the fruit-room proper must be strongly built, and covered with zinc, to support the immense weight and prevent leakage. While the structure remains in good order, the design seems to be accomplished. Summer fruits, such as strawberries, can thus be kept for a long time. They have been preserved for a month, when fully ripe, but the moisture deprives them of their sprightliness, and it is necessary to eat them immediately upon their exposure to the air. The fault of the invention is that the moisture and a constant circulation of air encourages fungi, which destroy the life of the timbers which settle under the weight of the superincumbent ice, and 
leakage commences. All manner of expedients have been tried, and failed to prevent this. It is unnecessary that the fruit-room be such an elaborate structure, or that so large an expense be annually incurred in procuring the supply of ice, and in repairs. The humblest can have one, containing all the principles of the very best, which will be within the reach of all, pecuniarily. Thus a small barrel, set within a large one, will answer the purpose. The space between the two should be carefully closed at the top, so as to preserve a close stratum of air between them, and a cover, pierced with holes, fitted upon the inner one. Fruits have been kept thus for a long time.

Upon a more extended plan an excavation is made in the side of a hill of the size required for the room, exceeded by about three feet in each direction. It is then enclosed by a wall, and the top arched over, the earth being thrown over the whole; or it may be covered by a wooden roof, if trees are planted so as to shade it. The inside of this wall is covered with cement. Within this the frame of the fruit-room is raised, and covered with well-matched boards, so as to leave a close airchamber between it and the wall. From the top of the room should be ample ventilation, but not connecting with the surrounding air-chamber. The entrance should have double doors, and the passage between them be also lined with matched boards 
so as to preserve the air-chamber perfectly tight. Such a room will answer every purpose in both summer and winter.

Fruits should never be placed where the temperature descends below forty degrees Fahrenheit, for the effect is much the same as in freezing; the ripeening process is checked, seldom to be resumed.

As a general rule those varieties of fruit which have the highest tint will mature earlier than those which are green, and in some linds, such as the Vicar of Winkfield pear, those specimens which have not a red cheek are difficult to ripen at all in the fruit-room, and must be used for culinary purposes.

In packing apples or pears for transportation, the boxes or barrels should be filled so full that there will be no jolting, as that would bruise and ruin the whole. They should be pressed so hard that the upper layer will be destroyed, and then they will be transported safely. Packing them in mahogany sawdust will prevent decay.

Formerly grapes were packed closely in bran, but by this means they were rendered unfit for exhibition. 'They are now sent hundreds of miles without any packing whatever among the bunches. They should be laid on the thickness of four sheets of cotton wadding, and tied down by the shoulders with stout cotton thread, which has previously been fastened to the bottom of the box. Let the layer 
of grapes be composed of bunches laid closely together, and as nearly of equal thickness as possible. Put no paper over them, but let thin boards be fitted to rest securely over the bunches as closely as possible without actually touching them. Pad the upper sicle of these boards with cotton, on which secure another layer, and thus proceed until the box is filled.' These directions are for grapes grown under glass, whose skin is thin and tender; so great a thickness of cotton would not be necessary for the native grapes of this comntry.

For the preservation of grapes they should be cut with a joint or more of wood below the bunch. A clean cut should be made, and sealing-wax applied to exclude all air from communicating through the tissue of the wood with the fruit. The bunches should then be hung on cords suspended across a closet in a cool, airy room, taking care that they do not touch each other; and they can be cut down as wanted. They must not be exposed to a current of warm air, nor yet be so damp as to cause mould. The proper sealing of the bunches is a most important feature in the operation. 'This is best clone by charring the end of the stem. This process closes the vessels, and prevents the escape of the sap, and, of course, also the decay of the berry where it adheres to the stem. We have thus kept autumn grapes in a perfect state during the whole winter, till carly in the succeeding spring.

1 Gardeners' Clironicle of 1818. 


\section{CHAPTER XI.}

GRAFTING AND BUDDING.

INFLUENCE OF THE STOCK - OF THE SCION - THE SEASON - THE WAX - Metiods - tife cleft - GerfFe a dN SeUl ramead, dont une

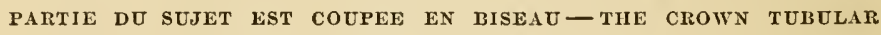
BUDDING WITH DORMANT EYES - THE PEG-GREFFe SYLVAIN, RENEWAL, SIDE, WHIP — GREFFE FENARI DE THOUIN - GRAFTING FRUITSPURS - INARCHING - GREFFE MORCEAT - COMMON INARCHING, IN

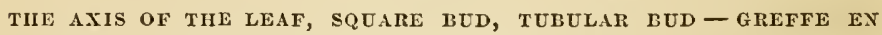
ECUSSOX - TIIE BUDDING-MACHINE - FOR IMMEDIATE FRUITING RENEWAL - GRAFTING THE VINE - MIDSUMMER - EMBRTONIC.

THESE are among the most interesting and important operations of the orchardist; for by means of them he can transform his trees from those of little value to such as are of rare excellence. Without these processes there would be no way of disseminating many desirable fruits; for, as each variety originated in a single tree, by the natural course of reproduction from seed, there would never be a certainty of another like it.

Although the influence of the stock upon the scion may be small in altering its specific character, yet there is no doubt that it does in some degree change its appearance and texture. The reader has probably seen two trees of the same sort standing side by side, exposed to the same influences, and 
receiving the same care, which universally have differed in the form, color, size, or flavor of their fruit, or in the growth and foliage of the tree. Two trees of the Beurré Superfin pear, both standards, stood within ten fect of each other, and received the same care. One of them always produced large, yellow russet fruit of very fine flesh, and of a delicious, vinous, nutty flavor, while the other as constantly bore large, green, smooth fruit, without russet, and of coarse texture and poor flavor. The influence of the quince stock upon the pear is very evident, as is that of the Paradise and Doucin stock upon the apple.

Yet while a given sort may vary, it does not lose those distinct peculiarities by which it can be readily recognized. A tree was grafted with three different kinds of pears, one naturally cracked and spotted, the second remarkably fair and clean in its appearance, and the third a russet. The tree soon fruited, and all these varicties produced the same year, each one preserving perfectly distinct its own peculiarities, while all were fed from a common root and stem. This faculty was supposed to result from the effect of the foliage of each, which elaborated its sap to suit its own wants. But against this hypothesis must be brought the oft-repeated experiment of grafting rings of bark, one above another, and not allowing a shoot to grow from them; even then they retain their distinctive characters. Thus we 
would say that while the foliage aids in accomplishing this result, yet the main work lies hidden in the secret recesses of each cell.

That the scion has a great influence over the stock, is also easily observed, particularly in the formation of roots. The amount of its influence depends greatly upon the fact, whether or not the scion forms the whole top. If a portion of the limbs of the old wild stock is retained, the native character will be prominent in the roots; but if the scion has full control, the name of the variety can be as readily determined by a careful observer of them as from the branches. The general habit of the tree beneath the ground corresponds usually with that above. When the tree throws an upright, stiff head, as in the Buffum pear, the roots as directly descend. Where the head is crooked, and the shoots turn with curious elbows, the roots correspond. Trees with abundant limbs, anci compact heads, have a close and generous supply of roots. Those which cast withy shoots, like the Winter Nelis pear, have wiry roots. Those which have a few fat branches, like the Vicar of Winkfield pear, have a few chubby roots. Men who have worked for years in nurseries, and have been accustomed to digging trees, are aware of these peculiarities. The Buffum pear tree, on account of its strong, straight top roots, will, as they say, "bear a pull," while such a method with the straggling Rostiezer would 
deprive it of all its valuable fibres. This formation of a system of roots corresponding with the top, must of course begin when the stock is young, to be perfect in its character ; for when it has reached a mature age, the insertion of a scion could not alter the peculiarities of those roots already in existence, although it would be a guide in the formation of those to be made.

The season of grafting varies according to the plan to be used. There are those adapted to all times in the year. As a general rule, those performed with ripe, dry wood should be done while the tree is dormant, or while the leaves are off, and after danger of serere frosts is past; and that with green wood, while the tree has such upon it during the summer. 'The knife to be used in the operation should be sharp, for the same reasons as were given in the chapter on pruning. If the scion is cut with a dull instrument, and the tissue torn and lacerated, the chances of its healing or joining with the main stock are much lessened. In all operations in gardening in which a knife is used, it is absolutely requisite that it should have a keen edge.

No tree of full size should have its whole head cut off and grafted at once, as it is too great a shock and disturbs disastrously the balance which nature keeps between the stem and the root. 'The result of such treatment would be likely to be an enormous growth, which if not killed the first winter, is 
almost sure to be the second, and thus the whole tree would be lost. Not more than one-third should be grafted at a time, and thus its vitality will be preserved.

After the scions begin to grow, water-shoots are often thrown out from the stock, which, if not removed, will exhaust the nutriment necessary for the growth of the grafts. If the scion grows strongly, it may need some support to protect it, while green and soft, from breaking by the action of the wind. In that case a stick tied to the stock, to which the scion is caught, will be a preventive.

Scions of the apple, pear, peach, and plum are better and more certain of freedom from injury in wintcr, if they are cut in the month of December, preceding the grafting of the next spring. They should be rolled in a damp cloth during the winter, being tied previously in bundles of from twenty-five to fifty, and the ends, which are cut, plunged into melted grafting-wax. Thus they will be preserved bright and fresh until the spring.

Grafting-vax is made of one part tallow, one part beeswax, and two parts resin. The tallow and beeswax should be melted first, then the resin, and the whole poured together and well stirred. Care must be taken that no fire be near, as the composition is highly combustible. After it is well mixed it is poured in small quantities into a tub of cold water, and worked like molasses candy. No more should 
be poured into the water at a time than can be worked at once, as it will cool very quickly and require to be melted again. This wax is greatly superior to any other within the knowledge of the author.

For some of the smaller grafts it is often better to use waxed paper. For this purpose strips of paper are floated in the melted wax for a moment, so as only to moisten one side, and then permitted to cool.

When the wax is applied, it should be carried in a pot of hot water, and the hands of the operator should be smeared with some oily substance. Below is a figure of a pot which is often used for this purpose.

(a) represents the pot containing the hot water in which is the wax.

(b) is the lamp.

(cc) are the holes which admit air.

$(d d)$ are the holes which complete the draft.

$(e)$ is the vessel containing the fat to be rubbed on the

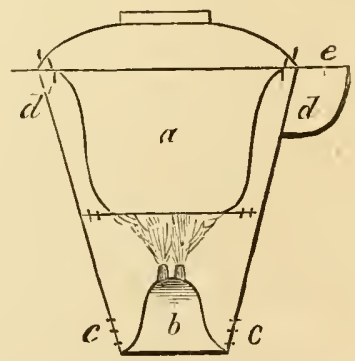
hands as the wax is used. The pot for the water can be taken out, and should, of course, be provided with a cover. 
THE METHODS OF GRAFTING.

1. The cleft graft. This is the most common method of grafting old trees. It consists in saving off the limb at the point where it is desirable to in-
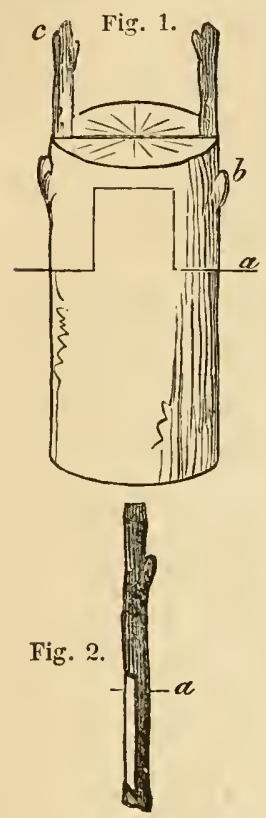
sert the scions. It is then smoothed with the knife. A clean cleft is made with a sharp knife and a mallet. The scion is cut. If the wood is of good growth, one containing two or three buds is enough. The scion is next pared down in the form of a wedge, one eye being on the part forming the wedge, as at $(a)$ in the cut No. 2, which, when inserted, is placed outside, as in $(b)$ of figure 1. The outer side of the wedge is left wider than the inside, as the grasp is then firmer. In setting the scion, no regard should be paid to having the outer surface of the bark of the scion and the stock even; for as the latter is much older and thicker than the former, such a proceeding would prevent the junction of the inner bark, through which the sap flows in its downward course, and by means of which the two are joined. Great care should therefore be used to have the inner bark of both meet. A peg should be used to keep the cleft open while the scions are 
being inserted, after which it should be withdrawn. The wax, having been formed into a thin plate in the fingers, is first placed upon the top of the stump, pressed firmly without moving the scions, and then brought over the sides to the dotted lines in figure 1 , except when the clefts are made, and it is carried down so as to cover the whole, save the eye at $(b)$. Thus the air will be entirely excluded.

It is not desirable in the end that both the scions should remain, as a crotch would be formed which would be liable to split in after years. Therefore, after the second year the scion should be selected which has thrown out the strongest shoot, and a cut should be made to it. This should be waxed thoroughly, and the wound will soon heal completely over, and care for itself. The inquiry may be suggested to the reader, Why not cut the other scion off at the top of the stump, as well as to cut in a slanting direction? The reason is, that the remaining scion will heal over a slanting cut much quicker than one that is square; and if it is merely cut off, that part is very apt to become diseased before it is calloused over. In some cases, when the limb which comes from the eye $(b)$ is desirable, it may be done; but it should be avoided if possible. The benefit of putting in two scions at first is, that the chance of success is greater, and that the balance with the roots is kept more even. Sometimes, however, a single scion is used, when is formed what the French call- 
2. Greffe à un seul rameau, dont une partie du sujet est coupeé en biseau, or Bertemboise.

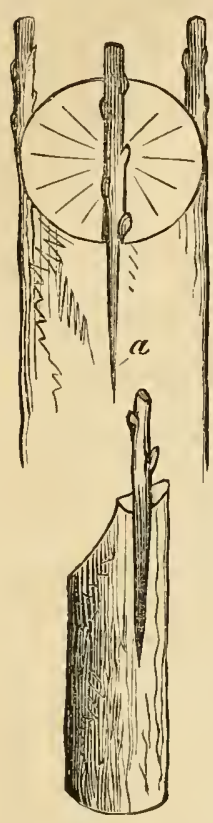

3. The crown graft. After the limb has been sawed off at the proper point, and the wound smoothed with the linife, one, two, or three slits are made in the bark (as at $a$ ), according to the number of scions which are to be inserted, and the bark slightly raised on each side of it. The scion is then carefully cut thin upon the inside, and is slid down between the bark and the wood, - the side which is cut being toward the wood.

4. D'Albret, or tubular budding with dormant eyes. This is similar to that performed with pushed eyes, to be described hereafter, except that the latter is done in August, when the sap is running, and upon those species of trees whose bark will not rise in the spring. This is done exclusively upon the young wood. The top is not cut off, as when grafting with pushed eyes, but the bark having been taken from the part to be grafted, the tube of bark to be put on is cut longitudinally, so that it will go on easily. The benefit in leaving the top on is that the new bark will partake of the growth of the shoot during the summer, and become united much better. 
5. Pey-grafting, De M. Thouin. A hole is bored into the stock, of an inch or more in depth, according to its size, and around the hole the outer bark is removed, so as to leave the liber exposed. Then a scion is selected of the size of the stock, and its lower end sharpened like a peg, so as to fit the hole. The scion must have a shoulder, and the liber must meet that of the stock; - upon the latter particular depends the whole success of the operation.

6. Greffe Sylvain. This consists in making a cut like that represented in $(a)$ upon two trees near each other, and bending them so that they unite. They are then fastened by a nail. This method is used only for ornamental purposes.

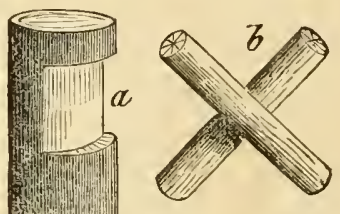

7. Renewal grafting. When a large tree is broken

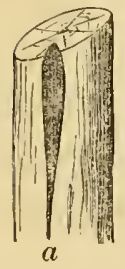
off near the ground, a new head is sometimes formed by a plan described by M. Thouin. A small tree is planted by the side of it, and a slanting, triangular cut is made in the side of the old trunk, as at (a), while the young one is pared to match it, as at $(b)$. 'This is then inserted and bound on. 'The scion thus derives strength from its own roots, and a union will soon be formed with the old trunk when the scion is separated from its own roots, and becomes the head of the large tree. 
8. Side grafting. A chisel is used to make the

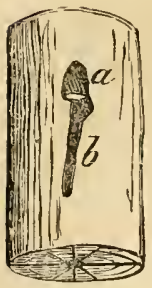
notch in the trunk, as at (a). A slit is then made down the bark, which is raised a little. The scion is then cut thin, that the bark at (b) may close over it, and a heel left at $(c)$, where it rests upon $(a)$. The sap, as it flows upward, is stopped by the notch, and tends to nourish the scion.

9. Whip grafting. Greffe en feute dite à l'Anglaise. The stock and scion are chosen of the same size, and each is sharpened on one side, by a cut of about equal length. That on the stock, of course, slants upward, and that on the scion downward. A tongue is then eut in both, the one being the counterpart of the other. 'These are interlocked, and the whole bound together.
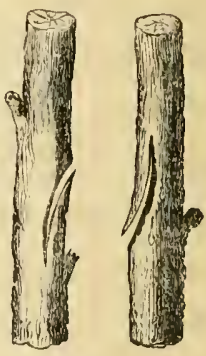

10. Greffe Ferari de Thouin. It is necessary here

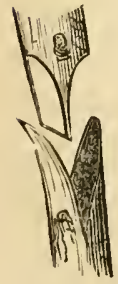
that the stock and scion be of equal size. The latter is now cut (unlike the Bertemboise) of the same thickness at both sicles or edges, in the form of a wedge. A piece of the stock of the same size is then taken out, instead of making a cleft. This method is more particularly adapted to soft-wooded plants.

11. The fruit-spurs of one tree are sometimes grafted upon another. This is advantageous where 
it is desired to prove a great many sorts, and the number of trees is small. The operation is performed in September. The bark upon the limb which is to receive the bud is cut in the form of a $\mathrm{T}$, and the sides raised a little with the ivory of the budding-knife, and the spur, its wood being pared down very thin, is slid in, bound and waxed, to prevent all access of air and moisture. The fruit produced upon these spurs is said to be of extraordinary size.

12. Inarching. Among the various plaus which are described by M. Thouin, is one for strengthening a tree by giving it the help of its neighbor. The tree of which it is intended to make the scion is bent over toward the one which it is to aid, so as to determine where it is to be cut. This is then done, and the part which is to be toward the tree is sharpened as if for a whip-graft. At the point where this is to be inserted in the main tree, a perpendicular cut is made, and an incision in the bark below, to allow the wedge to enter easily. The sharpened top of the smaller tree is then slid into the place prepared for it, and bound firmly, to prevent the wind from changing its position; the wound is then covered with wax. It is very important that the graft be well bound, that all moisture be excluded.

13. Greffe morceau. This is done with wood of one or two years' growth, and the scion and stock should be of the same diameter. The tree to 
be used as the arch or scion is bent as before,

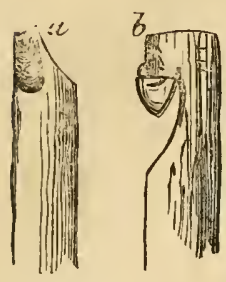
and when cut is sharpened on both sides like a wedge, as in figure $(a)$.

In the stock is made an incision from the outside, slanting upward to the very pith, as in figure $(b)$, when the wedge is slid into it, bound, and waxed as below.

14. The common method of inarching small plants is, after placing them both together, to pare a slice from the side of each, of about equal size, when they are simply brought together, and treated like the others. 'Those latter three methods are used when the species or variety will not endure grafting in the more independent ways.

15. Root-grafting of the vine. Some cultivators affirm that they have tried this process with great success ; but our experience is quite different.

16. Grafting in the axil of the leaf. In the axis of a young shoot or a leaf a downward slit is made almost to the heart, and into it is placed a wedge-shaped scion of the same size. It must be remembered, says Albret, that the cleft should be made in green wood as quickly as possible, else the knife will deposit oxide

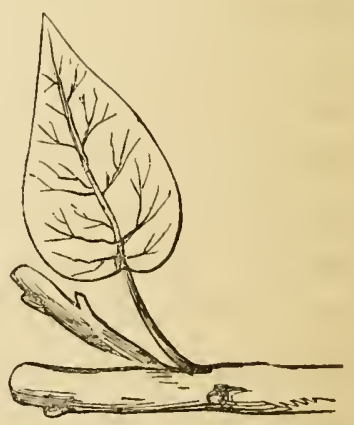
of iron, which is easily distinguished in the stained 
appearance of the wood, and which is very injurious.

17. Square bud-grafting. This is performed by cutting out a square piece of the bark, as at $(a)$, and putting in its place a similar one of the variety designed to be grafted, and binding so as to exclude the air.

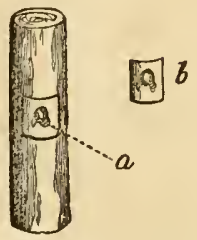

18. Tubular bul-grafting. When the bark will

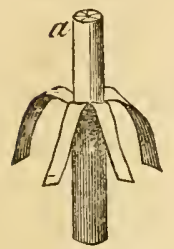
rise, the end of the shoot to be

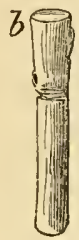
operated upon is cut off at a place where it is free from all inequalities, and the bark stripped down for about an inch, as in figure $a$. A scion is selected a little larger, and its limits marked out with the knife below. After being held in the hand a minute or two, the bark will expand and the tube come off, when it should be placed upon the bare wood, and the bark stripped down until it fits tightly.

19. Grefie en écusson (budding). This has the advantage that, if it does not succeed, the subject has not been injured by the operation, and another bud can be introduced. The proper season is when the sap is flowing, and the bark will rise easily. All shoots which would interfere with the young bud are first cut away. Detaching the bud is done in two ways. Some species of plants have tender wood and bark, and it is necessary that the wood be removed 
from the back of the bud, which is done as follows:

The knife is inserted at $(a)$, and drawn to $(b)$,

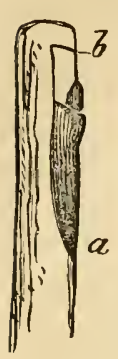
through the bark and wood; then a transverse cut is made only through the bark at (b), from the cut on the opposite side to that upon this ; the bud is then grasped by the thumb and finger, and by a slight pressure will separate from the wood.

Usually, however, it is not necessary to separate the wood from the bud, and then the long cut at $(b)$ is carried out. A cut is then made in the stock of the shape of a $T$, the upright part being the same length as the bud to be inserted. The bark is rolled back slightly to admit the bud, and it is slid down, the bark brought over it, and bound tightly.

The author invented a machine for doing this work, a few years since, which worked successfully. A description of it is given more as a matter of curiosity than in the belief that it would be of practical value in the hands of our common workmen.

The machine consisted of a cylinder about three inches long. The upper inch of this contained another cylinder, which was made to revolve. This contained on its exterior ten grooves, of a shape suited to hold each a bud ready for insertion, the part of the bud which was to go next the stock 
being turned outward. The casting of the machine was made of German silver, to prevent the oxidation which would be produced by iron. This cylinder was made to revolve but one of these grooves at a time, by means of a lever on the top, which locked into a notch at every move, bringing the bud toward the exterior groove in the machine, when the stock was claspec. 'These clasps were India-rubber, which opened when pushed against the stock, and clasped it when it entcred the groove. There was a knife that cut the top incision of the $\mathrm{T}$, which worked by a spring from behind. An erect shaft held a ploughshaped knife, which cuts the perpendicular incision of the ' $\mathrm{T}$ and opens the bark. The lower end of the bud fitted behind the plough, and was pushed down so as to leave the bud under the bark by means of a rod which followed; the plough-knife then sprang out, and back into its original place. It is kept against the stock by a spring which works against a lever in the interior of the machine. The placing of buds by means of it was much more rapidly performed than it could be by hand, and its execution was beautiful, at the same time that it was hard for the operator. The fault of the machine was that it was not sufficiently automatic.

20. Grafting for immediate fiuiting. When a new seedling promises well through its general growth, it is exceedingly desirable that some method be used, if possible, to determine, in a shorter time than 
would be required for the natural maturity of the young tree, the character of the fruit. $\mathrm{Mr}$. Robert Cornelius, of Philadelphia, has from his fund of ingenuity invented the following: As soon as the young seedling has grown sufficiently to mature from six to ten buds, a good strong shoot is selected upon an old bearing tree, and these buds are inserted in a spiral form, as they are always placed naturally. The next spring the terminal bud is allowed to grow, while the lower ones are pinched according to the rules for forming a fruit-bud. By this method fruit will often be secured much earlier.

21. Renewal grafting. Often the orchardist or the vigneron is puzzled how in the best way to fill the blank side of a tree with limbs. A system of inarching may be advantageously resorted to. A young shoot is bent forward to the place which the limb is desired to occupy, and a slice taken from it and from the trunk, either with or

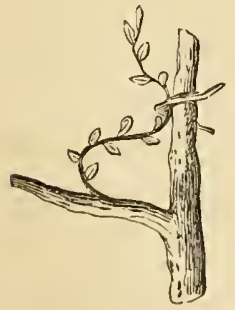
without a tongue. They are both placed together and bound firmly, as in the figure. After the limb is perfectly united, and has acquired sufficient strength, it is cut where the transverse line indicates.

22. Grafting the vine. The root-grafting of the vine is so incertain an operation, in the hands of most cultivators, that they must hesitate to cut down a whole vine to prove a new variety of no 
established merit. Our readers are again indebted to Mr. Cornelius. A joint of the vine which is to become the scion is selected, which bends ontward as much as possible, and each end being sharpened, is forced into a cut made for it, as seen in the figure. After becoming thoroughly established, the old wood is cut off at the transverse lines, and the sap is allowed to flow uninterruptedly to

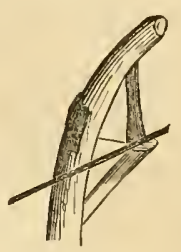
the scion.

23. Midsummer grafting the vine. The soft end of a growing shoot should be selected of not more than a half-inch in length, and sharpened with a

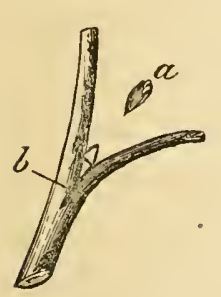
very keen knife. $(b)$ is where the incision is made for the scion $(a)$; it thus occupies the place of an anxiliary bud, and if the growth of the lateral is checked, this will push and grow very strong. The lateral must be shortened gradually, however, according as the scion is capable of disposing of the sap.

24. Grafting embryos. Dr. Lindley, on pages 627 and 698 of Volume I., 1855, of Gardener's' Chronicle, gives an account of this very curious operation. It is done, he says, in Egypt, where it is said to be a very old custom. It is claimed that thus an orange, citron, and lemon were all "combined into one fruit beneath a common rind." Of this fact there is no doubt. "It was said by the people of the country 
to be produced by grafting the embryos of the three fruits, which are allied to each other by family relationship. The mamner was as follows: One of the three seeds is wholly skimned, so as to lay the embryo quite bare; the skin of the others is removed from one side only. This being done, the naked embryo is placed between the others, so as to be in contact with their skimned sides, and the whole is bound with fine grass. They are then committed to the ground in the usual way. The embryos grow together into one plant, and ultimately the trifacial fruit in question is produced." Dr. Lindley thought the operation was possible because such things often resulted from accident. M. Decaisur found seeds often containing more than one embryo, "which occasionally grew to each

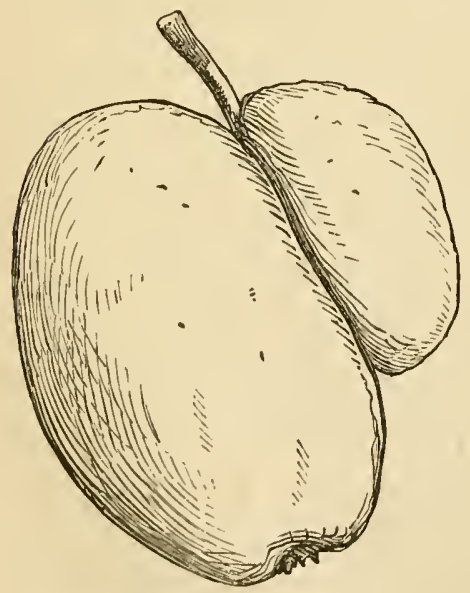
other, forming a true vegetable twin." $\mathrm{Cu}$ cumbers and nectarines are thus sometimes produced double. An example is presented by the monstrous apple of which a figure is annexed. In this instance, two apple-flowers, accidentally brought into close contact in the earliest state of the bud, being kept firmly in contact 
as they advanced in growth, ended by becoming half incorporated, notwithstanding they ended by finally becoming a twin fruit, consisting of two very unequal halves. In the smaller fruit four cells for seeds were formed, but in the larger but three. In other respects the structure was complete, but each was furnished with a vein of elevated lines on the side next the junction. The nature of these is unknown to us. What is particularly deserving of attention here is, that the hairy surface of the young apple offered no obstacle to the junction in question; possibly it took place before the hairs were formed. It remains to be proved by practice, but certainly appears a possible, but exceedingly difficult operation." 


\section{CIIAPTER XII.}

THE PRODUCTION OF NEIV VARIETIES.

CIIANGE IN THE VEgETADLE WORLD - EFFECT OF CLIMATE, SOIL, AND POSTTION - CULTIVATION, DEGENERACT, OR DETERIORATION - DECREPITUDE - METHODS OF PRODUCTION - SELECTION - VAN MIONS' TIEORY AS DISTINGUISHED FRON IT - CULTIVATED FRUITS NOT DESCENDED FROM TIEIR MILD TYPES - IMPORTANCE OF SECURING SEED FROM A YOUNG TREE - HYBRIDIZATION - EXPERIMENTS OF KOLREUTER, IIERBERT, INIGIT, GAERTNER, LINDLEx, PURKINJE, IIRBEL, ADOLPHE BROGNIART, CONRAD SPRENGEL, CASSINI, ALPHONSE DE CANDOLlE, SCHLEIDEN, FRITSCHE, THWAITES, MR. ROGERS - MANXER OF OPERATION.

ONE of the most interesting properties of vegetable, as well as animal nature, is its susceptibility to change. This does not extend, however, to species, genera, orders, or classes, but is confined to varieties; thus the seed of a pear or apple will always produce the same species of fruit, while a variety of these species always originates in its offspring a totally different character; and the improvements of which these varieties are capable, through the skill of man, are without end. Let us consider some of the means which man makes use of to create these changes.

Difference of climate. It is evident that, if a variety of peach or other fruit be brought from a 
warm climate to a cooler one, the effect would be to stunt its vigor, prevent the perfect ripening of the fruit, as well as that of the wood. A seedling raised from such a tree, we should expect, would be possessed of less vigor than its parent, bear fruit of inferior quality than when in its native clime, at the same time that it would gain greater hardiness of wood, which would adapt it to its new position. If this same tree should be removed from its native clime to another, more favorable, it would find physical influences as unadapted to its character as the parent found in its place of nativity, and the next generation would return again to the first type. Thus through successive generations nature adapts the variety to the conditions in which it is placed. Mr. Knight, in a paper which he read before the London Horticultural Society, in 1806, said: "If two plants of the vine, or other tree of similar habits, or even if obtained from cuttings of the same tree, were placed to vegetate during several successive seasons in very different climates, - the one planted on the banks of the Rhine, and the other on those of the Nile, - each would adapt its habits to the climate in which it was placed; and if both were subsequently brought in early spring to a climate similar to that of Italy, the plant from the north would instantly vegetate, while the other would remain torpid." We think, however, that the observation of Mr. Knight has not been sus- 
tained by subsequent investigation, and that it has been found that the qualities of the plant itself do not vary so much as he then believed. If this had been so, the foreign varieties of peach in this country should have obtained something near the hardiness of our native varieties. It is true that conditions may exist which will bring out in bolder relief some inherent quality which they possessed, and which was not evident in the country from which they came, because the influence did not exist to mature them; and in their new position these qualities, thus strongly brought out, may be stamped strongly upon their oifspring; yet we have no reason to believe that the constitution of the plant itself will be in the least degree altered.

Soil and position also influence the character of the offspring of fruit trees. Thus a pear tree requiring for its successful cultivation a light soil, if planted upon heavy land will be likely to produce progeny suited to such a soil. This, however, depends upon the care and skill used in its cultivation. If it be neglected, and the soil be cold and wet, it will be likely to entail disease upon the next generation, when proper cultivation would have secured an invaluable variety.

Cultivation. This does not improve the character of the plant itself, but has an immense influence to induce hardiness, vigor, early maturity, and productiveness. Those particular means should be used 
which will have the effect to bring out prominently some desirable trait in the offspring. If hardiness is desired, those methods should be employed which shall conduce to the perfect ripeness of the wood of the parent tree; if vigor, those which shall produce this ; if early maturity and productiveness, vigorous summer pinching and root-pruning, to produce such in the parent.

It may be suggested by some that there is no necessity for the production of new sorts as long as we have those which are delicious, and which satisfy our wants. But it must be remembered that varieties have a limit of existence. They increase in strength until they reach an age like that of manhood in the human race, when deterioration and decay commences. This is not confined to the original seedling tree, but extends to all the buds or scions obtained from it directly or indirectly. Thus, if we do not produce new sorts, the standard of excellence will become very much lower by the deterioration of the older kinds, and at last none will be left worth cultivation. This can be seen in the fact that many of the sorts which were once vigorous, hardy, and easily grown, with ordinary cultivation, now resist the nicest conditions to their production and health. The St. Germain pear was once remarkably fine and beautiful in this country, and was cultivated with comparative ease; but now it is almost impossible to bring it to any degree of 
perfection. By some this may be referred to the change which has taken place in the climate, to the felling of the forests; but this cannot fully account for it, because in new parts of the country, where these forests remain standing, it is the same miserable fruit when compared with its former beauty and excellence. The White Doyenne, or St. Michael, was once universally fair and beautiful; but in the most favored districts it is every year becoming more and more subject to the diseases which have expelled it from other regions.

We are aware that this limit to the life of varieties is denied by many able men, who state that disease rather than decrepitude is the cause of their disappearance: yet does not disease in these cases result from a weak state of the system on account of old age? Much room has been left for argument to those who oppose this theory, because many who have upheld it have endeavored hypothetically to state the exact life of varieties. This in some cases has been proved by actual experience to be false, which has cast obloquy upon the theory. It would be as difficult to state exactly the limit of plant-life as of that of man. That of the latter is put down, in a general way, at threescore years and ten; and yet, by great care, and through the possession of a strong constitution, some men live to half as much more, while thousands die in infancy. Just so some seedlings do not have sufficient strength to survive 
a single year in the seed-beds, while others, either because they never were affected by disease, or had sufficient strength to pass through those exposures which a plant, like a child, is peculiarly subject to in a state of infancy, survive. It seems evident that varieties die in obedience to some great law, higher than that of disease, which accomplishes the work.

"When, towards the end of the last century, Van Mons commenced his essays, and published the grounds of his theory upon the production of fruit trees by means of successive generations, pomology was entirely delivered from infancy and the dull routine which she had long followed, and took her position with the other sciences through the successive labors of Quintinie, Merlet, Legendre, and Duhamel. The culture, the form, and the description of fruit trees were from that time established. One point was not even alluded to in the works of these latter authors; this was that of the degeneracy or deterioration of varieties.

"According to Van Mons, the cause of this degeneracy is the age of the variety. He thus expressed limself :

" "The decay of the old varieties of fruit is generally complained of, and with reason. Every one remarks the imperfections of the old sorts, and avows it with gricf. I know nothing so deplorable, in point of culture, as to raise a tree in the hope of deriving pleasure from its fruit, and to see it go to 
ruin at the very moment when this hope ought to be realized. Is there anything more discouraging than the loss of the labor bestowed during the formation of the tree, without hope of being rewarded for its care in the future? It is attacked during its infancy by all the diseases to which old age is liable.

" "If disease results from decrepitude, it will be persistent, and no remedy can apply to it. When disease results from some foreign cause, which it is in our power to avoid, it ceases when the influencing cause is withdrawn. An imperfect form, an unseasonable pruning, a barren or too-wet soil, an exposure which the air and light cannot reach freely, are the causes of artificial diseases.

" The age of the variety dates from the moment when it is produced from the seed; its first step toward old age or decay dates from the time when it produces its first fruit; the good or bad quality of the fruit, and the greater or less productiveness of the tree, influence the length of its life. That which bears fruit of excellent quality, abundantly and ammully, wastes itself sooner than that which produces inferior fruit, and in small quantity.'

"Old age announces itself by loss of vigor, and inability to perform healthfully the functions of nutrition and reproduction. Before its entire decay, and during the time when the tree still produces fruit, its approach is to be discerned by bursting and cracking of the firuit, and that the flesh, without 
juice or flavor, is filled with gritty, vascular matter. In the lattcr stages of decay the wood becomes attacked with gangrene, the branches die, one after another, without apparent cause. Its inability for reproduction will be discovered by the absence of flower-buds, or, if they still remain, by the imbecility of the organs of generation.

"According to Van Mons (and it seems to us to be sufficiently proved), all our old varieties are in full decay; with many, also, and some of the best, this is attaining such a point that their culture is almost abandoned. It is very evident not only from the experience of the learned professor, but from causes which have passed daily under our observation, that many old varieties, and also those of less age which are not of much reputation in Belgium where they are not cultivated on the wall, are fast passing away.

"The Beurré d'Hardenpont, Delices d'Hardenpont, Passe Colman, Bon Cretien de Rance, Reine des Poires, Beurré Dicl, etc., - fruits known about the time when Van Mons commenced the application of his theory, - already show signs of yielding to this natural law of decay." 1

There are two methods by which new varieties are produced.

First, by selection. This consists in choosing the 
best seeds of the finest specimens of fruit, and planting them for successive generations. Nature uses this method more or less in the production of varieties in the vegetable kingdom as well as the animal. In the latter, the strongest and most perfect animals conquer and slay those which are inferior, according to a merciful provision of Providence, and thus a strong and healthy progeny is secured, and the race prevented from deterioration. Just so, it is generally only the strong, vigorous seedling which can resist all the obstacles which it meets in its growth; and such will overshadow and kill all which are of an inferior character about it. This selection is to be distinguished from that practised by Van Mons, in that he planted seeds of the wild fruit, and endeavored to produce valuable and stronger varieties, free from the diseases peculiar to cultivated fruits by amelioration and careful cultivation, upon the hypothesis that our table-fruits originated from these wild types.

Van Mons commenced his experiments upon annuals and roses, when less than twenty years old, and he gives as the result of his observations -

That successive generations remove the progeny further from their condition as wild plants, and make them more susceptible to variation according as it is repeated often and with the least interruption. That a plant once entered upon variation, does not return, if, through uninterrupted genera- 
tions, we do not allow it time to fix itself definitely; and that an interruption produces in the next generation a plant of so much worse quality as has been the length of this time.

That to delay the flowering, produced the most beautiful flowers.

That fertility increases with repeated generations.

That the plant, after being regenerated a certain number of times, loses in vigor what it gains in form; that is to say, that, in laying aside its rude and wild nature to take one more delicate and domesticated, it becomes more sensitive to the severities of the seasons.

At the age of twenty-two years Van Mons commenced to apply his theory, resulting from his experiments upon annual plants, to fruit trees. 'The first generation of Van Mons departed very much from its type, producing a crop, after ten or twenty years, of very small and inferior fruit. This he sowed immediately, and obtained the second generation of less wild appearance, but yet not suitable for table use. The seeds of this were again sown, and so on to five generations, when he obtained trees which bore in five to ten years.

Dr. Van Mons started upon the hypothesis that all our cultivated varieties of fruits were ameliorations, by cultivation and successive generation, of the wild sorts; and yet may not there be a vast difference in the specific nature of the wild and 
cultivated pear, as well as the three or four other fruits which are particular favorites of man? That is, have not the apple, pear, peach, cherry, apricot, vine, etc., always been cultivated since the origin of the human race, as the horse, ox, dog, and sheep have been domesticated? The mention of some of these fruits and animals in the very earliest history of man, would lead one to suppose so ; and that the results of the successive experiments of Dr. Van Mons in the production of thousands of seedlings of the pear from the wild type, were practically so barren, - not one variety being raised of particular merit. The large number of them which the author has had the privilege of examining in the garden of the Hon. Marshall P. Wilder, all exhibit the wild habit and the astringency of the wild type, even in the furthest generations from it. His experiments would almost seem to satisfy scientific men that some distinct line separated those cultivated sorts from those found in a wild state. So great is the difference between these remote generations of Van Mons, and of valuable sorts, that one can, without any view of the labels, easily point them out as a separate species of plants. These apparently specific properties are transmitted to their offspring, and they can be selected and separated in the seed-bed, when sown indiscriminately.

We are aware that some persons will urge, as an explanation of this, that by the long domestication 
of the cultivated sorts their characteristics have become fixed. Yet there are as great specific differences between the wild and cultivated varieties of fruit as between men and the baboon. One might as well argue that all the races of men are developments of the latter, or admit the mutability of species; and still the abandonment of man to the mere satisfaction of his animal appetites, as is the case with some of the Bushmen of Africa, continued for centuries, produces no more similarity to the baboon in him, than in the tribes elevated above him of his own race. The cultivated fruit, although left to be wild for a generation or two, still never fails to preserve well marked its domesticated character, any more than the wild sorts lose their character under the most accurate culture for generations. Among the millions of seedlings from the wild fruit raised for grafting the pear, we have never heard of the appearance of a desirable sort.

The seed should always be taken from young trees which are free from disease, so as not to entail upon the seedling any difficulty resulting from decrepitude in the parent tree. As an instance of the importance of securing perfect seed from healthy trees, it is stated by one having great practical knowledge concerning it, that estates in Scotland on which larches are grown, and producing a crop of timber worth ten or twenty thousand pounds, have been ruined by a disease called dry-rot, rend- 
ering them entirely worthless. Upon investigation, it was discovered to have resulted from having obtained seed from unhealthy trees, while seed from the Swiss forests had produced trees which were in perfect health.

Hybridization. From 1780 to 1790, Kolreuter published the results of his experiments in hybridizing vegetables. According to $\mathrm{Mr}$. Herbert, this interesting branch of horticulture commenced with this celebrated man ; but that his efforts were comparatively umnoticed, and induced no further efforts until those of Sir Thomas A. Knight, in England. Mr. Herbert commenced his experiments upon vegetables in 1819. While Mr. Knight considered a fertile hybrid as proof positive that the parents were of the same species, Mr. Herbert denied it, and extended it to the genus, and thought there was no difference between species and "permanent or descendable varieties." This will be denied, probably, by most modern physiologists. While varieties change according to physical influences, specific characters do not. No two species ever became so confused that there could not be drawn between them a distinct line, although this specific character may be varied in degree by these influences. One of the most remarkable proofs of the fallacy of the hypothesis which would make physical influences produce mutability of species, is found in the fact 
that there are certain periods marked by an entire extinction of the species of flora and fauna, and a re-creation under the same types, classes, and orders.

As Professor Agassiz remarks, this genesis is so various among all the different branches, taking place at the same time, how could the same physical influences produce such opposite characters? The four types of vegetable life are represented as present in the earliest formations; but each had its epoch of supremacy. The Carboniferous period was distinguished by its remarkable acrogens. The Lipodendra, or Club-mosses grew from fifty to sixty feet in height, and their appearance must have been beautiful. The stems of these giants were strengthened by bands or buttresses of vascular fibre running vertically. The curious Sagillaria was contemporaneous. The carvings in its trunk resembled designs for some highly ornamental style of architecture; knots single or double, circles, graceful grooves, crescents or eyes, protruded from their trunks at regular distances. Their roots were alike marked by peculiarities, and probably also their fernlike foliage. The Oolitic period brought the beautiful and varied Thujas, the Biotas, the Pine, and other relatives of the Conifera. Then the gymnogens were supreme - then wild forests of evergreens covered the earth. But in the Tertiary deposits, the plants of the Carbonifera sink to their present size, the Conifera occupy only a portion of 
the surface of the earth, which the Monocotyledons, or grain-bearing plants, and the Dicotyledons, or fruit-bearing make their appearance and predominate to prepare the earth for man, by affording food to the ruminating animals, which compose most of his meat, and the fruit tree to tempt his appetite. Instead of these different types of vegetation gradually succeeding and displacing one another, the change has been abrupt and simultaneous, accompanied by great physical commotions. These have been not a few; but, according to some writers, from sixty to one hundred. Thus the earth has been the theatre of a series of alterations and recreations, which have prepared it to become the dwelling-place of intelligent man.

Mr. Herbert asserts that hybrids between plants of the same species do not always produce fertile offspring; but that it " depends upon circumstances of climate, soil, and situation ;" and that "there does not exist any decided line of absolute sterility in hybrid vegetables; though, from reasons which I did not pretend to be able to develop, but undoubtedly depending upon certain affinities, either structual or constitutional, there was a greater disposition to fertility in some than in others. Subsequent experiments have confirmed this view to such a degree as to make it almost certain that the fertility of the hybrid, or mixed offspring, depends more upon the constitutional than the closer botanical 
affinities of the parents. The most striking and unanswerable proof of this fact was afforded by the genus Crinum, which is spread round the whole belt of the globe, within the tropics and a certain distance from them, under a great variety of circumstances, affecting the constitution of individuals, which nevertheless readily intermix by human agency. Crinum Capense impregnated by either Crimum Zeylanicum or Scabrum, produced offspring which, during sixteen years, proved sterile, probably because, notwithstanding their botanical affinity, the first is an extra-tropical aquatic plant, and the latter two tropical plants which affect dryer habitations, and readily rot, at least in this climate, in a wet situation." And yet this same plant, impregnated with others which were swamp-plants, yielded fertile crosses; and the two which were extra-tropical produced a more fertile offspring than one extra-tropical and the other tropical.

The constitution of the offspring will be more or less like that of both parents. Thus, if it is desired to give hardiness to the offspring of a tender fruit, and it is impreguated with the pollen of a hardy sort, there is every probability that, while it will endure the climate, it will be more sensitive to severe extremes, which would not injure its hardy parent. Mr. Herbert states that to obtain any peculiarity in the corolla, the parent which has it should be used as the male, and its pollen fertilize 
the other, because the corolla belongs to the male portion, and is, directly or indirectly, connected with the stamens.

Great care should be taken to protect the plant from which the pollen is to be taken from bees or other insects, which rob it of this powder. To do so, a light netting may be thrown over the twig, else they would soon put to an end any certainty of pedigree, by bearing pollen grains upon their bodies from other plants, which is easily brushed upon the stigma as the insect seeks the pollen. Another result to be guarded against is the fertilization of the blossom by its own pollen. This can be done by removing all the anthers, or sacs which contain it, and the petals, - for in the latter case the pollen seems to lose its attraction to the insect race. During dry weather, and when the stigma is in the proper condition, the fertilization may be performed. This state may be detected in some plants by a viscous exudation from the surface; in others it is not discernible. The pollen should be dry and powdery, which it will not be in cold, damp, or chilly weather. The distribution of the pollen thinly over the stigma may be performed either by a camel's-hair brush, or by dusting it directly from the anther, the stamen being held in a pair of nippers. 'The female has the advantage, it is generally conceded, in the process; and we should therefore use that one for the seed-bearer 
which has most of the qualities that it is desirable to retain in the offspring. Some have assigned the determination of habit to one parent, and the bearing properties to the other. But this is not absolutely true, as the characters of both are blended. For instance, the Rogers' hybrid grapes have, most of them, the vigor of the native, or female, but the short joints of the foreign, or male. They resemble the mother in vigor, hardiness, form, and texture of leaf, while the form of the bunch and berry, the sex of the blossom, and flavor of the fruit, resemble the father. Almost all natural seedlings of our native grapes are male, or staminate, and therefore fail, in a great degree, to set their fruit, and have broken bunches in consequence. But these hybrids are like the father in being pistilate or hermaphrodite.

Gaertner asserts that the juice of the pollen grains combine with that of the stigma to fecundate the germen, which Herbert considers as very questionable, and adds, that the superabundant viscous juice on the stigma of some plants obstructs fecundation.

The experiments of Mr. Herbert, in regard to the slowness of the process of fecundation, seem to agree generally with those of Kolreuter. It required at least one hour and a half for the pollen grains to become emptied; and the latter gentleman found that no more grains than were sufficient to complete 
the process would change color when placed on the surface; but that the more distant the relationship, or (as Herbert expresses it) the affinity, the greater was the amount of pollen required; and as the relationship was more or less distant, was the proportion of perfect seeds procured; - with the most distant, the least number. He thought that the life, or sensitiveness, of the stigma was longer when fertilized by foreign than by its own pollen. This change of the stigma was at very different periods in natural fecundation, from eighty-five minutes to several hours; that it probably merely saturates the stigma in that time, and does not really fertilize the germen. He reasons that, "if the fertilization was complete, and the office of the stigma defunct, it might be cut off without any detriment, unless necessary to the mere nourishment of the ovules, whether fertilized or not, which does not seem probable; but I have repeatedly cut it off a few days after I had applied pollen to the rhododendrons, and the result has been that no seed was formed. The whole of my observations have led me to think that, at any period before the decay of the stigma, the access of the natural pollen may supersede the influence of the foreign that may have been previously applied, if not from a closely allied species or variety; but that, on the other hand, no foreign pollen can act upon the germen after the stigma has been fertilized naturally. The incomplete sat- 
uration of the stigma in the first place enables the natural pollen to gain access ; but, if the absorption of the pollen first applied causes immediate fecundation, it cannot be explained how the subsequent access of the natural dust should supersede it ; and it has seemed to me that the natural pollen could supersede that of an Azalea on the stigma of an evergreen Rhododendron, even after the flower had fallen off.

"This point might be elucidated by cutting off the stigma with portions of the style of various lengths, at different periods after the application of pollen, and seeing in what manner the operation interferes with the fructification of the plant. Gacrtner thinks it doubtful whether the corolla is essential to the fertilization of the stigma; my observation is, that its early destruction is very prejudicial to the growth of the germen and stigma, but that after their development it is not usually essential. He observes that the corolla perishes more quickly and completely after fecundation, and is more persistent, and sometimes withers instead of falling off in cases of hybrid impregnation; but he seems not to have distinguished the cases of successful and abortive hybrid impregnation. I observe that he admits that the viscous juice remains on the stigma of Datura and Nicotiana two or three days after fecundation, which does not exactly agree with his theory, and seems to mark that the stigma 
has not become quite inoperative. Some days elapse before any other signs of fecundation appear after the fall of the corolla, such as the enlargement of the peduncle, or strengthening of its articulation, and that period seems to him longer in hybrid impregnation, as well as the interval before the seeds are vivified. Both he and Kolreuter observe instances, such as I have found, of false hybrid impregnation, producing an enlargement of the germen, or even seeds with an imperfect embryo, or without any. They remarked that they did not usually obtain the full complement of seeds from a hybrid impregnation, unless the affinity was very close. My own observation is that this circumstance depends rather on similarity of constitution."

The art of hybridization can be used not only in the production of new sorts by crossing different species, but its results are generally of more practical value, as applied to crossing the different seminal varieties of the same species.

When two plants are to be hybridized, it is important that both the stigma and the pollen be in a state to act upon each other immediately. All anthers should be taken off from the flower which is to be acted upon, so that its pollen can not anticipate the action of the foreign grains, and they must therefore be removed before they have approached the time of dehiscence. To do this it will be necessary to open the corolla, and cut these 
before the flower has blown. It is equally necessary, as was shown by the experiments of Gaertner and Herbert, that the flower be in a condition after fecundation in which it will not be liable to be affected by the natural pollen grains. The flower from which the aust is taken should be perfect, and not withered in the least.

When we consider how much greater is the effect of natural pollen upon its stigma than the foreign, does it not appear that hybrids are seldom produced in a state of nature? Many practical men have said that the pollen is conveyed so freely in all directions, by insects and the wind, that a great many of our accidental seedlings of merit are the result of this natural hybridization. But, if the anthers of the flower were present, their pollen grains would assuredly gain the ascendency, even if applied afterwards, which renders such a theory exceedingly questionable.

While the pollen of varieties remote in their relationship acts less freely than that which is closely allied, yet Herbert found that the production of seed by hybrid varieties is often increased by the use of the pollen from closely allied plants. In an experiment by him to elucidate this point, he states as a result, that "almost every flower that was touched with pollen from another cross produced seed abundantly; and those which were touched with their own, either failed entirely, or formed 
slowly a pod of inferior size with fewer seeds, the cross impregnation decidedly taking the lead. This circumstance may be analogous to the introduction of a male from another flock or herd, which has been found advantageous to the breeds of domestic animals."

Herbert was not successful in obtaining any results like those of $\mathrm{Mr}$. Knight from the blending of the pollen of several species before application. He says he "attempted to fecundate a plant with the pollen of twelve species, most industriously mixed together, but very few seeds were ripened, and they differed very little from those which had been procured by the pollen of one of the twelve species. I obtained mule and natural seed from the same capsule, but they were probably formed in different cells. Experiments should be made to ascertain whether, in cases of partial and imperfect fecundation, the pollen of another species, and even of a nearly allied genus, which could not alone fertilize the ovary, can act in conjunction with a single grain, or at least with an insufficient quantity of the natural dust to affect the fertilization, and occasion the seed to produce a variety, not exactly hybrid, but in some degree departing from the natural form. It is certain, by the result of many experiments made at Spofforth, that the pollen of a nearly allied genus, which can not affect the production of seed that will vegetate, will often cause 
some of the ovules to swell to a large, and occasionally to a preposterous size, and become seed-like masses without an embryo; and the same circumstance, has been observed in Germany; and, as it can act so far, I do not see the impossibility of its influencing the character of the seed when the access of natural pollen is insufficient: and it seems to me questionable whether some of the singular varictics which occur among vegetables may not have been so produced."

Dr. Lindley states, that "Purkinje demonstrated the correctness of Mirbel's opinion in 1808, that the dehiscence, or bursting open of the walls of the anther, which allows the grains to escape, is governed by hygrometrical causes; or that the inner lining of these walls is peculiarly sensitive to the dryness and moisture of the atmosphere, as well as the ripeness and dryness of the pollen; that this lining is of fibrous, cellular tissue, forming an infinite multitude of little springs," which by their concentrated action open the valves of the anthers when the pollen is ripe, and the atmosphere dry: "so that the opening of the anthers is not a mere act of chance, but the admirably contrived result of the maturity of the pollen," when the surrounding tissue, and of course this inner lining, has been exhausted of its moisture by the developing pollen grains. The observations of Mirbel confirm his statement, for he found a great quantity of sap in 
the cells surrounding the pollen, only a little before their maturity, while, "by a dislocation of these cells, the poilen loses all organic connection with the lining of the anther; and yet these same cells are exhausted of their sap and dry when the pollen is perfect."

'There are a variety of methods by which the pollen is conveyed from the anther to the surface of the stigma. In some plants it is by means of long hairs. M. Adolphe Brongniart states, "It has long been known that the external surface of the upper part of the style, and of the stigmatic arms of companulaceus plants, are covered with long hairs, which are very visible in the bud before the dispersion of the pollen, and which are regularly arranged in longitudinal lines in direct relation to the number and position of the anthers." These, and their connection with the pollen, he says, were first noticed by Conrad Sprengel, then by Cassini, and afterwards by Alphonse De Candolle. "At the period of the dehiscence of the anthers, before the expansion of the corolla, and when the arms of the style are still pressed against each other in the form of a cylinder, these hairs cover themselves with a considerable quantity of pollen, which they brush, so to speak, out of the cells of the anther; and for this reason they have been named collectors. At the period when the flowers expand, the arms of the style, or stigma, too, separate and curve back- 
wards, and the anthers that surround them retire and shrivel up, after having lost all their pollen; but at the same time the pollen, which was deposited on the outside of the style, detaches itself, and the hairs that covered the surface disappear." ${ }^{1}$

Dr. Lindley remarks in relation to these hairs, that if a longitudinal slice of a young style be examined before the pollen is emitted, that it will be seen that these hairs are found formed without any partitions, being an external lengthening of the epidermis. 'These hairs, having become covered with grains of pollen, begin to retract into cavities of about one-half their depth, immediately below them in the cellular tissue.

Soon after the pollen grains reach the stigma they commence to emit a tube, which, according to Dr. Lindley, does not exceed the one fifteen-hundredth or one two-thousandth of an inch in diameter. It reaches down to the placenta and to the foramen, or orifice of the ovule. Among the many methods which are provided for the fertilization of the ovule, when the position of the foramen is peculiar, and which are described by that distinguished author, is that of Euphorbia Lathyris, where " the apex of the nucleus is protruded far beyond the foramen, so as to lie within a kind of hood-like expansion of the placenta ; in all campylotropal ovules, the foramen is bent downwards by the unequal growth of the

1 As quoted by Dr. Lindley in his "Introduction to Botany." 
two sides, so as to come in contact with the conducting tissue" through which the pollen-tube containing the fertilizing matter forces itself. In some plants, "the surface of the conducting tissue actually elongates and stops up the mouth of the ovule while fertilization is taking effect. In plants of the genus Helianthemum the foramen is at the end of the ovule most remote from the hilum; and although the ovules themselves are elevated upon cords much longer than are usually met with, yet Brongniart ascertained that at the time when the stigma is covered with pollen, and fertilization has taken effect, there is a bundle of threads, originating in the base of the style, which hang down in the cavity of the ovary, and, floating there, convey the influence of the pollen to the points of the nuclei."

As was stated by Herbert, the process of fertilization is very slow, and it is often a great while (several days, or even weeks, after the fecundation of the stigma) before the pollen-tube reaches the foramen. Yet the life of the corolla, and the other parts of the flower, will be finished long before this time. The membrane immediately surrounding the embryo is called the amnion. Comparative mystery envelopes the operation which takes place in this amnionic sac.

Schleiden maintains that the microscopic observations of Fritsche prove that the molecules which exist in the pollen and its tubes are not animalcular, from the fact that they were undisturbed by alco- 
holic solutions of iodine, which would immediately kill such; and he pronounces the contents of these tubes as nothing more than a "solution of gum, and small crescent-formed bodies, which are starch."

He doubted the wisclom of tracing the analogy between the animal and vegetable kingdoms, and denied even the sexuality of plants as generally understood; that if the pollen-tube be followed to the ovule, it will be found that generally only one reaches the embryo sac, and, forcing and indenting that part which it comes against, it forms the "cylindrical bay which constitutes the embryo in the first stage of its development;" and that it consists only of a parenchymatic cell. Thus, on all sides except one end, the embryo has a double membrane, having that of the indented sac, and that of the pollentube. Thus the latter becomes the embryo. This he has proved, because he has been able to separate the tube from the sac after it had considerably advanced in development. He stated, even while the contents of the pollen grains and the tubes at first are simple starch, that they may be changed chemically in the inter-cellular passage, or they may not. Yet from this starch cells are formed at the terminus of the tube, which eventually become the parenchyma of the embryo. He found additional proof in the fact that where there was more than one embryo in a seed, there was a corresponding number of pollen-tubes present. Considered in this 
light, it was difficult to find which was the male and which the female element, as based upon analogies to the animal kingdom.

The extent to which hybridization can be carried is limited. Thus hybrids can, and have been, obtained from plants of an entirely distinct genera; and yet these were sterile, and not capable of producing a new genus of plant. The Creator has wisely ordered this, else confusion would take the place of order. Plants of two species often produce a hybrid; these are generally sterile, or productive only by impregnation from the pollen of one of their parents, to which type they will revert in the next generation. But this is one of the most fertile causes of the production of varieties. Thus, while species seem to be immutable, varieties are as mutable as the individuals from which they originate.

Sterility is not always a disadvantage, but sometimes positively the opposite, as regards cultivation. For example, such varieties of fruits as are destitute of seed are for that very reason eminently desirable, because the demand for nourishment which would have been made by the seed is not felt, and thus a much larger crop of fruit may be realized with less exhaustion to the tree.

In the Annals of Natural History, M. Thwaites said, "The most eminent physiologists seem to be arriving at the opinion, that the fertilization of the ovule, as it is termed, consists in the union of a 
part of the contents of a pollen grain with certain matter contained in the ovule, and that the embryo originates from this mixed matter. The correctness of this opinion is rendered still more probable by the consideration of what takes place under the circumstances of hybridization of species. The phenomena which present themselves in these cases are of the highest physiological interest; and it seems impossible, after a careful consideration of them, to doubt that the hybrid plant owes its existence toconsists in its earliest condition of - an endochrome made up of a portion of that of each of the parent plants; for the development of the hybrid embryo into the mature plant indicates a quality of the contents of this embryonic cell of a character combining that of the endochrome of each of its parents.

"The ovule of Fuchsia coccinea, fertilized with the pollen of Fuchsia fulgens, produces plants of every intermediate form between these two species, - some of the seedling plants closely resembling one, and some the other species, but the majority partaking equally of the characters of the two plants; scarcely, however, will any two be found so much alike as to be undistinguishable from each other. With respect to each of the hybrid seedlings, separately considered, there is a uniformity throughout in the mixed character of the various parts; so that it is easy, from the examination of the foliage, to arrive at a tolerably correct idea of what will be the 
character of the blossom. Some persons, perhaps, will be disposed to believe that an endochrome may be modified in its character, and that the peculiarities of the hybrid plant may be produced by the situation in which it is at first developed; but, if this were the fact, it is clear that the hybrid seedlings ought all to resemble each other as much as do individuals of one species, which is far from the truth, as has been just now stated. Moreover, a fact came under the observation of the writer which completely set aside the idea of such an explanation of the phenomena; for, in one example of the hybrid fuchsia seedlings, the singular circumstance occurred of one seed producing two plants entirely different in appearance and character. It cannot be doubted that these very dissimilar structures were the produce of one seed, since they were closely coherent below the two pair of cotyledon leares, into a single cylindrical stand, so that they had subsequently the appearance of being branches of one trunk. The plant was, before flowering, killed by an unexpected, severe-frost, but not before this peculiarity had been observed by many persons. In the case just cited, the idea of a modification of structure caused by a mere circumstance of situation in the early stages of growth is quite untenable; for, were such the case, it is clear there could not have been the great dissimilarity which presented itself in these twin plants - the product of a single seed." 1

1 As quoted by Dr. Lindley. 
'The conclusions which Mr. Knight drew from a series of experiments in hybridization were, that " new varieties of every species of fruit will generally be better obtained by introducing the farina of one variety into the blossom of another, than by propagating from any single sort. When an experiment of this kind is made between varieties of different size and character, the farina of the smaller sort should be introduced into the blossoms of the larger; for, under these circumstances, I have generally (but with some exceptions) observed in the new fruit a prevalence of the character of the female parent; probably owing to the following causes: The seed-coats are generated wholly by the female, and these regulate the bulk of the lobes and plantule; and I have observed, in raising new varieties of the peach, that when one stone contained two seeds, the plants these afforded were inferior to others. The largest seeds obtained from the finest fruit, and from that which ripens most perfectly and earliest, should always be selected. It is scarcely necessary to inform the experienced gardener that it will be important to extract the stamina of the blossom from which he purposes to propagate some days before the farina begins to shed. When young trees have sprung from the seed, a certain period must elapse before they become capable of bearing fruit; and this period, I believe, cannot be shortened by any means. Pruning and transplanting are both 
injurious, and no change in the character or merits of the future fruit can be effected during this period, either by manure or culture. 'The young plant should be allowed to extend its branches in every direction in which it does not injuriously interfere with another, and the soil should be sufficiently rich to promote a moderate degree of growth, without stimulating the plant to preternatural exertion, which always induces disease. The soil of an old garden is peculiarly destructive. The periods which different kinds of fruit trees require to attain the age of puberty are very varied. 'The pear requires from twelve to eighteen years; the apple from five to twelve; the plum and cherry four or five years; the vine three or four; and the raspberry two. The strawberry, if its seeds be sown early, affords a crop the succeeding year.

"A seed, exclusive of its seed-coats, consists of one or more cotyledons, a plumule or bud, and the caudex or stem of the future plant, which has generally, though erroneously, been called its radical. In these organs, but principally in the cotyledons, is deposited as much of the concrete sap of the parent plant as is sufficient to feed its offspring till that has attached itself to the soil and become capable of absorbing and assimilating new matter.

"The plumule differs from the bud of the parent plant in possessing a new and independent life, and thence in assuming in its subsequent growth dif- 
ferent habits from those of the parent plant. 'The organizable matter which is given by the parent to the offspring in this case, probably exists in the cotyledons of the seed, in the same state as in the alburnum of trees, and, like that, it apparently undergoes considerable change before it becomes the true circulating fluid of the plant. In some it becomes saccharine, in others acrid and bitter, during germination. In this process the vital fluid is drawn from the cotyledons into the stem of the plumule or bud, through vessels which correspond with those of the bark of the future tree, and are indeed perfect cortical cells. From the point of the stem springs the first root, which at this period consists wholly of bark and medulla, without any alburnous or woody matter; and, if uninterrupted by any opposing body, it descends in a straight line toward the centre of the earth, in whatever position the seed has been placed, provided it has been permitted to vegetate at rest.

" Soon after the first root has been emitted, the stem elongates, and, taking a direction diametrically opposite to that of the root, it raises, in a great many kinds of plants, the cotyledons out of the soil, which then become the seminal leaves of the young plant. During this period the young plant derives nourishment almost wholly from the cotyledons, or seed-leaves, and if these be destroyed it perishes.

"The bark of the root now begins to execute its 
office of depositing alburnous or woody matter; and as soon as this is formed, the sap, which had hitherto descended only through the cortical vessels, begins to ascend through the alburnum. The plumule, in consequence, elongates, its leaves enlarge and unfold, and a set of vessels which did not exist in the root are now brought into action. These, which I have called the central vessels, surround the medulla, and between it and the bark form a circle, upon which the alburnum is deposited by the bark in the form of wedges, or like the stones of an arch. Through these vessels, which diverge into the leaf-stalks, the sap ascends, and is dispensed through the vessels and parenchymatous substance of the leaf; and in this organ the fluid, recently absorbed from the soil, becomes converted into the sap, or blood of the plant: and as this fluid, during germination, descended from the cotyledons and seed-leaves of the plant, it now descends from its proper leaves, and adds in its course to the bulk of the stem and the growth of the roots. Alburnum is also deposited in the stem of the plant, below the proper leaves, as it was previously below the seed-leaves; and from this spring other ascending vessels, which give existence to, and feed, other leaves and buds." 


\section{CHAPTER XIII.}

\section{THE DISEASES OF FRUIT-BEARING PLANTS.}

§ I. GEXERAL OLSERTATIONS - BERIELEY'S THEORY OF CLASSIFICATION - WEIGMANX - CAUSES OF DISEASE - INSECTS. § II. DISEASES OF THE APPLE - OF TIE LEAF - FALL OF TIIE LEAF - FUNGI - CLADOS PORida Dexiniticen, Ceratites, RAEstelia - insects - APpleTREE LOUSE, COMMON APPLE-TREe CATERPILLAR, THE OAK-TREE CATERPILAR, THE VAFORER MOTH, THE PALMER WORM, THE HAG MOTH, THE UNICORN MOTH, THE CANKER WORM, THE MAXDMAID MOTH, THE DOTTED APPLE-LEAF WORM; OF TIIE FRUIT AND FLOWER - STERILITY - IMMATURITY OF THE FRUIT-INSECTS - THE SAW-FLY, TIE MIDGE, THE CODLING MOTI, THE ROSE-BEG; OF THE STEM - INSECTS - TIE GOAT MOTH, THE COMMON BORGR, ROOT-BLIGHT IXSECT, THE SNAPPING REETLE, TIIE BARK LOUSE, THE LOCUST OF THE SEVENTEExti TeAR; OF THE TREe Gexerally - PROFUSION OF SAP, HUNGER, STAGNATION Fron tRANSPLANTATION, CANKER, FrEeziNG, SPLITTING, WIND SIAKES, DROPST, SCN-STROKES, WOUNDS, LICIIENS, vitiation OF THE SAP. §III. DISEASES OF TIIE PEAR-OF TIIE LEAF - AMERICAN PEAR BLIGHT - IXSECTS - THE GOLDSHITI BEETLE, THE RED Hite, THE FLY, the LYDA, the ASTYAges, the hispa QUADRATA, FUNGI, DISCOLORATIONS; OF TIE FRUIT AND FLOWFR ROTTING AT TIIE core, INDURATION, LOSS OF RLOOM, ETC.; OF THE STEM - ROOT BLIGITT - INSECTS - TIE BLIGIT BEETLE, TIE BARK LOUSE, FUNGI, ETC. §IV. DISEASES OF THE PEACH - THE DOTTEN APPLE-LEAF WORM, PREMATURE FALL OF THE FRUIT, THE BORER, GUMING, ETC. § V. DISEASES OF TIIE PLUM - PLCM LOUSE, CURCELIO, THE PLUM WART, ETC. § YI. DISEASES OF THE CHERRY - TIE LOUSE, THE MAY BEETLE, ETC. § VII. DISEASES OF THE GOOSEDERTY - THE CATERPILlar, THE SWALLOW-TAILED MOTH, THE MIDGE, THE MILDEW, ETC. §VIII. DISEASES OF TIE CURRANT - FALL OF THE LEAF, THE BORER, ETC. §IX. DISEASES OF THE RASPBERRT - THE GRCB, ETC. § $\mathrm{x}$. DISEASES OF THE VINE - OF THE LEAF - INSECTS - THE VINe PLUNe, THE SAW-FLY, THE ANOMOLA VITIS, THE SPOTTED 
BeEtle, the piralis, the procris americaNa, the haltica CilaltBEA, THE LEAF HOPPER, THE BOMBYX QUATA, THE PHILAMELUS, THE CHOEROCAMEPA, THE RHYNCHITIS, FUNGI, COMMON MILDEW, ERYSIPIE, BOtRTtIS; OF THE FRUIT AND FLOWER-THE ROSE-BUG, SHANIKING.

\section{\$1. - GENERAL OBSERVATIONS.}

Tue diseases of plants have never received the attention which they deserve.' Of latter years investigation has been directed to insects injurious to vegetation; but this has been done more in relation to entomology than to pathology. We had described a great number of diseases affecting fruit trees, and had classified them in such a manner as we had hoped might contribute to the progress of vegetable pathology, when we discovered that its introduction to this volume would increase its size beyond proper proportion. Therefore we are constrained to retain many of the results of our investigation on this topic, which we may hereafter issue in a separate form. In this chapter we insert only some leading facts on the more common diseases. Even these we must treat with special regard to practice, omitting, for the most part, those novelties and freaks of nature which should be noticed in a full pathological treatise.

We shall not confine ourselves to a strictly philosophical method; because, in the cultivation of some plants, the very state which we desire to induce is one of clisease, provided this be considered as a departure from the normal type. For instance, the 
enlargement of the flesh of a fruit, the entire or partial absence of seed, are the results of disease, strictly considered; and yet these conditions are very desirable in fruit culture. Therefore, practically, we will regard as disease whatever is unfavorable to the growth of the plant for the purpose intended. This view is taken by Mr. Berkeley, of England, who defines disease as "a deviation from the normal condition of species." He treats the subject practically only as it is unfavorable to these deviations from nature produced by cultivation.

- Species have no natural tendency to disease, because this might destroy them; yet individuals or varieties have such a tendency, which they manifest in whatever condition they may be placed, and which they transmit to their offspring.

Berkeley thus classifies diseases: Internal, or Constitutional; External, or Accidental; Doubtful, or Conjectural. Weigmann arranged them thus: Those which affect the organs of Nutrition, of Respiration, and of Reproduction. But we shall adopt a classification better suited to the object of this chapter, and shall speak of the diseases of different species of fruit according to the part of the plant which they affect. This arrangement will enable the fruitgrower to avail himself readily of the results of our investigation.

While far the larger part of the diseases of plants may be rather mechanical and accidental than con- 
stitutional, yet there is a large class of the latter which have not been sufficiently studied to be described in detail. They are undoubtedly those which result from causes analogous to inflammation in the animal system, taking that term in its largest acceptation; yet their proportion is small. In some cases, during the inflamed condition of the organ there is an increased degree of heat, like that so often accompanying the same state in animals; while in other cases no difference in the temperature is perceptible. ${ }^{1} \quad \mathrm{M}$. Huber found when the heat of the atmosphere stood at twenty-one degrees centigrade, that the instrument, surrounded with spadices of the arum cordipolium, during the process of fecundation, rose as high as forty-two degrees. While plants have not as definite a form as animals, and it is therefore more difficult to detect malformation, yet they exhibit a peculiar sensitiveness to external influences during their growing season.

Mons. J. De Jonghe, of Brussels, states the causes which produce disease in fruit trees as follows: ${ }^{2}$

1st. Constitutional weakness of the varicty. Some sorts are weak because the conditions in which they are placed are unfavorable; perhaps they originated in a warmer region, and the severity or vicissitudes of the climate induces disease. Other varieties are

1 Gross's Elements of Pathological Anatomy.

2 In a paper published in "Gardeners' Chronicle," vol. for 18.57. 
constitutionally weak. This, according to Dr. Van Mons, is owing to a diseased state of the parent at the formation of the seed.

2d. The attacks of insects, induced by a state of weakiness. Many insects attack more readily a weak tree, and, feeding upon its vitiated sap, decrease its strength, and cause ultimately its death.

3d. The influence of a poor stock on which the tree is grafted. As these stocks are seedling plants, they of course vary as much in constitution as the cultivated sorts. If the stock be naturally weak, the scion inserted therein partakes of this weakness, and seldom attains full size; while, if the stock be constitutionally strong and robust, and the scion inserted therein weak, the vigor of the former will overcome the weakness of the latter. This accounts not only for the varying strength, but for the difference in the quality of trees of the same variety, and under the same conditions of culture.

4th. The use of improper scions. Fruitfulness is often delayed by using scions from young undeveloped trees; or weakness may be produced by the use of those from an old and decrepid tree. If possible, the scions should be taken from a tree which has just commencel to bear, and is in the prime of life.

5th. Bad soil. If the soil is cold, however great may be the constitutional vigor of the tree, canker, or some other disease will, sooner or later, appear. 
But if the earth is warm, yet exhausted, the roots do not find sufficient food, and weakness ensues.

6th. Improper management. If the tree has been planted too deep or too shallow, the roots not properly spread out in planting, the pruning injudicious, or the cultivation of the soil during the summer insufficient, the effect will be for the time to weaken the tree, and, it may be, permanently to injure it.

7th. Accident. Contusion, gnawing by animals, sun-strokes, or cutting the roots severely with the plough, may prevent the tree from becoming vigorous.

But there are many other causes of weakness besides those above mentioned, such as superabundant production. Yet weakness is not always the cause of the diseased action, although it may often produce it. But there are multitudes of maladies, where this is only the effect of the disease. A parasite may have been at work for years, sapping at the life of the tree, before its results are visible weakness. Some insects attack a tree when in full vigor, - the apple-tree caterpillar, or the cankerworm, - and they soon reduce the tree from vigor to debility.

But we are too much accustomed to consider all insects as our enemies. If they cross our path, our first impulse is to crush them; if one of them falls upon us, our flesh crawls with repugnance. That 
is more mortifying to a host, disgusting to his guest, or disheartening to the amateur, than to discover a writhing worm wounded by his teeth in a fruit which the sun has painted with the image of God's glory, and to which the morning breezes have imparted a delightful fragrance, and from which he anticipated an almost ambrosial morsel ? While some insects, destructive to our fruit, are real enemies, others are true friends and valuable allies, destroying the former. Insects cause a number of diseases, and we will consider briefly a few facts respecting them.

The life of an insect is divided into three periods. The first state is that in which it is hatched, then called a larva, and is wingless; it may be a maggot destitute of legs and sight; a caterpillar or grub. The latter has six legs, sometimes with an additional pair of false legs attached to the posterior segment of the body. 'The caterpillar has six true legs, like the grub, and several pairs of false legs, amounting altogether to from ten to sixteen.

From this state, in which it feeds enormously, and grows very fast, it passes to the second state. In this it is called a pupa, or chrysalid. The latter is distinguished by the gilt spots. In this state some insects eat, and are active; but most of them are dormant, and enclosed in a cocoon.

In the third state they are generally provided with wings. The females deposit their eggs, and 
die. In the first of these states they do the most injury.

The following description of the orders of insects was suggested by those of Burmeister, Harris, and Glover.

1. Coleoptera-Beetles. These undergo a perfect change of form, as described above. They have a mouth, furnished with jaws formed for biting; two thick, wiry covers, meeting in a straight line on the top of the back; and two filmy wings underneath them, folded transversely. The larvae are grubs; the pupae with wings and legs distinct and unconfined.

2. Orthoptera - Cockroaches, crickets, grasshoppers, straight-winged insects. These have only an imperfect change of form; and in their mature state are like grasshoppers. They have a mouth like the preceding, furnished with jaws for biting or masticating; two thick, opaque upper wings, overlapping a little on the back; and two larger, thin wings, folded in plaits, like a fan. The larvae and pupae are active, but wingless.

3. Neuroptera - Net-veined insects. These have a perfect change of form: the month is furnished with jaws for biting. They have four wings, of 
similar texture, of which the hinder are the largest, with narrow, meshed netted veins.

4. Lepidoptera - Butterflies and moths. These undergo a perfect change of form; have a mouth with a spiral trunk, furnished with a piercer, or sucker, and not capable of biting; four wings, of similar texture, wholly or only partly covered with fine dust-like scales; the larvae are caterpillars, and have six true legs, and from four to ten fleshy prolegs; pupae, with the cases of the wings and of the legs indistinet, and soldered to the breast.

5. Hemiptera - Bugs, locusts, plant-lice. These have an imperfect change of form. The mouth is armed with a beak, furnished with a piereer, or sucker, and not capable of biting. They have four wings, generally standing up, when at rest, like the roof of a house, and frequently all of the same membraneous texture. The larvae and pupae are nearly like the adult insect, but are wanting in wings.

6. Diptera - Mosquitos, gnats, and flies. These undergo a perfeet change of form; the mouth has a proboscis for sucking, sometimes having small lancet-like appendages for piercing concealed inside the trunk, as in the horse-fly. They have two naked, transparent wings, and in place of the two hind wings a slender stalk-like appendage on each 
side; this terminates with a button, or knob-like end. The larvae are maggots without feet, and with the breathing-holes generally in the hinder extremity of the body. The pupae are mostly incased in the dried skins of the larvae; sometimes, however, they are naked, in which case the wings and the legs are visible, and are more or less free or unconfined.

7. Hymenoptera. These insects have a perfect change of form. Their mouth is armed with distinct mandibles, or jaws, and also has a ligula, tongue, or proboscis for suction. 'They have four' membraneous wings, divided into large cells. The larvae are mostly maggot-like, or slug-like; that of some species are caterpillar-like pupac, with legs and wings unconfined.

\section{§II. DISEASES OF THE APPLE.}

I. Those affecting the Leaf. 1. The fall of the leaf-Phylloptosis. In most plants there is a point of articulation between the leaf-stock and the wood, but not always. Nearly all the plants which come under our notice in this work possess such a junction. When the leaf is about to fall, a chemical change takes place in the chlorophyl, which gives the green color to plants, - a change by which they assume the hue so familiar to us as that of autumn. Thus the leaf clies, and is no longer of any value to the tree. 
Dr. Schacht describes this more in detail. He says, "The cells at the place of separation are cork, and the scar is subsequently covered with it. The transmission of sap is consequently impeded, and at length entirely cut off, insomuch that the leaf hangs loose, and finally falls."

But, with much reason, Dr. Berkeley contends that this is not the cause of the phenomenon, but only an effect, by which these cells endeavor to cover the live wood of the tree in such a manner as to prevent the transmission of any morbid matter. This transmission he often observed to be the cause of canker. The fall of the flower and the fruit he considered as belonging to the same class of phenomena. It may be said that, in the case of a fruit, death has not taken place; but it will be seen, upon a moment's reflection, that as far as its relation to the tree is concerned, the fruit has really ceased to live as soon as it stops drawing nutriment from the tree. "The parts have all arrived at maturity, and therefore neither require any more food from the mother plant, nor are they in a condition to make any further interchange," (fermentation having probably commenced) " and separation takes place. The fall of the leaf, considered as a disease, is when this phenomenon takes place at an improper time, and results either from some constitutional or accidental cause."

'The Flemish Beanty and the Paradise d'Automne 
pears may be cited as examples of this disease resulting from the first of these causes. These drop their foliage oftentimes before the fruit is sufficiently mature to pluck from the tree. This makes the fruit less in size and inferior in quality.

Among the varieties of the currant, the Red Dutch is, especially in this country, liable to shed its foliage prematurely, in which case the fruit shrivels and dries up; or, if gathered, possesses a peculiar acidity, showing that the saccharine fermentation had scarcely commenced. While this is the character of the Red Dutch, some varieties, like La Versaillaise, retain their foliage. This increases the size of the fruit, and its adhesion to the bush.

2. The presence of fungi. Mr. Berkeley, in a review of the work of Mons. Muger on the causes which induce fungi, states them as follows:

(1) Fungi always originate on plants which are young and full of sap; and hence it is in spring that they are found on the young and tender parts.

(2) Young shoots of trees are more liable to be attacked.

(3) Younger trees are more predisposed than those which are older. Many species occur in young plantations, which are rarely found in those of older growth.

(4) Galls are frequently covered with fungi. 
(5) The lower branches are more affected than the upper, and the propagation of the parasite takes place from the base to the summit.

(6) Land too highly manured induces rust.

Among the occasional causes producing fungi are -

(1) An atmosphere habitually charged with moisture.

(2) Absence of light.

(3) Sudden changes in the atmosphere, as a transition from heat to cold, or from a dry to a moist state.

(4) Long-contimued drought.

(5) Crowded growth.

(6) Plants with creeping stems.

(7) Leaves soiled with earth, or other impurities.

(8) Changes of climate, causing corresponding changes in the development of the plant.

(9) Inundation.

Of Fungi, these kinds deserve special notice-

(1) Cladosporium dendriticum. This fungus attacks not only the leares, but also the fruit of the apple and pear. It completely exhausts the foliage, spreacling over it, and causing black spots which, in the fruit, often produce cracks. Those caused by fungus must be distinguished, however, from those cracks caused by a sudden and superabundant flow of sap. This fungus is very persistent, and seldom leaves a tree in which it has once obtained 
a sure lodgement. Some vegetable physiologists have even thought it was transmitted to the next generation by the seed.

Like the species Botrytis, it does not work upon the surface, but beneath it; and the disease is on that account not so easily exterminated as those which result from fungi, and run upon the surface. The only alleviant for the disease is to gather all the lcaves after they have fallen, and burn them. At the same time the whole tree should be washed with a mixture of sulphur and lime-water, as recommended for mildew on the vine (Oidium Tuckerii). Thus, whatever spores may have been deposited on the buds and wood will be destroyed.

(2) Ceratites. This fungus attacks the apple, pear, and quince. It more often appears upon the pear, not only upon its leaf, but also on its fruit. This has a single lobe at the orifice of the peridium, from which the spores escape for reproduction (Berkeley).

(3) Raestelia. This fungus has a number of lobes, all connected together, so as to form a little cage, through the interstices of which the spores escape. When a pear tree is once affected by this pest, it seldom escapes its influence in future years; on the contrary, the evil generally increases, spreading to every neighboring tree, and thus propagating itself indefinitely. 'The better plan is to pick the leaves which are infected, as soon as the orange-col- 
ored, thickened spots appear, and before the spores are developed. (Berkeley.)

\section{Insects. (1) Apple-tree Louse-Aphis mali.} This is a small, green insect, which crowds upon the tips of the young shoots, and of the leaves. It sucks the juice of the tree, and causes the leaf to curl under. This provides it with a shelter from the dew and rain. It is very prolific. In the autumn the male and female produce eggs, which, during the winter, are laid in the crevices of the bark. The females are hatched early in the spring, and arrive at maturity in a few days. Without any intercourse with those of the opposite sex in this generation, they give birth to living young, bringing forth about two daily for a period of two or three weeks. The young soon become parents, and they are thus multiplied almost inconceivably. From twenty to forty generations are produced in a single season. Mr. Curtis states that, from a single egg, in seven generations, seven hundred and twenty-nine millions of lice will be bred, if unmolested ; and if they all lived the allotted time, by autumn everything upon the face of the earth would be covered with them.

On this account it is a source of gratitude that Providence has given this insect so many enemies; perhaps no other has an equal number. These are wasps denominated Crabonidae, and a number of flies called golden-eyed and lace-winged. But one of 
its most active enemies is the common lady-bug. This bug grasps the lice, and sucks out all their juices, leaving nothing but the skin. But while they have so many enemies, they also have friends and protectors. These are large black or reddish ants, which run over their backs and tickle them, inducing them to exude a drop of sweet fluid, which the ant consumes. The lice do not seem to flourish as well where the ants are not their attendants.

As these insects attack only the tips of the shoots, where the skin is young and tender, the best method of destroying them, if the tree is small, is to immerse the shoot in a pail of water in which a piece of whale-oil soap of the size of the fist has been dissolved (Fitch).

(2) Common Apple-tree Caterpillar - Clisiocampa Americana. The territory which is the theatre of operations for this worm is extensive. Although it can subsist upon the leaf of almost any species of the order of Rosaceae, yet it always chooses first the wild cherry, then the apple. Dr. Fitch, of New York, attached nests of them to trees and bushes of various kinds, and found, while they generally existed, that they did by no means flourish, and did not become strong enough to spin cocoons. The seasons which are the most propitious for fruit, are also for the development of these as well as of other insects. This is a sage provision; otherwise our whole crop might be destroyed in an unfavorable 
year, while in seasons of abundance we can afford to lose a portion. The eggs are placed in a cluster, forming a ring about the twig of three-quarters of an inch in length. In one of these belts is at least three hundred eggs - the product of one female. They are deposited early in July, and remain until the latter part of the next April or first of May, when they begin to hatch. 'The young larvae at first feed upon the glutinous matter which surrounds and covers the eggs; but when they have gained sufficient strength, they begin to forage upon the leaves. Each one, as he travels, spins a thread, attaches it to the bark, which secures his foothold. When he arrives at a fork in the limbs, he commences the dwelling by spinning threads in erery direction. These caterpillars, having eaten sufficient, repose upon the outer surface of their netting. When others return, they spin another net over these, and walk over those which are asleep. Thus a nest consists of several of these nets, one over the other, with space enough between them to allow the passage of the insect.

When they first come forth from the egg they are not more than one-tenth of an inch in length. But they throw off their slins five or six times, and at each change become larger. They seem to be destitute of sense to guide them toward their food. They will sometimes pass, and almost touch fresh leares, when they are half starved, without noticing 
them. Neither do they have any mode of communicating information to their companions in regard to food. One hungry worm after another examines the end of every twig upon a limb unsuccessfully for food; and, returning, they meet others going out upon the same errand. They take daily three meals, - one in the morning, another in the afternoon, and a third at night. Each worm will consume about two leaves per diem ; and as each nest contains about three hundred individuals, they will destroy at least six hundred leaves daily. In the early part of June they separate, and select some retreat where they spin their cocoons. They repose about three weeks in the pupa state; and early in July they pair and deposit their eggs. At this time they are the dingy, dusty moths which flutter about the lights in the evenings. If these insects are unmolested, they will often entirely strip the tree of foliage.

The best method of preventing their ravages is to take the nests from the trees with the hands, immediately after their appearance, and to stamp them so as to crush the young. If they are merely thrown upon the ground, they will soon crawl up again, and resume their attacks upon the same, or another tree (Fitch).

(3) The Oak-tree Caterpillar - Clisiocampa sylvatica. This caterpillar attacks the apple and the oak. It not only eats the leaves of the former, but 
gnaws the stem of the fruit, making it fall to the ground. It is found generally in the more southern parts of our country. It makes its appearance a little later in the season than the common eaterpillar, and its nest is attached to the sides of the tree, instead of to the fork of the limbs. In other respeets, it is very much like those in the preceding description.

There are various insects which prey upon this eaterpillar in the pupa state. Some of them spin small cocoons upon the larva, and consume the pupa. As in respect to the preceding, it is often necessary to destroy the nest several times, as a portion of the worms will be foraging, who will reconstruct their abode on their return (Fitch).

(4) The Vaporer Moth - Orgyia leucostigma. The caterpillar of this moth " is slender, with pale yellow hairs and tufts, and black pencil-marks; its head, and two small protuberanees on the hind part of the back, are bright coral red." It is about one inch in length, has sixteen feet, and is very beautiful in its appearance. Among the fruits, it feeds upon the leaves of the apple and the plum during the month of July. It is not gregarious, but lives solitary, and eats only the soft parts of the leaf and the smaller ribs. Their cocoons which are to produce females are spun, in the latter part of this month, to twigs and limbs, while those from which the male moths are to be hatched are often attached 
to fences. Two leaves are often drawn together, and tied by their threads, to form the cocoon of the former. The cocoons of the females are always placed where the eggrs are to be deposited. The implantation of this instinct is a wise provision, because the females are wingless.

Early in August the moth appears. Its color is dark brown, with very few spots or streaks. The flight of the male is peculiar, made up of short jerks. The body of the female is at first very thick and unwieldy, but, after the deposition of her egg, appears slender and flabby; and she soon becomes so weak as to drop to the ground and perish. The number of her eggs is from one hundred to two hundred. They are placed upon the exterior' of the cocoon just vacated, where they are covered with a frothy matter, which glues them together, and prevents their destruction by birds.

The caterpillar, however, is not without enemies. It is attacked by a very small, bee-like insect, that punctures its skin and inserts an egg, soon hatching a maggot, which feeds upon the fatty matter of the caterpillar, and finally kills it.

The vaporer moth can easily be destroyed, because the cocoon of the female, upon which the eggs have been placed, can be readily distinguished, when the leaves have fallen, by the prominence of the dry leaf forming a part of it. They should then be gathered and burned (Fitch). 
(5) The Palmer Worm-Chaetochilus pometellus : Harris. There seems to be seasons when this insect is very destructive. Generally they make their appearance only in small numbers; when in quantity, their numbers are prodigious, and they destroy all the foliage upon a tree in an almost incredibly short space of time. They prove most injurious after a hot, dry season, when the orchards which they attack appear as though fire had gone over them. If an infested tree is shaken, hundreds of them lct themselves down to the ground by a fine thread. Their attacks are not confined to the leaves, but also extend to the fruit. They are very variable in color; and this circumstance has given rise to their division into several species; but specific difference does not, probably, exist. Their bodies have thirteen segments, and sixteen feet. Their general color is greenish yellow; but a shade of pink, or a tendency to white, is often observed among them. They have upon them several small black dots, each giving rise to a single hair. Where they exist in small number, they spin their cocoons upon leaves; but where they are numerous they so completely destroy the foliage that this becomes impossible, and they take refuge under dead leaves, • or some other material upon the surface of the ground, or in any secure position. Their cocoon is very superficial, when compared with that of some other insects, as they remain in it a very short time. 
In ten or twelve days, or about the middle of July, the moth appears. This worm is attacked by a parasitic insect, which feeds upon it until it has attained its growth, and then perforates the skin of the palmer worm, and spins its own cocoon. Of course it kills the worm upon which it has preyed.

The most effectual method for the destruction of the palmer worm is to syringe the tree, by means of a garden engine, with a strong solution of whaleoil soap. Heavy showers dislodge the worm; and it is therefore only in a season of long drought that they can increase so as to become injurious to any great extent (Fitch).

(6) The Hag Moth-Limacodes pethecium: Smith. In its very slow motion, this resembles a slug. It attacks the apple and the cherry. Its color is brown, and it is covered with short, downy hairs. Its body is nearly oblong square, and about one inch in length. 'The moth appears in June, and the larvae consume the leaves until the middle of September (Harris).

(7) The Unicom Moth-Notodonta unicomis. This attacks both the apple and the plum. It is an inch or more in length, and is generally solitary in its - habits. "The top of the fourth ring of this caterpillar rises in the form of a long horn, a little sloping forward." The tail and hindermost legs are always raised, except in walking. Its head is large, and brown in color; the sides of the next two rings 
green; and the rest of the body brown, variegated with white. It has two broods during the season; but, as they are generally small in number, they seldom do sufficient injury to produce a noticeable effect (Haris).

(8) The Canker Worm-Phalaena vernata: Peck. In the male moth of this species the atennae have a narrow, almost downy, edging on each side, scarcely perceptible to the naked eye. The wings are large and thin. It is ash-colored, variously marked with white. The female is wingless; the atennae short, slender, and naked. These insects rise from the ground, where they have undergone their transformation, in the autumn and winter in small numbers; but the larger part of them do not come forth until about the middle of March. The females advance toward the nearest tree, and climb slowly up the trunk. The winged males flutter' about, and accompany them. The female deposits upon the limbs of the tree from sixty to one hundred eggs, glues them together, and dies. These eggs hatch early in the succeeding May. The larvae attack generally only the foliage of the apple and the elm, but occasionally the cherry and the plum. These worms vary exceedingly in color, from green to dusty brown, and blackish. At full size they are about an inch in length.

A month after their appearance, they stop feeding, and leave the trees, creeping down the trunk, 
or suspending themselves by threads. They then burrow in the soil to the depth of a few inches, and become transformed. They are prevented from spreading over any new tract of country very rapidly, by the wingless condition of the female. They are exceedingly voracious during the period of their growth, often entirely depriving the tree of leaves.

To prevent ravages of the larvae we should stop the female from ascending the tree. For this purpose various methods have been adopted. Strips of paper, covered with tar, have been used; but the necessity of a frequent application renders this only a partial preventive. Boxes or troughs are sometime fitted arsund the tree, so that the female is obliged to make her way over them in ascending. These are filled with a noxious fluid, or some liquid which drowns the insects, and proves beneficial. The Messrs. Clapp, of Dorchester, Massachusetts, used this remedy when their orchard was troubled, and state that for a few evenings during the ascension of the insect the boxes became so completely filled with moths that others travelled over the bodies of their dead and dying companions.

The most simple and efficient remedy is to place a strip of zinc, four inches in width, around the tree, so that the upper edge shall grasp the tree tightly, and the lower stand out two inches from the trunk. Then all the little interstices between the upper edge and the tree should be stuffed to prevent their 
ascent. They cannot pass over the lower edge, and therefore slide off and fall to the ground, to repeat the attempt until they become aware of their inability to reach the limbs. This collar must be made of zinc, and not of tin, for the latter will rust, and thus afford the worms access to the top of the tree. Orchards thus treated have been entirely free from these pests, while those in the immediate vicinity were entirely deprived of foliage.

(9) The Handmaid Moth-Eumetopona ministra: Drury. This is one of the worst insects affecting the apple. It commences at the tip of the limb, and entirely strips the tree of foliage. Like the palmer worm, these seldom make their appearance in sufficient numbers to do any great harm. The caterpillars are yellow or black, feed while huddled together on the under surface of the leaves, and gnaw at the margin. If they are alarmed, they throw their tails at right angles to their bodies, and their heads up over their backs, and remain in this posture until the danger is past. They are from six to eight weeks in attaining their full size, and appear as moths about the middle of June. They then deposit from seventy to one hundred eggs, which are glued together on the surface of the leaf. In the latter part of July, when the worm is hatched, it commences to consume the leaf. In September it enters the soil to the depth of two or three inches. No effectual method for their destruction is known 
except that of plucking them off individually (Fitch).

(10) Dotted Apple-leaf Worm - Brachytaenia malana. 'This insect is of a pale green color, is dotted with white, and has fine whitish lines running longitudinally. They make their appearance in the latter part of May, and attack the under surface of the foliage of the apple, cherry, and peach; and after their growth they spin a very peculiar and ingenious cocoon. 'They draw the edges of a leaf so as to perfectly enclose themselves, and thus provide a dwelling for the pupae. They are transformed into moths in July. They deposit their eggs in the leaves, and produce another generation the same season. This new race, having entered their cocoons, fall with the leaves, and come out as moths the next spring. But some of them, encouraged by the heat of the autumn, come forth, and hide themselves under the old bark, or in some such safe position, where they remain fiozen all winter, and come forth in early spring. This insect, like many other species, seldom appears in sufficient numbers to do any very serious injury; but, when it does, the tree can be shaken, - a sheet having been spread under it, - and the worms gathered and burnt (Fitch).

II. Diseases affecting the Fruit and Flower. 1. Sterility. This is not always an injury to the cultivator of fruits, but is often a positive benefit. 
It denotes, not the non-production of fruit, but of seed, the entire or partial loss of which, though a disease strictly considered, is generally attended by the production of fruit, because the resources of the tree are not exhausted. The Vicar of Winkfield pear seldom produces perfect seed; and hence it is a very regular and abundant bearer. There are some varieties of grapes which do not produce seed, and this is regarded as a point of excellence.

But, in a practical view of sterility, it will be well to consider it only affecting the production of fruit. Though all the parts of the flower may be perfect, and proper fecundation take place, and even an embryo be formed, yet the plant may be sterile as to seed from habitual abortion, which is especially liable to take place in those varieties in which the walls of the ovary are highly developed. Hence, in some of the finer varieties of pears, perfect seed is a comparatively rare product. As the properties which make the fruit valuable are altogether independent of the seed, it is sufficient for all ordinary purposes if impregnation has taken place to such an extent as to insure the swelling of the sarcocarp or intermediate flesh. Many cases of sterility result from the fact that fertilization takes place only sufficient to stimulate temporarily the contents of the embryo sac and the fleshy walls of the fruit, but not sufficient to ensure its growth to maturity. Hence, after a time, the embryo ceases to grow, and 
the sarcocarp withers. This is especially the case in stone fruits, as is well known to every cultivator, whose fruits so frequently drop just when they are undergoing the process of stoning. Meyer studied this subject as regards forced cherries. From a very early stage of growth he could predict, from a change in the external form, and sometimes from a peculiar intensity of color, what fruit would ultimately prove abortive. But the shrivelling of the embryo takes place previous to the peculiar elongation of the fruit (Berkeley).

The prevalence of rainy or cloudy weather at the time of flowering may prevent the style, or female element, from receiving the pollen. The anthers require dry weather in which to burst open, or dehisce, and throw forth their pollen. If this weather does not occur at the proper time, the style may fade, and its sensibility to the process of fecundation cease. Or, if the pollen has been already deposited, a heavy rain may wash it away before it has commenced its work.

Upon this subject Dr. Berkeley remarks, that the secretion of viscous fluid, which is exuded from the surface of the style, and which develops the tubes that insert themselves down the style to the ovule from the pollen grains, is often washed off in rainy weather, so that even if the pollen falls upon the style afterwards, it produces no result. Sudden heat succeeding a fog or clondy weather, he thinks 
one of the most powerful agents in drying up and destroying the delicate tissue of the blossoms; and sometimes this takes place in flowers which have been impregnated, as well as those which have not. Such cases of failure are repeatedly noticed in this country, as well as in England. There is no doubt that sterility sometimes occurs from a superabundance of this viscous fluid.

Fungi and insects often attack the organs of fructification, and cause more or less injury, according to the stage of progress in which the blossom then is. Sterility is sometimes occasioned by injury of the embryo, before the time of blossom, by extreme changes in the temperature. Those seasons which are usually called the most severe, are generally best suited to plants. A low degree of the thermometer is not necessarily injurious if it is regular, and not intermitted by warm seasons, which excite the bud and cause it to swell, and sometimes even to put forth blossom. If such seasons are succeeded by extreme cold, they destroy the embryo. Such extremes are not so liable to injure the bud in the early part of winter, because then it would not be natural for the bud to start; but towards spring, when the sap is just beginning to flow, such changes are more serious.

Sensitiveness to extremes is almost always confined to foreign fruits, and is never noticed in native varieties unless such extremes are very severe. 
The buds of apples are covered with thick scales, and these are lined with pubescence, which make them still less conductors of heat; and therefore these are not so easily affected by the warm days in severely cold seasons. But the peach and the cherry are natives of a warmer climate, where, as such, a protection is unnecessary. Hence nature did not give them these peculiar properties. As species never lose their specific character, it is impossible to raise a peach which shall have scales thick enough, or be coated with sufficient hair, to defend them from these vicissitudes.

After an extreme of cold has just passed, and it is again comparatively warm so that decay can go on, a cultivator can easily determine whether the vitality of the buds is destroyed by cutting one smoothly in halves, and seeing whether there are any dark spots in the centre, since these denote the death of the embryo.

"One of the ordinary causes of sterility," says Dr. Berkeley, "whether permanent or temporary, is the hypertrophy or absence of some particular part of the plant. The nutriment which should have been employed in the formation and perfection of the organs of fructification is thus diverted to some other purpose. 'These organs may be apparently perfect, and yet no impregnation take place, even though the pollen grains may germinate. It is possible that, in such cases, there is some deficiency 
of power in the ovules, or in the vegetable force, by which they are excited, and not in the pollen grains themselves; - an inference supported by analogy in the animal kingdom."

In the fruit tree this hypertrophy is often seen in the unnatural growth of wood, induced by a highly nitrogenous soil. The force of this growth is often so great, that if any fruit-buds are formed, they are changed into wood-buds the next spring, and shoots start from them. This disease can be remedied by severe summer pinching, as described in the chapter upon pruning, and by root-pruning, which will effectually check undue luxuriance. This condition is often induced by too severe and injudicious spring pruning. As was noticed in another chapter, the limbs which proceed from the buds at the base of the shoots do not produce fruit as readily as those from the terminus, or even at midway; and, therefore, by pruning back to these at the base, the fruit-grower is constantly producing either partial or total sterility.

In some cases sterility is caused by the monacious character of the plant (or the possession of only one of the sexes, the other being absent or sessile), and consequently by a defective fecundation, or none at all. This is particularly the case with strawberries. Some of our most valuable varieties are utterly unable to produce a large crop without the presence of other varieties in the line, or near 
them, which have a superabundance of pollen, and can part with it for their benefit. The former are called pistillate, because the female element largely predominates; while the latter are staminate, because the male element is the stronger. Sterility in a pistillate plant can easily be remedied by planting through the bed, or in an adjoining line, those which are staminate.

Again: sterility often results from bad cultivation, which allows the tree to produce too large a crop, and to exhaust itself in maturing its seed. The production of some varieties only once in two years is owing to the fact that the tree becomes so weak in maturing such an inordinate number of seeds, that no strength is left for the formation of fruit-buds in the autumn for the succeeding year. This can be prevented by judiciously thinning the fruit, which does not diminish the quantity; for, as before mentioned, what exhausts the tree is the seed; and therefore, by taking a part of it away, the fruit becomes larger, and the measure remains the same, with only a diminished number of fruits.

2. Immaturity of the fruit-Carpomosia: Ré. This is a condition of the fruit in which the cells are woody, and the juice acid, as it is before the commencement of the saccharine fermentation. It is impossible to ripen fruit when infected by this disease, which results from one of three causes: First, from excessive dampness and coldness of soil 
during the season of growth. This may be remedied by proper drainage; secondly, from gathering the fruit before saccharine fermentation has commenced; and, thirdly, from absorption of too much oxygen. This may generally be remedied by judicious pruning, which admits the light. A ray of light is composed of several colors, each of which has independent and peculiar qualities, and produces distinct chemical results. By the union of two or more rays, compound colors may be produced, which combine the effects of the rays composing them. Every vegetable cell has a nucleus, which, exposed to the light, takes some color, generally green. Upon the skin of fruits these colors, changing from green to yellow, and then to brilliant red, seem to mark or produce chemical changes which result in the ripening of the fruit. When this change of color in the skin of the fruit does not take place, the fruit seldom ripens; or, if it does become mellow, the flavor will be very inferior, showing that the usual chemical changes have not been thoroughly performed. The amount of color neccssary to a fruit to bring it to perfection varies, of course, in different varieties. The Rhode Island Greening apple, in its most highly colored state, is yet very pale when compared with a Baldwin only moderately so. Those fruits which require little color are generally peculiarly sensitive in regard to the least. Such is the Vicar of Winkfield pear, which 
never becomes very highly colored, and yet is scarcely edible unless it has some little shade of brown or red upon its cheek, when it becomes aromatic and delicious.

While this disease sometimes attacks the apple, yet it is more frequently noticed in the pear.

3. Insects. (1) The puncture of the firuit by the Apple Sau-fly - Tentredo testudinea. 'This insect makes its appearance during the last of June and first of July, when the apple is one-quarter or one-third grown, and causes the fruit to drop to the ground. If the apple is immediately examined, it will be found to contain the larva, or worm, which very soon escapes to the ground. The fly deposits its egg as early as the period of florescence. Its wings are light brown; its legs and body orange, with the exception of the upper surface, which is a glossy black. Its length is about five-eighths of an inch. The caterpillar, which appears as a borer, is of a pale orange color, having twenty legs, three pairs of them being thoracic, six pairs of them short ventral, and one pair at the extremity. The larvae increase in size with the growth of the apple, eating the heart of the fruit, which at last causes it to drop. The only remedy for this serious malady is to pick up immediately the fruit which has fallen, and destroy the larvae before they have escaped, either by boiling them, or feeding them to some other animals. Some per- 
sons allow their swine to run in the orchard during this period, and pick up the apples as they drop (IVestwood).

(2) The Apple Midge - Molabrus mali. The flesh of an apple which has been attacked by this little insect becomes spongy and dry, with deep fissures perforating it. It is probable, although not altogether certain, that the fly deposits her eggs at the calyx, or flower-end of the fruit, and that the worm then perforates to the core, where it becomes a pupa. The dampness of the apple seems necessary to aid the fly in its transformation; as $\mathrm{Mr}$. Fitch found that the exposure of the insect to the air resulted in the immediate arrest of its growth. They, of course, spin no cocoon in such a position, but surround themselves with a peculiar glutinous matter (Fitch).

(3) The Codling Moth - Tinea pomonella, Linn, Pyralis Pomana: Fabr. This moth appears the latter part of June. "The fore wings are crossed by numerous gray and brown lines, scalloped like the plumage of a bird; and near the hind angle there is a large, oval, dark brown spot, the edges of which are of a bright copper color. The hind wings and abdomen are yellowish brown." It lays its eggs upon the calyx, or flower-end of the fruit; the moth generally selects early varieties. 'The eggs hatch in a few days, and the worm burrows in the core, from which he bores a hole to the side of the 
apple; through this he thrusts its fragments. 'They leave the apple either before or immediately after it falls to the ground, so that it is then almost impossible to destroy it.

Dr. Trimble, of New York, found that many birds, such as the chickadee and the downy woodpecker, devoured these insects; and although the worms are under the bark, where they have spun their cocoons, yet the latter of these birds seems to have a remarkable instinet for discovering their position, striking through the bark with its bill at the exact spot, bringing them forth and consuming them. He thought that the instinct of this worm, leading it to seek shelter for the winter in the old bark and in any old material, might be made a means of destroying it. "A most effectual remedy," he says, is "tying a hay rope two or three times around the trunk of the tree, when they seek refuge under this rope and can be destroyed, if it is taken off and burnt when winter approaches. The expense and trouble of such an operation is very trifling, and the experiment is certainly worth trying.

(4) The Rose Bug-Macrodactylus subspinosus : Fabr. 'These attack the fruit of the apple, grape, plum, cherry, and peach. 'They devour not only the fruit, but also the leaf and the blossom. They make their appearance about the middle of June, when they crowd in immense numbers upon the fruit or blossom and entirely consume them. They sometimes 
appear in orchards year after year, and deprive them of every fruit. The beetle is only about onethird of an inch in length, and is covered with little scales, which cause it to appear as of a deep yellow color. After about a month it is not to be seen: the female has crawled into the soil, and deposited her eggs, which hatch in about three weeks; the grub descends below the frost, and remains torpid during the winter.

The dragon-fly and several sorts of birds destroy great quantities of this bug; but when it appears in great numbers, these seem wholly insufficient. The only method of preventing its ravages is to pick it off by the hand, and shake it into a vessel of hot water.

III. Diseases which affect the Stem of the Apple Tree. 1. Insects. (1) The boring of the Goat Moth-Cossus ligniperdu. This is an insect which attacks, especially, large trees of the apple. It bores holes in to the trunk, and, by the admission of air and water, promotes the decay of the tree. The moth is about three inches in the spread of its fore wings, and is of a grayish-brown color, shading into that of a darker hue, and is covered with a quantity of black streaks, which are very narrow and irregular. The posterior wings are darker, with more minute lines; the thorax is yellow near the head, becoming lighter as it reaches the back, where there is a black bar. 
The head of the caterpillar of this moth is black; the prevailing color of the body, lemon, with a slight pink tinge. The back is brownish; and the first segment of the body has two black dots, and the skin has no hairs. It is about three inches in length, and very stout. The effects of its attack are to be seen in the decay of the ends of the branches, which gradually extends until the whole tree dies. The insect collects the chips which he has gnawed from the tree, and with these he protects himself. Inside of these he constructs his cocoon under the bark. The best time to hunt for and destroy him is when he is just emerging from the chrysalis state, and is coming forth from his burrow (Harris).

(2) The common Apple-tree Borer-Saperda bivittata: Say. "The winged beetle, which is from one-half to three-quarters of an inch long, covered with a white pubescence, and having three broad stripes above, makes its appearance early in June, and Hies only in the night. In the course of this and the following months the female deposits her eggs, one in a place, low down upon the bark, at or very near the surface of the earth. But when these beetles are numerous, some of their eggs are placed higher up, particularly in the axil of the lower limbs, or where they proceed from the trunks. From each of these eggs is hatched a minute maggot. It is white, with a yellowish tinge upon its head. It eats its 
way directly dowuwards in the bark, producing a discoloration. If the outer, dark-colored surface of the bark be scraped off with the knife the last of August, so as to expose the clear white bark beneath, as can easily be done without injury to the tree, wherever there is a young worm it can readily be detected. A blackish spot, a little larger than a kernel of wheat, will be discovered wherever an egg has been deposited; and by cutting slightly into the bark, the worm will be found. It gradually works its way through the bark, increasing in size as it advances until it reaches the sap-wood. There it feeds upon the soft fibre, and forms a round, flat cavity. It keeps its burrow clean by pushing its excrement out of a small opening through the bark at its lower end. These castings resemble fine sawdust, and enable one to detect the presence of the worm.

"When it is half grown, it seems to become conscious of the danger of its situation from woodpeckers and other birds, and gnaws a cylindrical retreat for itself in the solid heart-wood of the tree. The excrement now, instead of being ejected, is crowded into the hollow part at the bottom of the cavity. This hole runs first inward and then outward to the sap-wood, and is only covered from the external air by the bark. But, as though the castings at the entrance were insufficient to keep out some marauding insect, it seems to turn itself around 
in its hole, and tear down some of the woody fibre upon the sides, which it crowds also to the bottom. While this is going on, its excrements are placed at the top of the passage, leaving a chamber, in which the insect turns around, enters the pupa state, and, at its close, bursts the bark covering at the top of its hole, and comes forth a beetle" (Fitch).

Several methods of destroying these worms, or of preventing the deposition of their eggs, have been proposed; of these we mention washing the trunk and lower limbs with strong soft soap at the time of the deposition of the eggs; scraping the bark during the latter part of August, and discovering the young maggot before it has commenced to burrow, by the discoloration of the bark; digging them out with a knife when the excrement is discovered, or any indication given of their presence; running a tolerably flexible wire into the hole, and stabbing the grub. When this latter method has been efficient, it will be shown by the stained color of the wire when withdrawn. This borer is one of the greatest pests of the apple orchard, and needs constant attention. The woodpecker is one of its greatest enemies, and should, therefore, receive our protection.

(3) The Apple-root Blight-Pemphigus Pyri: Fitch. Pemphigus Americanus: Walker. Trees affected by this disease lose their vigor, and their foliage becoms pale yellow. If this is not attributa- 
ble to borers, or to some unfavorable condition of the soil, it very probably results from the attacks of the little woolly louse named above.

In the autumn the female of this species penetrates the earth, following down near a root, deposits her eggs, and dies. As these eggrs hatch, the young insinuate their beaks to the liber of the roots, and draw from them the sap, upon which they subsist. This irritates the part, and induces a greater flow of sap to that point, and causes little excrescences to be formed upon the roots, from a very small size to that of a pea. It is very evident that these excrescences must very seriously weaken the tree, if they increase to any extent. The larvae are almost invisible to the naked eye, being not more than four hundredths of an inch in length. From the tip of the abdomen protrudes a short thread of "cotton-like matter, variously curled and crinkled. This renders them more perceptible. The insect afterwards become winged, attains a quarter of an inch in length, and is covered with a mass of white down."

The disease which they produce is often seen in its primary stages in young trees as they come from the nursery, and can be detected by the excrescences upon the roots. Thousands of trees have been uselessly thrown away as valueless when this has been found to be present. Dr. Fitch suggests that if these roots were immersed in, or washed with, a strong solution of soft soap, the in- 
sect would be killed, and the tree soon recover from its temporary weakness (Fitch).

(4) The Snapping Beetle-Chrysobothris femorata: Fabr. This very much resembles the common borer, and preys upon the apple and peach. The worm is about one-half an inch in length ; greenishblack in color; and its burrow is flat, instead of round. It has a very powerful enemy in a little parasitic bee-like insect, about c ne-tenth of an inch in length. The female of this parasite probably discovers the borer when it is lying just beneath the bark, before it has commenced its burrow ; and, piercing the bark and the skin of the insect, it deposits its egg, the larva from which is to subsist on it, and finally to destroy the borer. The same means may be used in this case as were with the common borer (Fitch).

(5) The Bark Louse - Aspidiotus conchiformis: Gmelin. Coccus arborum linearis: Modeer. Diaspis linearis: Costa. Although very small, this is one of the most injurious insects which attack the apple. It probes the bark, consumes the sap, checks the vigor of the tree, and, where it makes its appearance in considerable quantity (as is often the case), causes death in three or four years.

Its appearance is that of a dark-colored, or black scale, resembling an oyster-shell in shape, adhering to the bark, and particularly attacking young trees. This scale is about one-eighth of an inch in length, 
and is the remains of the female, who shelters the eggs which are placed beneath it. These eggs vary in number from twenty to one hundred, according to the health of the tree. Those which are the most vigorous have the greatest number. About the middle of May the eggrs begin to hatch, and the larva to run about. It is pale yellow in color, has three pairs of legs, and appears upon the wood only as a minute dot. It has an enemy in a maggot which finds shelter beneath the scale, and feeds upon the eggs. This louse seems to be advaneing westward, and is particularly injurious in the new districts, probably because it does not meet so many enemies.

Two methods of destroying it are practised; in one, the trees are thoroughly painted in early spring with tar and linseed oil, heated together, and applied warm. When this becomes dry it peels off, bringing the seale with it. In the other method, tobaccoleaf is boiled in strong lye until it is reduced to an impalpable pulp, and soft soap is mixed with it to make the mass about the consistency of thin paint; the object being to obtain a preparation which will not be washed off by the first rain. The trees are first eut in, and the mixture applied with a paintbrush to every twig. This will destroy the insect, or prevent the deposition of eggs for the next season, so that an application once in two years will suffice (Fitch).

(6) The effusion of sap caused by the puncture of the $39^{*}$ 
wood by the " locust of the seventeenth year" - Cicada septemdecim. This is a most remarkable beetle, appearing only once in seventeen years. There are six or more broods of them in this country, which have their distinctly defined routes; and while the length of time from the first to the second appearance of each brood is always seventeen years, yet these seasons are not identical in the different broods. One of them appeared in 1843; another in 1847 . They utter a note considerably prolonged, the middle of which is piercingly shrill. They do not seem to be very discriminating as to the species of plant which they attack. Dr. Fitch, entomologist to the State of New York, said that the tops of the forest trees for more than a hundred miles seemed as if they had been scorched by fire, a month after these beetles had left them. The injury was done by the deposition of the eggss. The female punctures the wood, making a cavity large enough to contain about twenty eggs, and continues to lay in this manner from four hundred to five hundred eggs. From these punctures the sap weeps, weakening the limbs, and often causing, ultimately, their death. The larvae penetrate the earth to a considerable depth, sucking the sap from the roots of all sorts of plants (Fitch).

IV. Disenses which affect the Tree generaLLY. 1 Profusion of sap-Profusio simplex. 
This is sometimes constitutional, but oftener the result of cultivation. It becomes a disease when all the energies of the tree are directed to vigor, rendering the tree partially or wholly barren. It may be general; or it may be confined to a part of the tree, which is robbing the remainder by the production of gourmands, or watery shoots. Or it may result from the growth of suckers from adventitious shoots at the base of the tree; perhaps from the wild stock in which the scion or bud were inserted. When it is general, it may be produced by excessive manuring or by injudicious pruning. Profusion of sap seldom results from the former of these causes in the eastern part of this country, because the soil is of so poor a quality; but it frequently occurs in the fertile soils of the West.

As was remarker in the chapter upon pruning, a very severe cutting-back in the spring leaves the roots much stronger than the top. Therefore, as in this case, the roots are capable of supporting a much larger area of foliage than will remain to be supplied with sap after such a severe pruning. In the endeavor to restore the equilibrium, it will push all the remaining buds with great vigor; and even the fruit-buds may be transformed, and throw shoots. Continuance of severe pruning of such trees will cause the disease to become more and more settled. The remedy is vigorous summer pinching, and rootpruning. 'These are tescribed in the chapter upon "Pruning and Training." 
2. Siagnation of the sap, resulting from hungerStagnans effames. This is not the decrepitude occasioned by old age, but that which occurs when the tree is young, and should be in full vigor. It may result from the barrenness of the soil in which the tree stands, the presence of stagnant water, or from a substratum of poor soil near the surface, through which the roots cannot penetrate. From whichever of these it immediately results, the primary cause is insufficient or improper food. When a tree has become possessed with this disease, it ceases to grow ; the foliage is diminutive, and of a yellowish color. The bark adheres very closely to the tree, which, if it produces fruit, is of a most insignificant character. After this disease has become settled, it is.incurable; but in its earlier stages it is very susceptible to proper treatment. When simple barrenness of the soil is the cause, abundance of good, rich manure should be applied. Stagnant water can be removed by draining, and an impervious stratum broken up by proper subsoiling.

3. Stagnation of the sap from transplantation Stagnans elethargia. This disease is principally confined to trees which have been set late in the spring. If the season of planting is followed by drought, the tree does not burst its buds, although it is alive, because the production of rootlets is prevented by the dryness of the soil. It can be prevented, and is sometimes remedied, by mulching the ground about the tree, and by moistening the stem. 
Mr. Berkeley, in a paper published in the Gardeners' Chronicle, says: "Where moisture has been long withheld from a plant, the vitality descends so low that it is unable to endure a sudden or extreme change. Under such circumstances, if water is too rapidly admitted, it stagnates, and therefore reduces the quality of those supplies on which the development of buds or adventitious roots depend. This may cause decomposition. Or it may carry noxious matter into the circulation" (if the water was applied at the roots) "in such abundance as to act as a putrefactive ferment upon tissues already in a weak and languid condition. If the foliage flags, the power of evaporation will also be diminished. Mr. Knight found that shading and moistening the bark of trees long removed from the soil was better than supplying water directly to the roots. The young and tender bark partially performs the functions of the leaves, and in some succulent plants supersedes them. By judicious moistening, the vitality of the cellular tissue is gradually restored to its former strength, and the consequent formation of new roots at length enables the plant to sustain itself under ordinary cultivation."

4. Cankier of the Apple Tree - Carcinodes mali. This disease is not confined to the apple, but is here more frequently seen. It attacks the pear, as well as almost all the cultivated fruits, and results, when not constitutional, from one of three causes. 
(1) Excessive rain succeeding a long period of dry weather which had hardened the sap-vessels.

(2) Severe pruning while the roots extended themselves, under high cultivation, and disturbed the equilibrium.

(3) A sudden change of temperature.

This malady is most likely to appear first where the tree has been bruised, or cut with the knife. When it results from excess of moisture in the soil, thorough draining is a most effectual preventive; when from improper pruning; cutting the roots will restore the equilibrium; but when from vicissitudes of temperature, it is entirely uncontrollable. This malady is not as common in the United States as in Great Britain, but nevertheless occasionally appears.

Mr. Berkeley says: "I have before me some branches of the Golden Pippin apple, which, in the living portion, is still strong enough to bear very fine fruit, though the tree is evidently fast approaching the end of its existence. 'The fruit appears on two kinds of branches, equally fertile; the one, tall spring twigs, grown with great rapidity; the other stunted, more or less divaricate branchlets, whose growth has been extremely slow. Both are equally affected with canker, though not visibly, in the same way; that upon the vigorous branches apparently growing downward and casting their thin bark, while the other perishes first at the base, and deprives the upper parts of nutriment. On closer 
inspection, however, the difference is only apparent; for even the smooth twigs have decayed spots, involving the superior organs.

"If the cankered branch be examined as soon as the mischief is visible, a vertical section through the pith generally reveals the point at which decay has commenced; some bud, frequently a fruit-bud. The flowers, in the first instance, may not have set, on account of some one of the causes which usually produce sterility. The foot-stalks may have separated from their point of attachment, leaving the bud in a state unfit for further vegetation. The young fruit may still remain withering on its matrix, which has not vitality enough to throw it off. Either the matrix itself or the dry fruit decomposes as the season advances. The morbid matter is carried down to the tissues surrounding the pith. If the branch has strength enough to resist the infecting matter, the wound is soon covered over with fresh layers of wood, and no permanent injury results. On the contrary, if the constitution be weak, and the vitality low, the woody tissue perishes, and soon involves the bark which covers it, so that both are incapable of transmitting the nutritive fluids, and it perishes as if by a flash of lightning.

"Where there is great weakness of constitution, it is obviously very difficult to contend against the disease. Something may be done by very careful inspection of the trees, and by the removal of every unhealthy spur" (Berkeley). 
5. Decay. There is a time when all vegetables must decay; but this is often very much hastened by constitutional or accidental disease. The tree in a healthy state grows in circumference, and throws off the old bark, replacing it by a layer of new beneath it: a similar process goes on in the wood. This is annually increased in thickness by layers upon its outside. The sap ascends from the roots to the foliage through the wood of the last two or three years, the latest being the most active; and the sap, as it returns elaborated by the leaves, forms these new layers of wood and bark.

In process of time the ducts of the new wood receive such a coating of woody fibre on their interior surface as to fill up the orifice through which the sap passed, and thus become useless. This old wood is now as dead as the old bark; but, not being exposed to the air, it remains sound as long as it is not so exposed, and is useful, mechanically, in strengthening the structure of the tree. But if an accident breaks this outer covering of new wood, the air will be admitted, and the limb decay, spreading the disease to the very heart of the tree. Although this does not essentially weaken the nutritive power, yet the tree will not have proper mechanical support.

The proper remedy for a tree thus diseased is to cut out carefully all the decayed parts, and fill the cavity with a cement made of sand or gravel, lime, 
and coarse stones or brickbats. This furnishes mechanical support, and the tree may flourish as well as before.

6. Freezing-Congelatio. Plants vary in their natural capability to endure frost. Late in the autumn, and early in winter, the tree is not easily stimulated; and a severe frost, even after a warm season, does not necessarily injure the tree. But late in the winter, and early in the spring, when the energies of the tree are active, a frost is very injurious; and if the buds are swollen, or the tree in leaf, it is disastrous, possibly fatal; because the tree is then full of fluids, expanding as they freeze, and the thin walls of the cells are thereby broken and destroyed. When these thaw, the sap runs out among the intercellular spaces, and deranges the whole circulation. From the decomposition of the stagnant sap it spreads decay through the whole plant.

Duhamel and Buffon maintain that frost-splits occur more frequently - "Aux expositions du Nord et du conchaut" - on exposures to the north than on other aspects, because they were colder. On the contrary, Ehrhart says: "Those trees or shrubs planted on the southern side of the heights suffered more than those on the north side."

Dr. Caspary believed that these frost-clefts did not depend upon cold winds coming in any one direction, but upon injuries received, either from the decay of 
limbs, accidents, or the work of man. These injuries cause a mechanical weakness in that part. $\mathrm{He}$ had at first supposed that a thaw caused the clefts by the contraction of the outer layers, which were then too small to contain the inner, and therefore burst. But, upon observation, he found that they occurred in the severest cold, and closed upon the approach of a thaw.

That these clefts were occasioned by freezing and thawing, was the theory of Gaudichaud. He examines the conjecture of Goppert, that those that occur in the axils of the branches are to be attributed to the influence of wind. But he found that clefts seldom, if ever, occur here; but are beneath the branch, in the toughest and strongest place: and that the wind, at the time of the clefts which he observed, was very gentle.

'They may have occurred from the outer layers being reduced in volume by evaporation. Thus they were unable to endure the expansion of the inner layers not affected by this evaporation. This theory exploded on discovering that the moisture of the atmosphere, when the cleft took place, was greater than for some time preceding. The author states that De Vriese, in his "Principles of Vegetable Physiology," expresses the opinion that the sap rises in the winter, and that the cold splits the stem, and allows the juice to run out. But, as the tree is frozen to its centre, there can be no ascension of the 
sap; and there being no foliage, and in consequence no evaporation, this theory cannot be sustained. Besides, no sap runs from the clefts. The most popular theory attributes this phenomenon to expansion in the act of freezing; but, according to Brumner, ice reaches its greatest bulk at the moment of congelation. At thirty-two degrees Fahrenheit it acquires about one-eleventh of its bulk; therefore, if a tree becomes cleft at all from this cause, it must be at this moment; for, as the cold increases, Brunner found its volume to diminish. He observed that the linear contraction of ice is one twenty-six thousand seven hundredths for every degree Centigrade. But the clefts did not appear until the cold was below twenty-three degrees Fahrenheit; so that the freezing of the sap could not have been the cause.

Duhamel, Buffon, and Treviranus entertained the opinion that the stems are burst by the "volume acquired, on congelation, by a mass of moist, decayed wood, or an accumulation of sap in the interior of the tree." Although Dr. Caspary allows that such may sometimes cause a cleft, yet he had never seen an example of it. He had never found ice in the splits, and the decayed wood seemed to be dry. He finds the same difficulties to this theory as to the last: if they cleave for this reason, it should be at the moment of congelation.

He thus sums up his observations: "The bursting takes place at night by severe frost, not less than 
fifteen degrees Reaumer (one and one-half degrees Fahrenheit). Remeaux has shown that the temperature of the concentric layers of wood by night increases from outside to inside. A very severe, sudden frost, that cools down the outer layers, must occasion an important difference in temperature between these and the inner, and at the same time a considerable difference in relative bulk. The inner layer's, whether frozen or not, must considerably exceed the outer, and thus increase the strain upon them," and eventually causes the cleft.

Sir James Ross, in the history of his antarctic voyage (Vol. I. p. 223), says: "We have often, in arctic regions, witnessed the astonishing effect of a sudden change of temperature during the winter season, causing great fissures in the ice of many miles in extent. A fall of thirty or forty degrees in the thermometer immediately occasions large cracks in every direction, attended with loud explosions. Some of them open several inches by the contraction of the upper surface in contact with the extreme cold of the atmosphere." Dr. Kane's observations are similar, in his explorations of the arctic regions.

7. Wind Shakes - Anemosis : Berkeley. Aside from the injury done by winds in breaking down the limbs of trees, is that to the young and soft shoots. By whipping these one against another, 
the lesion, or breakage, of the young cells results. This causes the death of a part or the whole of a shoot. Although this may not injure the tree permanently, yet it gives it a very severe check. It may be prevented by proper shelter.

8. Dropsy. This is a disease which may not closely resemble that to which this name is applied in animal pathology, yet it is the best term that can be used to express the idea. During a long season of rainy weather the plant becomes gorged with moisture; the circulation is slow, and the evaporation small. Growths made at such a season are watery and tender, and the fruit is almost without flavor. If this condition lasts for any length of time, the fruit never ripens, and may decay upon the tree; the foliage of the young shoots becomes white, or a sickly yellow, on account of a deficiency of light; and both the fruit and foliage drop off prematurely. This disease scarcely ever exists where the drainage of the soil has been thorough (Berkieley).

9. Sun-stroke-Desiccatio. This embraces the drying up of the fluids in either the roots or the foliage. The former may be occasioned by a drought, particularly in undrained land, which bakes in the sun; or the latter may follow as a result of the former, be occasioned by the work of insects, or 
some atmospheric agency. It is very evident that the destruction of the rootlets cuts off the supply of sap, which is most disastrous. While the death of the tree may not always result, great weakness always follows. This disease is particularly liable to attack newly-planted trees, especially those set in the spring. When this is the case, and the drought continues, the tissue of the whole tree dries up. The best preventive is a well drained and thoroughly pulverized soil, where it has never made its appearance.

10. Wounds - Vulnera. These are more or less injurious, according to their nature. If a large limb has been cut or broken down, the inner wood, which has lost its vitality, commences immediately to decay; and, unless it is prevented, it extends through the old wood of the tree. To prevent this loss of mechanical strength, it is necessary to cover all wounds which penetrate deeper than the vital wood with grafting-wax, paint, or some other material, protecting the wound from immediate contact with the air. If the tree is healthy, the new or vital parts soon extend over it.

Cattle should not be allowed within the precincts of a young orchard, since they are likely to rub against and break the limbs. Mice or rabbits often totally destroy trees by gnawing off the bark around their base during the winter. Thus, when the sap 
starts in the spring, and has ascended to the foliage through the young wood, it is arrested in its backward passage by this girdling of the bark of the tree. If the least channel exists upon any side, the tree will often recover; but if the girdling is entire, certain death results. Field-mice are encouraged by the presence of turf, or any rubbish in the vicinity of the orchard. After deep snows, when other supplies are cut off, they are especially active; when found, they should be killed if possible, and the snow about the base of the tree trodden hard, to prevent their burrowing.

11. The presence of Lichens. These give to an orchard a very neglected appearance. Although they are not directly injurious, yet they are so indirectly, by affording harbor for insects. They are also often an index of a poor state of health in the tree. They grow upon the dead bark, which has not been cast off because the vital functions are not sufficiently active, and the tree did not grow fast enough to burst this outer coating. In old trees it may be a proof of decrepitude; in which case the vigor of the tree can hardly be permanently restored. But, with young trees, it results from some unfavorable condition; generally the want of thorough drainage and liberal manuring.

12. The circulation having been vitiated or poisoned 
- Veneficium. Plants, in common with animals, are sensitive to the influence of poisons. These may enter the plant through the root by solution, as the power of selection in the root is, to a degree, limited, or through the stomates of the leaf, as a gas. Many substances, poisonous or not, affect plants and animals in a similar manner. A twig of the sensitive plant was placed in a glass tube which contained sulphurous ether; it soon unfolded, and could be handled without recoiling in the least; but, through the influence of the external air, it gradually resumed its former character. The specific characters of poison may be as different as the number of substances which are poisonous, and the species of plants which they affect. The vicinity of gas-works, and that of some chemical works, are generally considered as unhealthy for plants; yet it would be impossible, except in a monograph, to describe, even if it were known, all the different effects produced, and state remedies for them.

§III. - DISEASES OF THE PEAR.

I. Diseases which affect the Foliage. 1. American Pear Blight - Effusio subcutanea. There have been a variety of conjectures relative to the origin of this disease. In this country it is the worst malady with which the cultivator of the pear has to contend. Sometimes, entering a nursery, it will 
entirely destroy blocks containing thousands of trees, or leave them to struggle for years against the poison thus introduced. Some varieties are peculiarly susceptible to it, as the Belle Lucrative (Fondante d'Automne), and particularly the Glout Morceau. The latter sort shoots a great many soft twigs, and grows late, unless prevented by summer pinching.

Blight commonly makes its appearance in districts, more or less extensive, not exposed to any severe sweeps of wind during the season of growth. A gentleman in Western Massachusetts once doubted the truth of this assertion, and said that his orchard had been severely attacked, and yet it was on the top of a hill. It was visited on a stormy day in autumn, when the wind was very severe; but, on entering, the air was calm and still; for, while the orchard lay open toward the south, at all other points it was skirted by forests.

The strength of timber grown upon mountains, or in exposed positions, is known to be much greater than that grown in low valleys or on plains, where the air is more or less stagnant.

Trees growing on the former sites always better endure the severities of winter than those on the latter. As before suggested, the gentle breezes of summer are of immense importance to the tree during the growing season, supplying the leaves with abundance of carbonic acid, so that the wood be- 
comes firm. After a young cell has been formed, the interior of its membraneous walls is constantly receiving an increased coating of woody fibre. This takes place most rapidly in the cool weather of the autumn, after the growth has stopped, and the whole force of the sluggish circulation seems to be directed to this deposition. Consequently, it is then that the young wood requires the greatest abundance of carbon; and therefore an all-wise Providence supplies strong winds and gales to ripen their substance.

If a frost sufficient to destroy vegetation occurs when the soft growth has just put forth, as in June, 1861 , in some sections of the United States, all the young parts of the' tree present the same stained appearance as after blight. This results from the cells' lesion, which precipitates the sap into the intercellular spaces. This causes the burst cells to decay, with all the other parts, which have been corroded by the fusion of sap. As vegetable, like animal tissue, is extremely sensitive to decaying matter, not only these may be destroyed, but also the decay may spread through the young parts of the whole plant.

The pear blight frequently occurs about the time of thunder showers. According to experiments made under the direction of the London Horticultural Society; it was found that just before, during, and immediately after a thunder-storm, the growth 
of vegetation was considerably retarded. The difference in that of the hop was from sixty-four to eighty per cent., while in others it was not more than four. If this occurred when the wood was soft, it cansed a sudden stagnation of the sap in the leaves, while the cells were distended with the circulation. Their lesion, and the discharge of their contents, can easily be accounted for in a district where a plant had not been furnished with sufficient earbon to properly strengthen its cell walls. Thus it seems to result from lesion produced by weakness of the cell wall from want of carbon, acted upon so as to produce stagnation. The only remedy yet discovered is immediate amputation of the part. The prevalent idea that it is contagious, results from the rapidity with which this poisonous sap conveys the elements of decay, when the circulation is restored, and it becomes mixed with healthy sap.

\section{Insects. (1) The attack of the Goldsmith Beetle} - Areoda lanigera. This appears about the middle of May. It flies during the night, and clings to the under surface of the leaf during the day. It consumes the young leaves of the pear and those of some forest trees. It is not usually sufficiently prevalent to injure the tree. If it becomes unduly multiplied, spread a sheet under the tree, and strike the stem a smart, quick blow, when it falls, and can be picked up and burnt. It is "nine-tenths of an inch 
long, colored lemon above, glistening like burnished gold on the top of the head and thorax; the body beneath is copper colored, and thickly corered with whitish wool "(Harris).

(2) The Red Mite - Acarus geniculatus: Linn. This little insect is gregarious, congregating in the spring at the base of the twigs, and is often found in great numbers. It attacks the foliage of many fruit trees, particularly the pear: It causes a peculiar and sickly hue on the leaf. It can be distinguished at a distance by the reddish tinge of its body. If unmolested, it destroys the tissue of the leaf, and thereby induces one of those diseases resulting from weakness. The insect becomes darker colored with age, attains about the size of a grain of very fine gunpowder, and during the winter lives under old bark or lichens. It may be destroyed by a profuse syringing of whale-oil soap-water, like that used for canker worms.

(3) The Pear-tree Slug - Selandria Aethiops. This is the slimy larva of the saw-fly, and feeds upon the leaves of the pear. It is found upon the upper surface, solitary, or in groups of two or three. It is about five-eighths of an inch in length, is green in color, becoming darker with age. It eats nothing but the soft parts of the leaf, and commits its ravages in June and July. If unmolested, it strips the tree of its foliage. It is particularly injurious in seasons of drought. In that of 1864 , two generations 
were developed, the last of which did not disappear until October. Prof. Peck discovered a minute ichneumon fly, which deposits an egg in that of the saw-fly, and which, when hatched, feeds upon the contents, becomes transformed, and flies away upon its mission. This slug may be destroyed by dusting slacked lime upon the foliage when the dew is upon it.

(4) The Pear-tree Lyda-Lyda fosciata. During the month of July the larva of this insect attacks the foliage of the pear. It is of a pale yellow color, with a black head, and is nearly one inch in length. It spins its silken web round the young leaves, and quickly consumes them. After its work is done, it lodges in the earth, and comes forth the following May as a moth. The male is black, with a yellow front of the head and abdomen. It is about a halfinch in length. The female is a little larger, but of the same color, except it has the yellow only between the atennae, at their base, on the mandibles, the legs, and the latter half of the abdomen. The larvae can be destroyed by dusting the foliage with slacked lime ( Westwood).

(5) Large Pear-tree Astyages - Astyages Hemerobiella. "My attention was directed, at the end of May, 1850, to the state of several pear trees trained against a wall in the gardens of the Horticultural Society at Chiswick. 'These were infected by myriads of small caterpillars in a blackish, cylindrical, 
movable case. The leaves exhibited large brown patches where they had been attacked. The case of this caterpillar is about half an inch long, enclosing the body of the insect, and both ends are open. Through the lower the animal can protrude its head and fore segments, and from the upper it discharges its excrement. On alarm it withdraws to its case. This stands erect at right angles to the leaf with which its mouth comes in contact. Its general position in walking is oblique. When it is fixed upon a spot to feed, it carefully forms a circular orifice in the cuticle of the leaf. It then attaches the mouth of the case to the edges of the orifice, and feeds upon the cellular matter. It soon introduces its head and the fore segments of its body to the cavity between the two surfaces of the leaf, and then adopts the habits of the ordinary leaf-mining caterpillars. When it has consumed this patch, it withdraws to its case, and fixes upon another spot." This insect is generally found not in sufficient numbers to do particular injury; but, when it abounds, the only method of destroying it is to pick it by hand (Westwoodl).

(6) Hispa quadrata: Fabr. H. Marginata: Say. II. rosea: Weber. This little insect; whose grub is about one-fifth of an inch in length, deposits its eggs in numbers of from one to four on the surface of the leaf. The larva bores through the epidermis, and feeds upon the soft pulpy matter of the 
interior. Its presence may be detected by a brown or black spot upon the leaf; and wherever it is noticed, the leaf should be plucked off and burnt.

3. Fungi. (1) Ascomyces bullatus. This is a regetable parasite attacking the leaves of the pear, and causing shallow, brilliant spots. Another, much like it, affects the leaves of the peach, and resembles large blisters, which distort the foliage. It is induced by cold weather in spring, and by want of drainage. When the disease commences, the foliage should be dusted on its under surface with dry flour of sulphur, or syringed with water mixed with sulphur and lime, as for the vine mildew (Berkieley).

(2) Ceratites. Page 432.

(3) Cladosporium dendriticum. Page 431.

4. Discoloration of the foliage-Chlorosis. In the cells of growing vegetation are nitrogenous globules, containing a substance called chlorophyll. This takes various colors, but in leaves and new wood is generally green. The deeper colored the foliage, the richer it is in this substance. This shows that the globules are larger, and therefore that the cells containing it are more fully developed, active, and vigorous. Some varieties of fruit are constitutionally remarkable for deep-colored foliage; and such are vigorous and healthy under almost any circumstances. 
Berkeley says: " $A$ portion of the plant, greater or less, does not assume its natural green hue, but acquires a yellowish tint. This may spread to other tissues, or remain isolated." "No chlorophyll is formed; the walls of the cells become flaccid ; their contents undergo chemical changes, and the whole either dries up, leaving additional work to be done by those tissues which remain healthy, or the walls give way, decomposition takes place, the putrefying mass spreads its contagion in every direction, and involves the neighboring structures. When the tissues dry up, the process may be slower, but the result is not less sure. Every part of the plant is liable to be affected; and even the tissue of the seed may be unhealthy, and transmit the disease through succeeding generations. Thus, what was at first accidental, may eventually become constitutional, or even hereditary."

This disease results from weakness, produced by superabundant bearing, barren soil, or imperfect drainage. In the first case, rest and good care must be the remedy; and in the latter two, these must be combined with fertility and thorough drainage.

5. Premature fall of the Leaf - Phylloptosis. Page 428.

II. Diseases affecting the Flower and Fruit. 1. Bletting, or Rotting at the Core- Hyposathria. 
"In some cases, no sooner has the fruit arrived at that condition which renders it available for the uses of man, than a further change takes place. The cell walls and their contents pass into a state of incipient decomposition, acquiring the brown tint so frequent where decay takes place in vegetables. The peculiar aroma vanishes, and the whole becomes a soft, vapid, tasteless mass, devoid of every useful quality. Some varieties of pears so rapidly pass into this condition that they are scarcely worth cultivation, though some of them are of first-rate quality when in perfection. The change generally takes place in a centrifugal direction. This distinguishes its condition from many forms of putrescence" (Berkeley).

This disease, if constitutional, condemns the variety. Yet very many of our best pears are subject to undergo this change so slowly as not to materially injure them for table use.

2. Induration - Sclerogenia. This disease is more common with the pear than with any other fruit. The vascular tissue becomes a tough, woody mass, which, of course, lessens the amount of sugar, and destroys the fruit for use. Although it is often accidental, depending upon soil or climate, yet some varieties are more liable to it than others, as the Easter Beurré upon cold soils; but in the rich, warm lands of the West, or California, it is 
very. juicy and excellent. The Glout Morceau is subject to induration in the youth of trees, but in their maturity and age is free from it.

\section{Sterility. Page 444.}

4. Immaturity of the Fruit - Carpomosia: Ré. Page 450.

5. Deficiency in the cutaneous secretion - Ephidrosis. Fruits, when grown most perfectly, are covered with a sort of waxen secretion. This prevents the escape of their juices by decomposition or evaporation. It forms a coating, and renders the fruit almost air-tight. When this is absent, they cannot be preserved for so long a time, and very soon wither. The entire or partial absence of this may arise from some derangement of the secretion, occasioned by atmospheric causes, or by an uncongenial soil. It has often been remarked that this bloom is more abundant where the land has been drained.

Some times its absence is accidental, resulting from handling the fruit. Therefore it should never be touched more than is necessary while in growth; and in gathering and preserving, great care should be practised that it be retained. The secret of the superior preservation of fruits, when barrelled immediately after being plucked, is that they are not handled, and consequently this coating is undisturbed. 
III. Diseases affecting the Stem. 1. Root Blight. This especially affects young dwarf pear trees. Very soon after the trees begin to grow, the leaves and wood turn to a deep brown color, approaching bronze. It differs entirely in appearance from the common pear blight, because that is black, and at first extends only orer a portion of the tree; while this is general, and takes place earlier in the season. On examination, the roots will be found dead, which, in the young dwarf pear, are very near the surface of the earth, and possess no strong taps to keep them in place; and therefore, in undrained land, when the ground freezes and thaws, the tissue of the root is destroyed by the constant strain.

2. Irsects. (1) The Pear-blight Beetle - Scolytus Pyri: Peck. Tomicus Pyri: Harris. "This insect causes a blight of the limbs, which, in its outward appearance, resembles the common pear blight. The limbs which it attacks, turn black, and die in early summer, while other parts of the tree remain healthy. The disease is caused by the larva of this insect, whose egg was laid in the axil of a bud, who ate his way inward, and followed the eye of the bud toward the pith. Around this it passes, and partially consumes it. Thus the insect, after penetrating through the alburnum, forms a circular burrow or passage in the heart-wood, contiguous to the pith. By this means the central vessels are 
divided, and the circulation cut off." 'Thus the whole part above becomes deprived of its necessary nourishment, and dies. The Hon. J. Lowell, of Massachusetts, who discovered this insect, recommended the following method for its destruction: As soon as the blight appears, the limb should be cut off below the point of his burrow, and the whole be burned before he has time to come forth as a beetle, and provide for the extension of his race. (Harris).

(2) The Pear-bark Louse - Secanium Pyri: Schrank. This is similar in its habits to the applebark louse; but it is considerably larger. The remains of the female, under which the eggs are placed, is a brown scale, about one-fifth of an inch in diameter. When this comes off, a white spot of the same size remains, which is easily distinguished. It is injurious to the tree, because it sucks the sap through the young bark. For methods of destroying them, see those used for that of the apple.

(3) Cicada Septemdecim. The puncture of the wood by the locust. Page 462 .

3. Fungus upon the Root. Pear trees sometimes do not thrive, notwithstanding they are surrounded by all those conditions necessary to insure health. This is often occasioned by a fungus, which has attached itself to the root and wound around it; 
and if the tree is taken up, its threads can be seen. It feeds upon the sap, and thus deprives the tree of its proper nourishment. It results from the presence of decaying matter in the soil, or often from the remaining roots of trees of a former generation.

IV. Diseases Affectrng the Tree generally. 1. Profusion of Sap. Page 462.

2. Stagnation of Sap after transplanting - Stagnans elethaigia. Page 464.

3. Vitiation of the Sap -Veneficium. Page 476.

4. Canker - Carcinodes. Page 465 .

5. Decay-Caries. Page 468.

6. Freezing - Congelatio. Page 469.

7. Wind Shaties - Anemosis. Page 472.

8. Dropsy - Anasarca. Page 473.

9. Sun-stroke - Desiccatio. Page 473.

10. Wounds - Vuhnera. Page 474.

11. Lichens. Page 475. 
§ IV. - DISEASES OF THE PEACH.

I. Diseases affecting the Leaf. 1. Dotted Apple-leaf Worm-Brachytaenia malana. Page 444.

2. A Vegetable Parasite - Ascomyces. Page 483.

II. Diseases affecting the Fruit. 1. Rose Bug - Macrodactylus subspinosus. Page 454.

2. Sterility. Page 444.

3. Premature fall of the Fruit. This results from the bursting of the stone in consequence of injury during the spring, by a late frost after impregnation.

III. Diseases affecting the Stem. 1. Insects. (1) Peach-tree Borer - Buprestis divaricata: Say. This derives its name from the fact that the wingcovers are spread apart a little at the tips. "The beetles are copper colored, covered with punctures. They are from seven to nine-tenths of an inch in length." The larvae bore the trunks of the peach and cherry. When they are found in the tree, a flexible wire should be run into the hole, so as to stab the worm.

(2) Snapping Beetle - Chyrsobothris femorata. Page 460. 
2. Gumming-Apostaxis. Plants contain in their economy a substance called gum. This is transformed as occasion requires. Its composition is, of carbon twelve parts, of hydrogen and oxygen eleven each; while that of starch is one part less of the latter two, which are the elements of water, so that the elimination of these two parts transforms it into starch. Sometimes the tree stores up gum for future use. The cells become full, and often, by their lesion, cause the spaces between them to be filled. If one cell is broken, the gum will flow until there is no more room for it, the cell being constantly replenished. So far, its effects may not be injurious; but if any break takes place in the outer bark, the gum exudes; and, as the air and moisture are admitted, the decay of a part, or even the whole of the tree, may be the result, either from simple decomposition or from corrosion.

3. Profusion of Sap. Page 462.

4. Vitiation of the Sap-Veneficium. Page 476.

5. Decay - Caries. Page 468.

6. Sun-stroke - Desiccatis. Page 473.

7. Wounds - Vutnera. Page 474. 
§ V. - DISEASES OF THE PLUM.

I. Diseases affecting the Leaf. 1. Insects. (1) The Plum Louse - Aphis pruni. This affects the leaves of the plum, curling them as upon the apple and cherry, and the same remedy applies. See page 433.

(2) The Vaporer Moth - Orgyia lencostigma. Page 437.

(3) The Unicorn Moth - Notodonta unicomis. Page 440.

II. Diseases affecting the Fruit. 1. Insects. (1) Curculio - Rhynchaemus nenuphar. This is a native of America, and has wonderfully increased within the last fifty years. It is a small beetle, of about one-quarter of an inch in length. Its color is a grayish-brown, varied with spots of white, yellow, and black. It has a curved beak or bill, and appears in small numbers as early as the first of April, but not in quantity until the middle of May.

Early in June, when the fruit is sufficiently large, it begins to deposit its eggs. It seems to prefer the nectarine and plum, but also attacks the apple, pear, peach, and cherry. The crescent-shaped mark is made by its jaws at the end of its beak. 'This is not so distinguishable in the apple, because it soon heals over, and only a little speck remains. Having 
made this aperture, it drops in one egg. From this is hatched a maggot, which feeds on the flesh around the core or stone, and appears during the latter part of July as a bectle, like its parent. Not only does it deposit its eggs in the fruits above named, but also in the soft substance of the plum-wart, or knot. It also pierces little holes in the bark with its beak, like the puncture of a pin, by which it draws the sap. What becomes of the bectle between this time and the spring has been a mystery. Dr. Harris says, through the spring, beetles come forth from larvae which were retarded in growth, so that they remain in the ground as pupae all winter. Dr. Fitch very properly remarks, that the carth is warmer during the month of August than it is in July, and an insect whose transformations under ground are completed in three weeks in July, would not remain in the earth during the whole month of August. He says, these beetles, perfected in July, deposit eggs in the soft bark of the young wood, particularly in that of the butternut; that these eggs are hatched, and become maggots, which eat out a space so as to form a little cavity, where they remain during the winter, and come forth in the spring. He found that a fly, somewhat resembling the gall-fly, gives birth to a parasite which preys upon the curculio. It is furnished at the tip of the abdomen with a very sharp, bristle-like sting, with which it penetrates the skin of the larva of the 
curculio, and deposits there an egg, and soon hatches a worm. This fly is called Sigalphus curculionis. It is hoped that it will so increase as to prevent the ravages of the curculio.

A great many preventives of the destruction caused by this insect have been proposed. The one most widely practised is that of spreading a sheet under the tree, and striking the stem smartly, when the beetle falls, as if dead. It should then be taken up and committed to the flames. If left to itself, it soon starts up and flies away.

Dr. Fitch speaks highly of an application suggested by Mr. Cummings, of the "New York Observer." This consists of four ounces of sulphur, with a pound of whale-oil soap, added to four gallons of lime-water, the whole poured into an equal quantity of strong tobacco-water. But he thinks the effect will be equally efficient if sulphur and lime were omitted. This is syringed over the leaves of the tree, and repeated as often as it is washed off by the rain. The process should begin at the time when the curculio first makes his appearance.

(2) The Rose Bug-Macrodactylus subspinosus. Page 454.

2. The fall of the Fruit. Page 490 .

3. Sterility. Page 444. 
III. Diseases affecting tue Stent. 1. The Plum Wart-Sphaeria morbosa. This is a fungus common in the Uniterl States, where it attacks particularly, but not exclusively, the plum. It sometimes appears on the cherry. It produces great, gouty swellings upon the branches, and the glands of the bark look as if they had received poison. 'This is its appearance in the autumn. In the spring the part is very much enlarged, the skin broken, and the soft substance exposed, leaving the wound raw. It soon changes from its natural yellowish-green color to black; and the fungus then becomes quite visible. The curculio takes advantage of this soft place to deposit its eggs. It is doubtful whether there is any remedy for the disease; but it can be checked by vigorous amputation.

By some this wart has been attributed to the sting of the curculio, because its larvae are so often present. But this is not always the case; and the disease is often very prevalent where the curculio is not very abundant, and where it could find many other more natural and desirable positions in which to deposit its eggrs.

By others it has been attributed to rankness of growth, or the absorption of some poisonous material. Another writer thinks it is the result of the extremes of temperature which take place during the period of growth. He says that his opinion is corroborated by the fact, that years ago, before the 
forests were cleared away, and when the seasons were more equable, it was not troublesome; and now, in many new comntries the plum can be raised with ease previous to the clearing which precedes a growing population. But he overlooks the fact that, if such be the cause, it should be more prevalent in the interior districts, and less so on the coast, where the ocean tends to equalize the temperature. But this is not sustained by experience.

2. Gumming - Apostaxis. Page 491.

IV. Diseases affecting the Tree generally. 1. Profusion of Sap - Profusio simplex. Page 462.

2. Vitiation of the Sap-Veneficium. Page 476.

3. Freesing - Congelatio. Page 469.

4. Dropsy - Anasarca. Page 473.

5. Wounds - Vulnera. Page 474.

§ VI. DISEASES OF THE CHERRY.

I. Diseases affecting the Leaf. 1. Insects. (1) Cherry-tree Louse - Aphis cerasi: Fabr. This is wonderfully reproductive. It makes its appearance from the fifteenth to the twenty-fifth of June, when 
it feeds upon the young foliage. Its number is then almost incredible, - more than one thousand being accommodated on both surfaces of a leaf one inch in length. The young sometimes lie two deep, only caring for room to run their beaks into the tissue of the leaf and feed upon the juices of the tree. The foliage is often black with them. It is necessary that the cultivator should use the preparation of whale-oil soap, as recommended for the apple louse (Fitch).

(2) The May Beetle - Phyllophaga quercina: Knock. "This insect is chestnut-brown in color" smooth, covered with little impressed dots; each wing-case having two or three slightly elevated longitudinal lines. The breast is clothed with yellowish down." It is about an inch in length, and feeds upon the leaves. It can be shaken from the tree in the morning upon sheets, and burned; or killed by immersion in hot water. The grub, while in the earth, lives upon young roots (Harris).

(3) The Hag Moth-Limacodes pethecium. Page 440 .

(4) The Dotted Apple-leaf Worm - Brachytaenia malana. Page 444.

II. Diseases affecting the Fruit. 1. The Rose Bug-Macrodactylus subspinosus. Page 454.

III. Diseases affecting the Stem. 1. WoundsVulnera. Page 474. 
2. Insects. (1) The Borer-Buprestis divaricata. Page 490 .

(2) The Cylindrical Borer - Linodendron cylindricum. Page 464.

3. The Wart - Sphaeria morbosa. Page 495.

4. Gumming - Apostaxis. Page 491.

IV. Diseases affecting the Tree generally. 1. Profusion of Sap - Profusio simplex. Page 462.

2. Decay-Caries. Page 468.

3. Freezing - Congelatio. Page 469.

4. Dropsy - Anasarca. Page 473.

5. Sun-strolie - Desiccatio. Page 473.

§ VII. - DISEASES OF THE GOOSEBERRY.

1. Insects. (1) The Goosebervy Caterpillar. The moth has four transparent wings. The body and legs are yellow; the head, atennae, and feet black. The male is smaller, and is all black except the tip and sides, which are yellow. These insects, as flies, emerge from the ground in the spring, and lay their eggs on the under surface of the leaves. The larvae, when hatched, feed upon the leaf, piercing 
it with holes, which soon enlarge until the leaf is destroyed. This not only ruins the crop of fruit of the present year, if the attack is made while it is growing, but it prevents the ripening of the wood, and thus destroys the prospect of a crop for the next year. Various methods have been resorted to for preventing their ravages; as catching the flies when they emerge from the ground in the spring. But this is impracticable. Others have picked them from the leaves, or removed the earth while the pupae were in the soil; or have covered it with some material, like fresh tan, which was óbnoxious to them.

The powder of white hellebore is understood to be a most effectual remedy if dusted upon the under part of the leaf when the caterpillar is at work. Its efficacy depends, in a great measure, upon the dryness of the powder. If it has absorbed moisture, it is sure to be inoperative. It should, therefore, be thoroughly dried before the fire previous to use.

(2) The Swallow-tailed Moth - Ourapteryx sambucaria: Limn. This infests the leaves of the apricot, and the gooseberry among fruit-bearing plants. The caterpillar is brown in color, and is two and one-half inches in length. On the sixth and eighth segments of the body are two tubercles each. The termimus is divided into two points. Attached to the first three segments of the body are 
three pairs of jointed legs, and behind one pair of ventral, and one of pro-legs. It is of the genus Geometridae, rising upon its hind legs and throwing forward those at the front, and measuring a regular distance each time. The tubercles are their distinguishing peculiarities. The moth is about two and one-half inches in the spread of its fore wings, and is of a pale yellow color, with light green lines. The posterior wings end in points, which have two brownish-red spots.

(3) The Gooseberry Midge-Cecidomyia grossulariae. The fly of this insect deposits her eggs in the fruit when it is very small. The presence of the larvae can be detected afterwards by the prematurity of the berry. It turns red, is putrid, and, if examined, a number of small, yellow maggots will be found, which have been hatched from the eggs. 'These cause the fruit to fall to the ground, when the insect becomes a fly, and produces still another generation the same season. The maggots of this second family seek shelter in the ground during the winter, and come forth as flies the next June. To prevent their attacks, all those fruits which show this prematurity should be plucked and burned before the maggots have time to leave.

2. The Gooseberry Mildew - Erysiphe mors uval. This is the common brown mildew which attacks the smooth varieties of the gooseberry. It some- 
times renders a whole crop utterly useless. It consists of tufts of brownish strings of spores, "in a sac which opens above." It covers not only the fruit, but often the leaves and young wood. Dr. Berkeley represents it, in its first stages, as similar in many respects to the grape mildew. Sulphur, as applied to the vine, will prove an effectual remedy, if used during the first part of its growth.

\section{$\S$ VIII. - DISEASES OF THE CURRANT}

\section{The fall of the Leaf - Phylloptosis. Page 428.}

2. The Currant-bush Borer-Aegeria tipuliformis: Linn. "The moth is blue-black; the under side of the feelers, the collar, the edges of the shouldercovers, and three very narrow rings on the abdomen, are golden yellow." It deposits its eggs during the latter part of June, at the axil of a leaf; and, when the larva is hatched, it bores to the pith, which, with the bordering cells, it consumes for a great distance. The limb becomes very weak, the foliage sickly, and the fruit small: Whenever a branch exhibits these marks, and, upon examination, a borer is found to be at work, the diseased part should be cut off, with the borer, and the whole burned, to prevent their multiplication (Harris). 
§IX. - DISEASES OF THE RASPBERRY.

The Raspbery Grub - Tinea corticella: Linn. This insect, in the larva state, attacks the cane. It commences in the bud that is to produce fruit, which, from its tenderness, is a very acceptable meal. It then consumes the major part of the inside of the bearing-stalk, which wilts and dies. By pinching the wilted bud and stalk vigorously between the fingers, the grub may be killed. It is about a quarter of an inch in length, of a scarlet color, and has a black head, with one longitudinal light line over the centre. The first segment has two double, black spots, with very few hairs; and is largest in the middle of its body, which is furnished with sixteen legs. The first three pairs are upon the first three segments. There are then four pairs of ventral legs, and one pair of anal pro-legs. By the first part of June the caterpillar will have. accomplished all the injury he will do; then it becomes a chrysalid among the dead foliage, and appears in about a fortnight as a moth.

The fore wings of the moth are brown, covered with livid yellow spots. The hind wings have no spots. The head has a great many yellow hairs covering it. The life of the moth is only about a month or six weeks in length, during which time it deposits its egrs upon the young shoots. They soon 
hatch, when the larvae eat the leaves until they have acquired sufficient growth, when, with the approach of winter, they take up their abode upon the stem (Westwood).

\section{$\S \mathrm{X} .-$ DISEASES OF THE VINE.}

I. Diseases affecting the Foliage. 1. Insects. (1) The Grape-vine Plume - Pterophorus periscelidactylus. The larvae are about one-half an inch in length, having sixteen feet, and fourteen segments to their bodies. They are pale green in color, "and have two rows of elevated white spots along the back, and one on each side, from all of which little white bristles stand out." These insects become moths the latter end of June or first of July ; and very probably give birth to another generation the same season. They may be easily detected upon the vine when in the larva state, for they draw together two or three leaves by means of threads. When this is observed, the leaves should be cut off very carefully, so as not to disturb the worm, else he will escape; and the whole should be burned, or trampled under foot, so as to destroy the insect (Fitch).

(2) Saw-fly of the Vine-Selandria vitis. The color of this fly is generally black, except the under part of the thorax, which is red, and also the fore legs and under part of the other legs, which are pale yellow. The wings are of a smoky color, with 
brown veins. The female is one-quarter of an inch in length; the male, somewhat shorter. They rise at irregular intervals from the ground, and lay their eggs on the under part of the terminal leaves. In July these hatch.

The larva commences at the edge of the leaf, and consumes all the soft parts, working in company with a dozen or twenty. It is a little more than an inch in length, and has twenty-two legs. The head and tail are black, the upper parts of the body light green, and the lower yellowish; becoming more yellow at every moulting. After attaining their size they excavate, and line with silk little cavities in the earth. In about two weeks they come forth, and again lay eggs. The young from these remain in the ground as chrysalids all the winter. The larvae may be destroyed by immersion in a solution of whale-oil soap and water, or by dusting with air-slacked lime. The solution of soap should be in the proportion of two pounds to fifteen gallons of water (Harris).

(3) Aromala vitis: Fabr. This beetle penetrates the ground for a few inches, deposits its eggs, which amount to about a hundred. 'These hatch, and the worms feed upon the tender roots of all sorts of plants. During May they make their appearance. The bectles are brown; "the atennae nine or ten jointed ; the knob is of three leaf-like pieces, which open and shut. The visor is short and wide; the 
upper jaws are furnished at the base, on the inner side, with an oval space, crossed by ridges for grinding. The thorax is transversely square. At times they attack the vine very furiously, depriving it of foliage. The only remedy is to pluck them by hand" (Harris).

(4) The Spotted Vine Beetle - Pelidnota punctata. The larva exists in decayed wood and roots, and the beetle attacks the leaves, sometimes in large quantity. "The wing-covers are dull brownish yellow, with three distinct black dots on each. The thorax is darker, with a black spot on each side. The body beneath, and the legs, are deep bronzed green." They are about an inch in length, and can be readily detected and plucked off by hand (Harris).

(5) The Vine Pyralis - Tortrix vitana. This is an insect which causes immense damage to the vineyards of France, by consuming the young foliage. The moth is nearly an inch in the spread of its fore wings, which are green and glossy, with three transverse brown lines. The remainder is brown. The female deposits her eggs on the leaves during the month of July. When the larva comes forth it hangs from the leaf, and eats the young foliage during the summer. The caterpillar is green, except the head and first segment of the body, which are brown. When the winter commences they hide themselves, by a silken cover, under the dead bark. 
Several methods have been proposed to destroy them, among which was this: to collect the leaves upon which the eggs were deposited. But the method which is generally practised is that discovered by M. Raclet. Early in the spring, before the caterpillars have come forth from the bark, the whole trunk of the vine is washed with hot water. This effectually destroys them, and is found to be far from injurious to the vine, provided it is done after severe frosty weather is past (Westwood).

(6) Procris Amerciana. When in the caterpillar state, these attack the leaves of the grape-vine, consuming all except the framework. The eggs are laid in groups of about twenty, and the worms live together. They are yellow, with black tufts on each segment of the body. The eggs are laid upon the under surface of the leaves. The moth deposits them during the first part of July (Harris).

(7) Haltica chalybea-Illiger. This is a beetle, attacking the leaves and buds. It is, as its name indicates, generally blue, but not always. It is about one-seventh of an inch long. Two broods make their appearance each year: one in May, and the other the last of July. The eggs are deposited upon the surface of the leaf, and the larva consumes the interior soft part. Whenever this mining of the foliage is observed, the leaf should be plucked and burned. When they abound, if the foliage is sprinkled with lime, or with soap-suds, 
every day or two during the time that the eggs are deposited, the females will be prevented from laying (IIaris).

(8) The Leaf-hopper of the Vine - Tettigonia vitis: IIarris. This little hopper is about one-tenth of an inch in length. "Its color is generally pale yellow. The back part of the thorax, the scutel, the base of the wing-covers, and a broad band across the middle, are scarlet. The tip of the wing-covers are blackish, and some little lines between the broad bands and the tips, red." They live on the under surface of the leaves. In the larva state they feed upon the juices of the plant, drawn through its leaves. The effect upon the vine is that the sapflow is reduced, the vine becomes weak, the foliage yellow, and production prevented.

In August the insect arrives at maturity, but still sucks the sap, and on the approach of winter lides in any material which will give it shelter. After the deposition of its eggs in the spring, it dies. The only means by which it can be completely destroyed is by using a little tent, which is spread over the affected vine, and filled with tobaccosmoke. The tent should be tight, to prevent its escape (Fitch).

(9) Bombyx grate: Fabr. These attack and devour the foliage; not only the leaves, but also the stalks. They are solitary in their habits. They disappear before the first of September. The cater- 
pillar is about an inch and a quarter in length, of a blue color, transversely banded with deep orange across the middle of each ring. The bands are dotted with black; the head and feet are orange. They appear the middle of July, and the moths which produce them the last of June (Hamis).

(10) Philampelus. This caterpillar is fully three inches in length, and is a great consumer of the foliage. Its color is pale green or brown. It has a tail, curved like that of a dog, when it is young; but as it grows and changes its skin, this disappears. It enters the earth during August, and, after being transformed, comes forth as a moth early in the following summer. It is of so large a size that it can readily be detected and destroyed (Hawis).

(11) Choerocampa vitis. This is a large, fleshy caterpillar, like the preceding, feeding upon the foliage. But the injury which it inflicts does not stop here; for it nips off the young bunches of fruit and throws them upon the ground. It is fortunate that it is solitary, and that it does not increase to such an extent as to ruin the whole crop when half grown. It can be destroyed, like the preceding, only by hand-plucking (Harris).

(12) Rynchitis vitis. This insect has been very destructive to the vine in Europe, and in some parts of the United States. It rolls up the leaves in forming a retreat for its larva; and by this means a whole vineyard is sometimes deprived of efficient 
foliage. It also attacks fruit trees, but seems to prefer the vine. It can be destroyed by carefully gathering the leaves which are rolled, and burning them. This will kill the larva, and prevent further multiplication.

2. Fungi. (1) Vine Mildew-Oidium Tuckeri: This is a fungus appearing upon the under surface of the foliage, resembles a white powder, and is very rapid in its propagation. It often spreads upon, and destroys, the fruit. If not arrested, it will ultimately ruin both the folinge and the young woorl.

As fungus generally attacks vegetation when it is inactive, we must look to some previous cause. Certain writers have considered the oidium as epidemic; but it is probably endemic. It seems to depend upon a certain condition of the plant, and the fungus is really but the consequence. This is to be proved from the observations of so many cultivators of the grape, who describe it as attacking the vine in fine weather, after a cold or wet season. There seems to be no doubt that its appearance is due to a stagnation of the sap, resulting from a sudden transition from warmth to cold in the atmosphere. Among the instances of injury by it was one in which the vines were situated in a cold grapery, and a hail storm having broken some of the glass, the change in the temperature was immediately followed by mildew upon the vines. There 
is seldom an occurrence of this disease when it cannot be traced, in like manner, to a sudden extreme. The summers of 1862 and 1863 were remarkable, in the eastern part of the country, for these changes; and consequently there was a great prevalence of mildew, while in 1864 the opposite was the case.

The vine mildew which results from this oidium was so much feared in France, on its first appearance, that the Government offered a prize of ten thousand francs, in connection with the "Society for the Encouragement of National Industry," for a remedy. Three thousand francs were added for the best essay upon the disease ; and prizes of from five hundred to one thousand francs were given to eight gentlemen for their efforts in observing and explaining the nature of this fungus. It threatened at one time to cause as much suffering among the inhabitants of the vine districts of France and Madeira, by the ruin of the crop, as did the potato disease in Ireland.

The remedy is to apply water containing sulphur and lime, slacked together. In large vineyards it is almost impossible to apply this wash, and therefore dry flour of sulphur is thrown on the under side of the leaf. This should be a very fine powder; and the purchaser must be careful that the ground, coarser material be not substituted. It should be applied when the fungus first makes its appearance. The oidium of the vine creeps over the surface of 
the leaf, like the fungus of the hop, and therefore is more accessible than many other species which insinuate themselves among the intercellular parts of the foliage, and can only be affected by remedies when they make their appearance through the stomates.

Mr. Forrester, the author of a work upon the vine disease, states that in Portugal the flour of sulphur does not check the fungus as well as fumes of the same, or as a solution of penta-sulphide of lime. Three thousand four hundred and forty-four tons of sulphur were used in the French vineyards for arresting the oidium during the summer of 1856 .

Mr. P. Lazaris, of Athens, Greece, claims to have discovered, in the year $1858,{ }^{1}$ that "any substance which is dry and pulverized, and which does not injure the foliage, will cure the mildew." This he states as the results of experiments, and attributes his success to the fact "that, attaching itself easily, it dries the fungus, absorbs its juices. and thus cuts off its nourishment."

His experiments were as follows: "I powdered my vines with sulphur, except one corner which stood apart from the rest. This was divided into two portions: one was treated with the sulphurous earth of Kalimaki; the other, simply with clay which had been separated from sand or gravel, very finely pulverized, and dried a few hours in the sun.

1 Transactions of the New York State Agricultural Society, 1859. 
At the same time, a few vines were left in their natural state. The three portions treated with the different materials all showed the cure alike, while the vines not powdered at all were entirely destroyed by the disease." As some persons thought the sulphur exerted an influence at a distance, he determined to have another trial. He powdered the vines with clay before flowering, and twice at a later date. At one stage of his experiments there were some signs of the disease; but by repeating the application it was entirely arrested.

From these experiments he drew the following conclusions: earth should be free from all sand and gravel, dried a few hours, pulverized, and then sifted or bolted like sulphur. Clay is easily prepared, and adheres well to the vines. 'The application is best after sunrise, while the vines are moist with dew.

We have repeated the experiments of the abovenamed gentleman, but with success not equal to his. This, perhaps, resulted from inaccurate preparation of the clay; and it therefore deserves another trial.

(2) Erysiphe. "This word denotes white mealy fungi. Examined under the microscope, they are found to consist of necklace-like threads, springing from a creeping mycelium. These clothe the surface, and send down little suckers, which adhere firmly to the leaf and decompose its tissue, or crawl among 
the intercellular spaces, and send up fertile threads from the stomata. The joints of these threads vary in form. Some are cylindrical, others elliptic. The upper joints fall off, and germinate: thus the fungus is propagated with great rapidity. Sometimes the endochrome gives birth to multitudes of minute spondia (or seed-vessels), each of which is capable of germination within the external cell. Thus the original spore looks like a little hedge-hog, as the germinating threads project from its surface in every direction" (Berkicley).

(3) Botrytis. This is a branched mycelium which wanders among the intercellular spaces near the under side of the leaf. It penetrates to the air through the stomata, and scts free the spores which are to reproduce it. 'This is of the same genus as the potato murrain which caused such ravages in Ireland a few years ago. Not only does it rob the plant of nutriment, but induces decay by its own putrefaction. This disease can be reached only with great difficulty, and none of the remedies proposed are of much value (Berkeley).

II. Diseases affecting the Fruit and Flower. 1. The Rose Bug-Macrodactylus subspinosus: Fabr. Page 454.

2. Shanking. This is the decay of the stem of the bunch, or of the footstalks, caused by disagree- 
ment between the temperature of the soil and that of the air. It is particularly liable to appear after a long, cold rain. Thorough drainage is an efficient remedy. The rotting of the berry results from the same cause.

The preceding chapter is only an outline of the treatise which such a subject deserves. As was suggested at the outset, it treats only of the more common maladies, and is but introductory to a work, more strictly scientific, which may hereafter be given to the public. 


\section{N D E X.}

Adaptation of varieties,

Affinity of soils for moisture,

Air, essential to roots,

" importance of a circulation,

Altitude,

Alluminum,

Allumina,

$$
\text { " phosphate of, }
$$

Alluvial agencies,

Ammonia,

Anthers, dehiscence of

Apple, soil for,

" varieties adapted to different soils,

" age of tree proper to plant,

"6 root-grafted trees,

"6 disenses of :

I. Those affecting the leaf -

1. The fall of the leaf,

2. The presence of fungi, .

(1) Cladosporium dendriticum, 431

(2) Ceratites,

(3) Raestelia,

3. Insects:

(1) Apple-tree louse,

(2) Common caterpillar,

(3) The oak-tree caterpillar,

(4) The vaporer moth,

(5) The Palmer worm,

(6) The hag moth,

(i) The unicorn moth,

(8) The canker worm,

(9) The handmaid moth,

(10) The dotted apple-leaf worm,444

II. Diseases affecting the fruit and flower -

1. Sterility,

2. Immaturity of the fruit,

\section{2}

3. Insects :

PAOR

(1) The apple saw-fly, $\quad 452$

(2) " midge, 453

(3) The codling moth, 453

(4) The rose bug, 454

III. Diseases which affect the stem-

1. Insects:

(1) The goat moth, $\quad 455$

(2) The common horer, $\quad 456$

(3) The root-blight beetle, $\quad 458$

(4) The snapping beetle, $\quad 460$

(5) The bark louse, $\quad 460$

(6) The locust of the "seventeenth year,"

IV. Diseases which affect the tree generally-

1. Profusion of sap,

2. Stagnation of the sap from hunger,

3. Stagnation of the sap from transplantation,

464

4. Canker,

465

5. Decay, 468

6. Freezing, $\quad 469$

7. Wind-sliakes, 472

8. Dropsy, 473

9. Sunstrokes, 473

10. Wounds, 474

11. Lichens, 475

12. Vitiation of the circulation, 475

Apricot, soil for, 84

"6 training and pruning of, $\quad 318$

Aqueous vapor, $\quad 34$

Arrangement, intensive, $\quad 289$

" No. of trees per acre, 290

Aspect, 26

Bark, removal of, $\quad 346$

450 Berberry, soil for, 84 
Blackberry, pruning of,

Buckwheat for green manure,

Budding machine,

Calcium, chloride of, " sulphurate of, "6

Canada East, fruits adapted to,

"West, " "

206-243

Capillary attractiou,

Carbon,

" origin of in the soil, Cells, multiplication of,

Cherry, soil for,
" pruning of,
"diseases of:

I. Those affecting the foliage -

1. Insects :

(1) The cherry-tree Jouse,

(2) The May beetle,

(3) The hag moth,

(4) The dotted apple-leaf worm, 444

II. Diseases affecting the fruit-

1. The rose bug,

III. Diseases affecting the stem -

1. Wounds,

2. Insects :

(1) 'The borer,

(2) The cylindrical borer,

3. The Wart,

4. Gumming,

IV. Diseases of the tree generally -

1. Profusion of sap,

2. Decay,

3. Freezing,

4. Dropsy,

5. Sunstroke,

Chlorine,

Circles around trees,

Climate, island or coast,

"inland or continental,

"6 east of the Rocky Mountains, 30

" west " " 30

" influence of upon offspring, 384

Coast or island climate,

Cold,

Colors of fruit,

Contiuental climate,

Comnecticut, fruits adapted to, 206-243

" best 6 varicties of apples

for 100 trees for, 248

"best 12 varjeties do., 218
Connecticut, best 12 varieties of pears on pear stock for 100 trees for,

“ best ten varieties of pears on quince stock for, 248

"best 6 varieties of peaches for,

Corolla, withering of after fecunda-

tion,

Cultivation, shallow for summer, 347

173

175

Currant, soil for,

" training of, 283

" pruning of, 334

" diseases of:

1. The fall of the leaf,

428

2. The currant-bush horer,

501

Degeneracy, resulting from age, $\quad 389$

Dehiscence of anthers, $\quad 407$

" ly grometrical, causes of, 407

Delaware, fruits adapted to, 206-243

Dew, 35

Dilnvial currents, deposits of, $\quad 58$

Disease, general observations upon, 420

" manner of considering it, 420

" classification of, by Berkeley, 421

" " "Weighmann,421

" constitutional, 422

" statement of causes of by J.

De Jonglie,

Disintegration, chemical canses of

Disiutegration, chemical causes of,

District of Columbia, fruits adajted

to 206-243

Drains, direction of, $\quad 105$

" distance apart, 109

" depth of, 112

Drainage, $\quad 90$

" what lands require it, 104

"s materials for, 115

" manner of operation, $\quad 120$

" obstruction of, 121

" benefits of;, 121

Embryo, formation of, $\quad 411$

Evaporation, $\quad 100$

" loss of heat by, 10

Exposure, $\quad 26$

" tlse summit of liills, $\quad 44$

" varieties of pears for, 45 
Exposure, northern

" extending the season of fruit,

"6 for the vine,

" southern,

Fecundation, false hybrid, " obstruction of by superabundance of viseous juice,

" slowness of,

Fig,

Flemish Beanty, blowing off of,

Foramen, position of,

Frost, inland and ou coast,

Frost,

Frost-bitten plants,

Fruits for the amateur,

" " family use,

" " market,

" size of,

" adapted to different states,

" thinning of,

PAGE

45

" production of, not exhaustive, 05

" ringing of,

" trees, watering of,

" gathering of,

" preservation of,

" rooms,

" " temperature of,

" packing of,

Garden of one square rod,

" of sixteen square rods,

Gatbering fruit,

" time of,

" manner of,

Georgia, fruits adapted to,

"best 17 varieties of apples for 100 trees,

" best 12 do. do.,

" best 6 do. do.,

" best 6 varieties of pears on pear stock,

" best 12 do. do.,

" best 6 rarieties of pears on quince stock

" best 12 do. do.,

" best for 100 or 1000 trees

" best 6 varieties of peaches,

" best 12 " "

“ best for 100 or 1000 trees
Georgia, best varieties of freestone peaches, 259

Green erops,

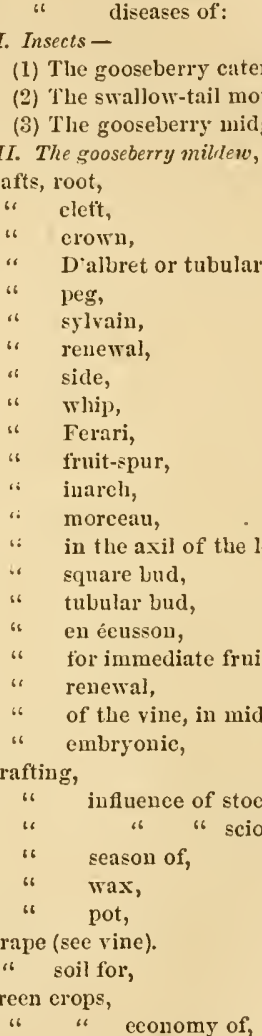

" " economy of,

" " adrantages of,

" " reteh and white lupine for,

" " buckwbeat for, 194

" " " rye, turuips, red elover, and sperry for,

Hardiness of speeies and varieties, 
Heat, linight's experiments with, upon melons and cucumbers,

" radiation of,

" effect of, on the quality and quantity of wine,

". of coil increased by drainage, 102

Heeling-in,

Hoar-frost,

Humus,

Hybrids, obtaining seed from,

Hybridization,

" manner of operation, 404 " qualities obtained from

the female and male parents,

Hydrogen,

Ice resting upon strawberry plants,

" trees girdled by,

"floods,

llinois, Northern, fruits adapted

$\begin{array}{ccc} & \text { to, } & 206-243 \\ \text { " Central, do. do., } & 206-243 \\ \text { " Sonthern, do. do., } & 206-243 \\ \text { " best } 6 \text { rarieties of apples for }\end{array}$

100 trees,

"6 best 12 do. do.,

268

" best 20 do. do.,

" best varieties of apples for

market for 1000 trees

268

Iudiana, Northern, fruits adapted to,

" Southern, do. dlo.,

206-243

Inland climate, 205-243

Inorganie substances,

Insects, life of,

$\begin{array}{ll}\text { " Coleoptcra, } \\ \text { " } & \text { Irtloptera, } \\ \text { " } & \text { Nemiptera, } \\ \text { " } & \text { Icpidoptera, } \\ \text { " Diptera, } \\ \text { " Ilymenoptera, }\end{array}$

Iodine,

Iowa, fruits adapted to,

Iron, oxides of,

" sulphuret of,

Irrigation of truit trees,

Island or coast climate,

Isothermal lines,

liansas, fruits adapted to, lientncky, fruits adapted to,

PAGE

" best 6 varieties of apples for 100 trees, 261

" best 12 do. do., 262

" best 20 do. do., 262

" best varieties of apples for 1000 trees, $\quad 262$

“ best varicties of pears on pear stock,

" best varieties of pears on quince stock,

" best varieties of peaches, 263

Land, value of, $\quad 135$

Light, $\quad 42$

“ experiment with, upon peaches, 42

" chemical properties of, 43

" of the moon, 43

Lime, $\quad 179$

" carbonate of, $\quad 179$

" sulphate of, 180

" nitrate of, 180

" phospliate of, $\quad 180$

" action of, 185

Magnesia, carbonate of, 181

Magnesium, cloride of, 181

Maine, fruits adapted to, $\quad 206-243$

" best varicties of apples for, 245

" " " " " " " " " " 245

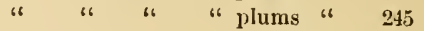

" " " " cherries " 245

Manganese, 181

Manure, adapted to clay earth, I83

:" " " peaty soil, 183

" " " sandy soil, 186

" heap, formation of, 186

" liquid, 191

" " value of, 196

" application of, $\quad 197$

" " "paper upon,

by Boussingault, $\quad 198$

" green, application of, 200

Marl, 185

Maryland, fruits adapted to, 206-243

Massachusetts, fruits adapted to, 206-243

" best 6 varieties of apples for,

"best 12 varietics of apples for,

" best varieties of pears ou pear stock for 100 trecs, 
Massachusetts, best varieties of pears on quince stock,

4 best varieties of strawberrics, best varieties of grapes, 246 Michigan, Northern, fruits adapted to, 206-243

" Southern, do. do., 206-243

" best 6 varieties of apples for 100 trees,

" best 12 do. do.,

" best 20 do. do.

"6 best varielies of apples for 1000 trees with a near market,

" do. where markot is distant,

4 best 6 varieties of pears on pear stock for 100 trees,

" best 12 do. do.

" best varieties of pears on quinco stock,

best 6 varicties of peaclies for 100 trees,

" best 12 do. do. best rarieties of peaches for transportation to northern markets,

Mississippi, fruits adapted to, 206-243

" best 6 varicties of apples for 100 trees,

6 best 20 do. do. best 6 varieties of pears on pear stock,

best 12 do. do., best 6 varieties of pears on quince stock,

"

6

" best 12 do. do.,

" best varieties of pcaches for 100 trees,

Missouri, fruits adapted to, 206-243

ALoisture, absorption of by soils from the air,

Moss, removal of,

Mulching,

$\begin{array}{ll}\text { " material for, } & 349 \\ \text { " time for, } & 349 \\ \text { " depth of, } & 349 \\ & \text { effect of upon the goose- } \\ \text { " berry, } & 350 \\ & \text { continuance of, }\end{array}$

Nectariue, soil for, $\quad 87$

$$
\text { " training of, }
$$

New IIampshire, fruits adapted to, 206-243

New J ersey, fruits adapted to, 206-243

" " best 6 varieties of apples for 100 trees,

" " best 12 do. do., 251

" " best 20 do. do., 251

" " best varieties for 1000 trees,

best 6 varieties of pears on pear stock,

best 12 do. do.,

best for 1000 trees, $\quad 252$

best 12 varieties of pears on quince,

best varieties for 1000 trees,

" " best 6 varieties of peaches, 253

" " best 12 varieties of do., 254

New York, Eastern, fruits adapted to,

206-243

" " Western, do. do., 20G-243

" " best 6 rarieties of apples for 100 trees,

" " best 12 do. do.

" " best 20 do. do., 249

" " best varicties for market for 1000 trces,

" " best 6 varieties of pears on pear stock,

" " best 12 do. do., 250

" "best 6 rarieties of pears on quince stock,

250

" " best 12 do. do., 250

" " best for market, 250

" " best 12 varieties of peaches,

" " best 6 do. do, 250

Nitrogen,

Ohio, Northern, fruits adapted to, 206-213

" " best 6 varieties of apples for 100 trees, 263 best 12 do. do., 263 best 20 do. do., 263 best varieties of apples for market, 264 best 6 varieties of pears on pear stock, 264 
Ohio, Northern, best 12 varieties of pears on quince stock, 264

" "i best 12 varieties of pears for market, 264 best 12 varieties of peaches,

" " best 12 varieties for 100 trees,

Ohio, Central, fruits adapted to, 206-243 " " best 6 varieties of apples for 100 trees, 265

" " best 12 do. do., 265

" " best 20 do. do., 265

" " best 6 varicties of pears on pear stock, 265

" " best 12 do. do., 265

" " best 12 varieties of pears for market, 266

" " best 6 rarieties of pears on quince stock,

" " best 12 clo. do., 266

" " best 12 varieties of peaches for 100 trees, .

Ohio, Southern, fruits adapted to, 206-243

\section{" " best 6 rarieties of ap-} ples for 100 trees, $\quad \mathbf{2 6 6}$

"6 best 12 do. do., 266

" " best 20 do. do., 267

" 4 best 6 varieties of pears on pear stock, 267 " " best 12 do. do., 267

" " best 6 varieties of pears on quince stock, $\quad 26 \pi$

" " $\quad$ best 12 do. do., 267

" " best 6 varicties of peaches,

" " best 12 do. do.,

Oxygen,

267

lacking fruit,

leach, soil for,

" age of tree for planting,

" training of,

"diseases of :

I. Thosc affecting the leaf -

1. Dotted apple-lear wor'm,

2. Vegetable parasites,

II. Diseases nffecting the fruit-

1. The rose lug,
2. Sterility,

PAGE

3. Premature fall of the fruit,

444

490

III. Diseases affecting the stem -

1. Insects:

(1) The peach-tree borer, $\quad 490$

(2) The snapping beetle, $\quad 460$

2. Gumming, 491

3. Profusion of sap, 462

4. Vitiation of the sap, $\quad 476$

5. Decay, 468

6. Sunstroke, 473

7. Wounds, 474

Pear, soil for, $\quad 88$

"varieties adapted to soils, 88

" age of trees for planting, 278

" lieight of tree not a criterion of value,

" deep planting for dwar'ss, 281

" pruning of, 319

" varieties for winter exposures, 45

"diseases of :

I. Those affecting the leaf -

1. American pear blight, $\quad 476$

2. Insects:

(1) The goldsmith beetle, $\quad 479$

(2) The red mite, 480

(3) The pear-tree slug, $\quad 480$

(4) The pear-trce lycla, 481

(5) Large pear-tree astyages, $4 \$ 1$

(6) Ilispa quadrata, $4 \mathrm{S2}$

3. Fungi,

(1) $\Lambda$ scomyees Bullatus, $\quad 4 \mathrm{S3}$

(2) Ceratites, 432

(3) Cladosporium dendriticum, 431

4. Discolorations, 483

5. I'remature fall of the leaf, 428

II. Diseases affecting the flower and fruit-

1. Bletting, or rotting at the core, 484

2. Induration, 485

3. Sterility, 444

4. Immaturity of the fruit, 450

5. Deficiency in the cutaneous secretion,

III. Disaeses affecting the stem -

1. Root blight,

2. Insects:

(1) The pear-blight beetle, $\quad 487$

(2) The penr-bark louse, 488

(3) T'lie locust of the "seventeentls year,

3. Fungus upon the root, 488 
Pears, diseases of:

IV. Diseases affecting the tree gen-

$$
\text { erally - }
$$

1. Profusion of sap,

2. Stagnation from transplantation,

3. Vitiatiou of the sap,

4. Canker,

5. Decay,

6. Freezing,

7. Windshakes,

8. Dropsy,

9. Sunstrokes,

10. Wounds,

11. Lichens,

Penusylvania, fruits adapted to, 206-243 " best 6 varieties of apples for 100 trees, 254

" best 12 do. do., 254

" best 20 do. do., 254

" best varieties of apples for 1000 trees,

“ best 6 varieties of pears on pear stock,

"best 12 do. for 1000 trees,

“ best 6 varietics of pears on quince stock,

(6 best 6 varieties of peaches for 100 trees, 255 " best 12 do. for 1000 trees,

Percolation,

Phosphorus,

Physical influences,

Planting, distances for,

Plum, soil for,

" diseases of:

\section{Those affecting the leaf-}

1. Insects:
(1) The plum louse,
(2) The vaporer moth,
(3) The unicorn moth,

11. Diseases affecting the fruit -

1. Insects:

(1) The curculio,

(2) The rose bug,

2. The fall of the fruit,

3. Sterility,

III. Diseases affecting the stem-

1. The plum wart,

2. Gumming,

Plum, diseases of:

PAGE

IV. Diseases affecting the tree generally -

1. Profusion of sap,

2. Vitiation of the sap,

3. Freezing,

4. Dropsy,

5. Wounds,

Pollen, manner of conreyance of, 408

" tubes, size of, $\quad 409$

Potash, carbouate of, 181

" nitrate of, 182

Potassium, chloride of, $\quad 181$

1'reservation of fruit, $\quad 359$

Protection of half-hardy plants, $\quad 40$

l'rotococeus uivalis, 36

Pruuing, designs of, $\quad 302$

" importance of a sharp kuife in,

" metlod of making the cut in.303

" severe, productive of vigor, 304

" formation of an equal system of branches by, $\quad 306$

" for the cure of disease, $30 \%$

" seasou of, 308

"winter, 308

" summer, 309

" after transplanting, 310

" the peach and vectarine, 311

" the apricot, 318

" the pear, 319

" the cherry, 324

" the vine, 326

" the vine, season of, 327

" the vine in the Ionian Island, 327

" the currant, 334

“ the gooseberry, 335

“ the raspberry, 337

" the black-cap raspberry, $33 \%$

" the blackberry, 3 "s

" the strawberry, 339

" root, 311

Pulverization, $\quad 127$

، increase of capillary by, 133

" effect of upou root-pasture, 134, 142

production of fresh soil 
Pulverization, admission of air to
roots by,
axperiments upon,

Purchase, time for, of trees.

Quince, soil for,

Radiation of heat,

Rain, fall of, in wine districts,

Raspberry, soil for,

$$
\begin{array}{ll}
\text { “ grub, } \\
\text { " pruning of, }
\end{array}
$$

Red clover as a green manure,

Retention of moisture by soils,

Rhode Island, fruits adapted to, 206-243

" " best 6 rarieties of apples for 100 trees, 246

" " best 12 do. do., 246

" " " best 20 do. do., 247

" " best 6 varieties of pears on pear stock for 100 trees,

" " best 12 do. do.,

" " best 6 varieties of pears on quince for 100 trees,

" " best 12 do. do.,

Ringing of fruit,

$$
\text { "best } 12 \text { do. do., }
$$

Roots of plants in undrained soil,

" do. do., drained soil,

" length of, on dwarf" pear trees, 145

" do. do., peach trees,

" selective power of,

" pruning,

liye as a green manure,

Saccharine fermentation,

Seed, selection of, from young trees, 395 Seediings, effect of pruning and transplanting upon,

" number of years before maturity,

Selection, in raising new sorts,

" of the tree,

" indiscriminate, of varieties, 201
Shelter on prairie lands,

PAGE

Silica

35

Sur , limbs broken by,

Soda, sulphate of

Soda, sulphate of, $\quad 182$

" carbonate of, 182

" phosphate of, 182

Sodium, cliloride of, $\quad 182$

Soils, disintegration of, 49

" description of fertile, 51

" galvanic power in, 53

" properties of specific gravity, 65

" affinity for moisture, 66

" retention of moisture 67

" absorption of moisture from the air,

" capillary attraction, $\quad 69$

" weight of, 66

" slrinkage of, . 68

" state of division of, 69

" absorption of oxygen, carbonic acid, ete. by,

" absorption and retention of heat by, 73

" heat of, depending upon color, 74

" classification of, $\quad 79$

" adlaptation of, 81

" adapted to the apple, 81

" drainage of, 90

" sourness of; unpulverized, 182

" temperature of, at different deptlus,

" temperature of, in different months,

" Joosening of,

" and position, influence of, upon

$$
\text { offepring, }
$$

Spurry as a green manure, $\quad 194$

Stagnant air, $\quad 34$

Staking limbs, $\quad 355$

Stigma, season of sensitiveness of, 402

Storms, nature of, $\quad 29$

" snow, 31

Strawberry, soil for, $\quad 89$

" pruning of, 333

" irrigation of, 341

Sulphuric acid, $\quad 182$

Suushine, importance of, $\quad 305$

Thinning fruit, $\quad 351$

Tile-pipe, cost of, 118

Trellises for the vine, $\quad 330$

Training the peach and nectarine, 311 
Training oblique rod,

" double oblique rod,

" standards,

“ alpluabetically,

" horizontal,

" the apricot,

، quenonille,

" wine-glass,

" the vine, simple cane,

" the vine Thomery,

" the vine in Ohio,

" the vine for renewal,

Transplantation, season for,

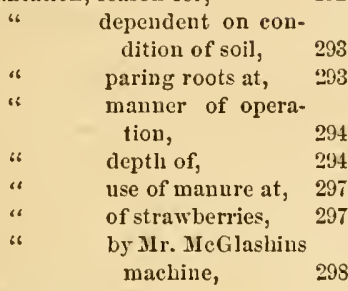

Transplanting, value of,

Turnips as a green manure,

Tying and staking limbs,

Tan Mrons, results of his experiments, 392 Varieties, production of,

" necessity for new,

a limit to life of,

“ production of; by selection, 391

" adaptation of,

Vermont, fruits adapted to,

Vetch as a green manure,

206-243

Vicar of Winkfield pear, ripening of, 43

Vine, limit of, in Europe,

“ age of, for planting,

" season of pruning,

" trellises for,

" pruning of, in Ionian Islands,

" simple cane training of,

"Thomery training of,

" training of, in Ohio,

" training of, for renewal,
PAGE

313

314

315

317

318

322

323

328

329

331

333
Vine, diseases of:

I. Those affecting the foliage -

\section{Insects:}

(1) The vine plume, 503

(2) The saw-fly,

(3) Anomala vitis,

503

(4) The spotted vine beetle, 505

(5) The vine pyralis, $\quad 505$

(6) Procris Americana, 506

(i) Haltica clialybea, $\quad 506$

(8) The leaf-hopper, $\quad 507$

(9) Bombyx grata, $\quad 507$

(10) Philampelus, $\quad 508$

(11) Choeroeampa vitis, 508

(12) Rynclitis vitis, 508

2. Fungi,
(1) Viue mildew,
509
(2) Erysiphe,
(3) Botrytis,
512
513

II. Diseases affecting the flower and fruit -

1. The rose bug,

2. Shanking,

Virginia, fruits adanted to, 206-243

" best varieties of apples for 100 trees,

" best rarieties of apples for 1000 trees,

" best 20 varieties of pears on pear stock,

" best 20 varieties of pears on quince stock,

Water, contiguity of large bodies of, $\mathbf{2 7}$

Watering of fruit trees, $\quad 354$

Weathering of rocks, agencies in, 63

White Lupine as a green manure, 193

Winds prevailing east of Rocky

$$
\text { Iountains, }
$$

" severe,

"6 in vicinity of Boston,

Wine, quantity and quality modified by heat,

Winters, mild,

IVisconsin, fruits adapted to, 






(x)

Ar onitis

W.

fol

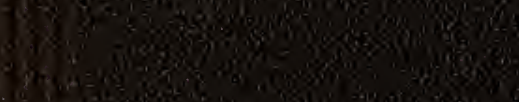

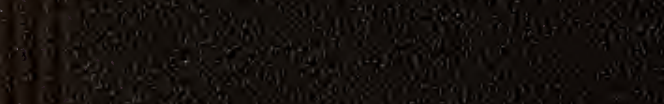

sing

8

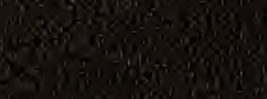

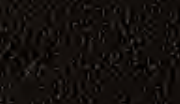

$x^{2} x^{2}$

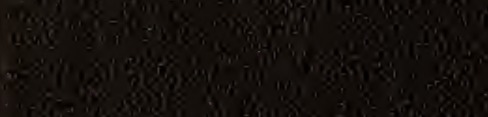

2.

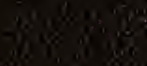

lon $x^{2}, x^{2}$

sin

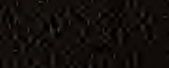

-2 3 in

$\operatorname{lin}^{2}$

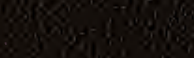

$2 x^{\prime}, 2$ sing

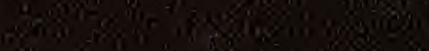

